University of Natural Resources and Life Sciences, Vienna (BOKU)

Department of Water - Atmosphere - Environment (WAU)

Institute of Hydraulic Engineering and River Research (IWA)

Österreichische Akademie der Wissenschaften

\title{
RAISE - \\ Research on Alpine sediment processes, morphodynamics and ecosystem behaviour considering extreme events
}

\author{
Submitted by \\ Dipl.-Ing. Dr. Marcel LIEDERMANN
}

Team:

Dipl.-Ing. Johann Aigner; Roman Dunst B.Sc.; Dipl.-Ing. Peter Flödl;

Dipl.-Ing. Dr. Kurt Glock; Prof. Dipl.-Ing. Dr. Helmut Habersack;

Dipl.-Ing. Marlene Haimann; PD Dipl.-Ing. Dr. Christoph Hauer; Dipl.-Ing. Dr. Mario Klösch;

Dipl.-Ing. Andrea Kreisler; Dipl.-Ing. Sebastian Pessenlehner; Dipl.-Ing. Rolf Rindler;

Dipl.-Ing. Sabrina Schwarz; Dipl.-Ing. Dorian Shire-Peterlechner;

Dipl.-Ing. Mag. Dr. Christine Sindelar, PD Dipl.-Ing. Dr. Michael Tritthart 


\section{Suggested citation:}

Liedermann, M., Kreisler, A., Shire-Peterlechner, D., Aigner, J., Rindler, R., Schwarz, S., Klösch, M., Sindelar, C., Hauer, C., Tritthart, M., Haimann, M., Glock, K., Flödl, P., Dunst, R., Pessenlehner, S., Habersack, H. (2020): RAISE - Research on Alpine sediment processes, morphodynamics and ecosystem behaviour considering extreme events; Österreichische Akademie der Wissenschaften - ESS Final Report

ISBN-Online:978-3-7001-8791-2

DOI: 10.1553/ESS-RAISE 


\section{Abstract}

Extreme floods in Austria of the years 2002, 2005, 2006, 2009, 2013 and 2018 demonstrate the vulnerability of mankind against such events. River geometry responds to heavy flooding with massive morphological rearrangements. Houses and infrastructure in the affected areas are thus at risk. Therefore, an improved understanding of sediment transport processes is crucial for the analysis of morphodynamics and thus for flood risk management. Also the success of river restoration projects depends on sediment transport and morphodynamics as boundary conditions, but there is a significant lack of knowledge regarding these processes and the connected ecosystem.

Sediment monitoring is intended to close these knowledge gaps, but their analysis has so far focused primarily on the sections of the river where the respective data were collected. The RAISE project now aimed to combine long-term and short-term sediment research (such as extreme flood events) in order to relate and integrate this data for the first time.

An important step could be taken by the integrative consideration of the sediment monitoring stations in Austria. The understanding of sediment transport processes could be increased and occurring phenomena could be explained. The term sediment forensics was introduced and describes well the level of detail that is sometimes necessary to get more clarity about the transport processes in a catchment area. Sediment intrusion or higher availability was identified as a source of increased bed load and the importance of the catchment area and anthropogenic influence was determined. However, it could also be shown how important a functioning sediment management is and that such a management is often lacking on Austrian rivers. It is often necessary to react after damage instead of acting before it occurs. It could be shown that only by an extreme event, on a river that basically suffers from a sediment deficit, a sediment surplus suddenly leads to problems. An integrative sediment management should therefore promote a certain sediment resilience of the river so that extreme events can take place without the recent very high damages. The analyses of the various catchment areas have shown how different the problems and approaches to solving them are in the individual rivers. With the developed questionnaire, an instrument was created that enables the transdisciplinary identification of problems and weaknesses of sediment management in a river. Now it is a task for the upcoming years to establish concepts for sediment management on Austrian rivers, which are supported by measurement data. 


\section{Kurzfassung}

Die Extremhochwässer der Jahre 2002, 2005, 2006, 2009, 2013 und 2018 in Österreich verdeutlichten die Vulnerabilität der Menschheit gegenüber derartigen Ereignissen. Die Gewässergeometrie reagiert bei starken Hochwässern mit massiven morphologischen Umlagerungen. Häuser und Infrastruktureinrichtungen in den betroffenen Gebieten sind somit in Gefahr. Daher ist ein verbessertes Verständnis der Sedimenttransportprozesse zentral für die Analyse der Morphodynamik und damit für das Hochwasserrisikomanagement. Auch der Erfolg von Gewässerrenaturierungen hängt von Sedimenttransport und Morphodynamik als Randbedingungen $a b$, es existiert jedoch ein signifikantes Wissensdefizit hinsichtlich des Prozessverständnisses von Sedimenttransport, Morphodynamik und dem damit vernetzten Ökosystem.

Sedimentmonitoring soll diese Wissenslücken schließen, doch bezieht sich deren Analyse bisher primär auf die Flussabschnitte, an denen die jeweiligen Daten erhoben wurden. Das Projekt RAISE zielte nun auf die Kombination von Langzeit- mit Kurzzeit-Sedimentforschung (z.B. Extremhochwässer) ab, um diese Daten erstmals in Beziehung zu setzen und integrativ zu diskutieren.

Ein wichtiger Schritt konnte durch die integrative Betrachtung der Sedimentmessstationen in Österreich getan werden. Das Verständnis von Prozessen des Sedimenttransports konnte erhöht und auftretende Phänomene konnten erklärt werden. Der Begriff Sediment Forensik wurde geprägt und beschreibt gut den Detaillierungsgrad, der manchmal notwendig ist, um mehr Klarheit über die Transportprozesse in einem Einzugsgebiet zu erhalten. So wurden Sedimenteinstöße oder eine höhere Verfügbarkeit als Quellen für erhöhtes Geschiebeaufkommen identifiziert und die Bedeutung des Einzugsgebietes und der anthropogenen Beeinflussung herausgearbeitet. Es konnte aber auch gezeigt werden, wie wichtig ein funktionierendes Sedimentmanagement ist und dass ein solches Management an den österreichischen Flüssen häufig fehlt. Oft muss nach Schäden reagiert werden anstatt davor zu agieren. Es konnte gezeigt werden, dass nur durch ein Extremereignis, an einem Fluss, der grundsätzlich unter einem Sedimentdefizit leidet, plötzlich ein Sedimentüberschuss zu Problemen führt. Ein integratives Sedimentmanagement sollte deshalb eine gewisse Feststoffresilienz der Fließgewässer fördern, damit Extremereignisse ohne die jüngst sehr hohen Schäden stattfinden können. Die Analysen der verschiedenen Einzugsgebiete haben gezeigt, wie unterschiedlich die Probleme und Lösungsansätze in den einzelnen Flüssen sind. Mit dem entwickelten Fragebogen wurde ein Instrument geschaffen, das die transdisziplinäre Identifikation von Problemen und Schwächen des Sedimentmanagements an einem Fluss ermöglicht. Nun ist es eine Aufgabe der nächsten Jahre, Konzepte für das Sedimentmanagement an österreichischen Flüssen zu etablieren, die durch Messdaten untermauert werden. 


\section{Executive Summary}

Extreme floods have occurred more frequently in Austria in recent years, highlighting the vulnerability of humanity to such events. River geometry responds to heavy flooding with massive morphological rearrangements. Houses and infrastructure in the affected areas are thus at risk. Therefore, an improved understanding of sediment transport processes is crucial for the analysis of morphodynamics and thus for flood risk management. Also, the success of river restoration projects depends on sediment transport and morphodynamics as boundary conditions, but there is a significant lack of knowledge regarding these processes and the related impact on ecosystems.

Sediment monitoring intends to close these knowledge gaps, but its analysis has so far primarily focused on the river sections where the respective data were collected. The RAISE project now aimed at combining long-term and short-term sediment research (e.g. extreme floods) in order to relate and integrate these data for the first time.

A holistic hydromorphological assessment, which considers the sediment connectivity, was further developed. The evaluation, which is based on the Hydromorphological Evaluation Tool (HYMET, Klösch and Habersack, 2017), now includes the creation of a map which displays the connectivity of the entire river network. This map allows decision-makers to quickly get an overview of the larger-scale effects of measure scenarios on the hydromorphology of downstream reaches. An exemplified application to the Drava River shows the effect of an additional hydropower plant on the hydromorphological status. According to the evaluation, the restored reach lost the "good" hydromorphological status given the construction of the hydropower plant at the Schwarzach River, despite the long distance far upstream in the catchment.

The state of the art measuring methods regarding transport of suspended solids and bed load were evaluated. The wide variety of hydraulic, morphologic and sedimentologic conditions in natural rivers require the usage of specialized monitoring equipment to fulfill the wide range of site-specific requirements. A laboratory test in the BOKU research flume was used to determine the strengths and weaknesses of the individual bedload samplers. All basket samplers used in Austria have advantages in special catchment areas and situations. The model tests now help to make the results comparable with each other by using correction factors.

Sediment budget calculation variants were compared and discussed and a summary of the shares of suspended sediment and bed load in the total sediment transport was prepared for all stations in Austria. The larger the catchment area, the more a homogenous ratio can be calculated; in small catchment areas, extreme events can often lead to very large fluctuations in one year. A further influencing factor are transverse structures, which accumulate especially suspended sediment over a long period of time, which is then released during major events (this is also relevant for the Danube). Based on a flood event in October 2018, an attempt was made to calculate a sediment budget from the Gail. Here, a river that had been subject to a 
sediment deficit over long distances in the past decades suddenly produced a sediment surplus through the mobilisation of material, which led to management problems in many areas. 1.4 million $\mathrm{m}^{3}$ of sediments were transported in the course of the event and possible sources and sinks could be identified. This example shows how important measurements, a good process understanding and finally a sediment management adapted to the catchment area are to meet the challenges of extreme events in the coming years. Through these and many other analyses in the RAISE project, the need for river resilience regarding sediments was identified. Thus, within the framework of a sediment management, both the lack and the surplus of sediments must be addressed.

The larger the catchment area, the more likely is a direct relationship between discharge and bedload transport. In small catchment areas, morphological events or a certain hydrological history can often lead to fluctuations in sediment transport of several orders of magnitude at the same discharge. This is often a major problem when evaluating measurement data, especially with regard to management issues. For this reason, the term Sediment Forensics was established within the project. The aim is to analyse occurring phenomena concerning sediment transport in detail in order to find the reasons for the high fluctuations. Five examples were given to show which events lead to otherwise unexplainable fluctuations in sediment transport. A sediment peak at the measuring station in Vent, for example, could be explained through the monitoring by the Bavarian Academy of Sciences. The melting of snow and a rainfall event at the Vernagtferner led to extensive morphological rearrangements directly below the glacier, which finally became visible with a time delay of five days in the measurement data of the geophone system in Vent. At the Urslau river and at the Drava/Falkensteinsteg, a high flow event led to a mobilisation of sediment during the first peak flow. Even after the peak flow has decreased, the bedload transport remained at a high level. At the Isel, the differences between a spring event and an autumn event were pointed out. In addition to the different characteristics between the seasons, the Isel also shows a bedload transport hysteresis, because the peak in bedload transport always occurs before the peak in discharge. This has effects on monitoring but also on the interpretation of the data. On the Drava/Dellach, a more detailed analysis of the data showed that a flood event in 2018 had a major impact on the bedload yield for the entire next year (2019). The annual yield of over 30,000 tons was not only much higher than the average yield, but also far exceeded the yield of the year with the corresponding event (2018: approx. 20,000 tons).

Based on the knowledge gained through process analysis (sediment forensics), management tasks can now be considered and improved through process understanding. Again, some examples have been worked through during the project and five of these examples are presented in more detail. Accordingly, at the Drava/Falkensteinsteg geophone impulses display a scatter of over three orders of magnitude for similar hydraulic conditions. The cause is to be found about $2 \mathrm{~km}$ upstream the monitoring station, where a $24 \mathrm{~km}$ long river section can be classified as residual flow reach. Due to these anthropogenically altered conditions, the water level in this river section is often not sufficient to mobilize and transport bedload material downstream. This leads to sediment deprived conditions with the formation of a distinct armor layer directly upstream of the monitoring station. During flood events, the sediment is mobilized 
in the residual reach, which, combined with the sediment influx by tributaries, leads to the formation of bedload pulses. With the detailed analysis of a long data series it was now possible to determine the time difference of the bed load pulse occurrence for different flow situations and thus improve the river management. At the same measuring station it was possible, due to the long data series and some findings gained from sediment forensics, to recalculate a data gap that occurred during a flood and thus to obtain a continuous budget, which in turn is decisive for good sediment management. At the Urslau river, the long data series and sediment forensics made it possible to classify bedload transport in terms of its relationship to flow. Four different event types were defined which occur depending on sediment availability and stream power. By associating the event types the calculation of the yearly yield and sediment management can be improved significantly. By continuously monitoring the bedload transport at the Drava/Dellach, the transport speed of a bedload influx from a tributary (Gailbergbach) could be determined. With this information a transport formula was calibrated and thus the speed of another bed load influx was predicted. This information is of great importance for a functioning bed load management. The increased understanding of the bedload transport processes and monitoring data have led to a better understanding of the sediment balance between the individual bedload measurement stations on the Drava and Isel. The methods used made it possible to draw up a conclusive balance, and further monitoring should clarify the exact sources and sinks of the sediments

The RAISE project made it possible for the first time to also apply hydrodynamic numerical models in the area of bed load measuring stations and to use their possibilities for extrapolation of data and scenarios. For example, the sediment transport model iSed was calibrated using the extensive monitoring data at the Drava river in such a way that it was possible to simulate a flood wave with an unsteady simulation. With the now calibrated tool, further waves can be simulated and thus sediment management can be improved. At the Rofenache, the sediment transport model iSed was used to calibrate bedload transport formulas to extrapolate rating curves. In the range of measured data this works very well; whether reasonable values could be estimated also for non-sampled high flow rates should be clarified by monitoring in the upcoming years. Moreover, the sediment transport model iSed was coupled with the habitat evaluation model HEM. Hence, habitats on the micro-scale as well as the meso-scale can now be evaluated under consideration of the morphological changes taking place during flood events. An example was given by modelling a flood wave with the new coupled module, showing that crucial morphodynamical processes creating habitat diversity can now be modelled and quantified.

Using the example of the Urslau, a methodology was applied that could have an impact on the future design of restoration measures. Large boulders may be implemented in alpine rivers were glacial deposits are evident in form of terminal, lateral or hummocky moraines. Structural features, such as boulders, have the advantage that specifically during high (scouring) flows, they provide sheltering habitats in the wake zone accompanied by reduced flow velocities and/or bottom shear stress. As exposed large roughness elements due to the glacial history were present at some sections of the Urslau, the option of implementing boulders may be of great importance for future sediment management in similar alpine rivers. 
Physical laboratory experiments were used to better understand basic hydraulic processes. For example, the initiation of motion of a Danube gravel was investigated with a tomographic particle tracking velocimeter (TOMO-PTV). For most experiments particle dislodgment took place at the peak of positive kinematic energy. The importance of sweep events was emphasized - although sweeps and ejections cause the highest turbulent kinetic energy peaks, the movements were observed almost exclusively at sweeps. These findings are of great importance especially for the Danube, where hydraulic structures are to be used for a later initiation of motion. The delta formation of a typical Austrian small waterpower plant was studied in another laboratory experiment. The delta formation experiments revealed that virtually all incoming sediments accumulated at the head of the reservoir. Over time, the resulting delta formation grows in height and moves further into the reservoir. The delta has the potential to increase the flood risk for high floods. It also has ecological impacts, as important spawning gravel fractions might accumulate on and in the delta and are missing further downstream. Recommendations for the drawdown of a reservoir were derived to improve the management situation.

Furthermore, methods for predicting sediment supply rates in ungauged river systems were developed and tested with focus on integrative analysis (flood protection and ecology), which are important to future socioeconomic strategies in river basin management. The role of sediments in alpine rivers was discussed with a novel perspective on a differentiation between non-fluvial, semi-fluvial and fluvial sources; - including aspects of habitat modelling and river restoration.

Many further analyses within the framework of the RAISE project showed the importance of well thought-out and functioning sediment management in rivers. Often damage is reacted to after an event instead of acting before it through a proper sediment management. In order to find out which questions have to be clarified for a functioning management and which data should be collected to set up such a management, a questionnaire was developed with a transdisciplinary approach, which addresses the crucial questions. With the involvement of different actors at the state governments and other responsible authorities, the questionnaire was set up and then tested for its functionality using the example of the Gail. People from different disciplines and activities related to river management were interviewed and it was shown that many valuable insights into morphological changes and relationships as well as extreme events could be gained. When interviewing people completely unfamiliar with the subject (neighbouring residents or similar), the questionnaire could only be used as an impulse, and valuable information could rather be obtained from personal conversations.

Through the research cooperation with the Bavarian Academy of Sciences (BAdW), which was started and established within the project, first interdisciplinary approaches could be implemented in the catchment area of the Vent measurement station. The linkage of the bedload measurement data with the monitoring data of the BAdW at the Vernagtferner offers the possibility to link long-term effects of climate change with the development at the bedload measurement station. The first promising results from the project are the starting point for a more extensive research cooperation with the BAdW in the future. 
In summary, an important step was taken by the integrative consideration of data obtained through the sediment monitoring stations in Austria. The understanding of processes concerning sediment transport could be increased and occurring phenomena could be explained. The term sediment forensics describes well the degree of detail that is sometimes necessary to obtain more clarity about the transport processes in a catchment area. But it could also be shown how important a functioning sediment management is and that such a management is often missing for the Austrian rivers. Often people only react after damages instead of being able to act before they occur. It was shown that already a single extreme event, on a river that is basically suffering from a sediment deficit, can alter the sediment balance into a surplus of sediment, which in turn leads to problems. A sediment management system should therefore promote a certain sediment resilience so that extreme events can take place without causing high damage. The analyses of the various catchment areas have shown how different the problems and approaches to solving them are in the individual rivers. The developed questionnaire serves as a tool that enables the transdisciplinary identification of problems and weaknesses in sediment management in a river. Now it is a task of the next years to establish sediment management concepts underpinned by measurement data at Austrian rivers. 



\section{Table of Contents}

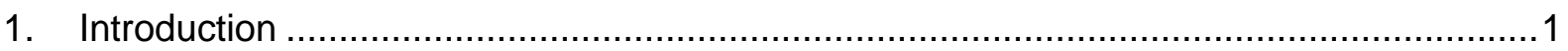

2. WP 1 - Catchment based boundary conditions …................................................ 4

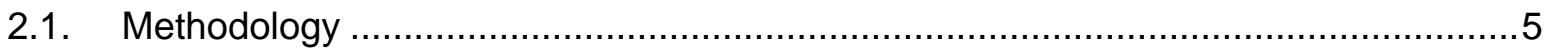

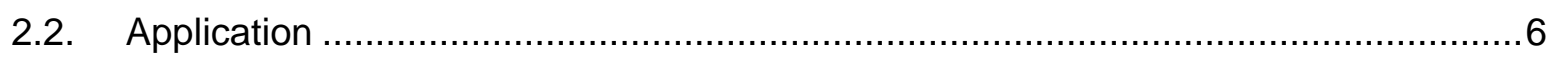

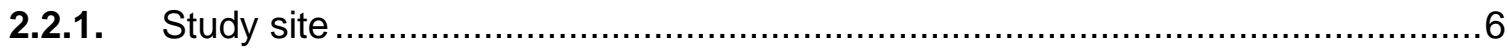

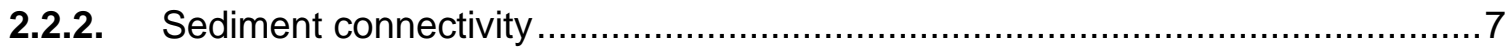

2.2.3. Artificial channel constraints ................................................................... 10

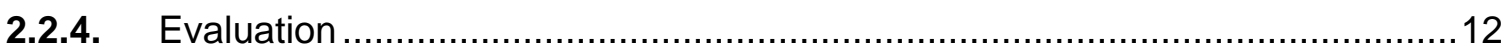

3. WP 2 - Monitoring of sediment transport and morphodynamics ...............................13

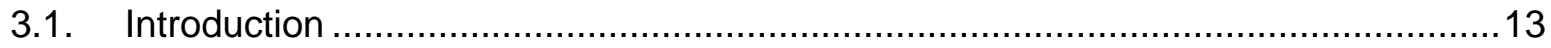

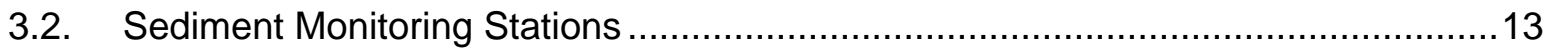

3.2.1. Suspended load monitoring stations....................................................... 13

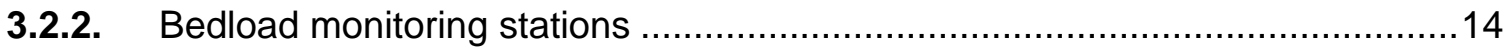

3.3. Sediment Monitoring - Methodology: Measurement Techniques/Devices .............22

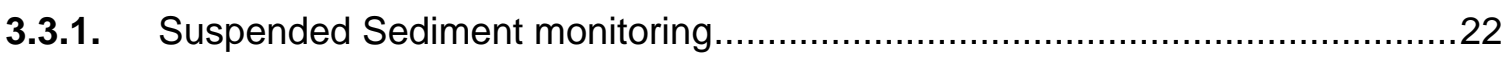

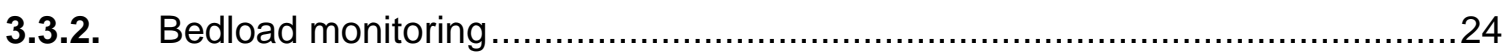

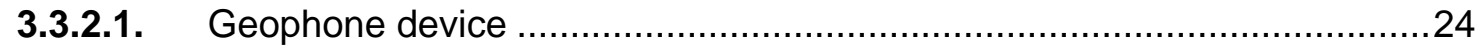

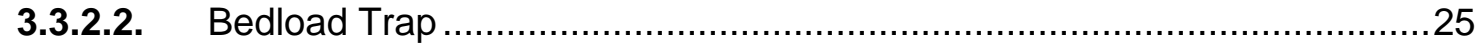

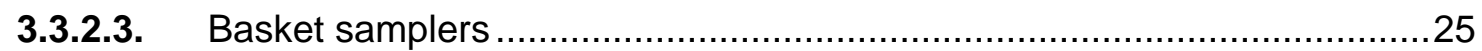

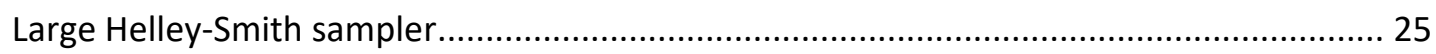

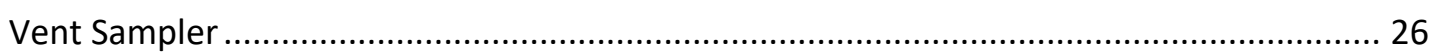

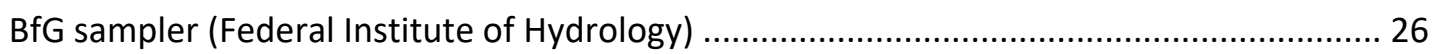

3.3.2.4. Flume and research channel experiment - Adaption and optimization of

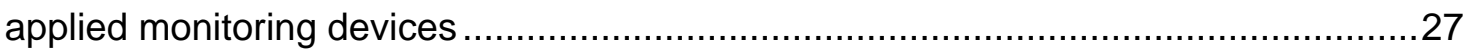

Results: Comparison of applied sampling devices - Hydraulic efficiency.............................. 28

Results: Comparison of applied sampling devices - Sampling efficiency .............................. 29

3.4. Sediment Monitoring - exemplary selection of regular measurement results ..........31

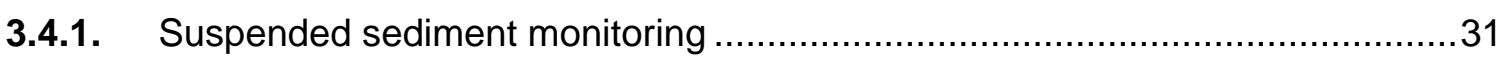

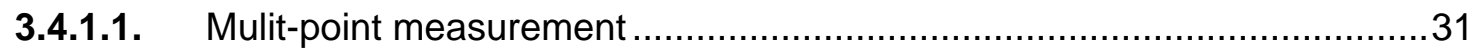

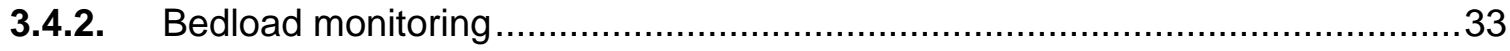

3.4.2.1. Cross-sectional basket sampler measurement …................................ 33

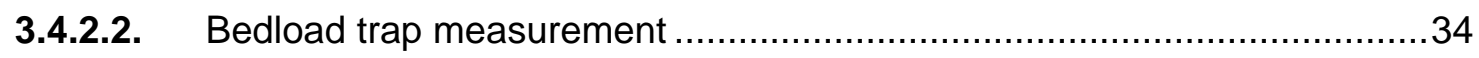

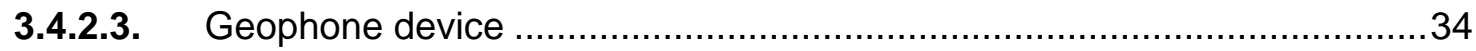




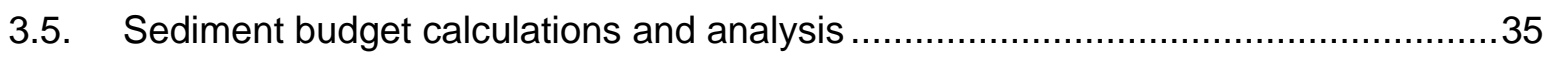

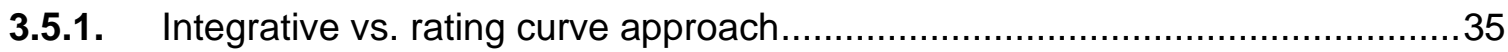

3.5.2. Calculation of Annual yield within the project Raise ......................................36

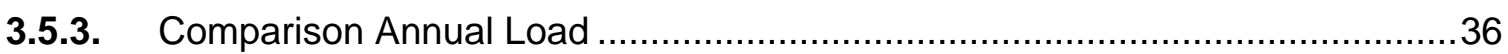

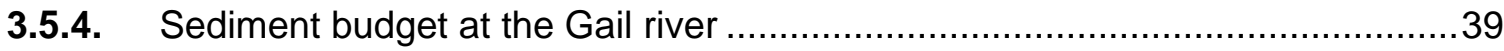

3.6. Sediment Forensics - Event based analyses to increase process understanding ...43

3.6.1. Example 1: Rofenache - Vent (bedload/suspended load input due to a

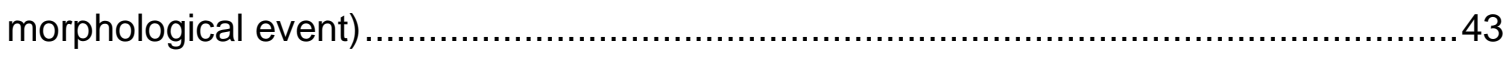

3.6.2. Example 2: Urslau (bedload availability strongly influences the transport) $\ldots . . . .47$

3.6.3. Example 3: Drava/Falkensteinsteg (Hydropower influence and bed armouring) 49

3.6.4. Example 4: Isel/Lienz (Different characteristics in different seasons of the year, hysteresis effect)

3.6.5. Example 5: Drava/Dellach (extreme event 2018 influences transport of the whole year 2019)

3.7. Process studies on sediment transport leading to enhanced sediment management 56

3.7.1. Example 1: Bedload pulses in a hydropower affected Alpine gravel bed river .56

3.7.2. Example 2: Falkensteinsteg/Drava: Correction of the data gap during the flood event 2018 .58

3.7.3. Example 3: Classification of bedload transport events at the Urslau 62

3.7.4. Example 4: Transport distances Dellach following bedload input downstream 64

3.7.5. Example 5: Bedload balance between the integrative sediment monitoring system Drava-Isel 67

4. WP 3 - Numerical sediment transport and habitat modelling …................................ 72

4.1. Improvement of sediment transport models: Coupling of sediment transport and habitat model

4.2. Setup, calibration and validation of model suite for selected river reaches ............74

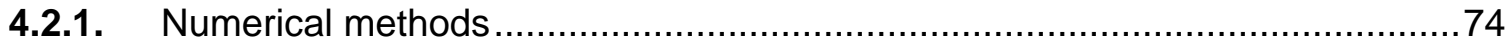

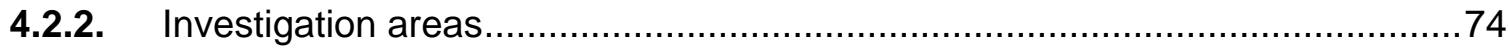

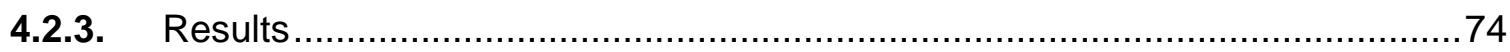

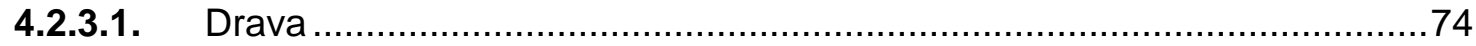

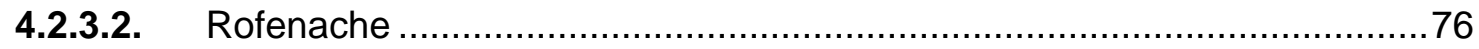

4.2.4. Improvement of conceptual habitat model components ...............................78

5. WP 4 - Physical, laboratory-based modelling on sediment transport processes ..........82 
5.1. Investigations on sediment particle entrainment.

5.2. Delta formation at the reservoir of head of run-of-river hydropower plants in gravel bed rivers

6. WP 5 - Interrelations between abiotic and biotic earth surface processes, human influences and socioeconomics

6.1. Integrative Sediment Management Concept. .94

6.1.1. Development of a questionnaire on the need for action regarding sediment budget, sediment transport and river morphology. .94

6.1.2. First application of the questionnaire - Test area Gail .99

6.2. Integration of numerical and physical model results with socio-economic indicators 100

6.2.1. Introduction 100

6.2.2. Assessment of sediment input and identification of sensitive areas 101

6.2.3. Discussion 106

6.2.4. Result dissemination 107

7. List of Tables 109

8. List of Figures 110

Bibliography 115 


\section{Introduction}

Global warming is expected to be accompanied by an increase in extreme weather conditions, which may lead to more severe flood runoff in river systems (Formayer et al., 2009; IPCC, 2012; IPCC, 2014; Ministry of Life, 2012). International studies confirm this dramatic increase at the beginning of the new millennium, which also leads to an increase in damage and economic losses (Barredo, 2007). Examples for Austria are the catastrophic flood events of 2002 (9 people killed, approx. EUR 3,200 million damage (Habersack et al., 2003)), 2005 (5 people killed, approx. EUR 555 million damage; Habersack et al. 2009; Habersack et al., 2006) and 2013 (5 people killed, approx. EUR 900 million damage). As the population continues to grow and the development space in the Alpine regions is very limited, settlement activities will mainly take place along river corridors and in former floodplains (Schober et al., 2015; Habersack et al., 2015) and will continue to strongly influence river regimes and the respective river morphology (De Kok \& Grossmann, 2010).

In addition to the frequently documented large-scale effects of flooding on the morphology of a river, a detailed short-, medium- and long-term understanding of the process is also required, as morphodynamics and sediment transport are also crucial for further hazard analysis. Changes in the availability of sediments due to climate change, e.g. due to changes in land use (e.g. increased supply of fine sediments due to agricultural land use and land drainage) or due to glacier melt (increased sediment supply) or reduction of permafrost also have an impact on transport balances. In addition, reduced runoff due to a warmer climate can also reduce land cover, which in turn tends to increase sediment supply (Knox, 1983).

Within the SED_AT project it could be shown that changes in the sediment budget, sediment transport and river morphology cause problems in each of the water-relevant sectors in Austria and that there is a need for action towards improved sediment management. Aware of the challenges that lie ahead, the National Water Management Plan 2015 identified the development of catchment-related sediment management concepts taking into account existing anthropogenic impacts as a central element.

Sediment management concepts should, among other things, bring together the different ecosystem services, improve the understanding of processes in the catchment area and identify and interpret the causes of the existing sediment problems. Furthermore, the concepts serve as a basis for comprehensive planning fundamentals for an improved flood risk management and the implementation of sustainable and ecologically valuable construction measures.

A concept, which is capable to meet these requirements, has to consider sediment-related processes at various spatial scales. Interactions of sediment related processes and problems within a river catchment are displayed in Figure 1. 


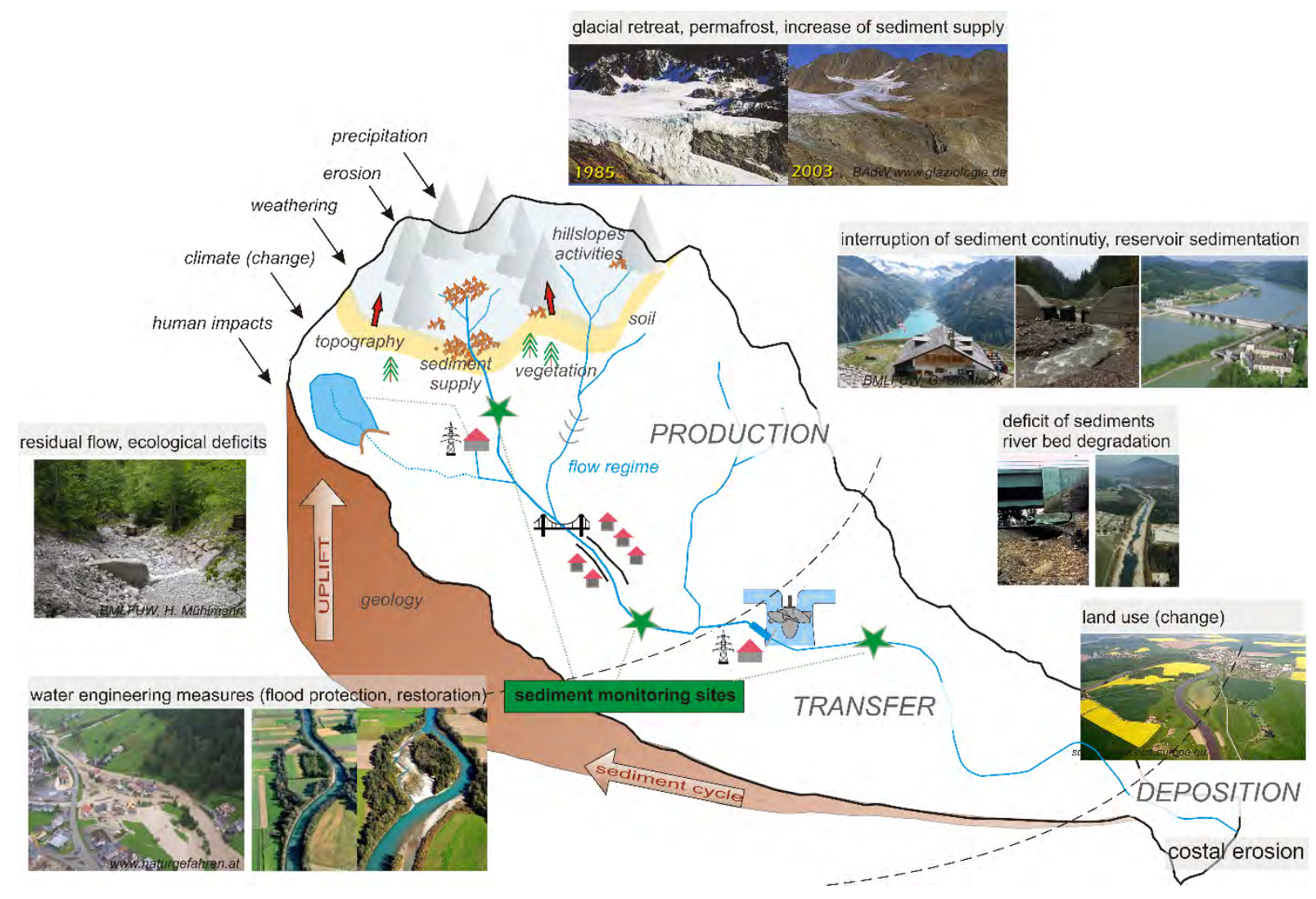

Figure 1: Sediment related process, influences and triggering factors within a river catchment.

The tools that can be applied for developing a sediment management concept are far-reaching and range from the catchment level down to detailed questions at the local level. In the RAISE project many of these tools have been applied:

Existing knowledge can be captured at the catchment area level through a necessary intertransdisciplinary approach (questioning of experts, interested and affected people). It is also important to compile catchment based boundary conditions (geology, hydrology, land use etc.) from existing data sets and construction measures already implemented in the river basin (crosswise and longitudinal structures, renaturation reaches etc.) at catchment area level. Application of a hydromorphological assessment method based on the Hydromorphological Evaluation Tool (Klösch and Habersack 2017) provides a map delivering quick information on the status of sediment connectivity along the river network. This map should support decision makers in estimating the larger scale effects of the construction, removal or increase of permeability of sediment barriers, including possible shifts of hydromorphological status which would endanger the fulfilment of the requirements of the Water Framework Directive.

Sediment monitoring, along with the determination of annual and event loads, is fundamental for understanding processes in the catchment area. Sediment transport mechanisms are currently the subject of intensive research efforts to close the existing knowledge gap regarding the predictability of morphodynamic changes. In particular, sediment transport processes during flooding for different river types, lateral erosion and the interlinking to ecological effects still require considerable research effort. The monitoring of key parameters and of bedload transport processes, which are also valuable for numerical modelling, shows a high variability 
of parameters. Turowski et al (2011), show that the threshold for the onset of movement has a dispersion in the range of one order of magnitude and explain the variability with a strong dependence on the hydrological history of extreme events. Especially small catchments are very sensitive to bedload input with a large scatter in the measured bedload transport rates (Kreisler et al., 2017, Turowski \& Rickenmann, 2009).

Sediment transport is best determined comprehensively by an integrative monitoring approach combining several direct and indirect methods. Deficits and limitations of individual measuring methods are thus compensated. In Austria, state-of-the-art measuring stations are operated by the University of Natural Resources and Applied Life Sciences (Aigner et al., 2017, Habersack et al., 2017, Kreisler et al., 2017, Liedermann et al., 2013). For these reasons, the suspended matter monitoring strategy applied on Austria's rivers also consists of a combination of direct and indirect measuring methods (BMLFUW, 2008; BMLFUW, 2018; Haimann et al., 2014). Gaps in knowledge exist here with regard to the detailed process understanding of turbulence effects on particle movement depending on possible differences in catchment area geology and/or unsteady flow hydraulics (hysteresis effects), natural phenomena (such as extreme floods) or anthropogenic impacts (such as hydropeaking in hydropower plants). In Austria, data are available from 24 suspended sediment monitoring sites and 7 bed load monitoring sites co-maintained by BOKU. This represents an extremely valuable data basis, which is also absolutely unique internationally. Up to now, however, the data from these measuring stations have primarily been analysed individually. The project RAISE enabled an integrative analysis of the extensive data.

Fundamental research is necessary to better understand the basic processes in sediment transport. For this purpose, physical laboratory experiments are suitable to provide a better understanding of the processes on the smallest scale. Sediment measurements of parameters involved in hydrodynamics and sediment transport processes, however, are inherently conducted on the local scale. In order to perform an upscaling procedure from the local scale to the reach scale, numerical modelling has proven to be a valuable tool (Habersack et al., 2008b). While three-dimensional hydrodynamic models are today capable of precisely capturing many processes in river flow even during flood conditions (e.g. Tritthart \& Gutknecht, 2007), there are still substantial research efforts needed to develop numerical modelling systems that reflect the natural variability associated with sediment transport processes under these conditions. In many Alpine rivers, sediment transport and morphodynamic processes are subject to a natural variability that requires further research to trace their origins; hence, by performing an upscaling operation based on numerical modelling, employing the available bedload and suspended load data sets for specific measurement stations throughout Austria, an enhanced process understanding is anticipated.

The RAISE project should now create the boundary conditions through basic research, the integrative consideration of all measurement stations, the consideration of the results on different scales and the transdisciplinary discussion of the topic to enable the development of a sediment management system within the framework of the NGP in the upcoming years. 


\section{WP 1 - Catchment based boundary conditions}

The hydromorphology of Alpine rivers suffers severe deterioration mainly due to channelization (narrowing and straightening) and transversal structures which act as barriers disrupting the natural sediment cycle (Habersack and Piégay 2007). Since the 1990s, restoration works targeted at the re-establishment of a more natural morphology based on local measures of widening (e.g. Habersack and Nachtnebel 1995) or, to allow self-initiated widening through riverbank erosion, local removal of bank protection. However, in reaches highly impacted by hydropower use in the catchment upstream, monitoring programmes often revealed a limited occurrence of lateral morphodynamics despite the restoration works. Monitoring at the Mura River along the border between Austria and Slovenia exhibited only limited riverbank erosion and widening after removal of bank protection (Klösch et al. 2011). Today, decision-makers and planners become increasingly aware that the limitation of lateral dynamics results from a lack of sediment supply given chains hydropower plants in the catchment.

A dependency of the lateral dynamics on the sediment transport was already conceptually described by Schumm (1985) and Church (2006). Mueller and Pitlick (2014) empirically confirmed this dependency of the braiding intensity on the bedload concentration. In addition to changes in plan view, rivers adjust their slope to the sediment supply, which affects the bed levels. A decreased supply causes a river to erode the river bed until it the slope establishes an equilibrium between sediment supply and sediment transport capacity. By affecting also groundwater levels, connection of side-channels and frequency of inundation, decreased bed levels affect the ecology of the riverine landscape at larger scale, next to technical consequences (e.g. scouring of bridge piers).

Recent restoration works increasingly consider this relevance of sediment supply, but deficits are often solved with one-time-measures including artificial supply or local removal of bank protection for a temporary supply of bank-derived gravel. Sustaining solutions would permanently increase the connectivity by implementing measures such as dam removal. In contrast, given the need to turn to emission-free energy production to limit climate change, the exploitation of hydropower increases worldwide, even in Austria despite its already high degree of hydropower development. As a consequence, a further decrease of sediment connectivity can be expected.

At the same time, the Water Framework Directive (WFD, European Commission, 2000) obliges the EU member states to maintain or reach a good ecological status of rivers. The revision of the Austrian 'Nationaler Gewässerbewirtschaftungsplan' (2017) acknowledged the important role of sediment connectivity in river restoration. Accordingly, to fulfil the conditions defined in the 'Nationaler Gewässerbewirtschaftungsplan', the GE-RMs ("Gewässerentwicklungs-und Risikomanagementkonzepte", English: "River Development and Risk Management Concepts"), which are developed for river catchments, need to apply holistic, catchment-based approaches.

Moreover, expert advices on the assessment of the environmental impact of new hydropower plant concessions often lack a consideration of larger scale effects of new sediment barriers. 
However, sequences of hydropower plants lead to a cumulative starvation of river networks regarding sediment supply for reaches downstream (Kondolf et al., 2014).

One objective in RAISE is to develop and apply a hydromorphological assessment method based on the Hydromorphological Evaluation Tool (Klösch and Habersack, 2017), which provides a map delivering quick information on the status of sediment connectivity along the river network. This map should support decision makers in estimating the larger scale effects of the construction, removal or increase of permeability of sediment barriers, including possible shifts of hydromorphological status which would endanger the fulfillment of the requirements of the Water Framework Directive.

\subsection{Methodology}

The methodology of the holistic hydromorphological assessment, which considers the sediment connectivity, is based on the Hydromorphological Evaluation Tool (HYMET, Klösch and Habersack, 2017). In RAISE, the method was developed further by creating a map, which displays the connectivity of the entire river network (Figure 2). At the catchment scale, throughput coefficients are assigned to the sediment barriers which are based on expert knowledge. These coefficients reduce the amount of sediment which is transported to downstream reaches. At the scale of the evaluated reach, the presence of artificial channel constraints and the effects on the morphology are evaluated similarly to the original HYMET, but according to the enhanced 'River Freedom Index' method developed by Klösch et al. (2019). This method allows considering constraints at 4 different elevations (Figure 2), instead of being restricted to the constraints present at one elevation. The constraining effect of every structure is longer than the structure itself. This additional distance (buffer) is estimated to be half the distance to the opposite line at the same elevation. Additionally, eventual vertical constraints or excavation/supply activities within the reach are considered at the reach evaluation. Dredging and supply activities upstream along the river network need to be considered already at the catchment evaluation. In RAISE, the method is applied by desktop analysis combined with expert knowledge of the field conditions. 
Sediment connectivity map:

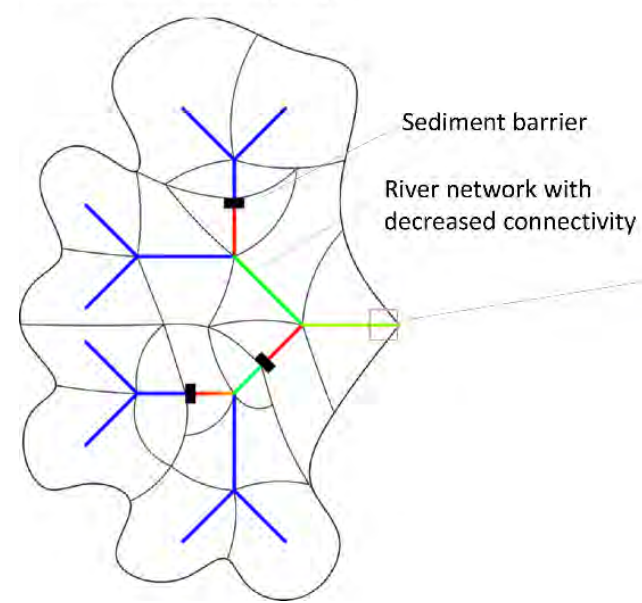

2. REACH EVALUATION

(Local artificiality and disturbance)

Lateral artificiality assessment:

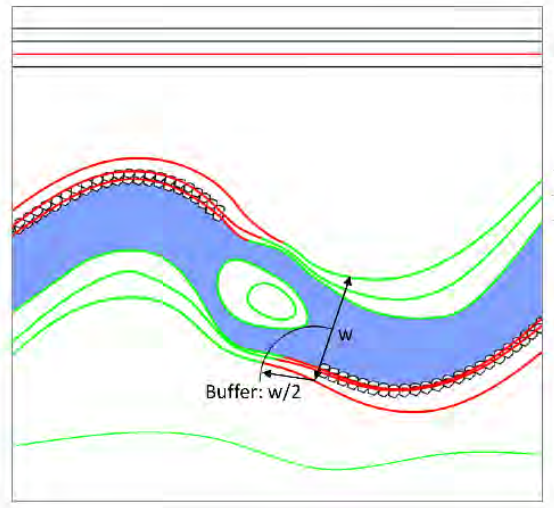

Flood water edge

Bank edge

Vegetation threshold

Low flow water edge

- free from artificial contraints

— artificially constrained

Figure 2: Two steps of hydromorphological evaluation: 1. Catchment evaluation assessing sediment connectivity along the entire river network as basis for all evaluations along the river network, 2. Reach evaluation with displayed assessment of artificiality (contact with artificial channel constraints at four elevations).

The reach evaluation comprises the River Freedom Index from Klösch et al. (2019), divided into the lateral and vertical $R F I\left(R F I\right.$ and $\left.R F I_{v}\right)$, and the index of disturbance $f_{d}$. The reach factor $F_{r}$ is calculated by multiplying these three factors:

$$
F_{r}=R F I_{l} R F I_{v} f_{d}
$$

$R F I_{v}$ and $f_{d}$ are set to 0 if any structure or disturbance (repeated sediment excavation or supply within the reach) is present, otherwise they are set to 1 . $R F l_{\text {I }}$ is calculated based on the 4 water edges displayed in Figure 2:

$$
R F I_{l}=\frac{f_{l 1}+f_{l 2}+f_{l 3+} f_{l 4}}{4}
$$

Where every water edge is calculated via:

$$
f_{l i}=\frac{L_{n i}}{L_{i}}
$$

Where $L_{n i}$ represents the unconstrained length and $L_{i}$ the total length of the line $i$.

\subsection{Application}

\subsubsection{Study site}

The new method which includes the sediment connectivity map is exemplified with an application to a restored reach of the Drava in the municipality of Kleblach-Lind. There, channelization works started in the $19^{\text {th }}$ century which increased the sediment transport capacity, while sediment supply from the upstream catchment was reduced given mining activities and the construction of hydropower plants and check dams. These impacts led to channel incision and degradation or loss of habitats for riverine species. In the 1990s, river 
managers started to restore the Upper Drava (e.g. Habersack and Nachtnebel, 1995). The unprecedented size of the restoration measure in the municipality of Kleblach-Lind (Habersack and Piégay, (2007), which was implemented in 2002 received much attention, which included intense monitoring activities (e.g., Formann et al., 2007).

Despite the large width that was provided to the river in relation to the channelized state, constraints strongly determined the channel's morphology. A new side-channel, which widened self-dynamically, quickly exposed the groins which were embedded in the floodplain to prevent from uncontrolled erosion of neighboring land. In the main channel, the widening was created along one bank during construction. There, the remaining and the new bank protections strongly determined the morphology by fixing bars in their position. Moreover, the sediment supply is reduced and endangered by further reductions given plans of new hydropower plants. Efforts to increase the sediment permeability of check dams, such as the redesign of the check dam at the Feistritzbach, are still limited. Further reduction of sediment supply may cause the bedload concentration to approach or fall below a critical threshold between a single-thread and braiding morphology (Mueller and Pitlick, 2014), which would strongly impair the original benefits of restoration.

It is therefore crucial to assess the constraints also in restored reaches like at the Drava in the municipality of Kleblach-Lind, and to monitor the sediment connectivity to the catchment upstream. The sediment connectivity map developed in RAISE is an important step for a holistic, catchment-wide analysis, which repeatedly needs to be updated and provided to decision makers for estimating larger-scale effects. In the case of the Upper Drava River, the use of the connectivity map helps raising awareness that the value of investments into river restoration may be impaired (and the ecological status put at risk) if the construction of hydropower plants is continued.

\subsubsection{Sediment connectivity}

The catchment was analysed regarding the sediment production by considering geology, land use, soil erodibility and gradient. Measurements at the monitoring station in Dellach served for calculating the annual bedload yield, which was then assigned to the sub-catchments by estimating a relative productivity for the local conditions. Comparison with the results of the revised universal soil loss equation (RUSLE) exhibited that, at least for the analysed catchment, the relative sediment production is well represented by the relative sub-catchment area.

Figure 3 shows the catchment of the Upper Drava River, including the three major hydropower plants. 


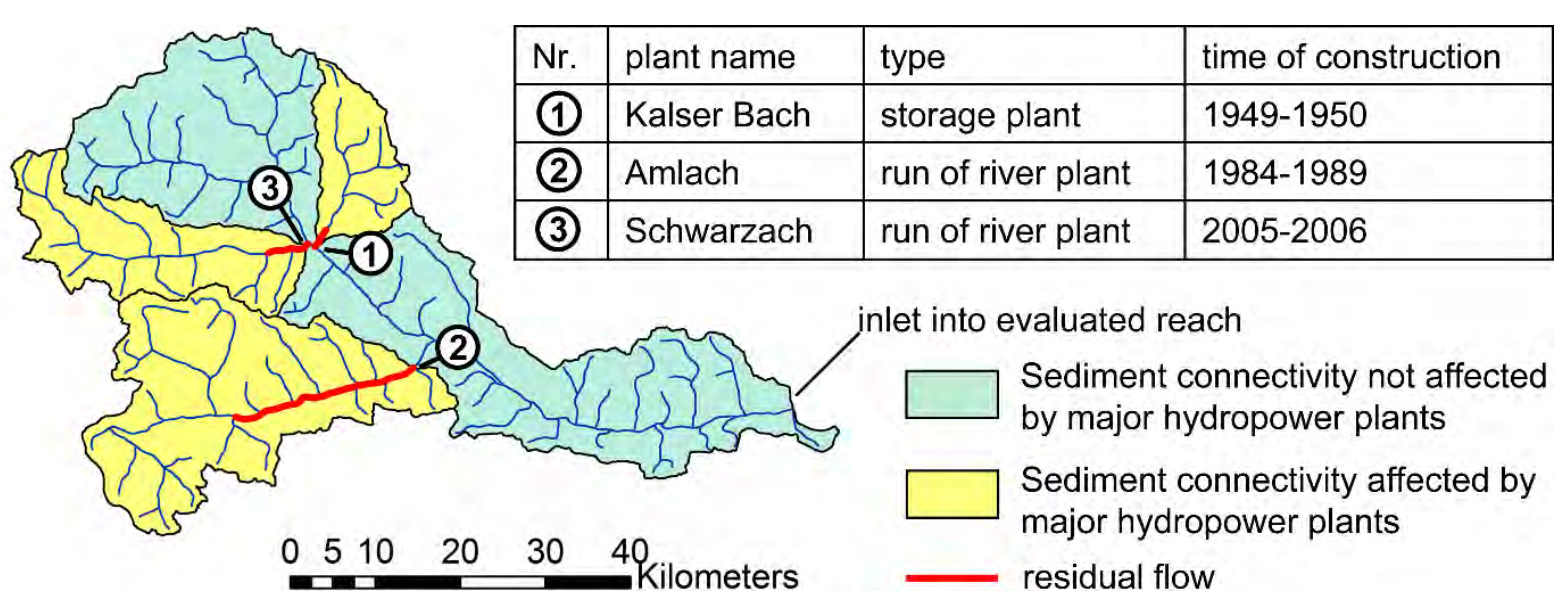

Figure 3: River network of the Upper Drava with disrupted connectivity to catchments given the three major hydropower plants, with indicated location of the evaluated, restored reach (Klösch and Habersack, 2017).

Knowing that the hydropower plants are partially permeable also to bedload, a throughput coefficient of $50 \%$ was assigned to these barriers, as estimated by Klösch and Habersack (2017).

Then, the sediment connectivity was assessed along the entire river network by means of a GIS-analysis. Directly downstream of a sediment barrier the sediment connectivity is reduced by multiplying the connectivity upstream of the barrier with the throughput coefficient. With distance downstream, the connectivity increases again as long as every sub-catchment along the river and every tributary is less affected by a sediment barrier.

Once this river network structure and the interplay with the throughput coefficient and subcatchment area was established, a spreadsheet allowed adding or removing sediment barriers to visualise the effects for the connectivity of the entire river network. Figure 4 shows the catchment connectivity in the years after construction of the second, but before construction of the third hydropower plant. The sediment retention caused by the storage plant Kalser Bach shows limited effects on the downstream reaches of the Isel River, given the relatively small size of the disconnected catchment compared to the overall catchment. Upstream of the city of Lienz the hydropower plant Strassen-Amlach disrupts the connection of the Drava to its catchment by $50 \%$. At the confluence with the Isel River, the Drava shows a sudden increase of the sediment connectivity, but which is still at a reduced level of $79 \%$ given a $50 \%$-disruption of connectivity to $42 \%$ of the catchment. Downstream of this confluence, the catchment is narrow and the river only slightly recovers with distance downstream until it reaches $83 \%$ at the restored, evaluated reach $(20 \mathrm{~km}$ downstream of the catchment displayed in Figure 4 , see Figure 3 for the location of the reach). 


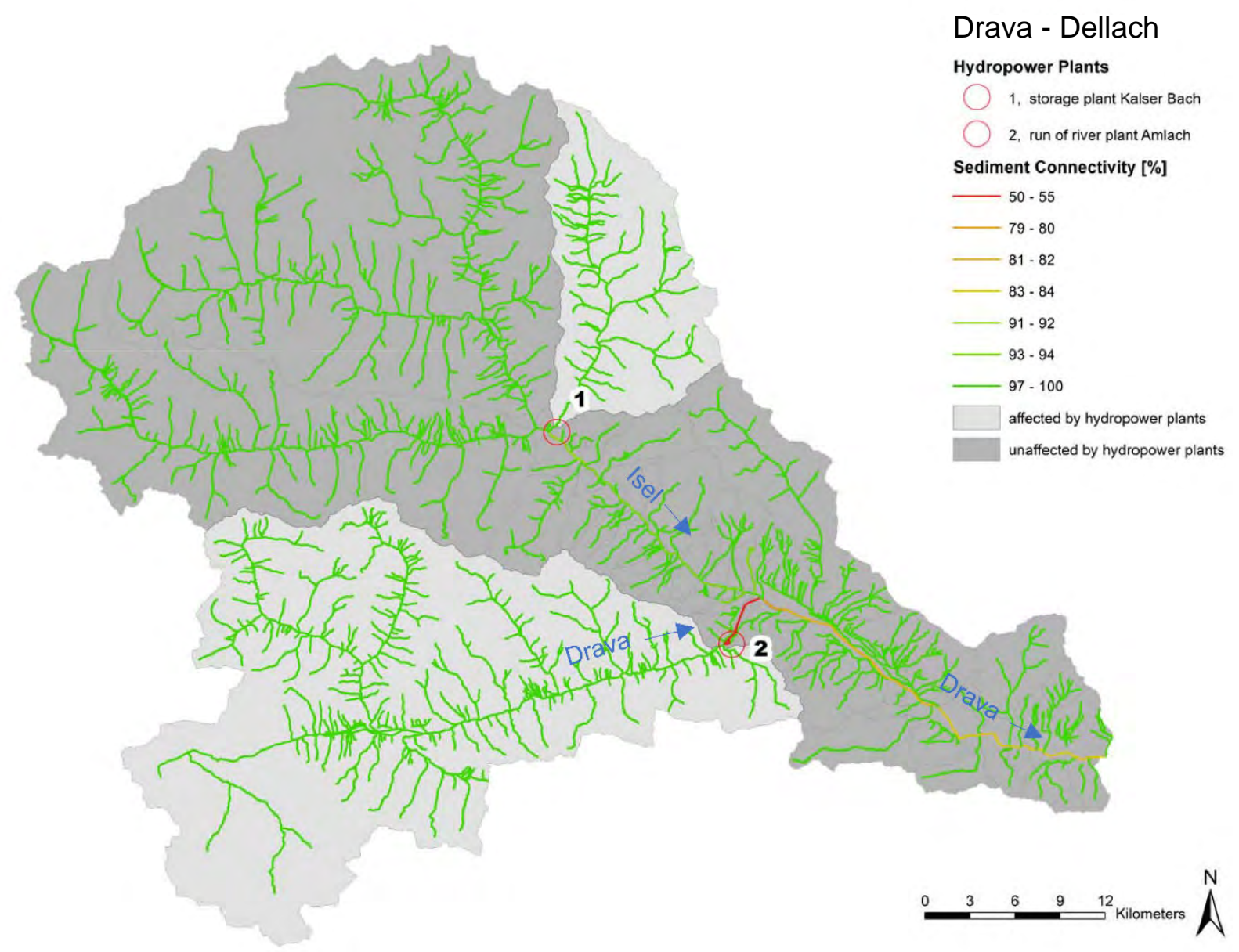

Figure 4: Sediment connectivity after construction of the second major hydropower plant and before the construction of the third major hydropower plant.

After completion of the third major hydropower plant in 2006, the Isel River and Drava River experienced a further decrease of sediment supply, which reduced the connectivity of the Drava at the confluence with the Isel River to $71 \%$ (Figure 5). Despite no other major hydropower plants in the section downstream of Lienz, the sediment connectivity increases to not more than $77 \%$ at the evaluated, restored reach.

The obtained catchment factor $F_{c}$ corresponds to the obtained sediment connectivity, accordingly, $F_{c}=0.77$. 


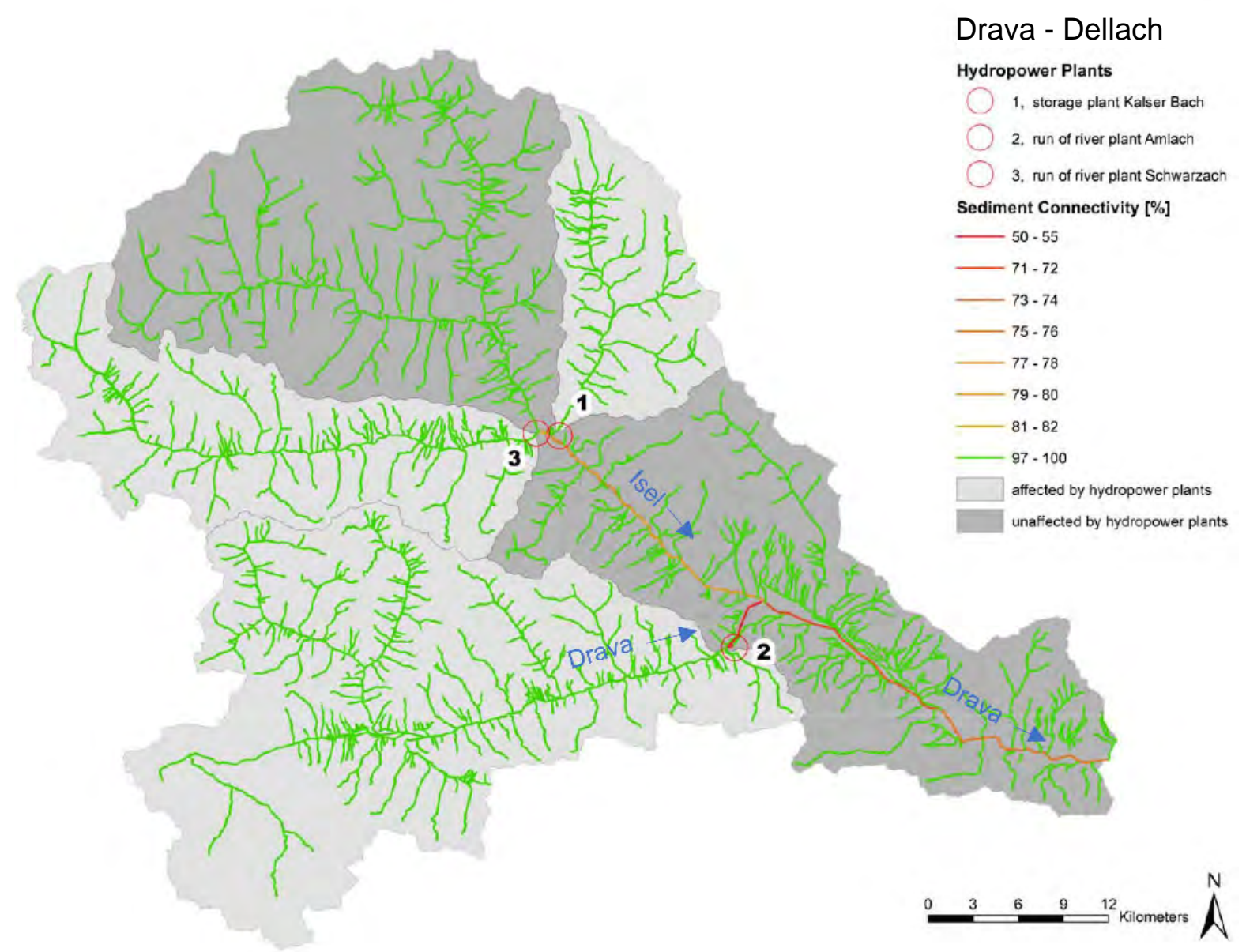

Figure 5: Sediment connectivity after construction of the second major hydropower plant and before the construction of the third major hydropower plant.

\subsubsection{Artificial channel constraints}

As no vertical constraints are present given the fact that no disturbing activities (excavation/artificial supply) occur in the evaluated reach, $\mathrm{RFI}_{\mathrm{v}}$ and $\mathrm{f}_{\mathrm{d}}$ are set to 1 and the reach factor corresponds to $\mathrm{RFI}_{\mathrm{I}}$.

Figure 6 displays a river section of the restored reach with indicated lines for RFI assessment. No flood edge was available for the right side, while the left floodplain showed to be fully affected by the railroad embankment. Considering that the right flood edge is longer than the straight railroad embankment given increased curvature, $f_{14}$ was estimated as 0.6 . The values for $f_{11}, f_{12}$ and $f_{13}$ are $0.42,0.42$ and 0.33 correspondingly, yielding together with $f_{14}$ an average value for $\mathrm{RFI}_{\mathrm{l}}$ and finally $\mathrm{Fr}$ of 0.44 . 

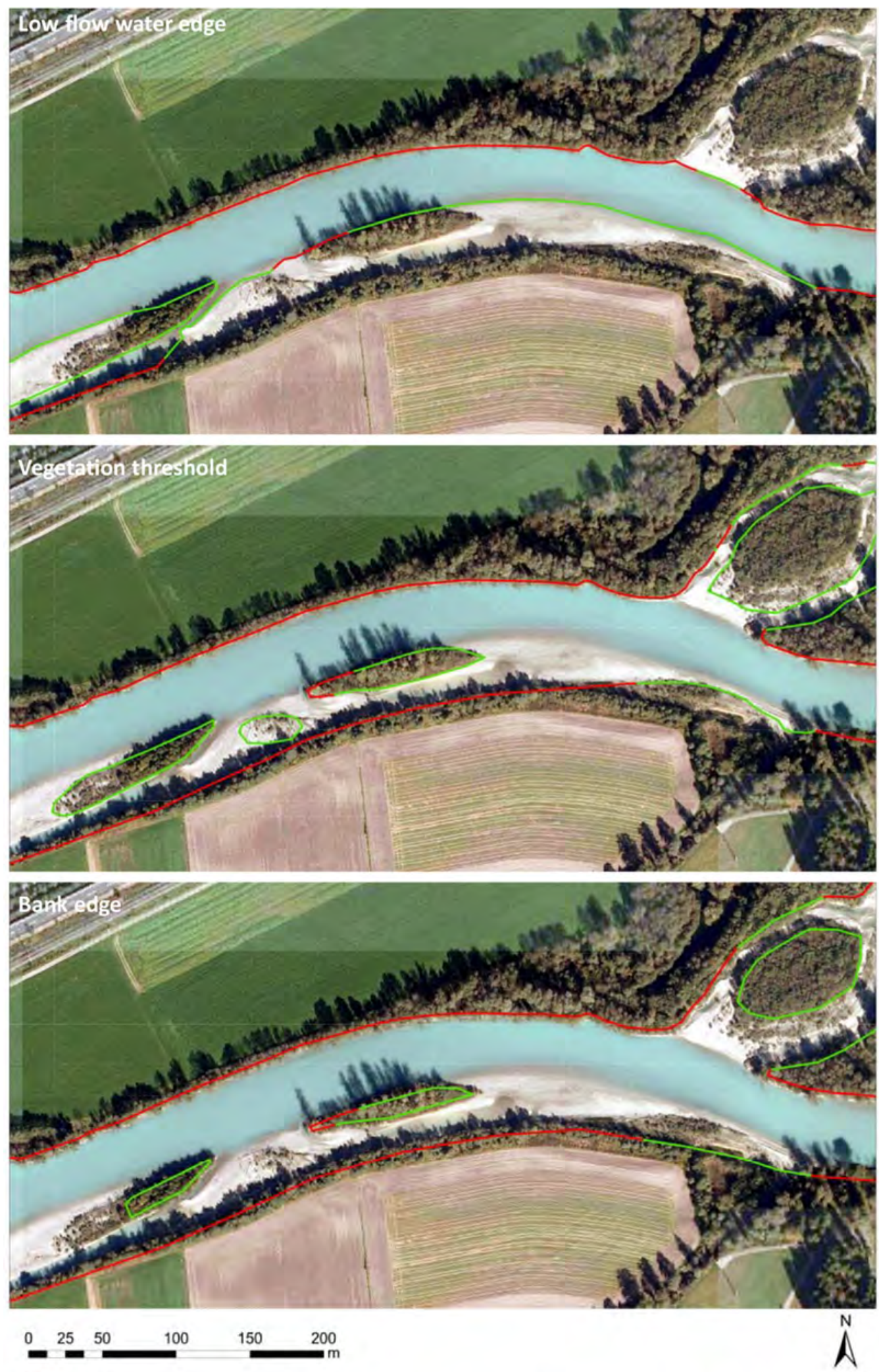

- Natural condition along this line and between this line and the line below Artificial constraint along this line and/or between this line and the line below

Figure 6: Artificiality along the low flow water edge, vegetation threshold and bank edge, already including buffer lengths to account for the larger-scale effect of bank protections as suggested by Klösch et al. (2019). 


\subsubsection{Evaluation}

The method of Klösch et al. (2019) suggests applying exponents to $F_{c}$ and $F_{r}$ to adjust the grading scale of the evaluation to a common understanding of hydromorphological state. When applying an exponent of 0.5 , as done by Klösch and Habersack (2017) in their three-steps procedure, the following evaluation result is obtained for the multi-scale score $\mathrm{S}$ of the state after construction of all three major hydropower plants:

$S=F_{C}{ }^{0.5} F_{r}{ }^{0.5}=0.58$

which according to 5-step marking-scale with constant intervals between 0 and 1 corresponds to an "acceptable" state. Before the construction of the hydropower plant Schwarzach in 2005, the hydromorphology would have reached a "good state" $(S=0.605)$, provided that the reach scale conditions of artificiality were the same.

In contrast to the original HYMET method, the presented methodology does not consider sediment budgets along the river network, which would show the sustainability of the present condition. Klösch et al. (2019) suggest that the step of river network evaluation should be replaced by assessing the trajectory of the local hydromorphology in the evaluated reach. For that purpose, the sediment budget within the reach can be assessed, bed levels can be evaluated, or morphological indicators such as braiding intensity can be analysed. The state of the trajectory may be included as an additional factor in the evaluation; then the score obtained here by the two-step procedure would only be reached at reaches showing a balanced sediment budget at dynamic equilibrium. By considering the trajectory, the score values would approach the smaller scores obtained with the original HYMET method. 


\section{WP 2 - Monitoring of sediment transport and morphodynamics}

\subsection{Introduction}

The work package aims on monitoring and analysing sediment data at existing measurement sites installed at a wide range of river types in Austria. Inherent restrictions and possibilities, when deploying these instruments were investigated by performing tests in the BOKU research channel. The main objectives of this work package are to continue monitoring work at the measuring sites and perform a comprehensive analysis of existing and new measurement data. Over the last decade (at some sites even longer) a lot of valuable sediment data was sampled at many different measurement sites but so far no project existed addressing the synopsis and integrative analysis of all this data. We aimed to increase knowledge concerning detailed bed load and suspended sediment transport processes and the interaction of these two sediment transport types (sediment forensics). Furthermore, we will present examples of applications in the field of sediment management, where previously difficult to explain sediment phenomena could be clarified by improved process understanding. In the future, this should enable a sediment management adapted to the respective catchment area.

\subsection{Sediment Monitoring Stations}

\subsubsection{Suspended load monitoring stations}

The hydrographic yearbook publishes suspended load data since the year 2008. The dataset includes load curves of the mean suspended load concentration and discharge, main figures and extreme values, as well as other representative figures. With a total of 34 measuring sites (Figure 7), the Austrian basic monitoring network provides suspended load time series which represent the basis for various applications.

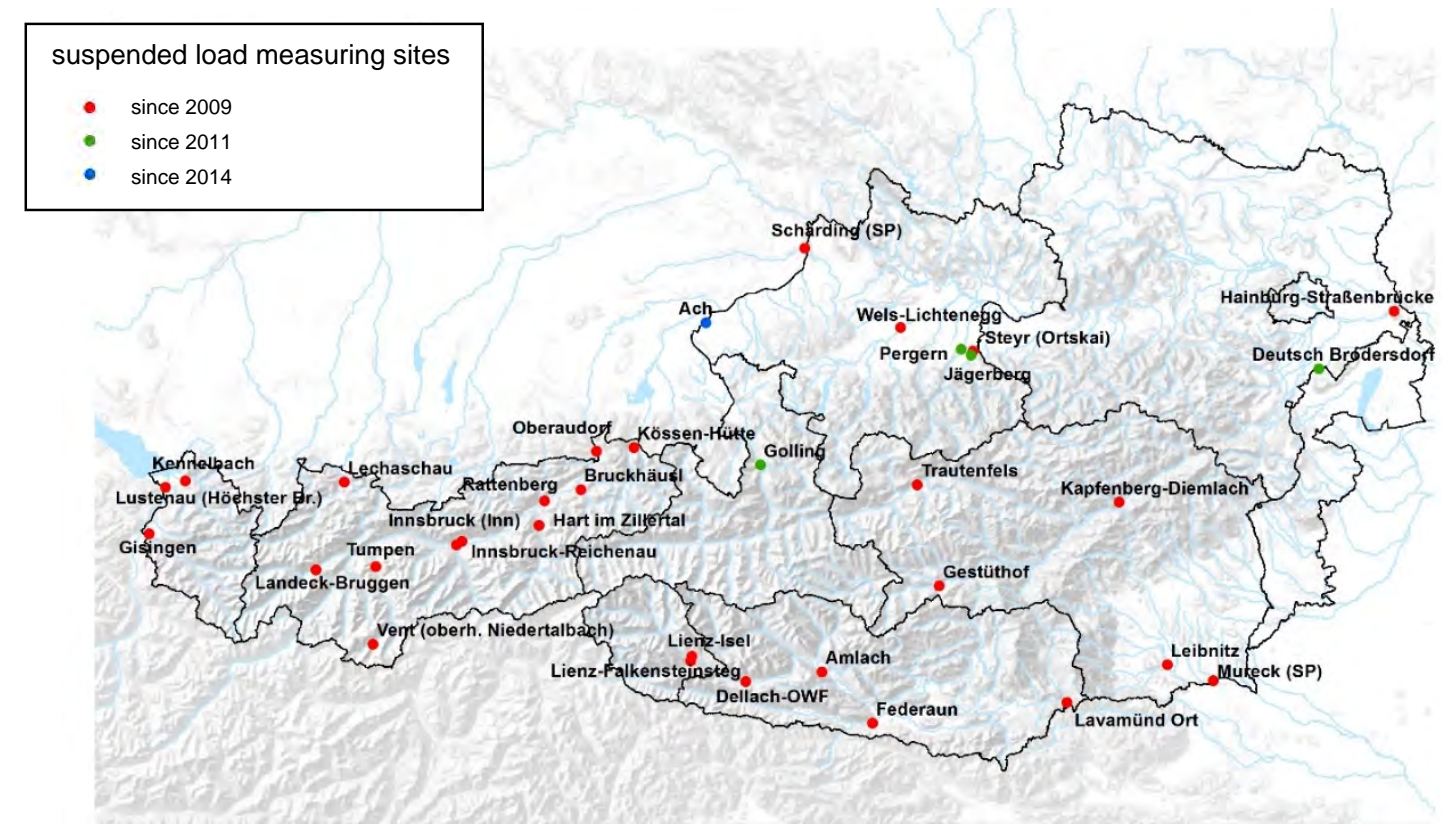

Figure 7: Suspended sediment measuring sites in Austria 


\subsubsection{Bedload monitoring stations}

The Institute of Hydraulic Engineering and River Research (IWA) is measuring bedload transport at 7 monitoring sites in Austria ranging from small alpine rivers (Rofenache) to large gravel bed rivers (Danube). Figure 8 gives an overview of the location of the bedload monitoring sites. The wide range of catchment characteristics (catchment area, river width, mean flow, slope) is displayed in Figure 9.

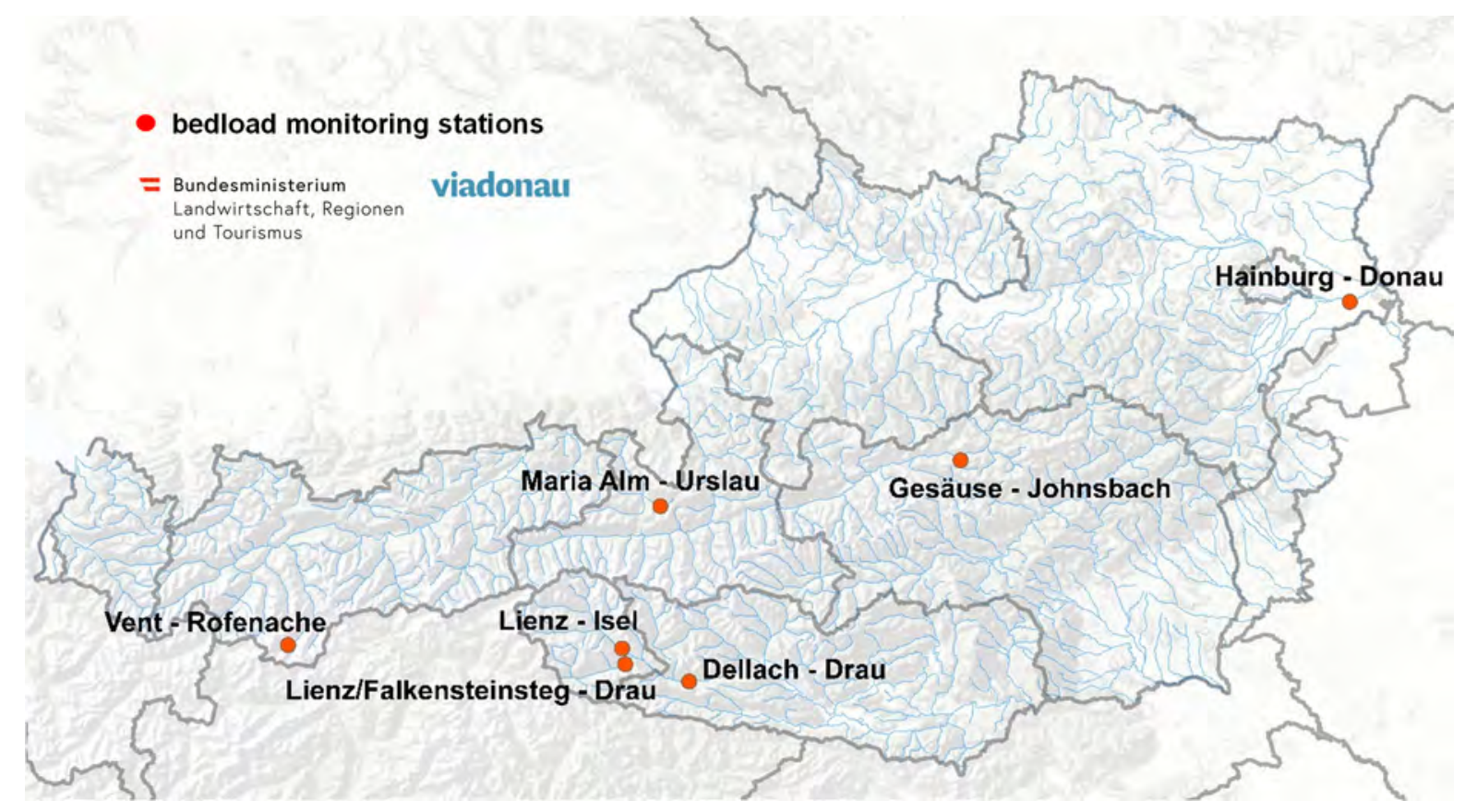

Figure 8: Bedload transport measuring sites in Austria operated by the BOKU Vienna

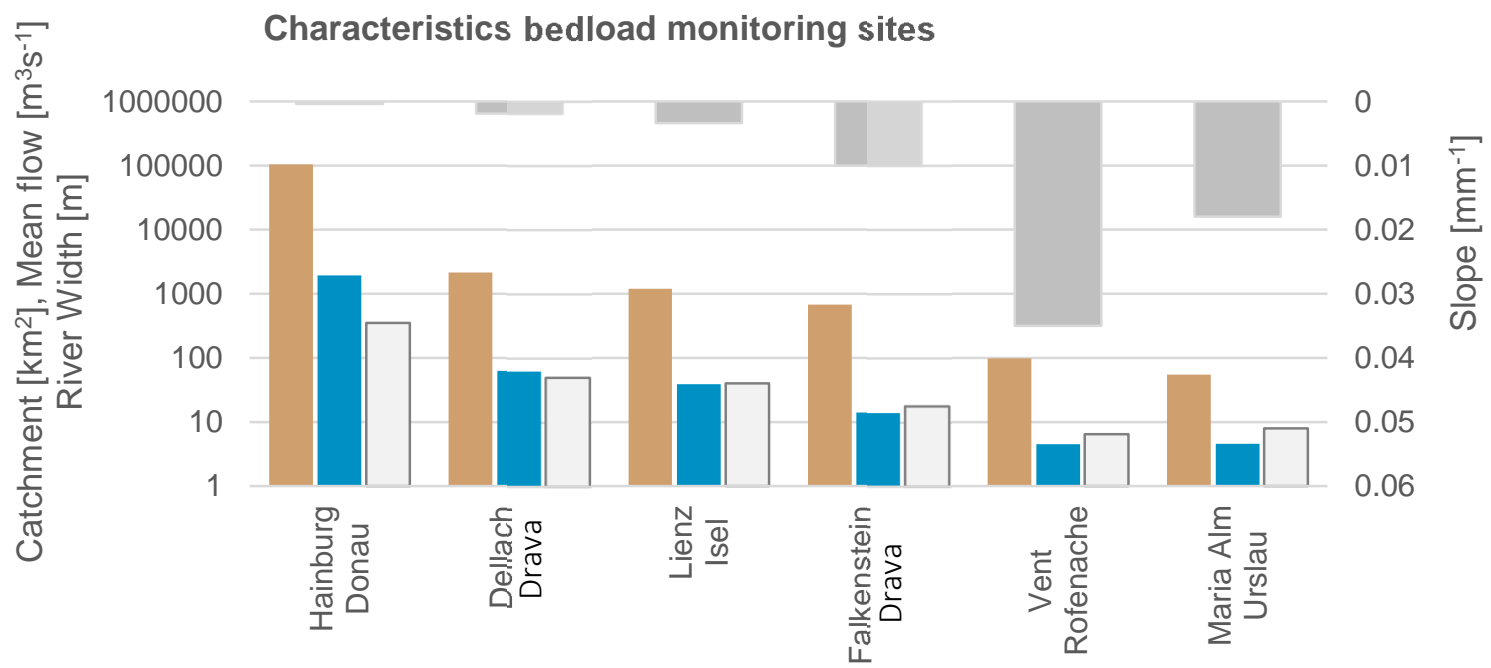

- Catchment

- MQ

口River Width

国 Slope

Figure 9: Characteristics of bedload monitoring sites 
Measuring site

River

Location

Measurement of water discharge,

suspended- and bedload

Elevation [m a.s.I.]

Sediment monitoring since

River slope $\left[\mathrm{mm}^{-1}\right]$

River width [m]

Measuring devices

\section{Catchment}

Catchment size $\left[\mathrm{km}^{2}\right]$

Elevation [m a.s.I.] *

Slope [\%]

Geology *

Land use *

6.5

98
1891

2000

0.035

geophone plates, vent sampler, turbidity sensor, water gauge

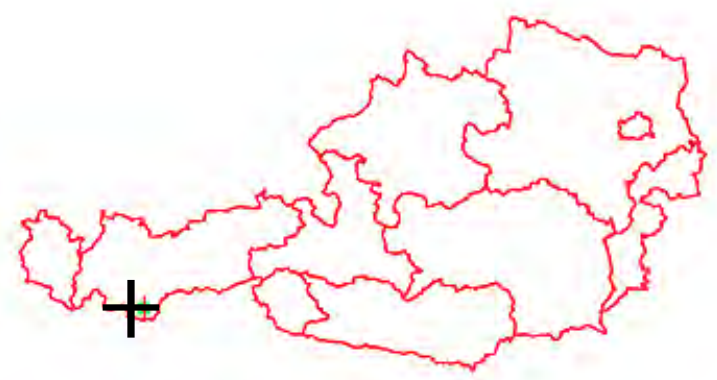

$\min 1890, \max 3763$, mean 2891

min 0, max 392, mean 50, STD 31

crystalline and migmatites $80 \%$, loamy materials $18 \%$, others $2 \%$

bare rocks $44 \%$, glaciers $29 \%$, sparsely vegetated areas $16 \%$, natural grasslands $7 \%$, others $4 \%$

\section{Hydrology}

$\begin{array}{ll}\text { Mean annual precipitation }[\mathrm{mm}] & \\ \text { MQ }\left[\mathrm{m}^{3} \mathrm{~s}^{-1}\right]^{* *} & 1862 \\ \text { NNQ }\left[\mathrm{m}^{3} \mathrm{~s}^{-1}\right]^{* *} & 4.55 \\ \text { HHQ }\left[\mathrm{m}^{3} \mathrm{~s}^{-1}\right]^{* *} & 0.09 \\ \text { * } & 109\end{array}$

\section{Distinctive features:}

Glacier: $29 \%$ of catchment area

Elevation: highest elevated sediment measuring station

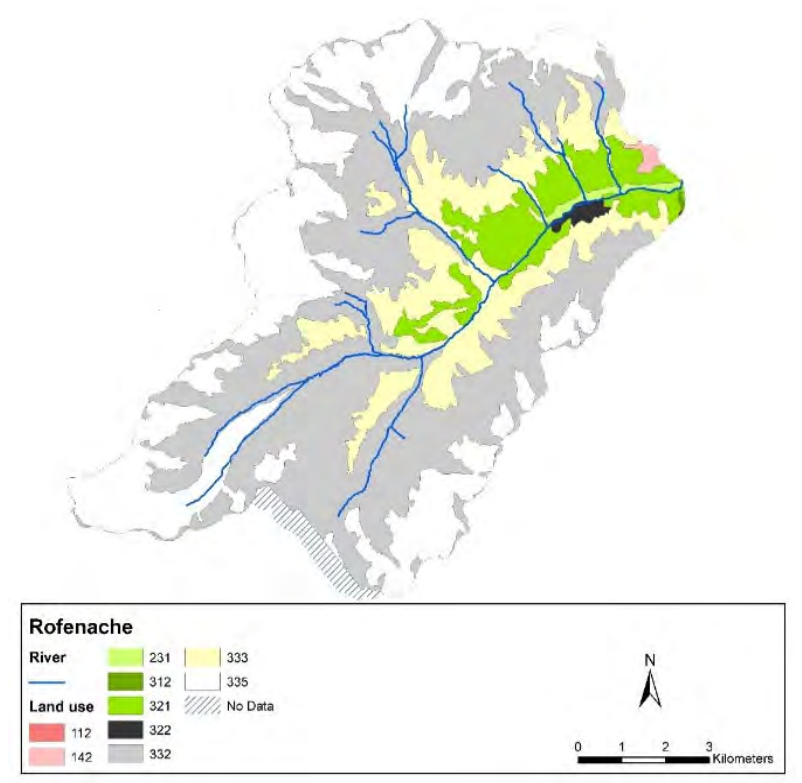

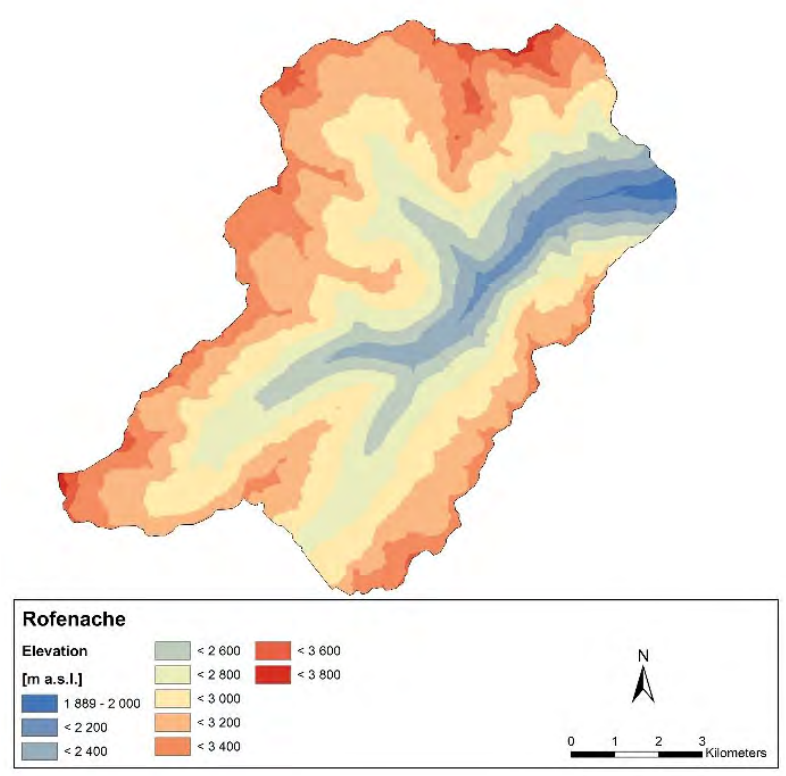

Mostly crystalline geology (80\%)

No sediment barriers until bedload monitoring station,

* Data from GIS catchment analysis, ** Hydrographic yearbook 2013 


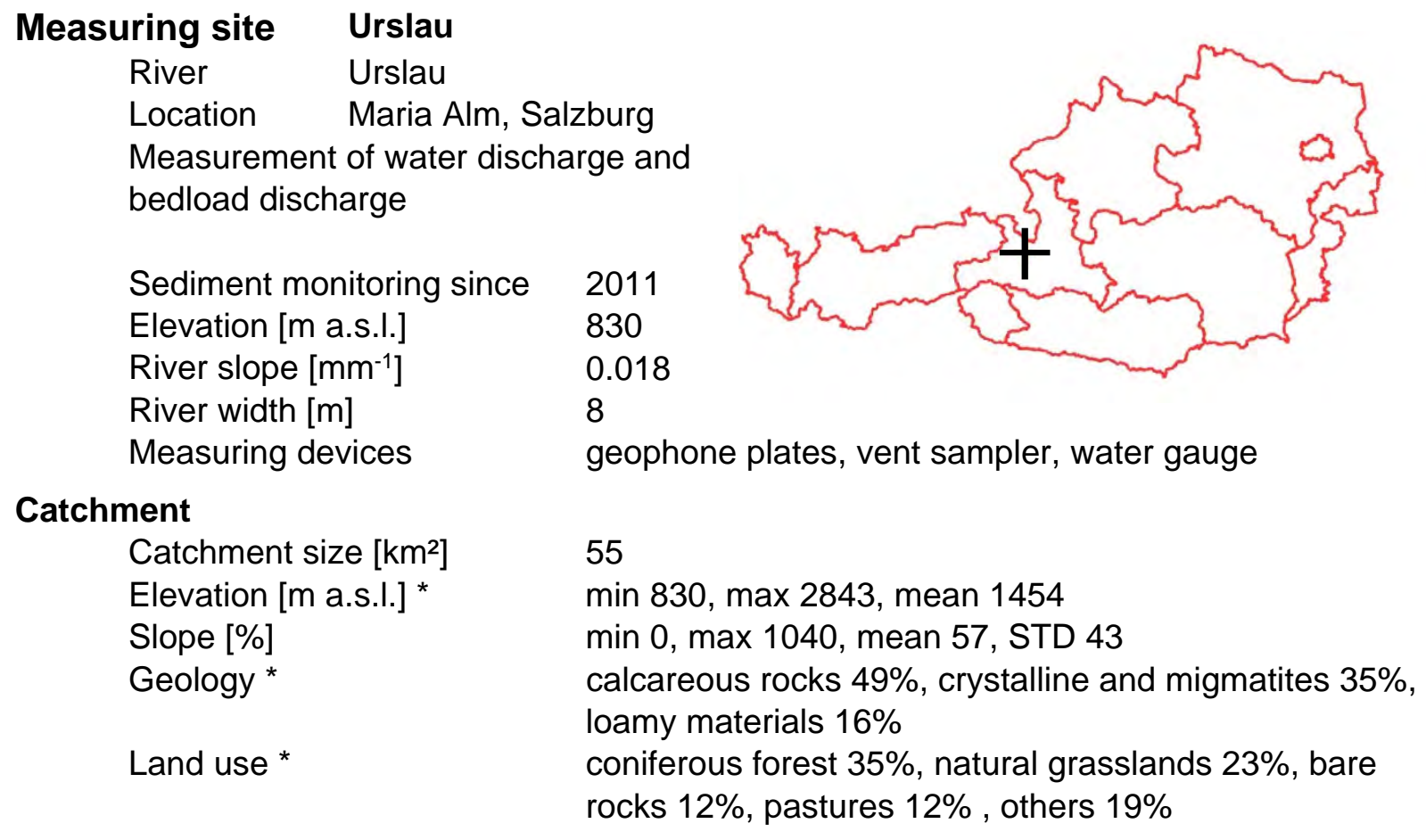

\section{Hydrology}

\begin{tabular}{|c|c|}
\hline Mean annual precipitation [mm] * & 1519 \\
\hline $\mathrm{MQ}\left[\mathrm{m}^{3} \mathrm{~s}^{-1}\right]$ ** & 4.57 \\
\hline $\mathrm{NQ}\left[\mathrm{m}^{3} \mathrm{~s}^{-1}\right] \star \star \star$ & 0.25 \\
\hline $\mathrm{HHQ}\left[\mathrm{m}^{3} \mathrm{~s}^{-1}\right]^{\star *}$ & 112 \\
\hline
\end{tabular}

\section{Distinctive features:}

Geology: 49\% calcareous rocks

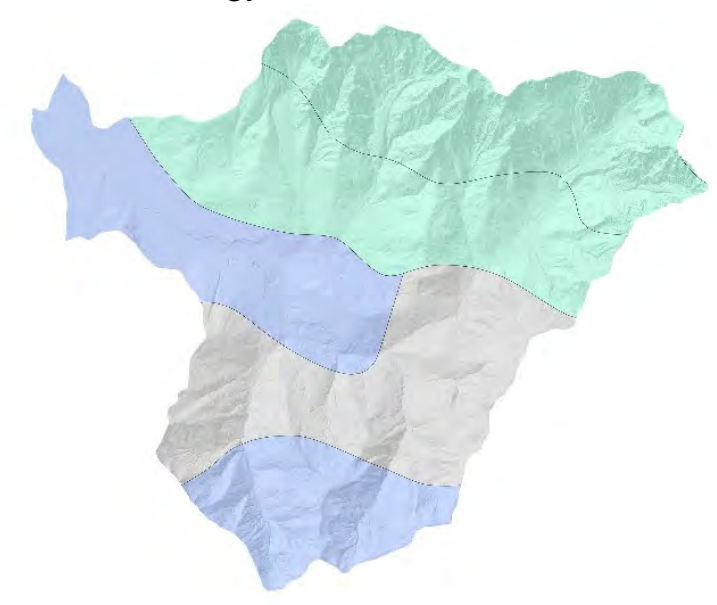

Slope: slope with max $1040 \%$ and mean 57\%
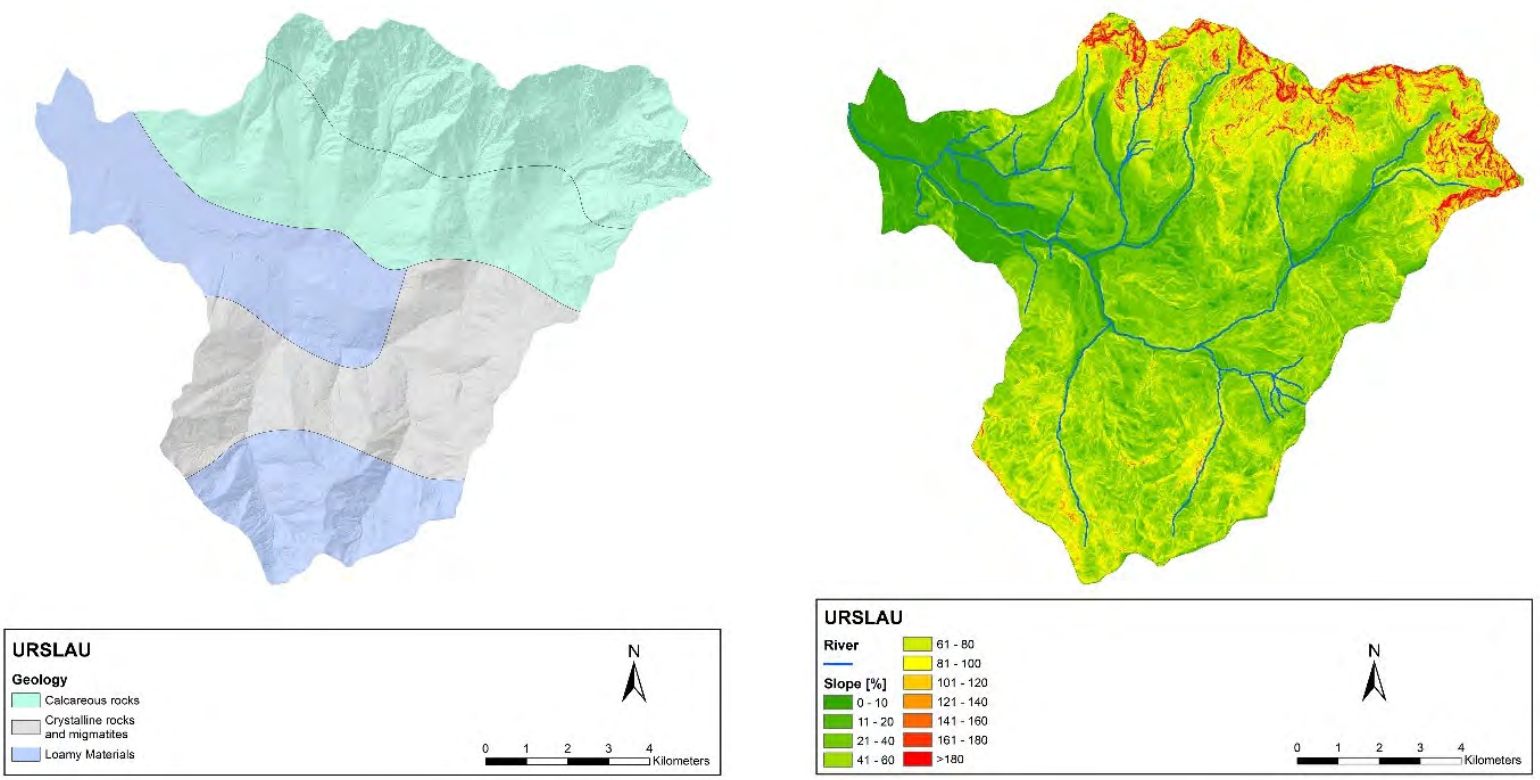

No sediment barriers until bedload measuring station Mostly secured riverbanks

* Data from GIS catchment analysis, ** Hydrographic yearbook 2015 


\section{Measuring site}

River

Location

Measurement of water discharge, suspended- and bedload

Sediment monitoring since

Elevation [m a.s.l.]

River slope $\left[\mathrm{mm}^{-1}\right]$

River width [m]

Measuring devices

\section{Catchment}

Catchment size $\left[\mathrm{km}^{2}\right]$

Elevation [m a.s.I.] *

Slope [\%]

Geology *

Land use * $3 \%$
Iselsteg

Isel

Lienz, Tyrol

2006

667

0.0034

40

geophone plates, Isel sampler, turbidity sensor, water gauge

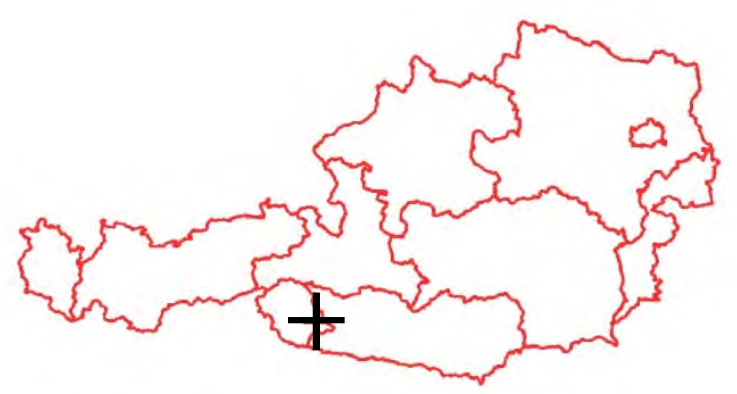

\section{7}

$\min 667, \max 3727$, mean 2147

$\min 0$, max 345, mean 55, STD 25

Crystalline and migmatites 93\%, Loamy materials 4\%, others

coniferous forest $25 \%$, bare rocks $24 \%$, natural grasslands $23 \%$, sparsely vegetated areas $15 \%$, glaciers $4 \%$, others $9 \%$

\section{Hydrology}

\begin{tabular}{|c|c|}
\hline Mean annual precipitation $[\mathrm{mm}]$ * & 1585 \\
\hline $\mathrm{MQ}\left[\mathrm{m}^{3} \mathrm{~s}^{-1}\right] \star \star \star$ & 39. \\
\hline $\mathrm{NNQ}\left[\mathrm{m}^{3} \mathrm{~s}^{-1}\right]^{\star \star}$ & 3.0 \\
\hline $\mathrm{HHQ}\left[\mathrm{m}^{3} \mathrm{~s}^{-1}\right]^{\star \star}$ & 720 \\
\hline
\end{tabular}

\section{Distinctive features:}

Glacier: $4 \%$ of catchment area

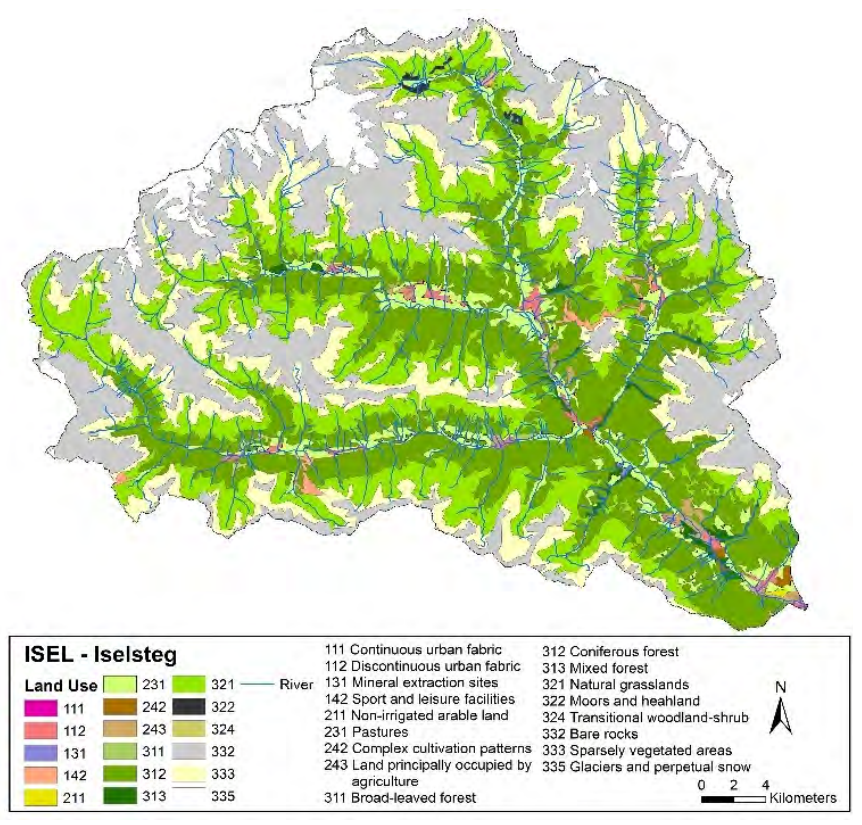

Geology: 92\% crystalline and migmatites

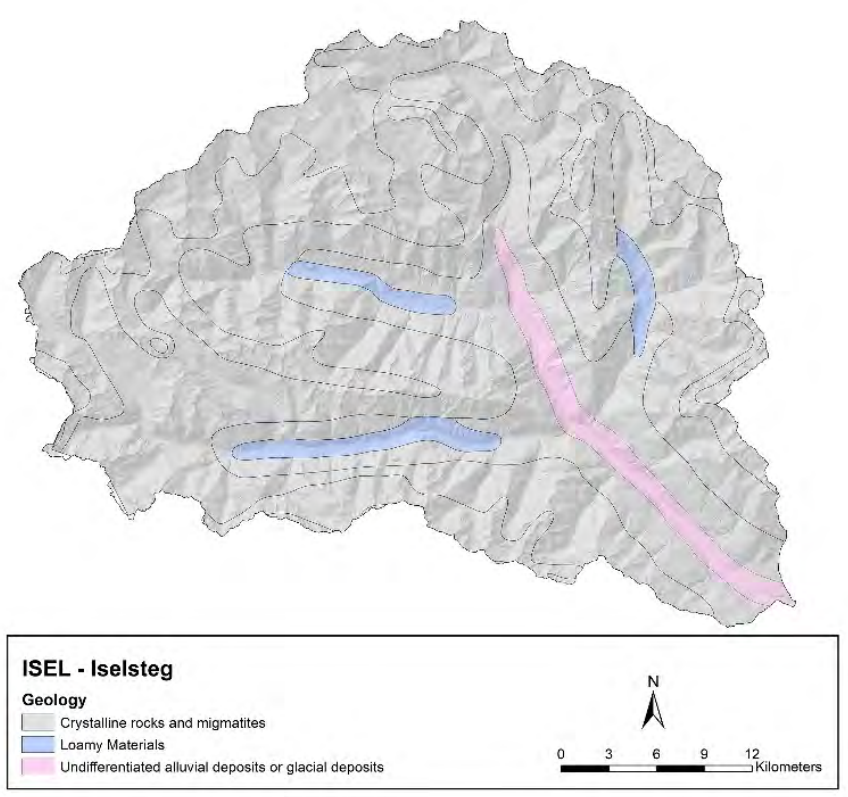

* Data from GIS catchment analysis, ** Hydrographic yearbook 2013 


\section{Measuring site \\ River \\ Location \\ Measurement of water discharge, suspended- and bedload \\ Sediment monitoring since \\ Elevation [m a.s.I.] \\ River slope $\left[\mathrm{mm}^{-1}\right]$ \\ River width [m] \\ Measuring devices}

\section{Catchment}

Catchment size $\left[\mathrm{km}^{2}\right]$

Elevation [m a.s.I.] *

Slope [\%]

Geology *

Land use *

680
2002

680

0.01

18

Geophone plates, vent sampler, turbidity sensor, water gauge

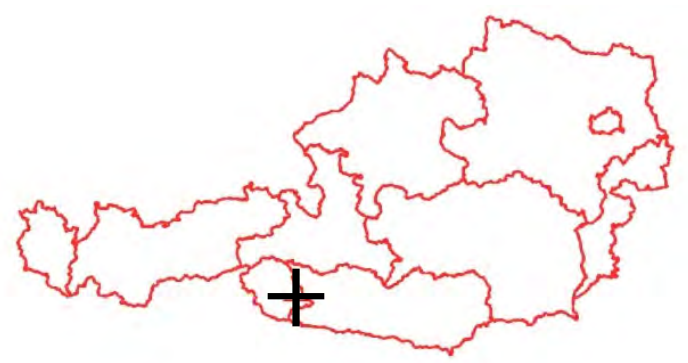

$\min 680$, $\max 3057$, mean 1848

min 0, max 368, mean 51, STD 27

crystalline and migmatites $45 \%$, calcareous rocks $13 \%$, loamy materials $18 \%$, others $34 \%$

coniferous forest $45 \%$, natural grasslands $18 \%$, sparsely vegetated areas $14 \%$, bare rocks $10 \%$, pastures $8 \%$, others $5 \%$

\section{Hydrology}

\begin{tabular}{|c|c|}
\hline Mean annual precipitation [mm] * & 1218 \\
\hline $\mathrm{MQ}\left[\mathrm{m}^{3} \mathrm{~s}^{-1}\right]$ ** & 14. \\
\hline$N N Q\left[m^{3} \mathrm{~s}^{-1}\right]$ ** & 0.7 \\
\hline $\mathrm{HHQ}\left[\mathrm{m}^{3} \mathrm{~s}^{-1}\right]^{\star *}$ & 156 \\
\hline
\end{tabular}

\section{Distinctive features:}

Sediment regime influenced by

hydroelectric powerplant

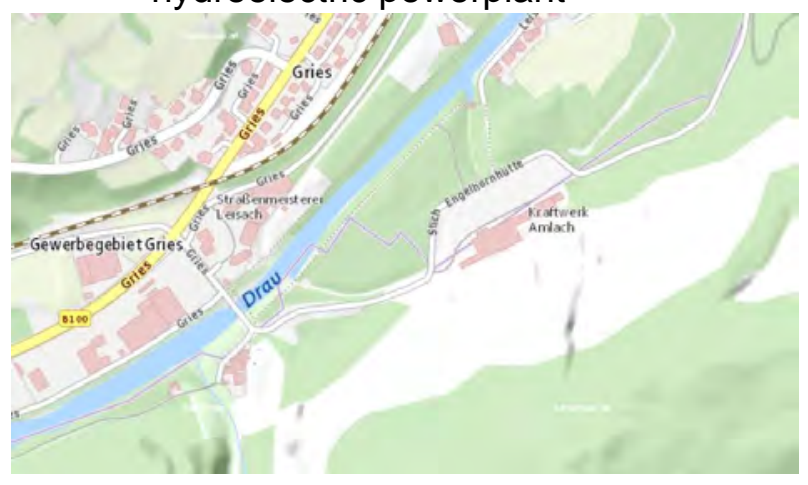

Vegetation: $45 \%$ coniferous forest

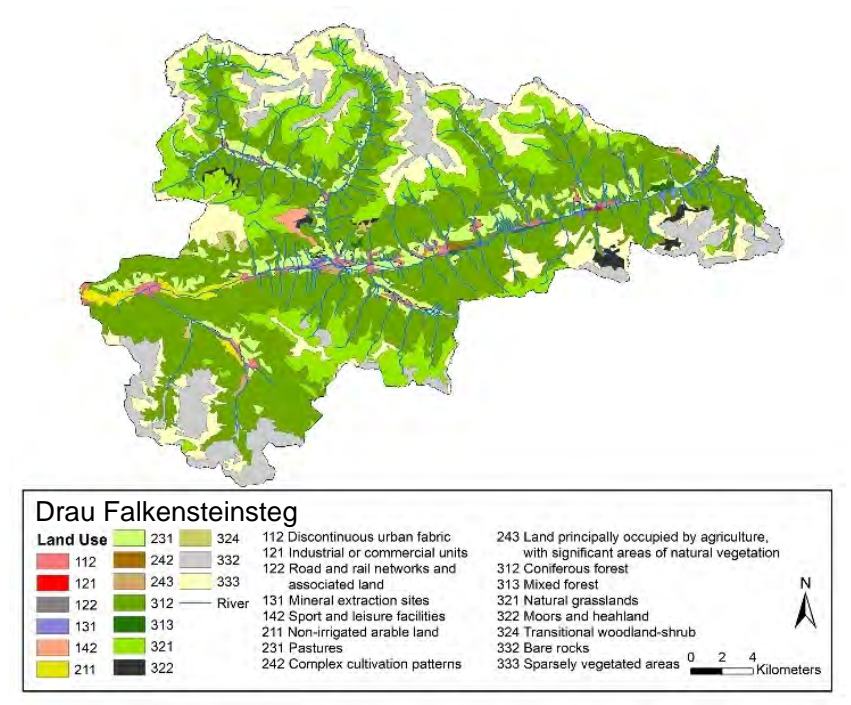

* Data from GIS catchment analysis, ** Hydrographic yearbook 2013 


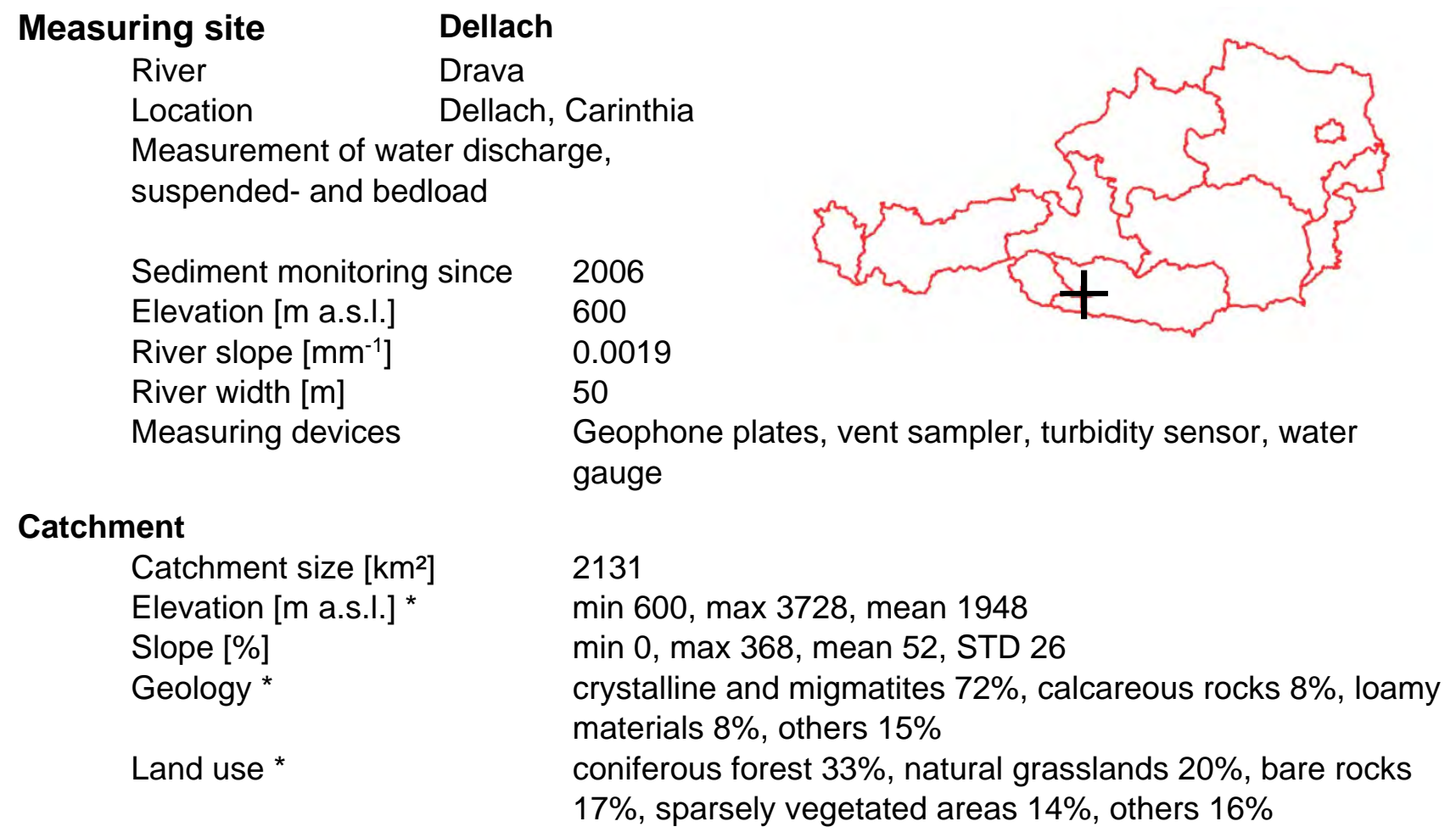

\section{Hydrology}

\begin{tabular}{|c|c|}
\hline Mean annual precipitation [mm] * & 1431 \\
\hline $\mathrm{MQ}\left[\mathrm{m}^{3} \mathrm{~s}^{-1}\right]^{\star \star}$ & 62. \\
\hline $\mathrm{NQ}\left[\mathrm{m}^{3} \mathrm{~s}^{-1}\right]$ ** & 8.4 \\
\hline $\mathrm{HHQ}\left[\mathrm{m}^{3} \mathrm{~s}^{-1}\right]^{\star \star}$ & 850 \\
\hline
\end{tabular}

Distinctive features: River system Drava and Isel

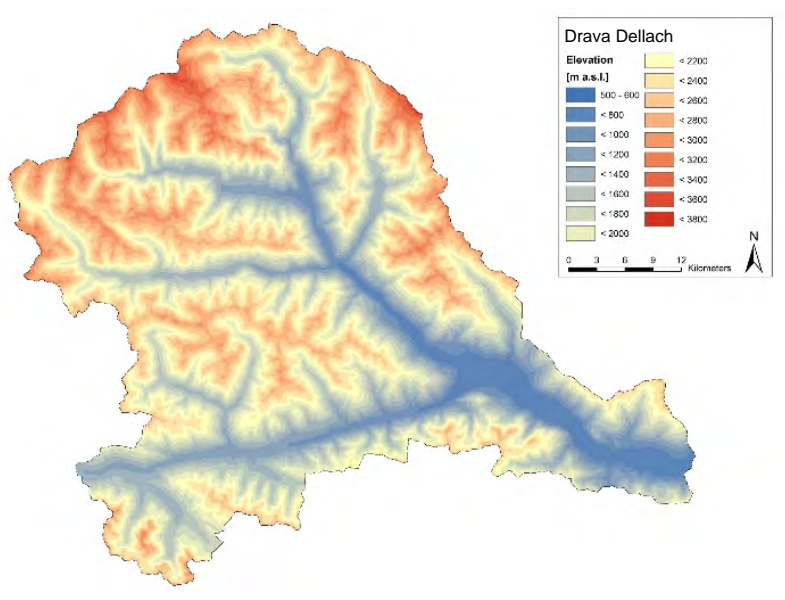

Large gravel bed river

* Data from GIS catchment analysis, ** Hydrographic yearbook 2013 


\section{Measuring site}

River

Location

\section{Donau Hainburg}

Danube

Hainburg, Lower

Austria

Measurement of water discharge, suspended- and bedload

Elevation [m a.s.I.]

Stream-km

Catchment size $\left[\mathrm{km}^{2}\right]$

Slope $\left[\mathrm{mm}^{-1}\right]$

With [m]

Measuring devices
138

1886.24

104177

0.0004

300-350

BfG-sampler, turbidity sensor, water gauge

\section{Hydrology}

$$
\begin{aligned}
& \text { MQ }\left[\mathrm{m}^{3} \mathrm{~s}^{-1}\right]^{* *} \\
& \text { RNQ }\left[\mathrm{m}^{3} \mathrm{~s}^{-1}\right]^{* *} \\
& \text { HHQ }\left[\mathrm{m}^{3} \mathrm{~s}^{-1}\right]^{* *}
\end{aligned}
$$

$$
\begin{aligned}
& 1930 \\
& 980 \\
& 10980
\end{aligned}
$$

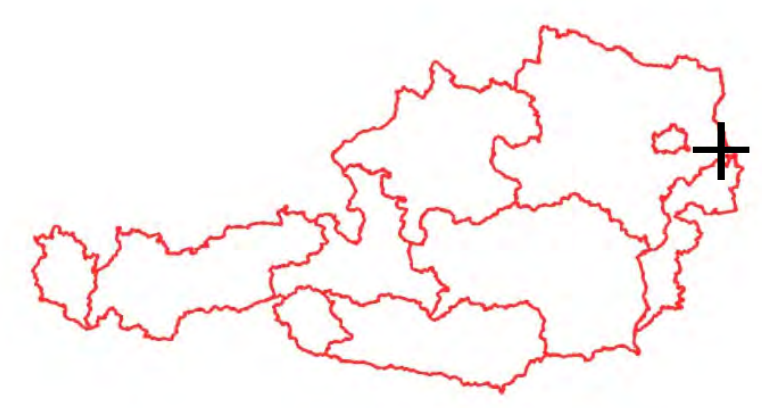

\section{Distinctive features:}

Largest river in Austria

Smallest gradient at measuring station

No natural sediment supply due to hydroelectric powerplants

Anthropogenic influences due to international waterway management

Movement of sediments within the Danube system
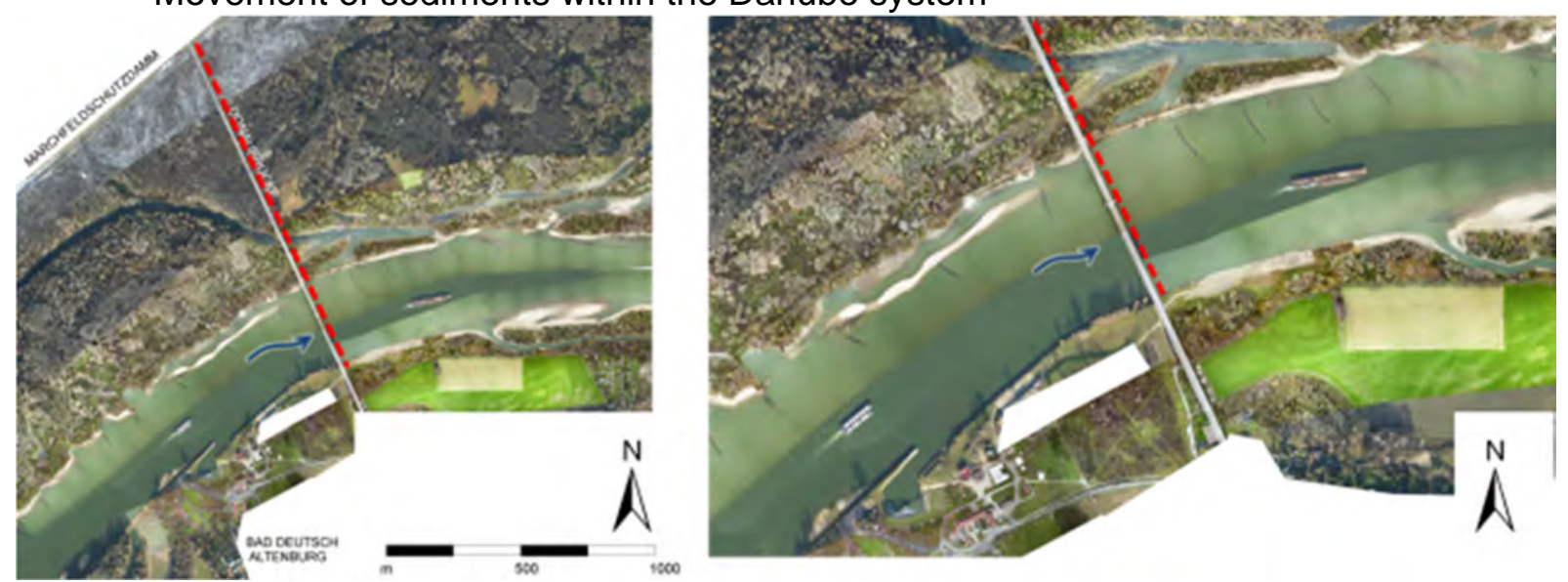

Figure 10: Plan view Hainburg Strassenbrücke / Donau - November 2014 - flow direction from left to right (IWA/BOKU; aerial images: viadonau)

** Hydrographic yearbook 2016 
River

Location

Gail

Rattendorf

East Tyrol, Carinthia

River slope $\left[\mathrm{mm}^{-1}\right]$

River width [m]

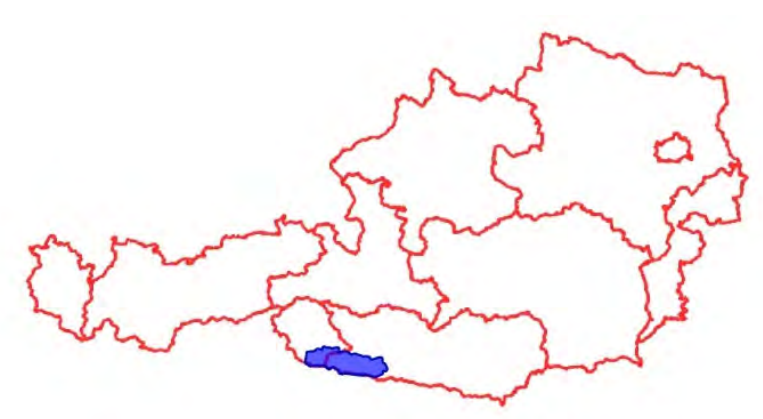

\section{Catchment}

Catchment size $\left[\mathrm{km}^{2}\right]$

\section{9}

Elevation [m a.s.l.] *

$\min 597, \max 2778$, mean 1476

Slope [\%]

Geology *

$\min 0$, max 1414, mean 58, STD 39

calcareous rocks $48 \%$, crystalline and migmatites $38 \%$, loamy materials $11 \%$, others $3 \%$

Land use * coniferous forest $38 \%$, natural grasslands $21 \%$, mixed forest $15 \%$, pastures $5 \%$, others $21 \%$

\section{Hydrology}

Mean annual precipitation $[\mathrm{mm}]$ *

$\mathrm{MQ}\left[\mathrm{m}^{3} \mathrm{~s}^{-1}\right]$ **

$\mathrm{NQ}\left[\mathrm{m}^{3} \mathrm{~s}^{-1}\right]$ **

$\mathrm{HHQ}\left[\mathrm{m}^{3} \mathrm{~s}^{-1}\right]$ **

\section{Distinctive features:}

88 transverse structures in the catchment

Slope: slope with $\max 1414 \%$ and mean $60 \%$
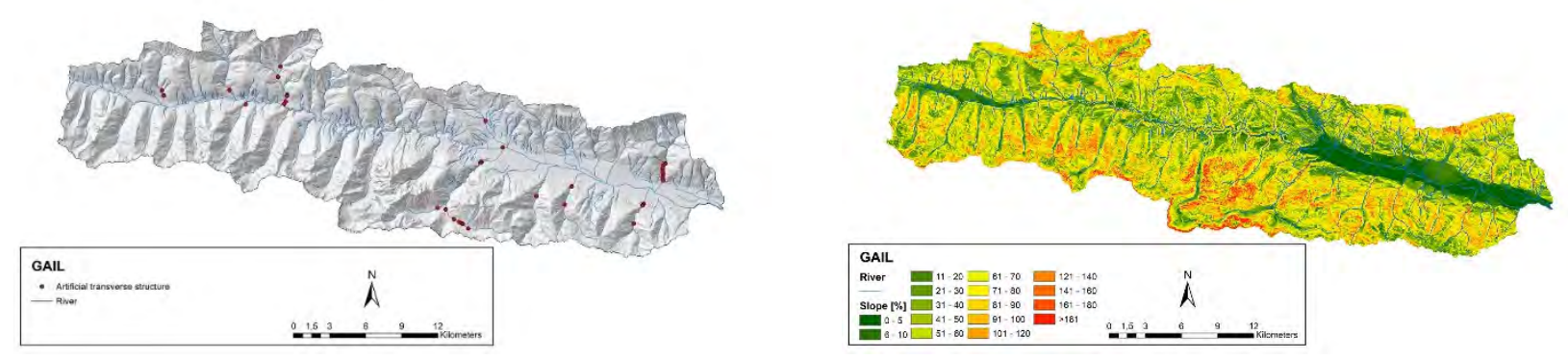

\footnotetext{
* Data from GIS catchment analysis, ** Hydrographic yearbook 2015
} 


\subsection{Sediment Monitoring - Methodology: Measurement Techniques/Devices}

\subsubsection{Suspended Sediment monitoring}

The purpose of the monitoring is to determine the suspended sediment concentration (SSC) (mg/l), suspended sediment load (SSL) (kg/s), annual SSL (t/y), suspended sediment yield $(\mathrm{t} / \mathrm{km} 2 \mathrm{y})$ and analyse the particle size distribution (PSD). The monitoring method, the suspended sediment load calculation method and the suspended sediment concentration measurement method refers to the guideline of surveying suspended sediment load (BMLFUW 2017).

The following devices are used during the measurements: US-P63 point-integrating sampler (Figure 11, left), US-P61A point-integrating sampler (Figure 11, right) and Solitax ts-line turbidity sensor (Hach-Lange) (Figure 12).
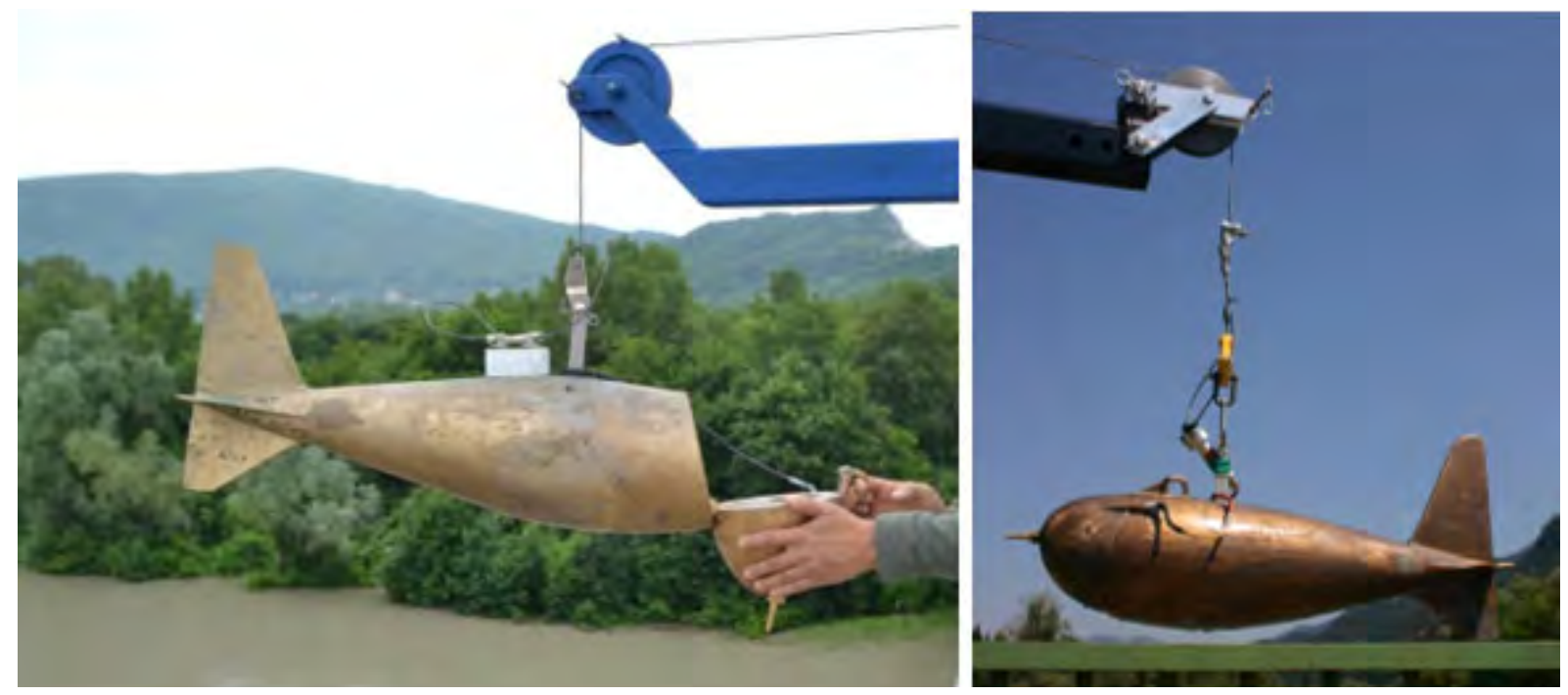

Figure 11: US-P63 (left) and US-P61 A1 point-integrating samplers (right) (IWA/BOKU)
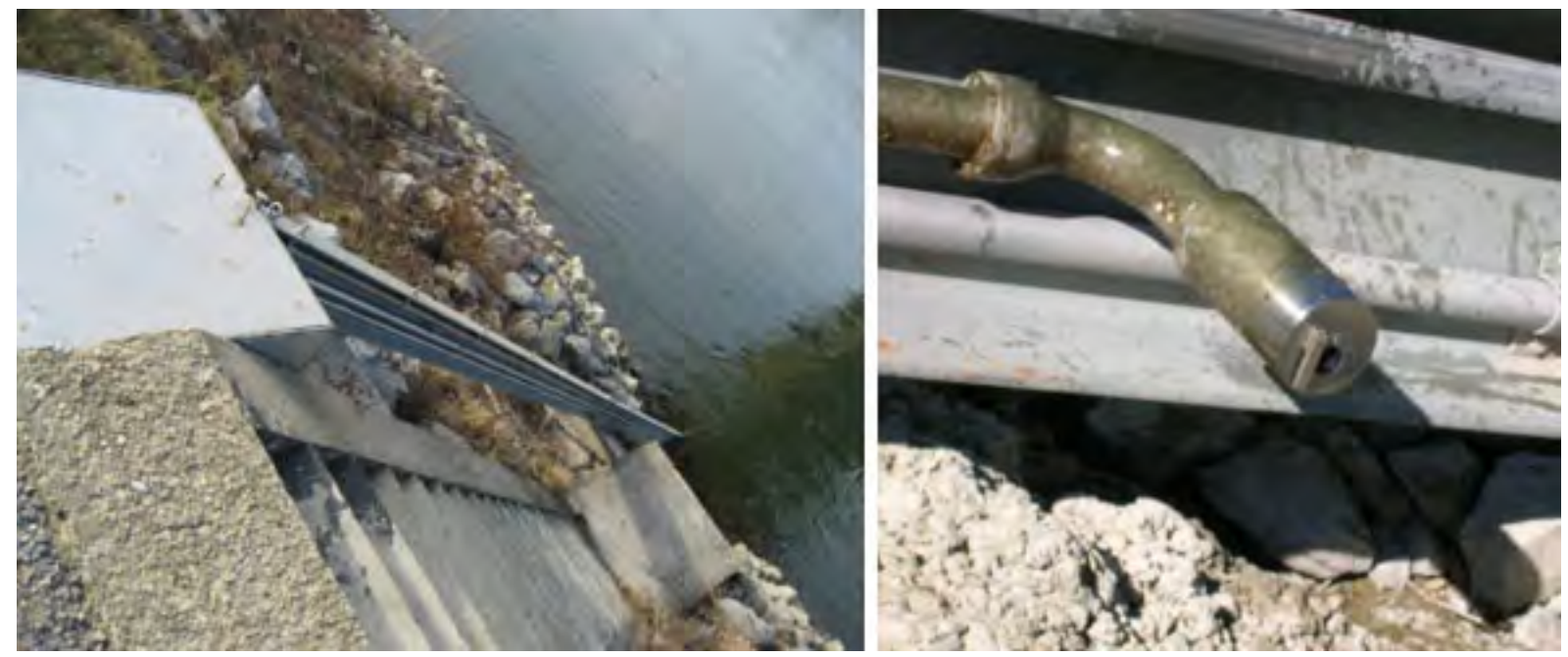

Figure 12: Solitax ts-line turbidity sensor (viadonau)

A combination of direct and indirect methods is applied to measure the suspended sediment transport. To measure the temporal variability of the suspended sediment transport, an optical sensor is installed, which continuously records the turbidity at one point in the cross-section 
(near the river bank). The optical sensor is calibrated using a Formazin turbidity standard and the data represent $\mathrm{mg} / \mathrm{l}$. The sensor has to be calibrated in-situ using water samples. The sampling frequency of the water samples taken close to the sensor is dependent on the suspended sediment concentration and varies from once a week up to several times a day during flood events.

Additionally, the distribution of the suspended sediment concentration in the cross-section (spatial variability) is considered. To establish the cross-sectional mean concentration, the multi-point method is applied. Using this method, the suspended sediment concentration and flow velocity are measured in various verticals and different depths.

The sampling is undertaken up to 4 times a year using a suspended sediment sampler applied with a trailer and a cable from the bridge. The flow velocities are measured by using an ADCP (Acoustic Doppler Current Profiler), an ADV (Acoustic Doppler Velocimeter) or a current meter.

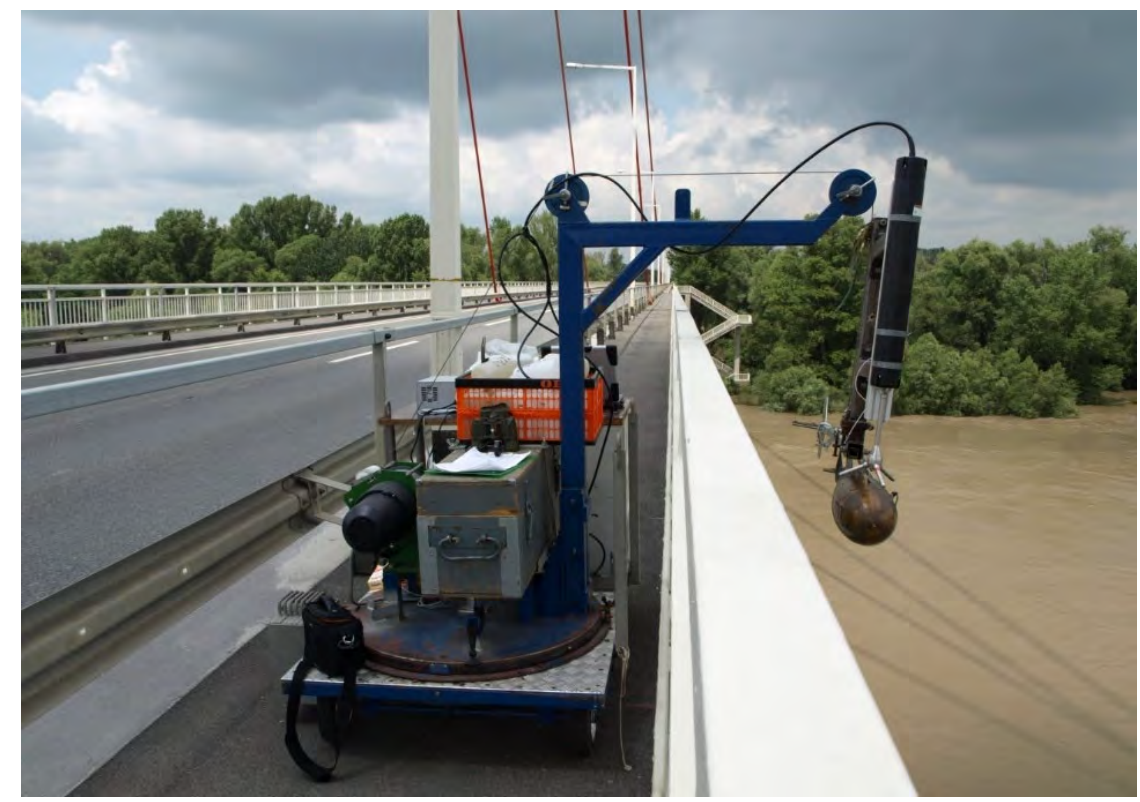

Figure 13: The trailer on the bridge with the sediment sampler and the ADV on cable (IWA/BOKU)

To calculate SS discharge, first the turbidity data has to be calibrated from the water samples. To calibrate the turbidity data, two different methods can be applied, which can also be used in combination. The first method calculates a correction factor between turbidity data and water samples for each occasion when water samples are collected. By using linear interpolation between these time steps, a correction factor (probe factor) is calculated for each turbidity value. The second method uses a simple linear regression (cross-sectional characteristic) between turbidity data and the calibration samples to convert the turbidity data into a record of SSC close to the sensor.

Furthermore, the SS transport and mean SS concentration in the cross-section is determined using the multi-point method, where the SS concentration and flow velocity are measured in various verticals and different depths. Alternatively, the SSC in the cross-section is calculated 
from the ADCP backscatter signal combined with water samples using the sonar equation. As the ADCP simultaneously measures the flow velocity, the SS transport and mean concentration in the cross-section can be calculated.

\subsubsection{Bedload monitoring}

Bedload transport shows a significant spatio-temporal variability. The choice of the most accurate measuring system is often difficult and depends on many parameters. Each individual technique is adequate, yet features particular boundary conditions and limitations related to hydraulic and sampling efficiency, functionality during floods, sampling duration or grain size. Habersack et al. (2017) summarize that the combination of several measuring methods alone enables comprehensive monitoring of bedload transport. Following an overview of bedload monitoring devices, applied at the BOKU/IWA is given. For more details see Habersack et al., 2017.

\subsubsection{Geophone device}

Geophones are vibration sensors originating from seismic technology. In order to detect bedload transport, the geophone sensors, which are surrounded by metallic cylinders, are mounted on the underside of steel plates $(0.36 \mathrm{~m}$ long, $0.5 \mathrm{~m}$ wide, $0.015 \mathrm{~m}$ thick) (see Figure 14). These steel plates are embedded parallel to the streambed and are distributed over the whole cross-section. The steel plates are equipped with geophone sensors (Type GS20DX Geospace Technologies). Bedload particles moving over the steel plates generate vibrations. These vibrations are registered by the geophone sensors. The geophone signal, which is sampled continuously at a rate of $10 \mathrm{kHz}$, is processed and the data are stored: sum of impulses per minute, maximum amplitude per minute, and integral of geophone signal. Impulses are defined as the number of exceedances of the geophone signal of a threshold of $0.1 \mathrm{~V}$. Bedload data originating from geophone measurements provide permanent information about the quality and distribution of bedload transport within the channel cross-section in high spatial and temporal resolution. The continuous recording allows, among others, a detailed analysis of various bedload transport events. The transported bedload mass is quantified by calibrating the geophone signal with direct bedload measurements (see Section 3.4.2.3).
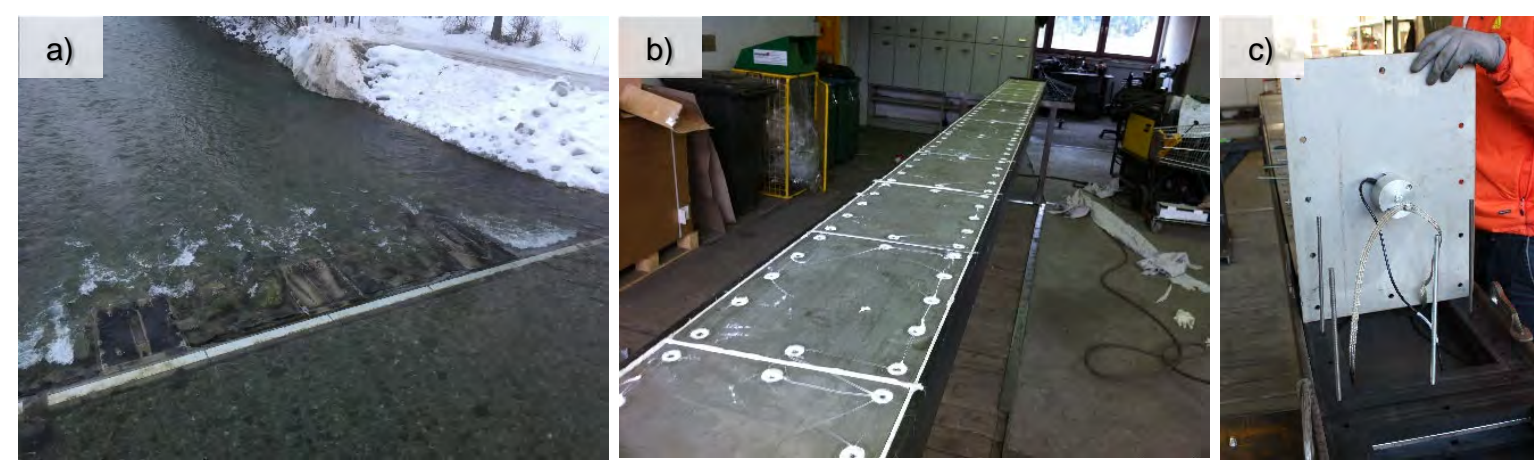

Figure 14: Geophone device: a) geophone device installed at Drava river, b) geophone device and c) steel plate with mounted sensor 


\subsubsection{Bedload Trap}

The slot sampler is mounted at the level of the stream bed, directly downstream of the geophone device. This device contains a sample box placed on load cells. The entire construction is covered with a lid, which contains a removable longitudinal sampling slot door. The slot door is closed using interlock bolts that can be opened hydraulically via manual control in the control house on the riverbank. As the door swing opens, it exposes the sampling slot and allows bedload particles to fall into the sampling box. The four bending beam load cells each have a capacity of 5-20 kN with a $0.03 \%$ accuracy. They are connected in parallel, and their output describes a single voltage that is proportional to the mass increase. Figure 15 shows a sketch of the monitoring device (a) and pictures of installed bedload traps at the measuring sites $(b-d)$.
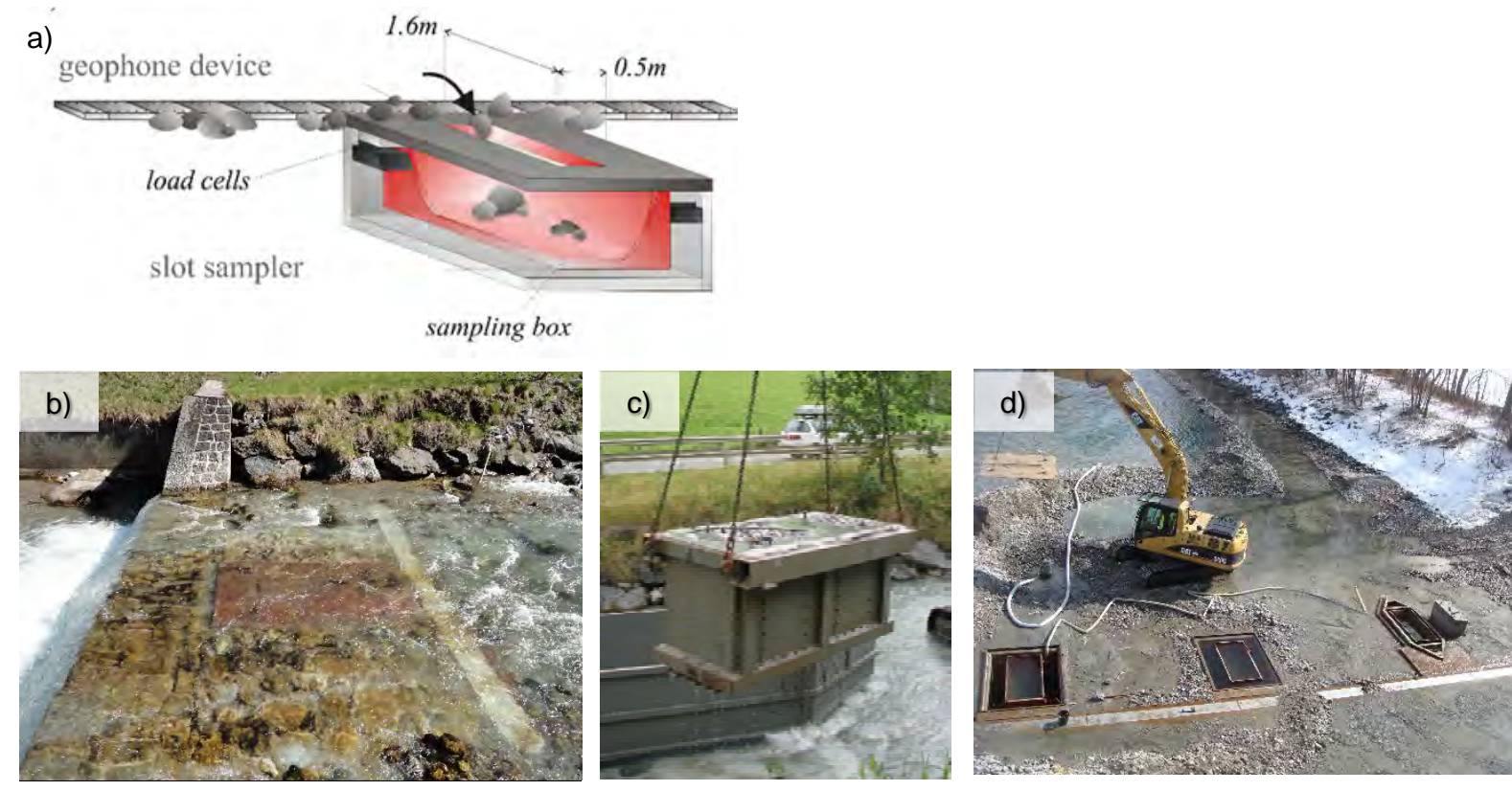

Figure 15: Bedload trap: a) sketch of bedlaod trap (Kreisler et al., 2017); b) Bedload trap installed at Urslau stream; c) bedload sample; $d$ : maintenance work at Drava river

\subsubsection{Basket samplers}

Basket samplers in general consist of a frame as sample inlet connected to a net (basket) to receive the particles. To compensate the hydraulic resistance, some basket samplers have a funnel like expansion of the inlet profile. Depending on the gravel size the sample net mesh size can be adapted to minimize effects of water resistance.

Depending on the river type the different mobile basket samplers find usage in the monitoring scheme of the monitoring stations in Austria. Depending on the river type (flow velocity and particle size) three mobile samplers were designed to cover the alpine streams to large gravel bed rivers.

\section{Large Helley-Smith sampler}

In gravel bed and sand bed rivers the Large Helley Smith sampler is used for bedload sampling. The funnel like expansion of the inlet compensates the hydraulic resistance of the sampler. The sampling net with a mesh size of $1 \mathrm{~mm}$ is mounted to the funnel-like expansion. 
With a back fin, the optimal alignment in the river is realized. Sampling bedload is accomplished on bridges using a cable winch on a trailer.
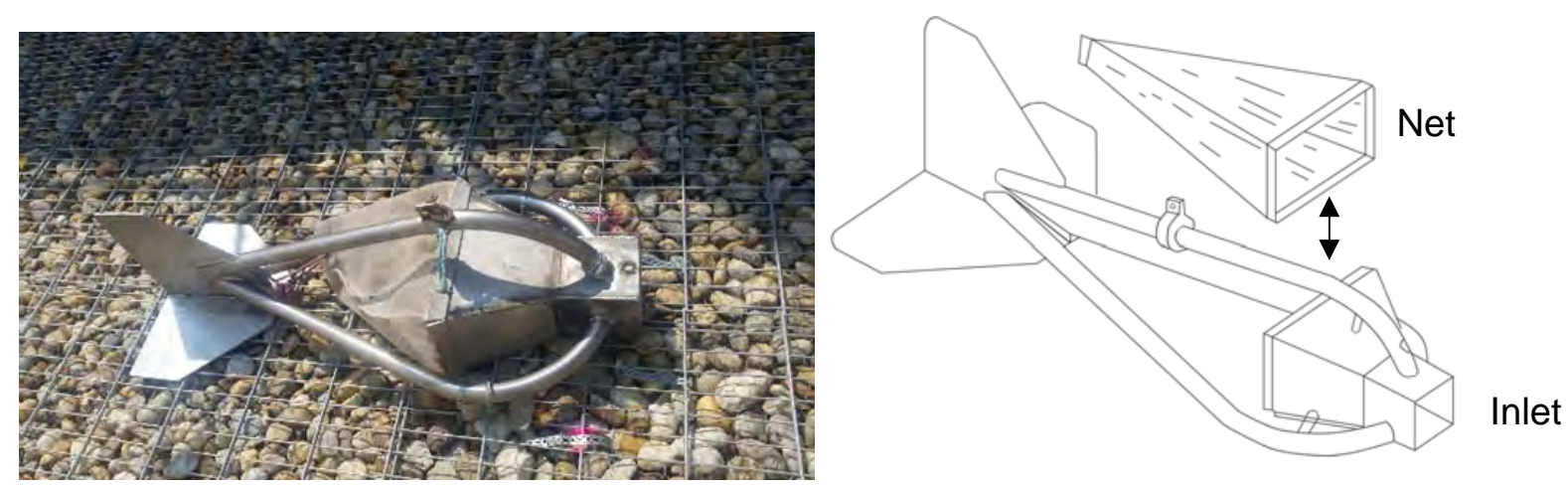

Figure 16: Large Helley-Smith sampler: mounted in the research flume (left), sketch after DVWK (Deutscher Verband für Wasserwirtschaft und Kulturbau 1992) (right)

\section{Vent Sampler}

The Vent sampler was designed after the sampler introduced by Bunte et al. (2004). The inlet frame has the dimensions of $0.5 \times 0.5 \mathrm{~m}$. The net can be exchanged since it is mounted to a separate frame which attaches to the inlet frame. Depending on the bedload discharge $[\mathrm{kg} \mathrm{s}$ 1] different nets with mesh sizes ranging from $1 \mathrm{~mm}$ to $8 \mathrm{~mm}$ come to use. With a crane (crane truck) the sampler is positioned in the riverbed for a defined time depending on the bedload discharge.
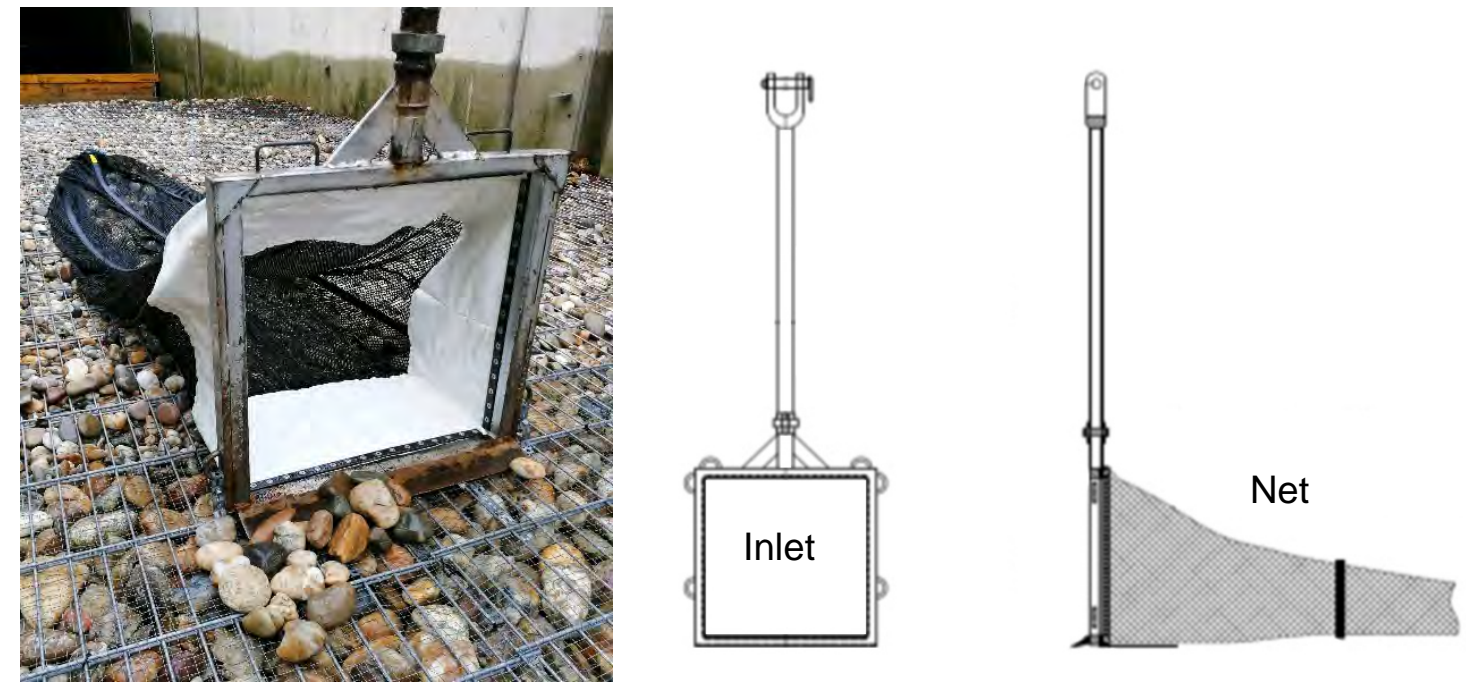

Figure 17: Vent sampler: in research channel (left), sketch by IWA (right)

\section{BfG sampler (Federal Institute of Hydrology)}

The BfG sampler is similar to the Large Helley Smith sampler only much more massive and the sampling container is attached to the main frame with a spring and wires. This sampler is used in large gravel bed rivers (e.g. Danube River). It is characterised by a mesh size of $1 \mathrm{~mm}$, an orifice size of $160 \times 80 \mathrm{~mm}$ and a device weight of approximately $200 \mathrm{~kg}$ because of additional 
solid metal cylinders which add weight to the main frame ensuring stable measuring conditions.
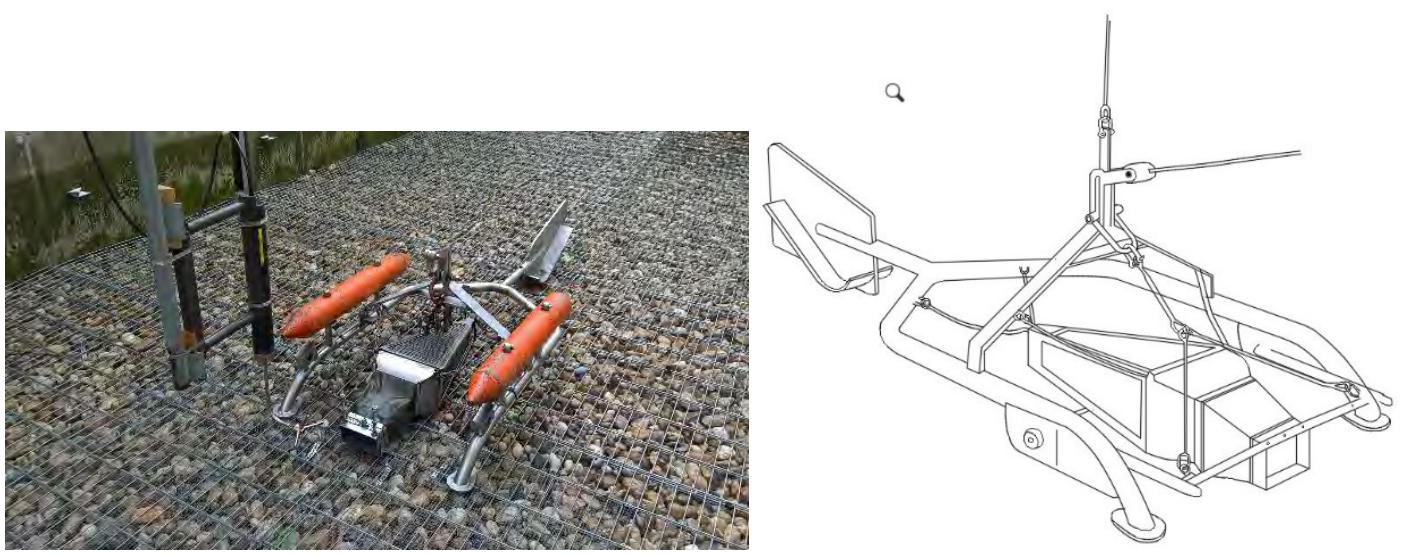

Figure 18: BfG sampler: in research flume (left), sketch after DVWK (Deutscher Verband für Wasserwirtschaft und Kulturbau 1992) (right)

The area of application of the different monitoring devices and different basket samplers is displayed in Table 1.

Table 1: Use of different monitoring devices by the IWA BOKU

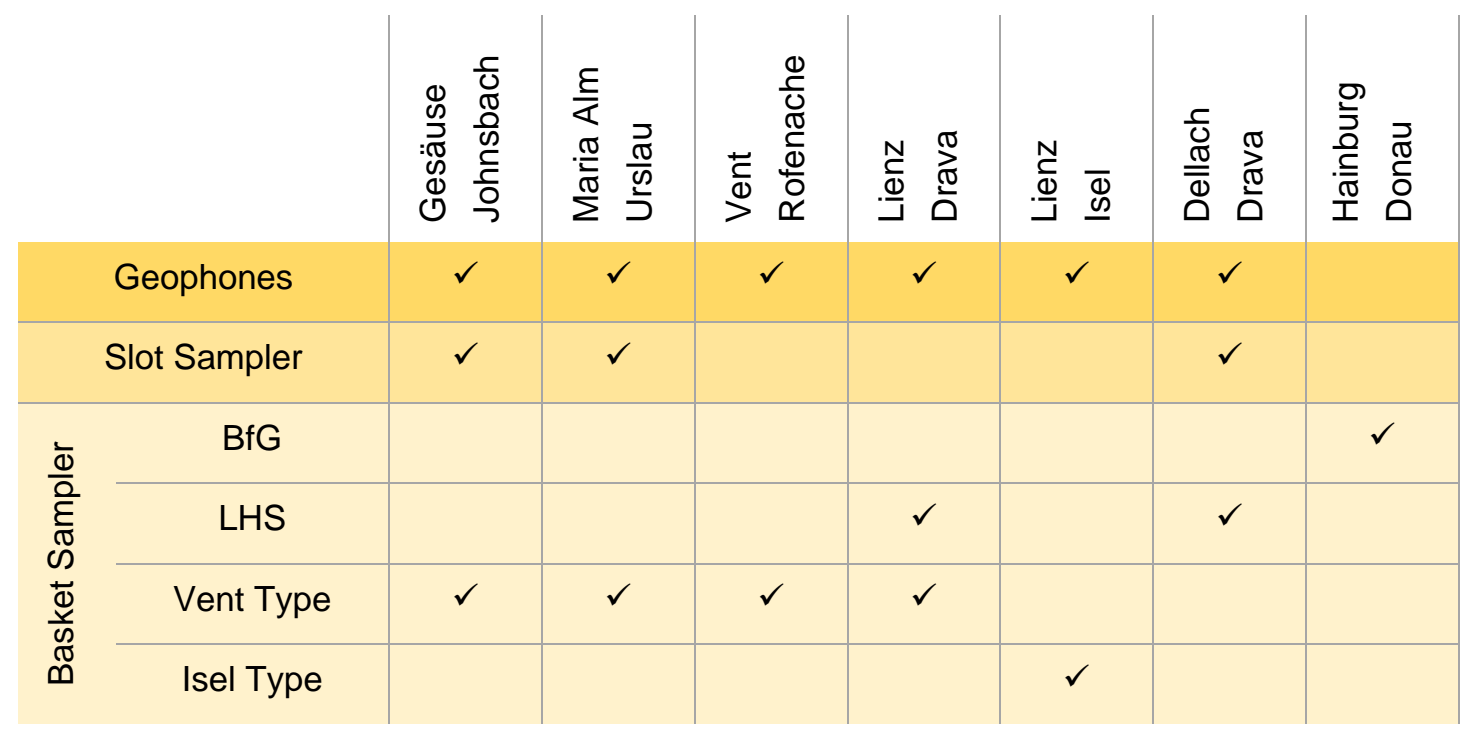

3.3.2.4. Flume and research channel experiment - Adaption and optimization of applied monitoring devices

The basket samplers were tested in the research channel of the IWA Boku Wien for both hydraulic and sample efficiency. First velocities of the zero state (no sampler installed) were measured with an ADV (Acoustic Doppler Velocimeter), ADCP (Acoustic Doppler Current Profiler) and a SLD (Side Looking Doppler Sensor) device and followed by velocity measurements of each sampler. Various measurements were realized at the location of the sampler inlet and at a non-influenced distance of $2 \mathrm{~m}$. Testing the sampling efficiency was standardized as displayed in Figure 19. Sediments representing the composition of Danube sediments were divided in three size classes (16-22 mm, 22-31 mm and 31-63 mm) placed on a $1 \times 1 \mathrm{~m}$ square in front of the sampler. Each size class was tested separately and then a 
sample with the full spectrum $(16-63 \mathrm{~mm})$. To enhance the sediment motion, the sediments were also inserted during the test by a slide.

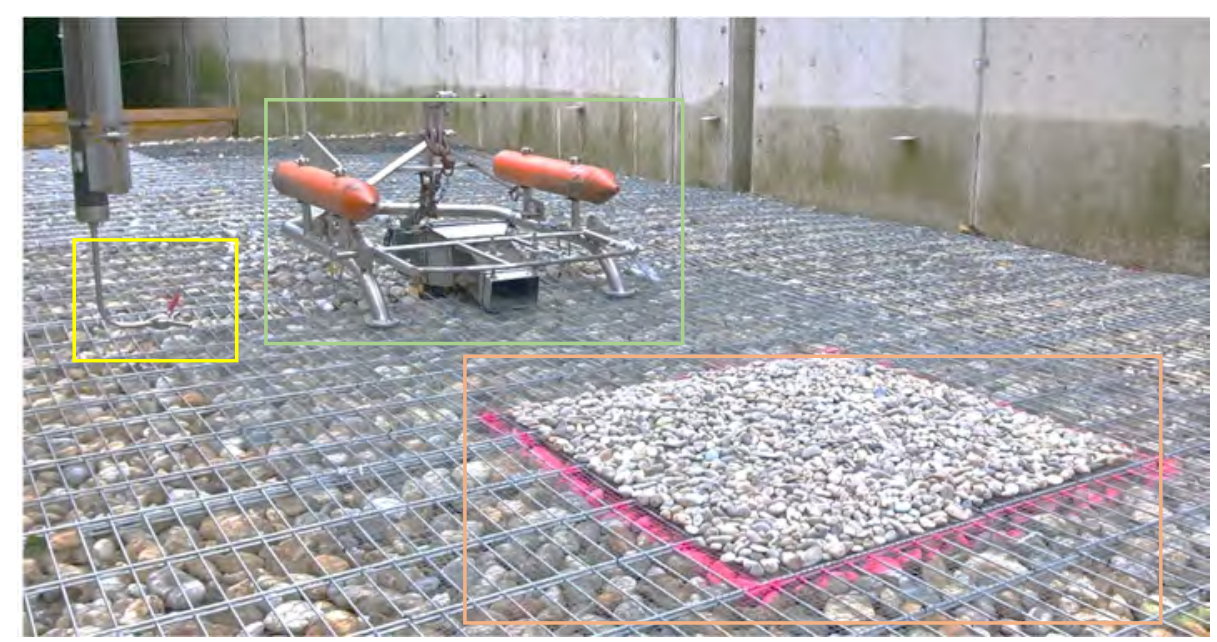

Figure 19: Flume test setup of the BfG Sampler: ADV yellow box, BfG Sampler green box and sediment sample orange box

\section{Results: Comparison of applied sampling devices - Hydraulic efficiency}

With the installation of the basket samplers the flow velocity is reduced and therefore the hydraulic efficiency is compromised. The flow velocity measurements of the ADV are combined to a spatial average to make them comparable. In Figure 20 the flow velocity distribution from the sampler inlet to $0.4 \mathrm{~m}$ above the channel bed is displayed. The Helley Smith sampler causes the least reduction of flow velocity, whereas the vent sampler causes flow velocity reductions from $0.3-0.5 \mathrm{~m} / \mathrm{s}$.

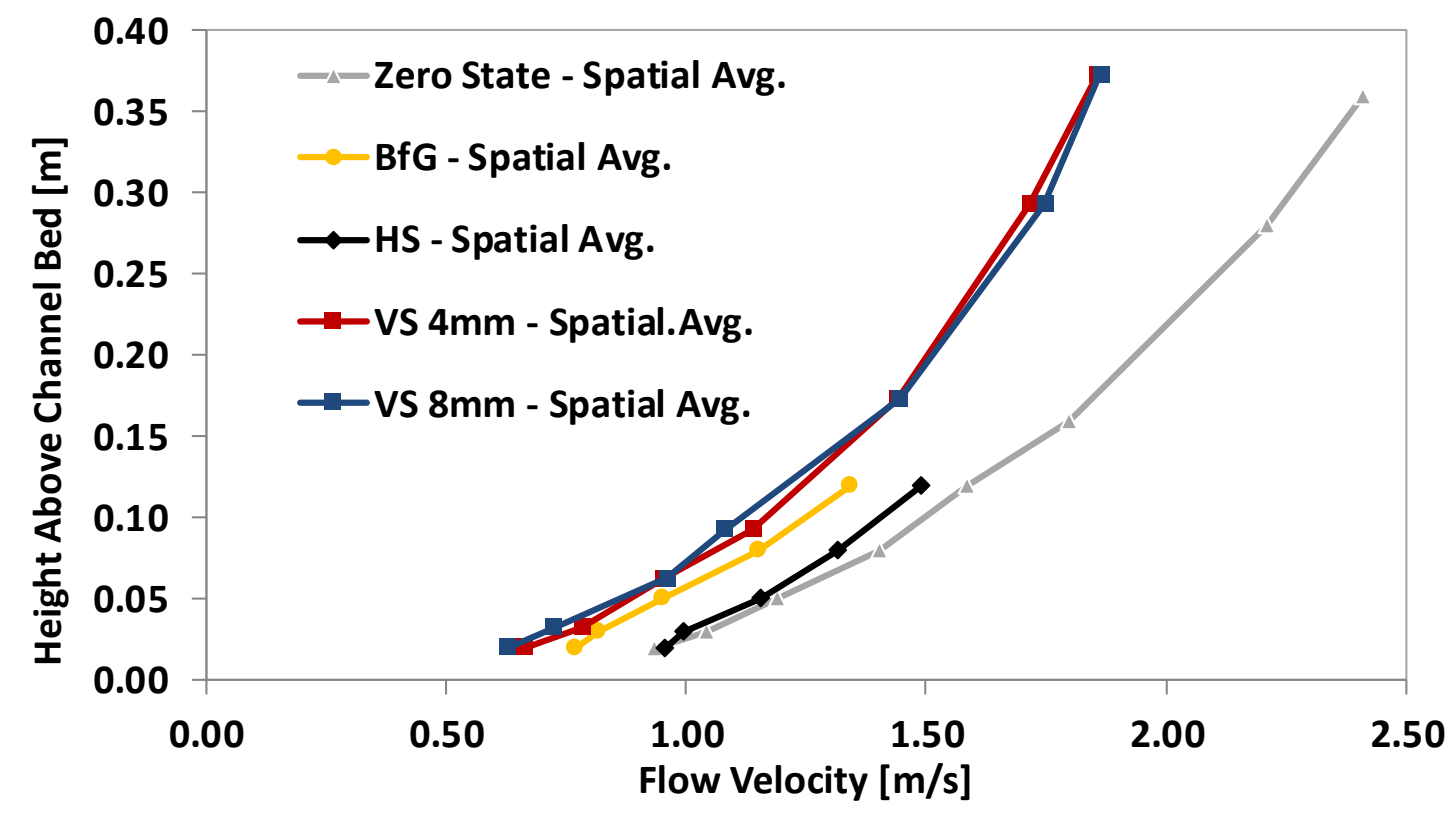

Figure 20: Flow velocities of the zero state and at the basket sampler inlet

The hydraulic efficiency displayed as the flow velocity at the basket samplers divided by the zero-state velocity is displayed in Figure 21. The Helley Smith sampler exceeds the $100 \%$ mark near the channel bed. 


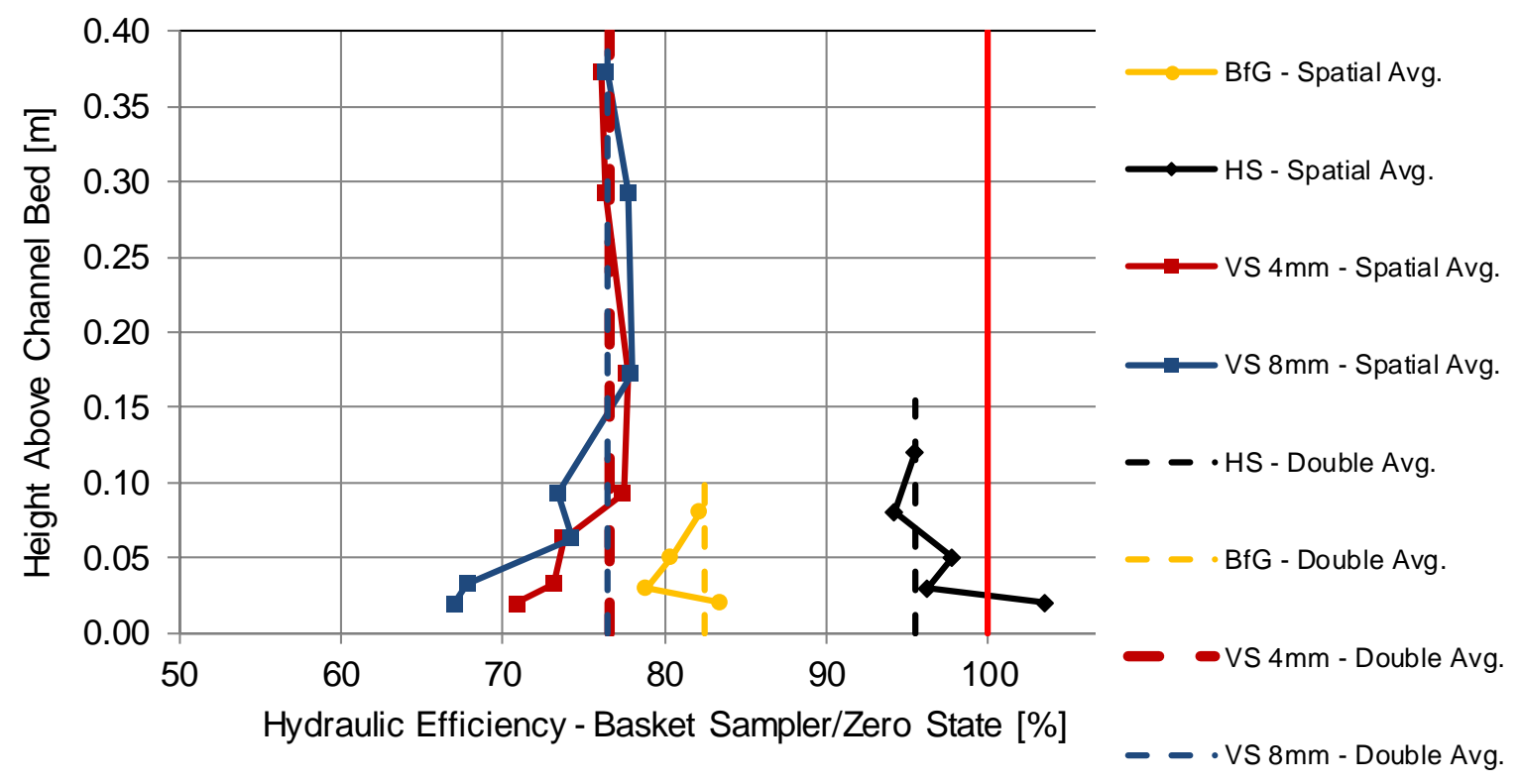

Figure 21: Hydraulic Efficiency - Basket Sampler to Zero State

\section{Results: Comparison of applied sampling devices - Sampling efficiency}

To make the samplers comparable the sampled weight was divided by the sampler opening width to receive the unit $\mathrm{kg} / \mathrm{cm}$, which is set in comparison with the sediments placed in front of the sampler. The sampling efficiency was calculated for each tested grain size class and varies according to the size classes, as displayed in Figure 22. The BfG sampler undersamples, whereas the Large Helley Smith sampler oversamples every size class.

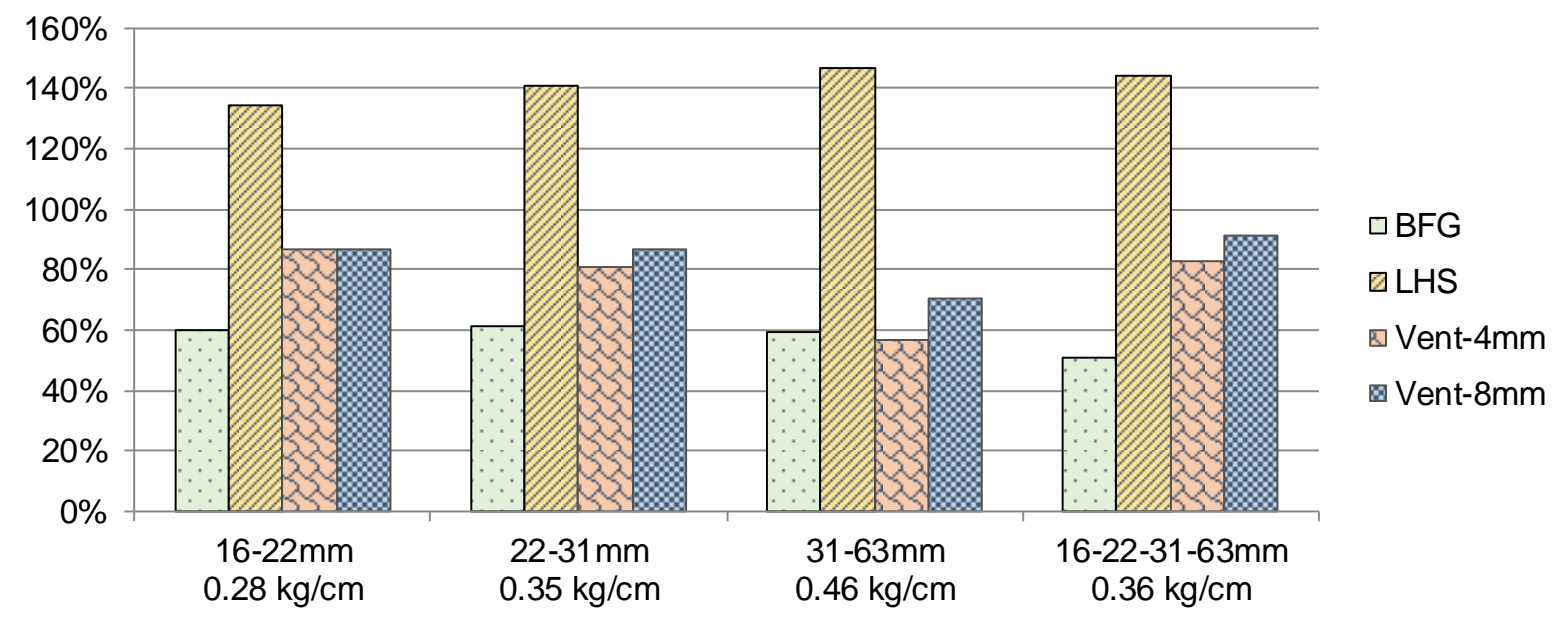

Figure 22: Sampling efficiency of different grain sizes classes 


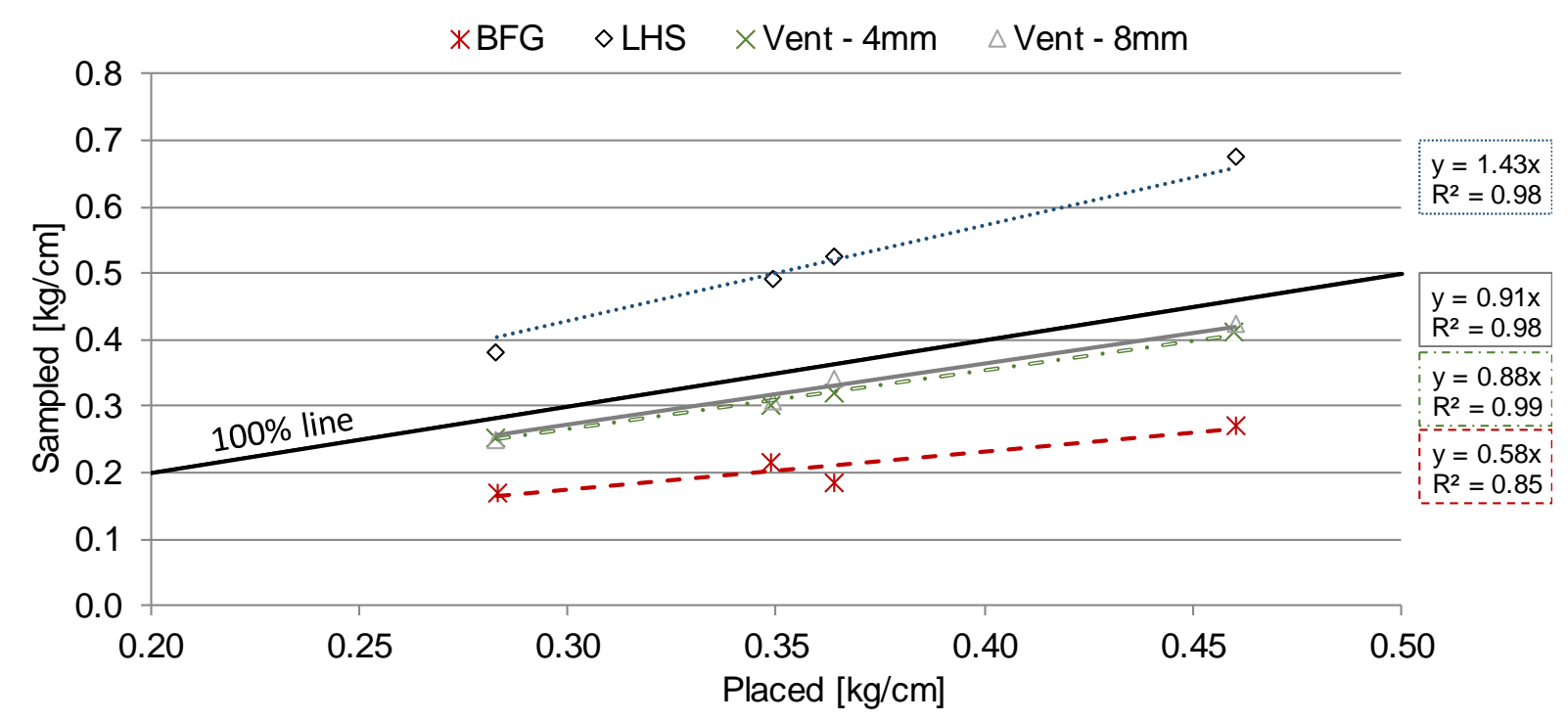

Figure 23: Efficiency of samplers

In order to make the different sampling devices comparable a correction factor was defined. This correction factor must be multiplied with the measured sample to generate unbiased comparable results. This correction factor compensates the amount of under- or oversampling of each sampling device. Since the gradient of the trend lines of Figure 23 share the intersection at $x=0.0$, the correction factors are obtained by the according gradient. In Table 2 the correction factor and the inverse correction factor is listed for each sampler type.

Table 2: Correction Factor of the basket samplers

\begin{tabular}{ccc} 
& Correction Factor & Correction Factor invers \\
\hline BFG & 0.5783 & $\mathbf{1 . 7 2 9 2}$ \\
LHS & 1.431 & $\mathbf{0 . 6 9 8 8}$ \\
Vent $-4 \mathrm{~mm}$ & 0.8821 & $\mathbf{1 . 1 3 3 7}$ \\
Vent - 8mm & 0.9121 & $\mathbf{1 . 0 9 6 4}$
\end{tabular}




\subsection{Sediment Monitoring - exemplary selection of regular measurement results}

\subsubsection{Suspended sediment monitoring}

\subsubsection{Mulit-point measurement}

In the years 2017 to 2019, eight multi-point measurements were carried out and analysed at the monitoring site Hainburg Road Bridge. The calculated mean suspended concentrations in the cross-section ranged from $8.5 \mathrm{mg} / \mathrm{l}$ to $590.1 \mathrm{mg} / \mathrm{l}$. Table 3: Comparison of discharge $\mathrm{Q}$, mean suspended sediment concentration sm and suspended sediment transport Qs

provides an overview of flow conditions $(\mathrm{Q})$, the mean suspended sediment concentration $\left(\mathrm{s}_{\mathrm{m}}\right)$ and the suspended sediment transport $\left(\mathrm{Q}_{\mathrm{s}}\right)$ of the individual measuring days obtained from the multi-point measurements.

Table 3: Comparison of discharge $Q$, mean suspended sediment concentration $\mathrm{S}_{m}$ and suspended sediment transport Qs

\begin{tabular}{cccc}
\hline Date & $\mathbf{Q}$ & $\mathbf{Q}_{\mathrm{s}}$ & $\mathbf{s}_{\mathrm{m}}$ \\
\hline 03.07 .2017 & $1,443 \mathrm{~m} / \mathrm{s}$ & $24.9 \mathrm{~kg} / \mathrm{s}$ & $17.3 \mathrm{mg} / \mathrm{l}$ \\
08.11 .2017 & $1,800 \mathrm{~m} 3 / \mathrm{s}$ & $38.6 \mathrm{~kg} / \mathrm{s}$ & $21.5 \mathrm{mg} / \mathrm{l}$ \\
19.11 .2017 & $1,630 \mathrm{~m} 3 / \mathrm{s}$ & $45.9 \mathrm{~kg} / \mathrm{s}$ & $25.1 \mathrm{mg} / \mathrm{l}$ \\
17.05 .2018 & $2,300 \mathrm{~m} 3 / \mathrm{s}$ & $102.1 \mathrm{~kg} / \mathrm{s}$ & $44.4 \mathrm{mg} / \mathrm{l}$ \\
23.05 .2018 & $1,630 \mathrm{~m} 3 / \mathrm{s}$ & $39.8 \mathrm{~kg} / \mathrm{s}$ & $24.4 \mathrm{mg} / \mathrm{l}$ \\
14.11 .2018 & $805 \mathrm{~m} 3 / \mathrm{s}$ & $6.7 \mathrm{~kg} / \mathrm{s}$ & $8.5 \mathrm{mg} / \mathrm{l}$ \\
19.11 .2018 & $740 \mathrm{~m} 3 / \mathrm{s}$ & $5.6 \mathrm{~kg} / \mathrm{s}$ & $9.2 \mathrm{mg} / \mathrm{l}$ \\
23.05 .2019 & $4,720 \mathrm{~m} 3 / \mathrm{s}$ & $1,602.2 \mathrm{~kg} / \mathrm{s}$ & $333.4 \mathrm{mg} / \mathrm{l}$
\end{tabular}

Figure 24 shows result of a multi-point measurement. The distribution of the suspended sediment concentrations in the cross-section as well as the depth-averaged flow velocities are displayed on the example of the measurement performed on the 23.05.2019.

For the calculation of the suspended sediment load, first the record of suspended sediment concentration near the sensor is converted into a time series of mean concentration of suspended sediments in the cross-section. For this purpose, the velocity weighted mean suspended sediment concentrations gained from the cross-sectional measurements are related to the suspended sediment concentrations close to the sensor determined at the same time. The new measurements carried out in the years 2016 to 2019 fit very well to the previous measurements (Figure 25). 


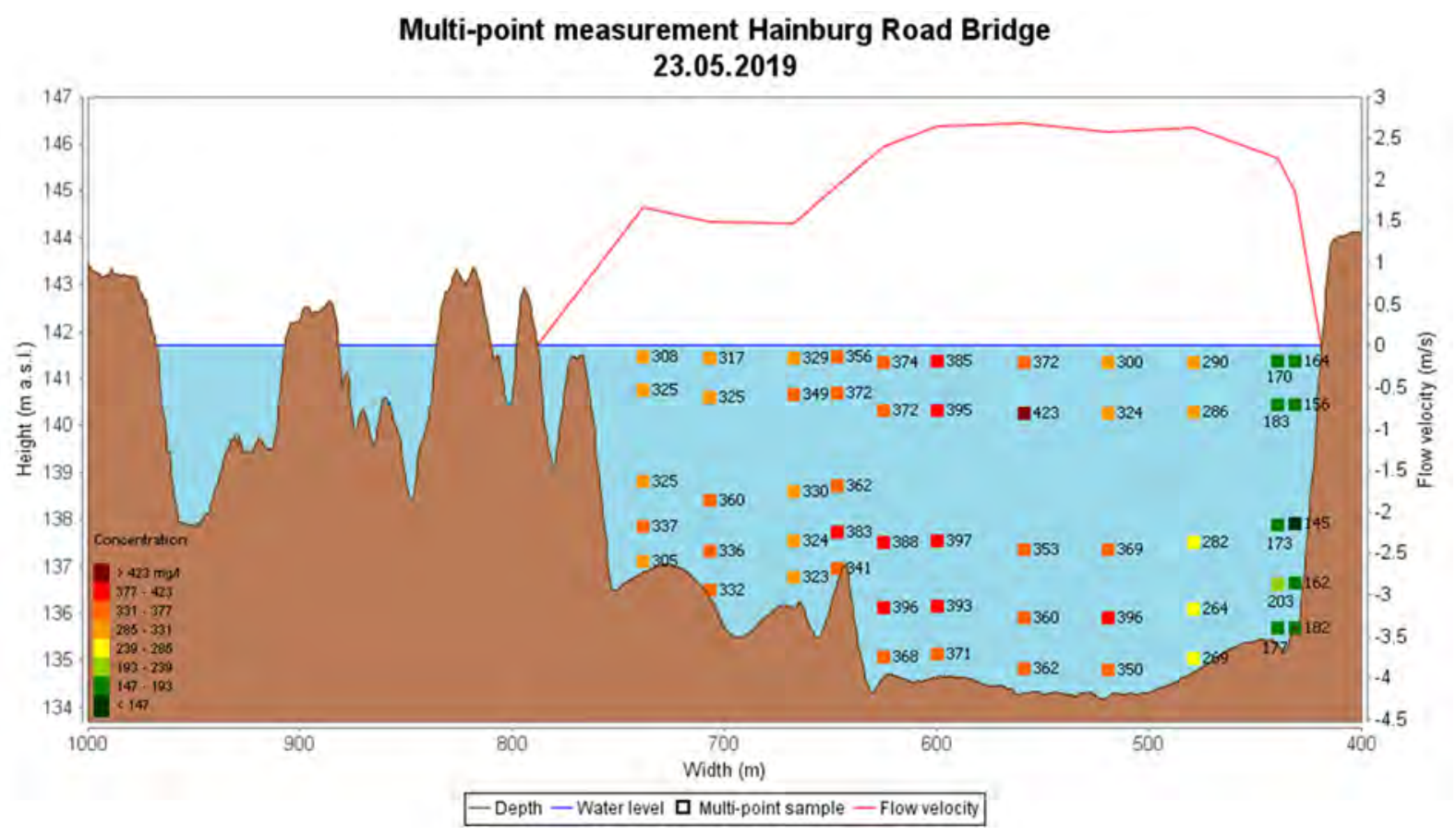

Figure 24: Multi-point measurement 23.05.2019 (Q = 4,720 m3/s)

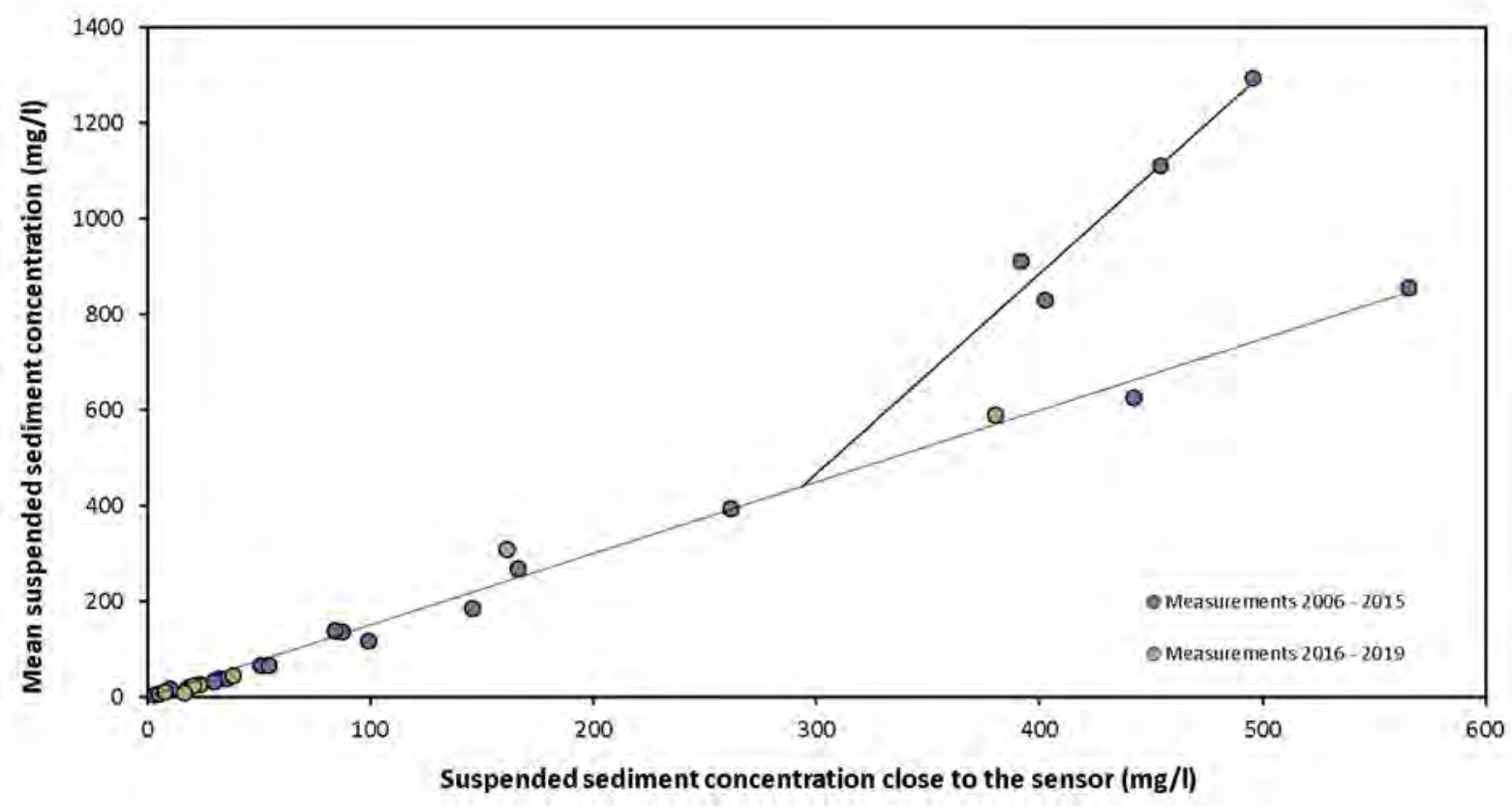

Figure 25: Relationship between suspended sediment concentration close to the sensor and mean suspended concentration at the monitoring site Hainburg Road Bridge/Danube

By multiplying the time series of the suspended sediment concentration near the sensor with the relationship shown in Figure 25, the time series of the mean suspended sediment concentration is calculated. By multiplying this time series with the discharge, the time series of the suspended sediment transport is calculated. By integrating the transport over time, the suspended sediment load is determined and loads can be provided for different time intervals (events, months, years). 


\subsubsection{Bedload monitoring}

\subsubsection{Cross-sectional basket sampler measurement}

The basket sampler comes to use at all bedload measuring sites. As an example, the measurement of 23.05.2019 with the BfG sampler at the Danube in Hainburg is displayed in Figure 26. The graph at the bottom shows the stream profile. The middle figure displays the spatial distribution of the specific bedload transport rate over the cross-section. The grain size distribution of the bedload samples is given in the upper graph. The mean water discharge was $4720 \mathrm{~m}^{3} \mathrm{~s}^{-1}$. The calculated bedload transport concludes to $44.46 \mathrm{~kg} \mathrm{~s}^{-1}$.

\section{Danube - Austria}

River-km 1886.24

23.05.2019

$Q=4720 \mathrm{~m}^{3} / \mathrm{s}$

$Q b=44.46 \mathrm{~kg} / \mathrm{s}$

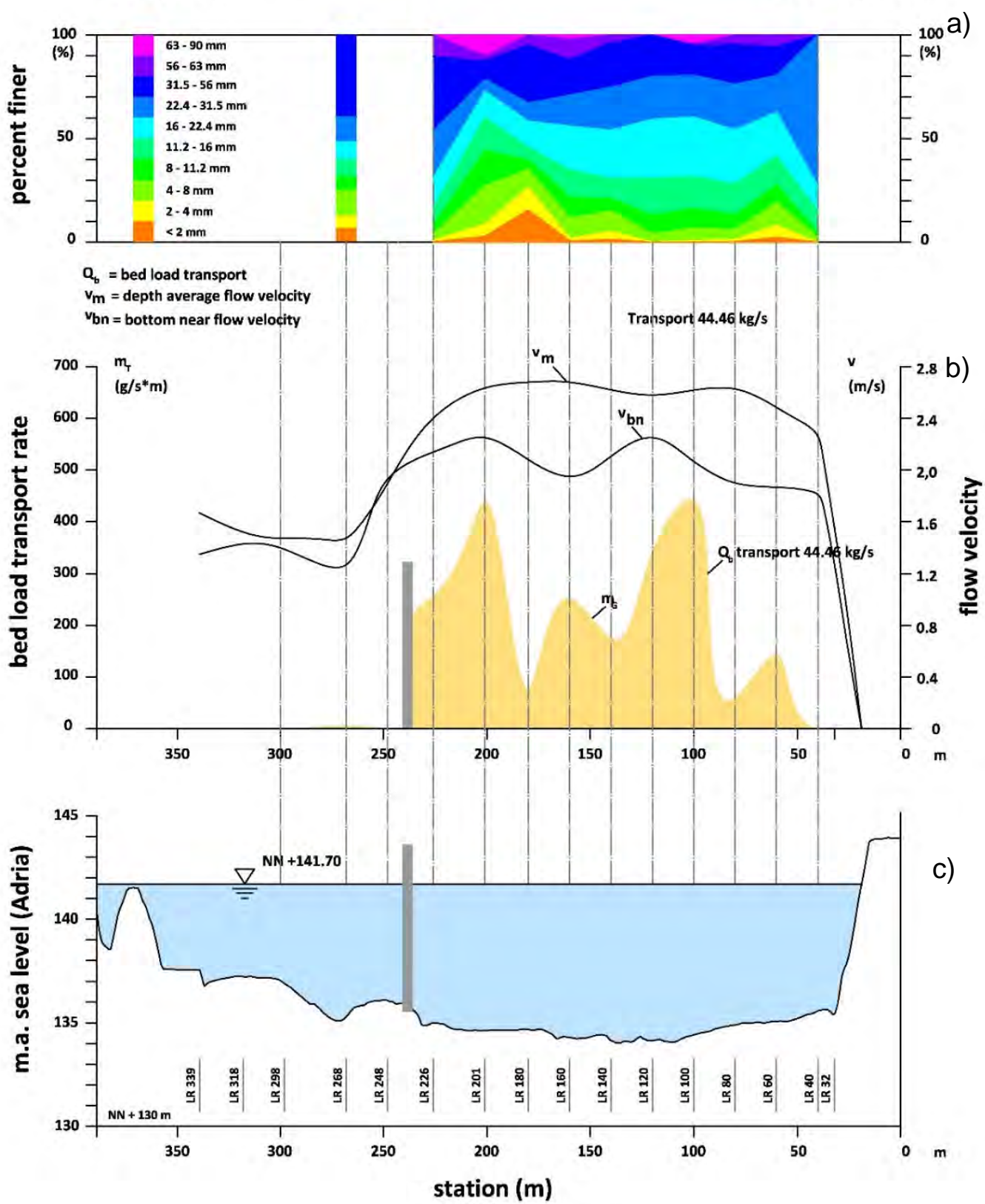

Figure 26: example of the bedload measurement at the Danube on the 263.05.2019. a) bed load texture, b) transport rates in each vertical (including bed load transport - shaded area middle panel), c) measurement cross section (IWA/BOKU) 


\subsubsection{Bedload trap measurement}

During the project period, several successful measurements with the bedload trap were undertaken. Figure 27 shows the measurement of 06.04.2019 on the Urslau river as an example. The recorded raw data of the measurement of 06.04.2019 are shown. In "blue" the filling stage in the bed load trap is depicted. The sum line of the geophone impulses (G\#4) recorded during the same period is shown in "red".

The bed load trap was filled after opening the measuring slot after about 45 minutes. This results in an average bedload rate of $0.5 \mathrm{~kg} / \mathrm{ms}(D>1 \mathrm{~mm})$. The mean flow rate during the measurement was $5.1 \mathrm{~m}^{3} / \mathrm{s}$.

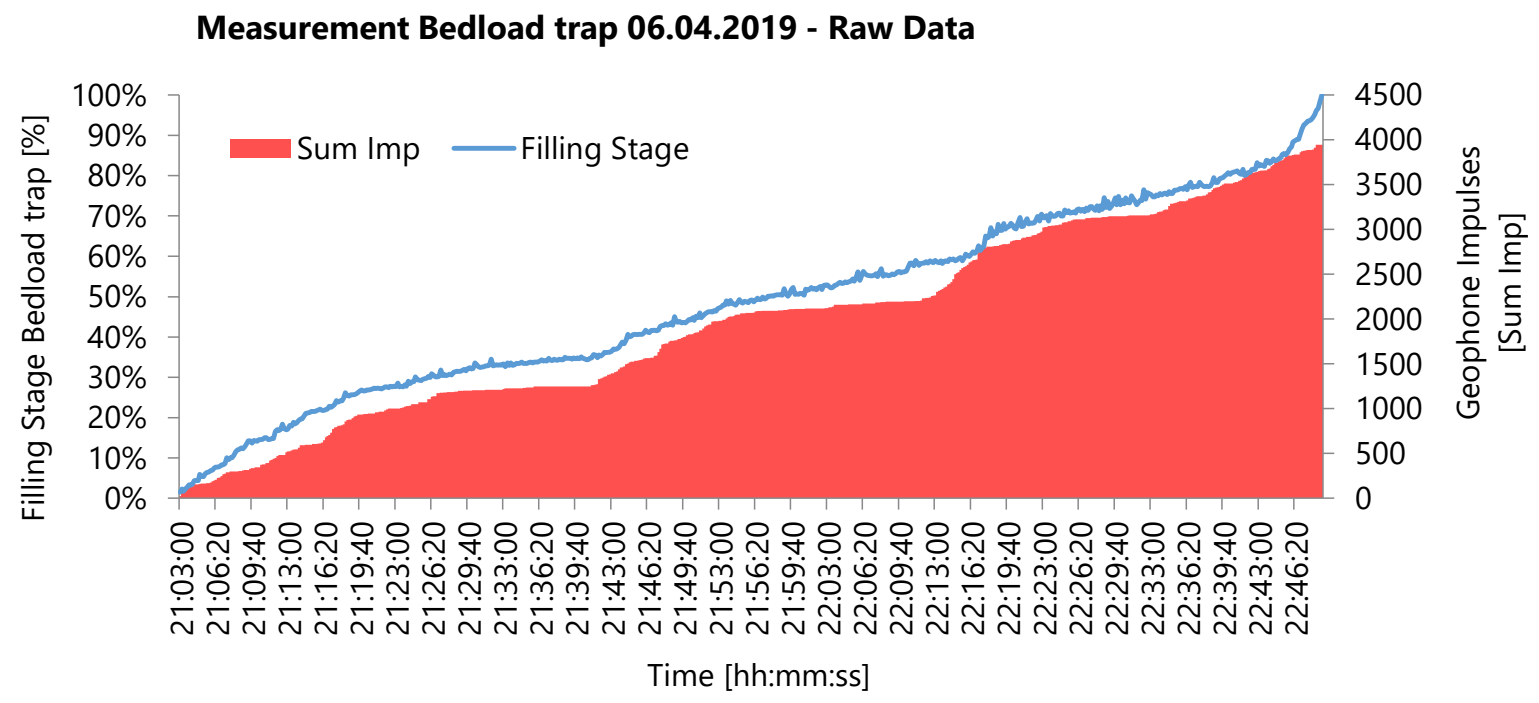

Figure 27: Measurement Bedload Trap Urslau River 06.04.2019

\subsubsection{Geophone device}

The direct bedload measurements with bedload trap and mobile basket sampler are performed immediately downstream of the geophone system. The bedload transport, which is registered by the geophones, is then recorded with the direct measuring methods - this enables a comparison of the measurement results.

The correlation between directly measured bedload transport rates and geophone data allows a calibration function for the geophone pulses to be established. This relationship can then be used to calculate from continuously recorded geophone recordings, specific bedload transport rates and bedload transport.

In Figure 28 the calibration function of the Urslau stream is shown. Bedload trap measurements are displayed in "turquoise", bedload trap measurements in "grey". The horizontal axis plots the specific bedload transport rates for particle diameters $>22,4 \mathrm{~mm}$ ), the vertical axis the mean values of registered geophones impulses in the corresponding time interval. The impulses increase approximately linearly with increasing specific bedload transport rates. Studies confirming the linear relation were published by Rickenmann et al. (2014). 


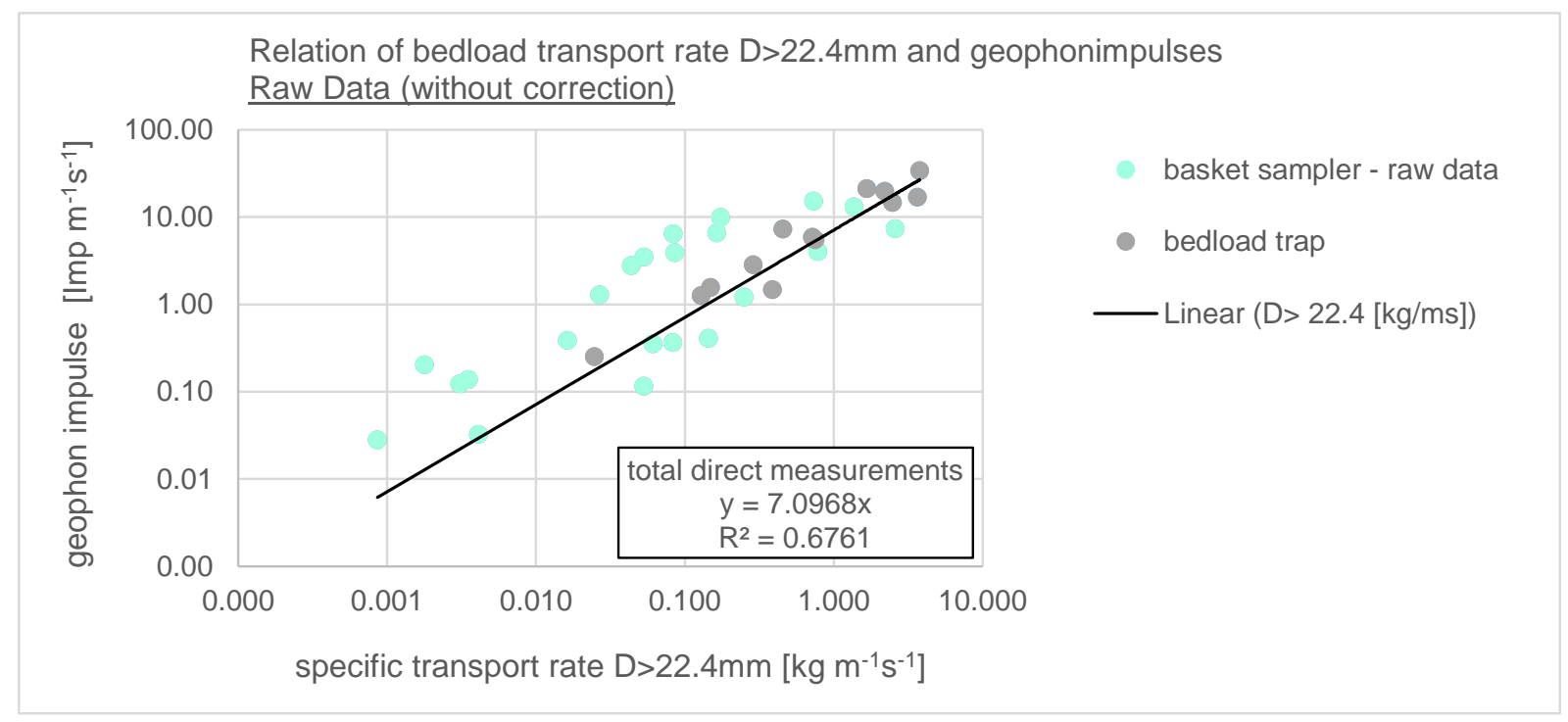

Figure 28: Relation of bedload transport rate $D>22.4 \mathrm{~mm}$ and geophon impulses 2012-2019 Urslau stream

\subsection{Sediment budget calculations and analysis}

In general, there are 2 approaches for the calculation of bedload yields, which are described briefly in the following chapter. At the Gail river, bedload measuring points are insufficient for reliable bed load yields statements. Estimates were made with the comparison of transect surveys at defined locations (chapter 3.5.4).

3.5.1. Integrative vs. rating curve approach

In literature mostly two bedload discharge calculation approaches find practice (Habersack et al. 2017). The Integrated bedload discharge calculation approach makes use of direct and indirect bedload measuring devices, whereas the rating curve approach combines direct measurement data with water discharge data to calculate the bedload discharge.

The integrated bedload discharge calculation approach combines direct and indirect measurement procedures. Therefore, indirect automated continuous bedload monitoring devices (geophone plates) measure the temporal variability and the distribution throughout the cross-section. Indirect measuring data is calibrated with direct measurement devices (slot sampler, basket sampler). Direct bedload measuring devices measure at a certain location in the cross-section (specific transport $\mathrm{q}_{\mathrm{b}}\left(\mathrm{kg} \mathrm{m}^{-1} \mathrm{~s}^{-1}\right)$ ). This data is used to calculate the crosssectional bedload discharge. Thereby, calculating bedload discharge of particles $<22.4 \mathrm{~mm}$ is not possible, since the geophone plates cannot detect material below that threshold.

The rating curve approach on the other hand combines direct bedload measurements with continuous discharge measurements. For this approach a relation of bedload discharge to water discharge is assumed. With adequate bedload transport measurements using direct measuring devices at different water discharge situations, a rating curve is generated. This approach will perform best if the scatter of transport rates at comparable discharge values is minimal. The natural temporal and spatial variability of bedload transport is not represented with this approach. Since direct bedload transport measurements using basket samplers can't be performed at most monitoring stations, during extreme events, the rating curve often is not 
precise for high discharge conditions. This results in an underestimation of sediment discharge at extreme events. Best results using this cost-efficient calculation method will be achieved at discharges with existing measurement data at rivers with low sediment transport fluctuation. Depending on the net size of the direct bedload measuring device smaller grain sizes $(\mathrm{D}>1 \mathrm{~mm})$ can be included in the calculation.

Therefore, best bedload discharge results will be achieved using a combination of integrated and rating curve approach.

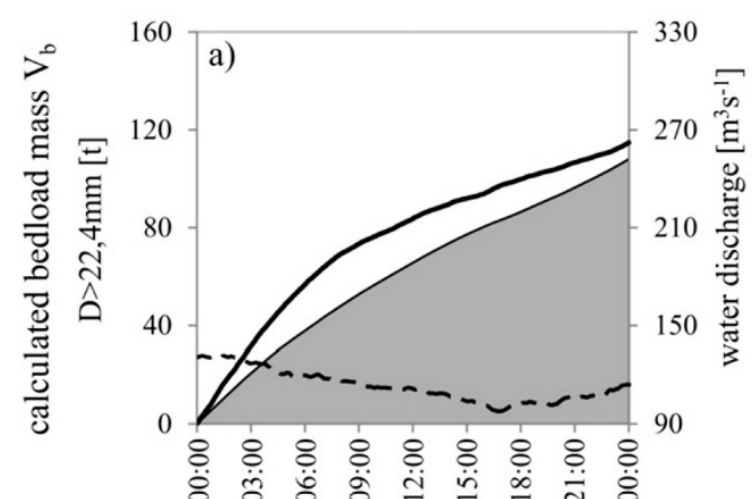

$\square$ bedload mass $\mathrm{V}_{\mathrm{b}}$ - rating curve approach

— bedload mass $\mathrm{V}_{\mathrm{b}}$ - integrated approach

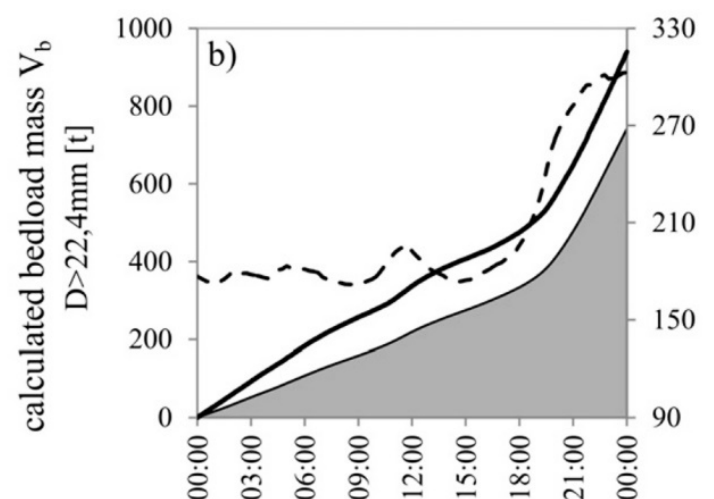

- - water discharge

Figure 29: Comparison of the rating curve and integrated approach for two different monitoring periods; (a) water discharge between 97 and $132 \mathrm{~m}^{3} \mathrm{~s}^{-1}$ on June 3, 2012 and (b) water discharge between 172 and $303 \mathrm{~m}^{3} \mathrm{~s}^{-1}$ on June 23, 2012. (Habersack et al. 2017)

\subsubsection{Calculation of Annual yield within the project Raise}

In the course of the RAISE project, bedload quantities from measuring stations where geophone data are available were calculated using an "integrated approach". This method has the disadvantage that only information about yields larger than a defined grain diameter can be obtained. This grain diameter usually depends on the threshold at which the geophones react $(\sim 10-20 \mathrm{~mm})$ and on the smallest grain size that can be measured with direct measuring instruments at the specific monitoring station. In order to compare the results of the individual measuring stations, the grain size $22.4 \mathrm{~mm}$ was chosen as the lower limit. At the measuring station "Hainburg/Donau" no geophones are available - therefore the "rating curve" approach has been applied.

\subsubsection{Comparison Annual Load}

Traditionally bedload data and suspended load data are contemplated separately, since often data and time series do not exist at the same location. With the integrative bedload and suspended load monitoring, the analysis of temporal and special variability of sediment transport is possible. With time series of several years, not only mean values but also significant peak values of both suspended and bedload material ranging from single events to annual loads can be calculated (Lalk et al. 2019). 
The suspended annual load in the time series of 2008 to 2019 range from $52.000 \mathrm{t}$ (2010) at the measuring site Falkensteinsteg/Drava, to over $11 \mathrm{~m} \mathrm{t}$ (2013) at the Danube river at Hainburg. In general, suspended load concentrations increase with the size of the catchment area (compare with Figure 30). Mean annual bedload load in the time series of 2008 to 2019 range from $985 \mathrm{t}$ at the measuring site Falkensteinsteg/Drava (2015), to over $580.000 \mathrm{t}$ (2013) at the Danube River. The graph in Figure 30 shows, that bedload load does not necessarily increase with catchment size. Bedload load of the Urslau and the Rofenache Stream are higher than Lienz/Isel and Falkenstein/Drava.

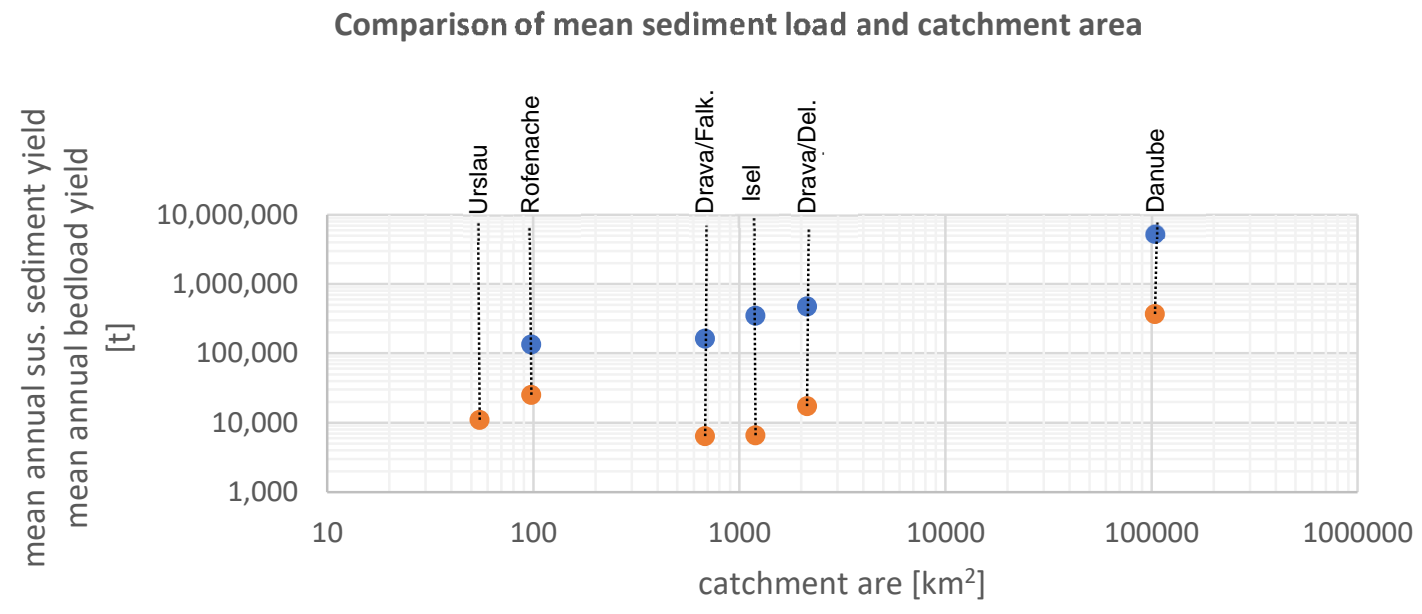

Figure 30: Comparison of mean sediment load and catchment area

Figure 31 summarizes specific annual flow load, specific suspended sediment load and bedload load ( $D>22,4 \mathrm{~mm}$ ) for the time series 2010 to 2019. Small, high catchment areas result in high specific sediment loads and lower discharge loads (note the adapted scaling). Relatively high specific suspended sediment loads for the size are observed on the Isel, which is mainly due to the glaciers in the catchment area. The Drava/Falkensteg monitoring station, on the other hand, has a completely different catchment area and is more influenced by debris flows. With $216 \mathrm{~g} / \mathrm{l}$, the highest concentration of suspended matter in Austria was measured there (2013) although the rest of the year was otherwise quite balanced. The measuring station Vent has really high erosion values due to the high alpine, glaciated catchment area. 


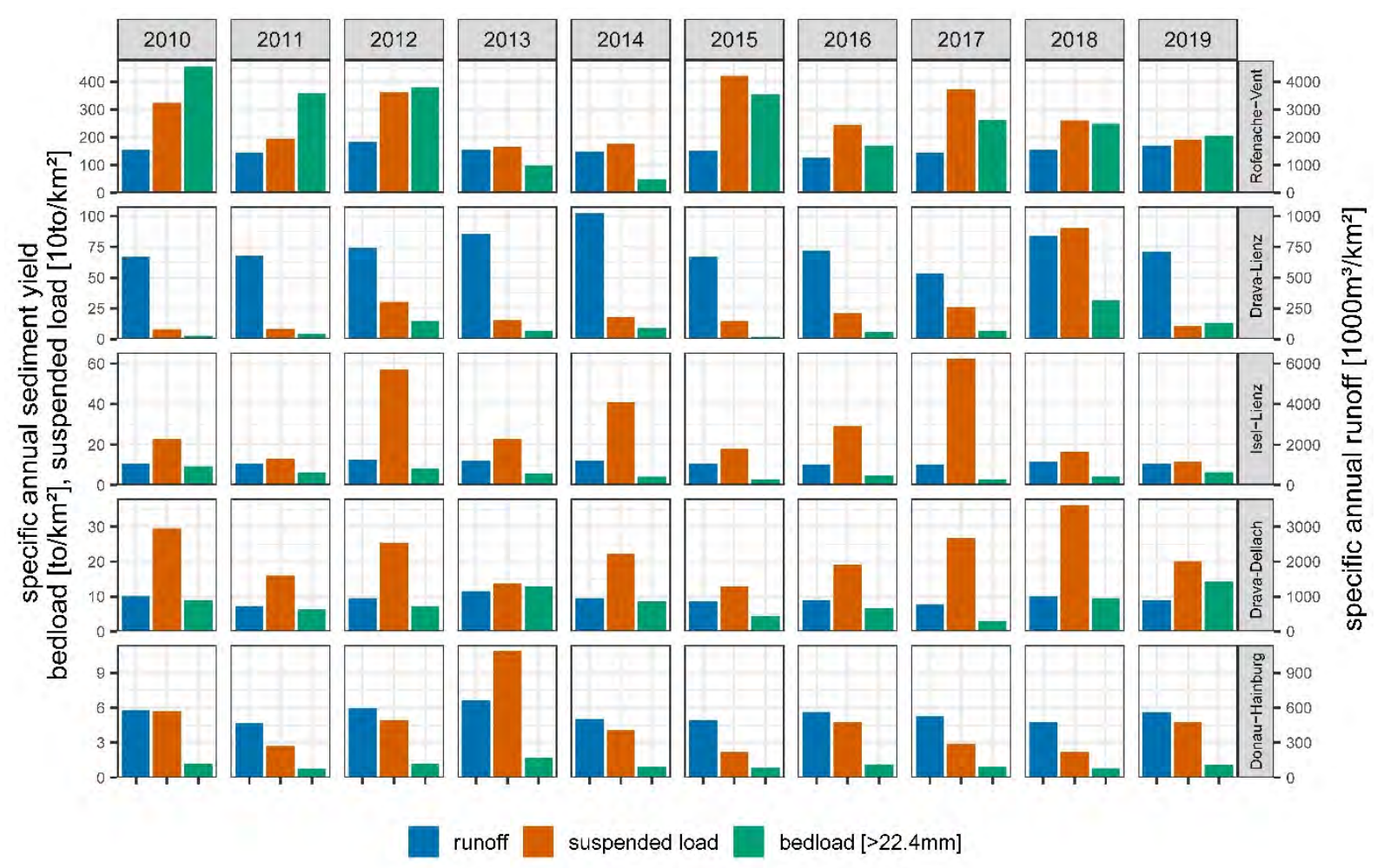

Figure 31: specific annual yield of runoff, specific suspended load and bedload (>22.4)

In Literature the percentage of bedload is often estimated between 10 and $20 \%$ of the total load (Turowski et al. 2010). To verify this Haimann et al. (2018) calculated bedload loads $\mathrm{D}>1 \mathrm{~mm}$ for the Drava and the Danube river. The result is given in Figure 32: . At the bedload measuring station in Dellach/Drava the percentage of bedload in the time series 2009 to 2014 concludes to 6 to $16 \%$ of the total load. In the Danube river at the measuring station in Hainburg, the percentage of bedload transport in the years with no flood events above a $\mathrm{HQ}_{1}$ is under $10 \%$. In contrast at the same measuring station the proportion of bedload transport was reduced to $5 \%$ during the flood event of $2013\left(\mathrm{HQ}_{200}\right)$. At the Danube river the effective discharge at which most of the sediments are transported is the MQ and at the Drava river just below $\mathrm{HQ}_{1}$ (Gmeiner et al. 2016). Whereas Individual flood events can contribute substantially to the annual load. Figure 32: displays the percentages of day, event, month and annual load of the Danube/Hainburg and Drava/Dellach. While the percentage of the 5-day event load at the Danube makes up to $45 \%$ of the annual load (flood event in June 2013), whereas the years 2012 and 2014 with no significant flood event (max. HQ $\mathrm{H}_{1}$ ) the percentage of the event load is below $10 \%$. In comparison the percentages of the day and event loads at the Drava within the same timeframe conclude to $20-25 \%$, however the flood events at the Drava were below the $\mathrm{HQ}_{5}$. Furthermore, the percentage of bedload to suspended load at the Drava is with $52 \%$ and $72 \%$ much higher as at the Danube. This could be linked to the higher discharges at the Drava during snowmelt and summer months (Habersack et al. 2017) whereas the Danube transports sediments throughout the year (Liedermann et al. 2018). 


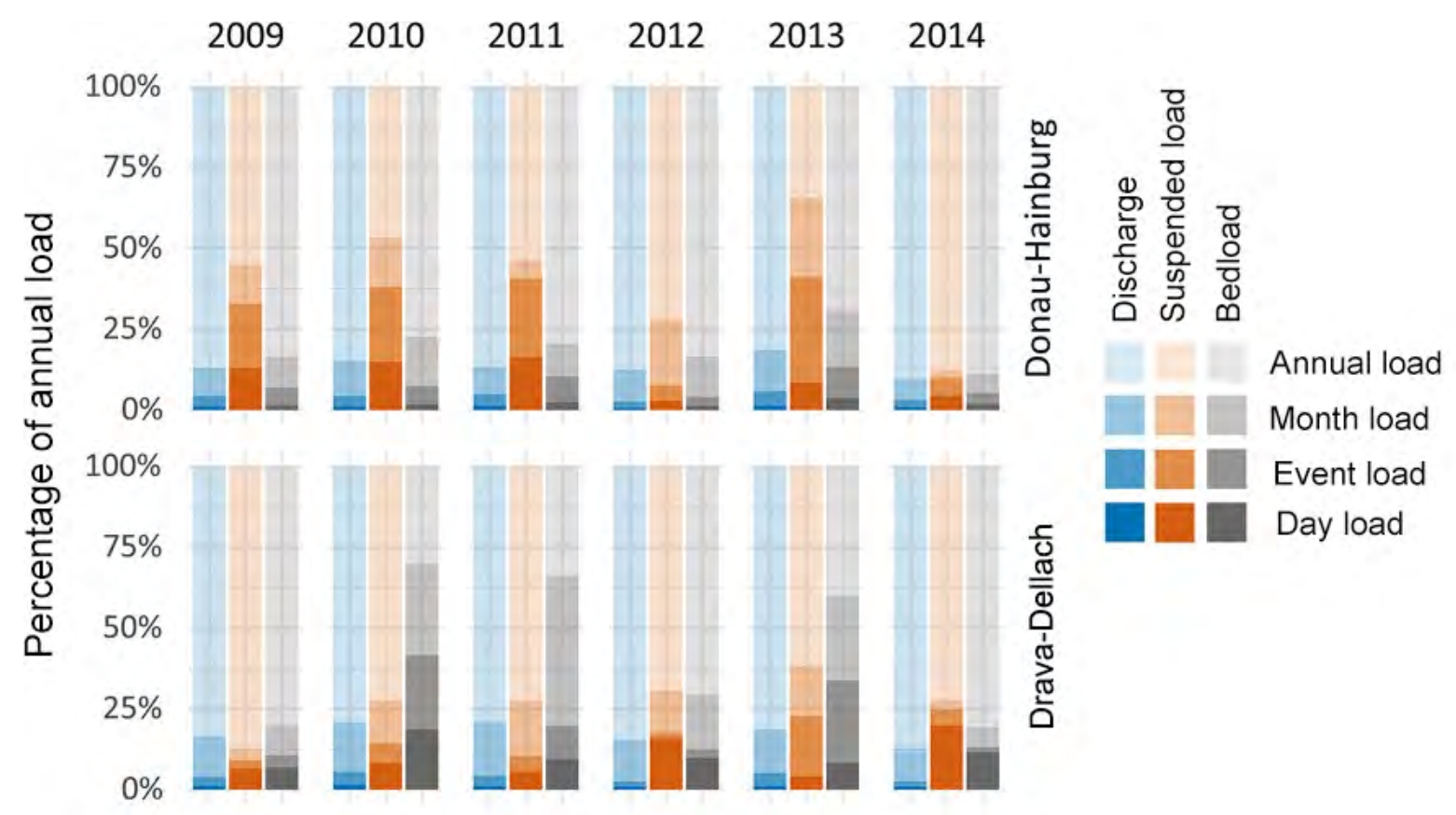

Figure 32: Percentage of year load (Haimann et al. 2018)

3.5.4. Sediment budget at the Gail river

With the comparison of transect surveys at defined locations at a $50 \mathrm{~km}$ long stretch of the Gail river, the sedimentation and erosion of the riverbed could be measured between August 2016 and November 2018.

Using the method of transect interpolation the single-beam sonar measurements were projected to predefined reference lines, enabling the comparison of the two data sets. By interpolating between transections, a volumetric analysis is possible. The difference of the vertical area of the different timesteps is measured and multiplied with half the distance upstream to the next transect and likewise half the distance to the downstream transect. This approach represents an element-based impoundment basin volume calculation. By summarizing the cubature of the individual elements, the total sediment volume can be determined.

The transect survey at the Gail at the section of $\mathrm{km} 20$ and $\mathrm{km} 73$ is displayed exemplarily in Figure 33. The red profile was measured in 2016 and the blue profile in 2018. The riverbed was elevated caused by sedimentation in the time between 2016 and 2018. 
River kilometer 71.891

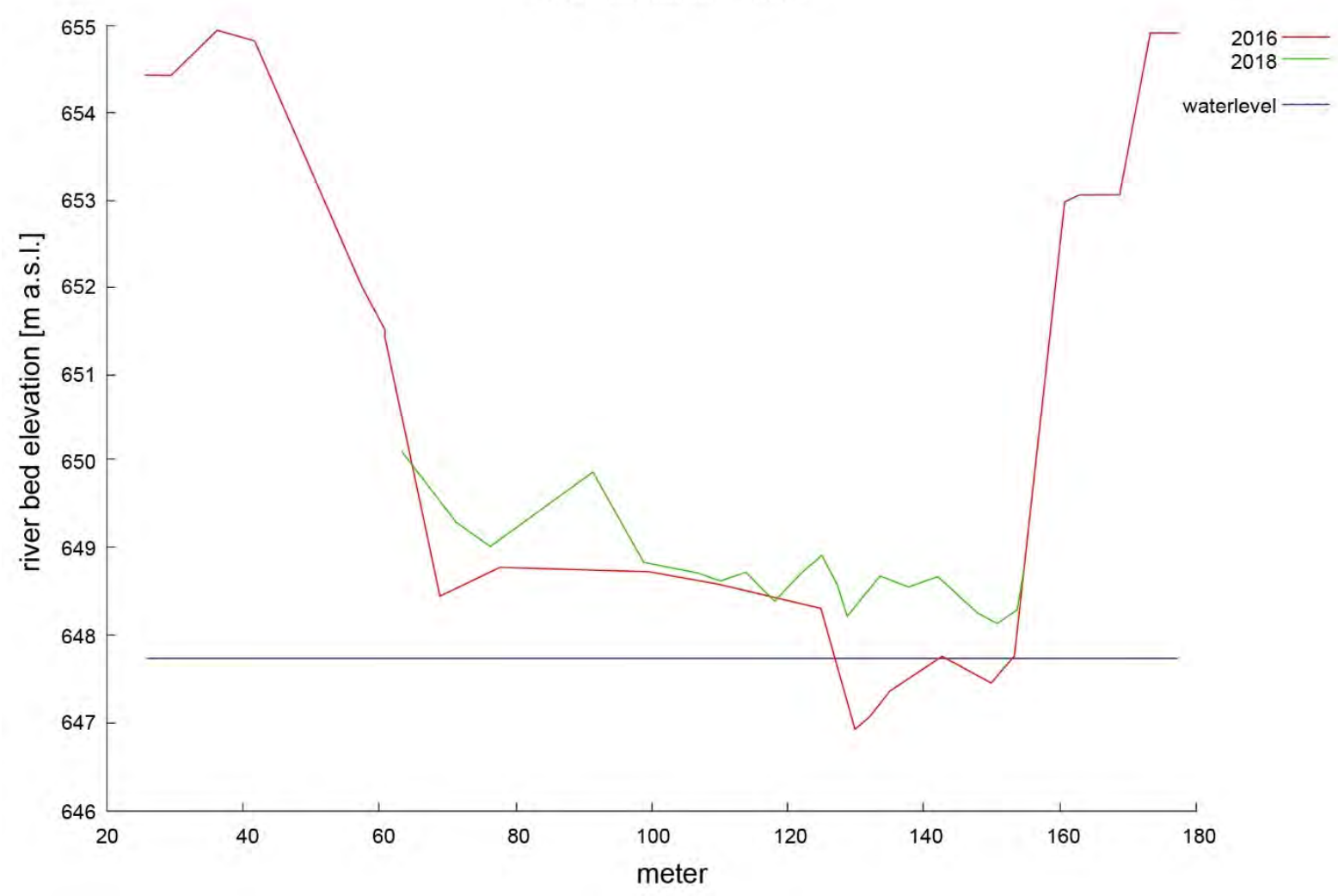

Figure 33: Development of a profile at the Gail river in the time between 2016 and 2018

Summating the element-based volume alteration the total river section can be displayed in the longitudinal profile (Figure 34). The mean fluctuation of the riverbed elevation is $14.5 \mathrm{~cm}$. In total an increase of the riverbed elevation is noticeable.

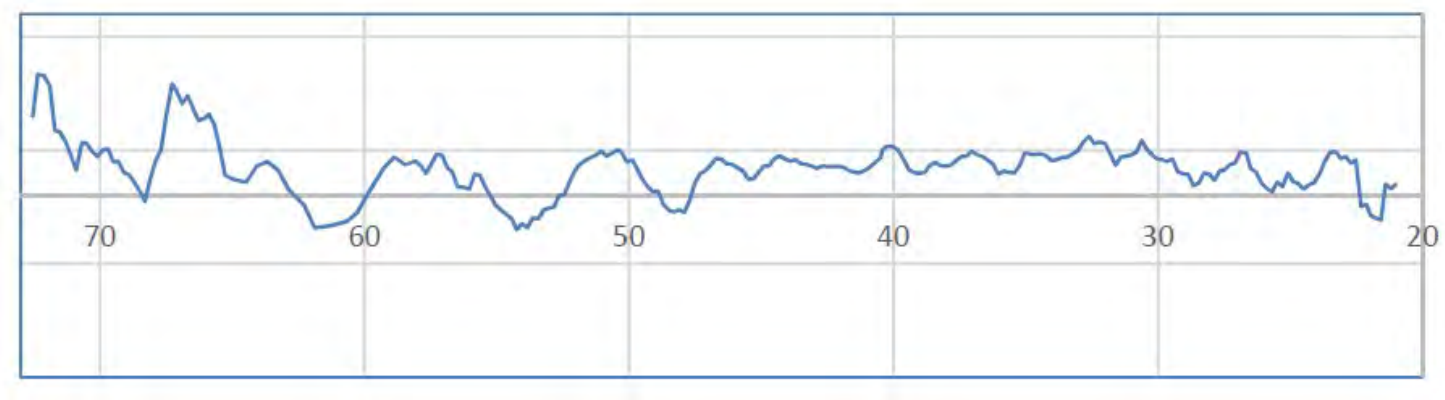

Figure 34: Longitudinal profile of the Gail ( $k m$ 20-73) with accumulation and erosion stretches

The cubature of each section along the investigation stretch and the corresponding accumulation are displayed in Figure 35. The total volume of accumulated sediments results to $250,000 \mathrm{~m}^{3}$.

With the transect analysis long-term morphological changes can be evaluated. A $52 \mathrm{~km}$ long river stretch of the Gail was examined. The office of the Carinthian government analyzed the morphological change comparing transections of the year 1992 and 2016. In that timestep generally erosions were detected. Comparing the surveyed Profiles between 2016 and 2018 morphologic change is dominated by an increase of the riverbed elevation of mean $14.5 \mathrm{~cm}$. 
This accumulation concludes to $250,000 \mathrm{~m}^{3}$ of sediments. Therefore, a change of the sediment budget could be detected.
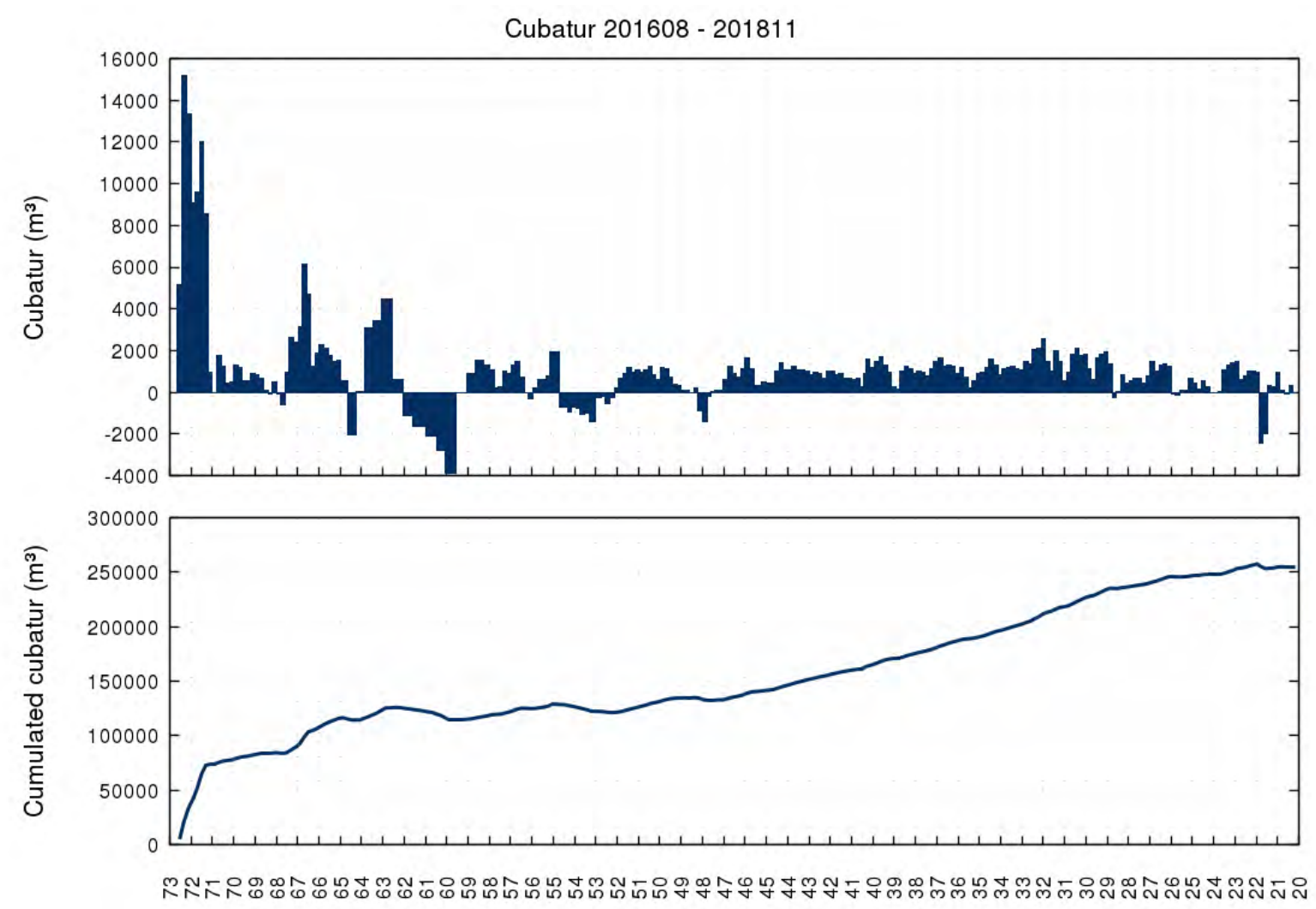

River-km

Figure 35: Accumulation of sediments in the river stretch km 20-73 in the time of Jul 2016- Nov 2018

In its $122 \mathrm{~km}$ length the Gail is divided into Lesachtaler Gail and Gailtaler Gail due to the clearly different channel shapes, bed slopes and grain size distributions. Figure 36 describes the potential sediment movements in the period from $27^{\text {th }}$ to $30^{\text {th }}$ October 2018 - during the flood event of the Gail in 2018.

The potential bedload transport was calculated at six Gail profiles using conventional bedload transport formulae. This results in a bed load impact of $197200 \mathrm{~m}^{3}$ from the Lesach Valley (profile 2). In Federaun (profile 6) suspended sediment was measured shortly after the flood event. Thus, a potential bedload transport of $16000 \mathrm{~m}^{3}$ could be determined by comparing the bedload/suspended load ratio with Dellach/Drava.

The potential suspended sediment output and input was both measured in Federaun and determined by Turowski et al. (2010). As a result, a suspended load input from the Lesach Valley of $189200 \mathrm{~m}^{3}$ and a suspended load output at Federaun of $592300 \mathrm{~m}^{3}$ could be estimated.

Due to bank erosion a bed load input of $34200 \mathrm{~m}^{3}$ and $34400 \mathrm{~m}^{3}$ suspended load was determined from the Mauthen profile (profile 3) up to its mouth into the Drava.

By profile measurements before and after the flood a sediment deposition of $250000 \mathrm{~m}^{3}$ bed load was calculated from $\mathrm{km} 73$ to $\mathrm{km} 20$. 
By area determination and estimation of the mean bed heights a deposition (floodplain sedimentation) of $603100 \mathrm{~m}^{3}$ was calculated in the retention areas. This load is added to the suspended sediment load.

The potential bedload and suspended load of four relevant tributary rivers are based on bedload transport calculations of a $\mathrm{HQ}_{100}$ flood (bedload) and on Turowski et al (2010) (suspended load). This resulted in a bedload input of $13500 \mathrm{~m}^{3}$ and a suspended load input of $366900 \mathrm{~m}^{3}$ from these tributaries.

Due to the abrasion, the bed load is reduced by $9450 \mathrm{~m}^{3}$ and added to the suspended sediment input.

During the flood in the year 2018 on the Gail, approximately 1.4 million $\mathbf{~ m}^{3}$ of sediments were transported.

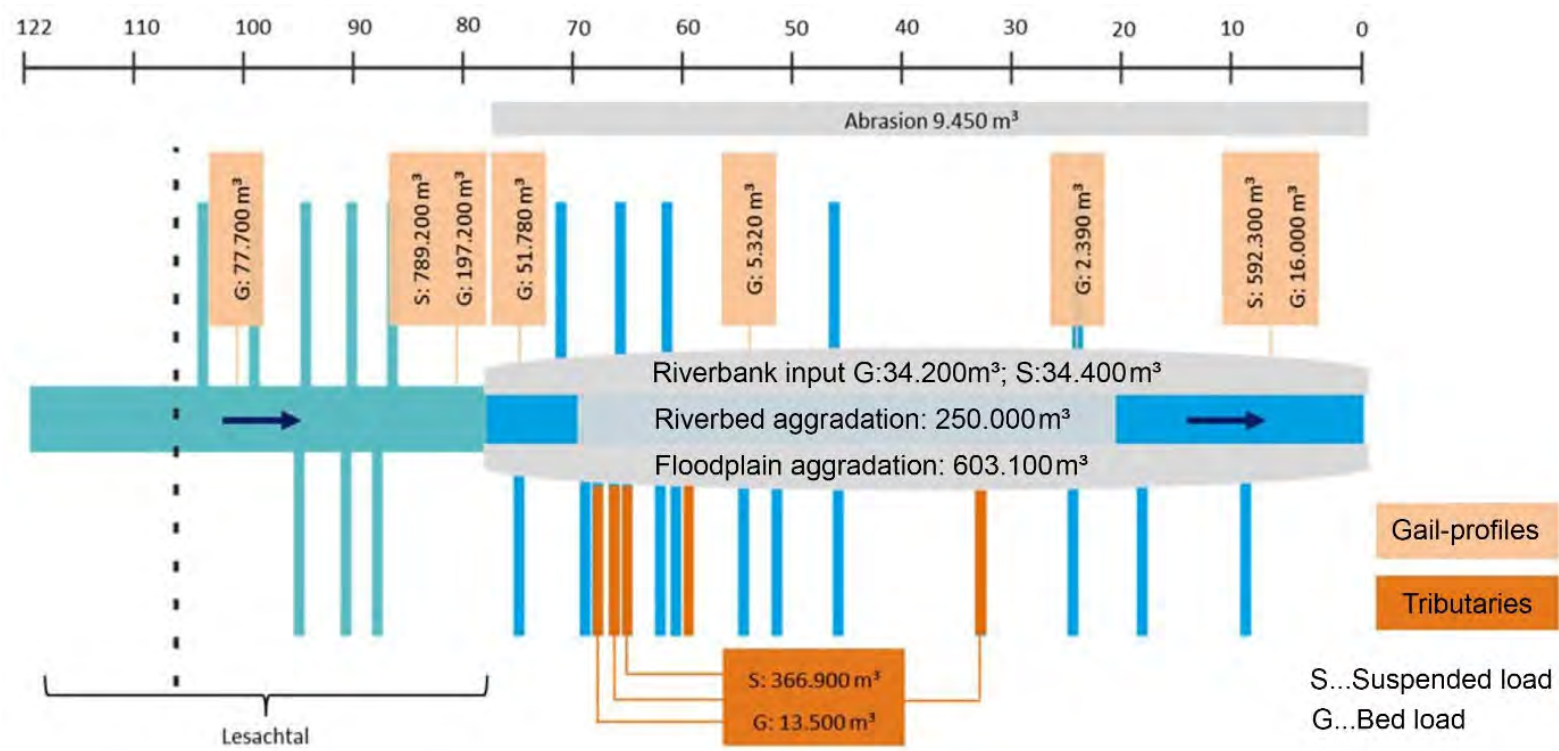

Figure 36: schematic overview of the estimated sediment yield balance of the flood event (27 to $30^{\text {th }}$ October) 2018 at the Gail river 


\subsection{Sediment Forensics - Event based analyses to increase process understanding}

With the use of integrative measuring systems in sediment monitoring the temporal and spatial variability of individual events can be measured. In general, the sediment transport is linked to the hydraulic condition, where an increase in discharge mostly resumes in an increase of sediment transport. Data from the monitoring stations show that this relation is not necessarily accurate. With the classical approaches and methods it may happen that certain phenomena concerning sediment transport are poorly represented or cannot be explained at all. Following the dependence of stream specific characteristics, sediment supply and event type (snow melt, flood event...) these unsolved problems can be cleared up resp. such appearing phenomena can be explained. We have defined these analyses with the term sediment forensics, where the aim is to explain and describe individual event-based occurrences by specifically looking at the boundary conditions in order to be able to explain a fundamentally valid relationship as well as the event-based specialties. In the following five examples are listed, where it was possible to explain phenomena (especially in connection with extreme events) in sediment transport by a targeted combination of different data sources and research.

3.6.1. Example 1: Rofenache - Vent (bedload/suspended load input due to a morphological event)

\section{Snowmelt-Event}

Figure 37 shows the course of discharge, bedload transport and suspended sediment transport at the Rofenache from 24.05.2018 to 08.06.2018. During this snow melt period, a clear diurnal course of the flow and solid transport at the Rofenache can be observed. Both transport processes follow the diurnal course of the flow. The total solid matter budget in this period (8771 t) is divided into $89 \%$ suspended matter transport and $11 \%$ bed load transport (D>22,4mm).

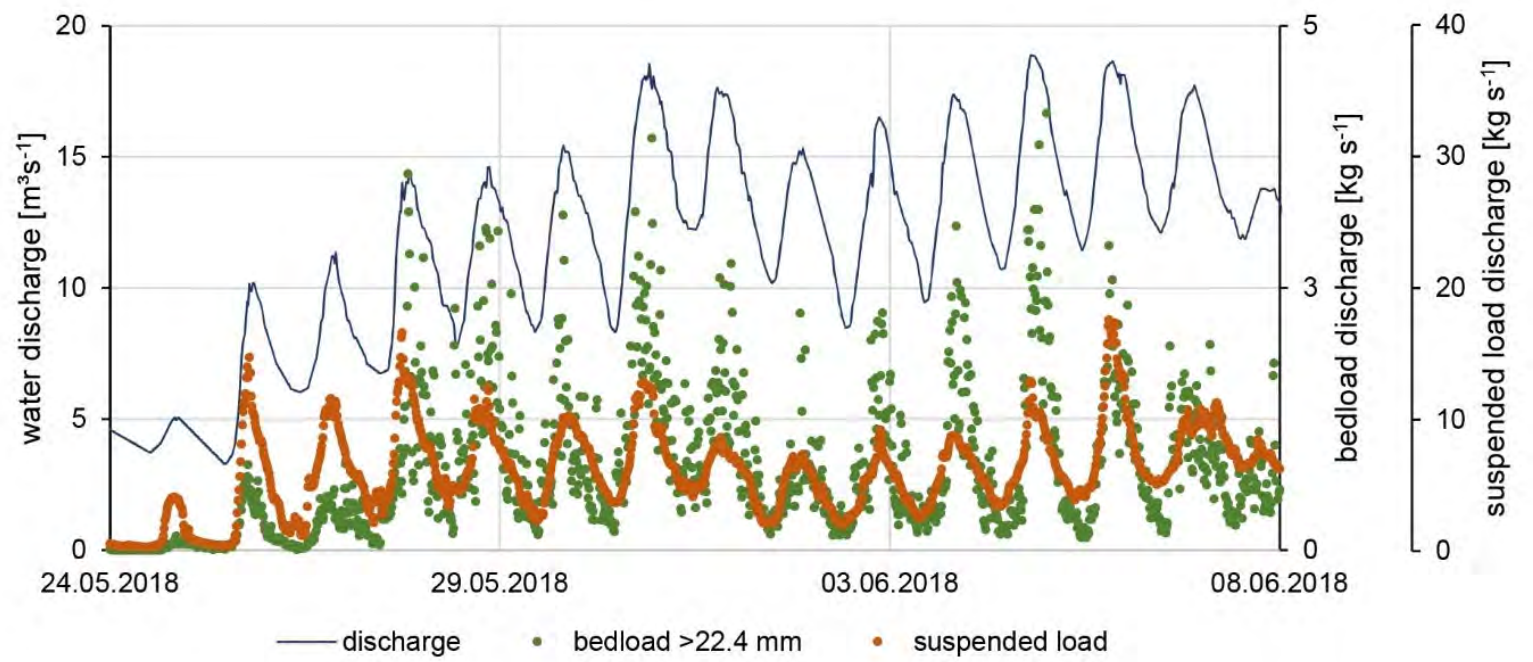

Figure 37: Vent snowmelt induced discharge

An examination of the climate data in the catchment area suggests a significant snowmelt period. Figure Figure 38a shows the cumulative line of the flow at Vernagtbach. The increase 
of the flow data with the beginning of June is clearly visible. The temperature curve (maximum and minimum temperature in Figure Figure 38b) also shows that for the first time in the course of the year the temperatures here are above zero. In addition, images taken by the BAdW camera show a significant decrease in the snow cover on the glacier (Figure 39).

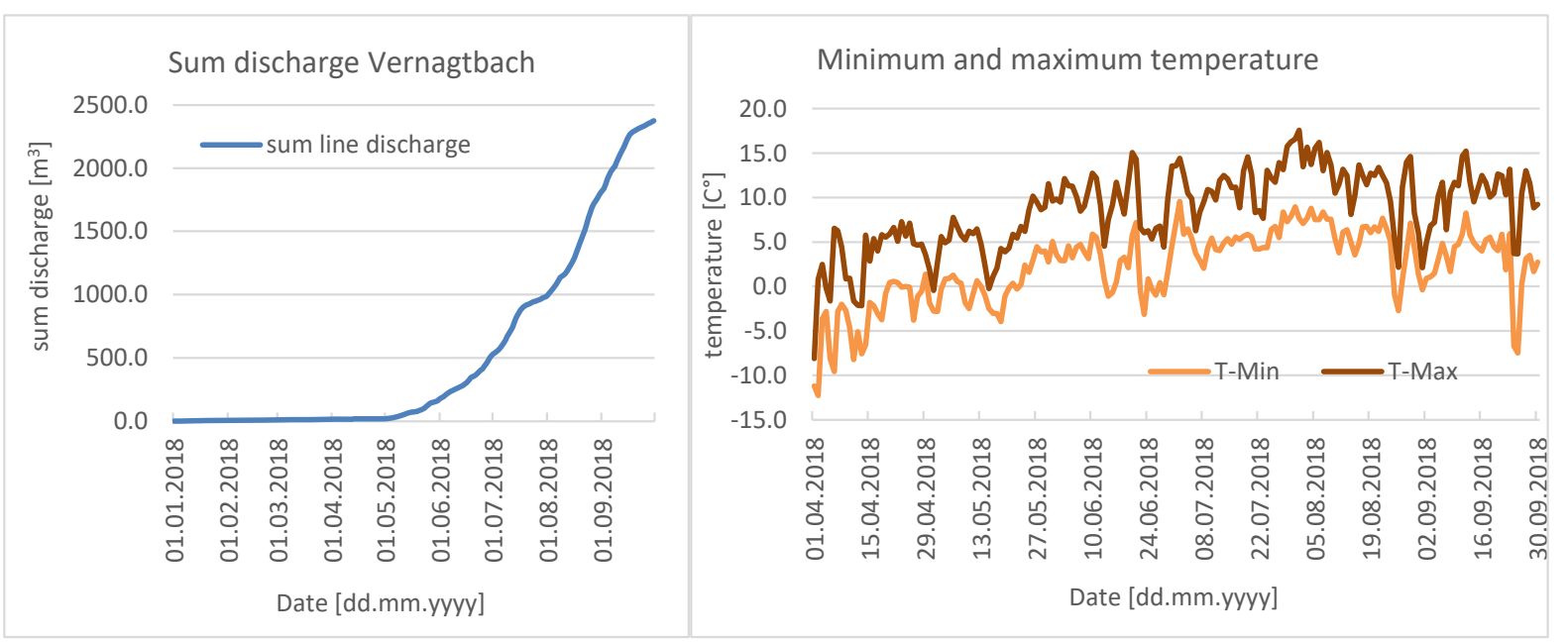

Figure 38 a: sum line discharge Vernagtbach, $b$ : minimum and maximum temperature

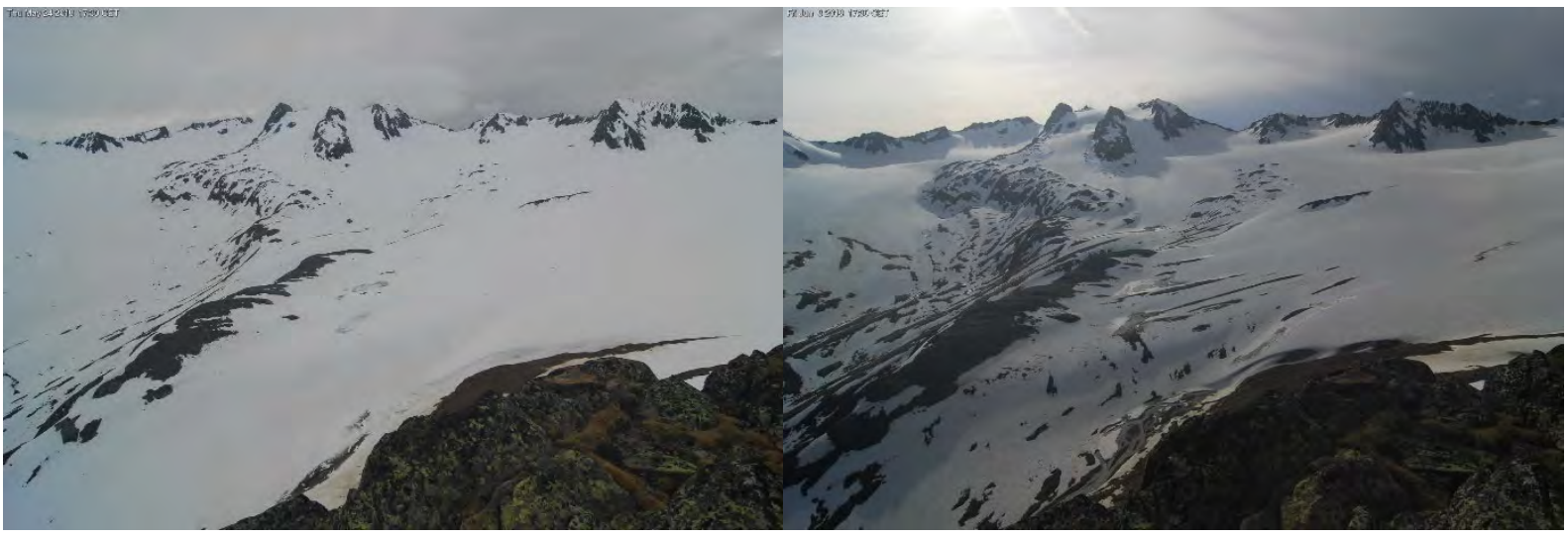

Figure 39 a: Photo 24.05.2018; b: Photo 8.06.2018 (http://www.glaziologie.badw.de)

\section{$\underline{\text { Rainfall Event } 2018}$}

Figure 40 shows a summer event with very high bedload and suspended load transport. A prominent peak of suspended matter occurred at the same time as the discharge peak on 2.08.2018. At this date bedload transport is on a low level. Bedload transport starts with a time delay of $\sim 5$ days on 7.8.2018 (see detail in Figure 41). From 7.8.2018 to 9.8.2018 even more bedload than suspended load was recorded at the measuring station (60\% bedload, $40 \%$ suspended load). 


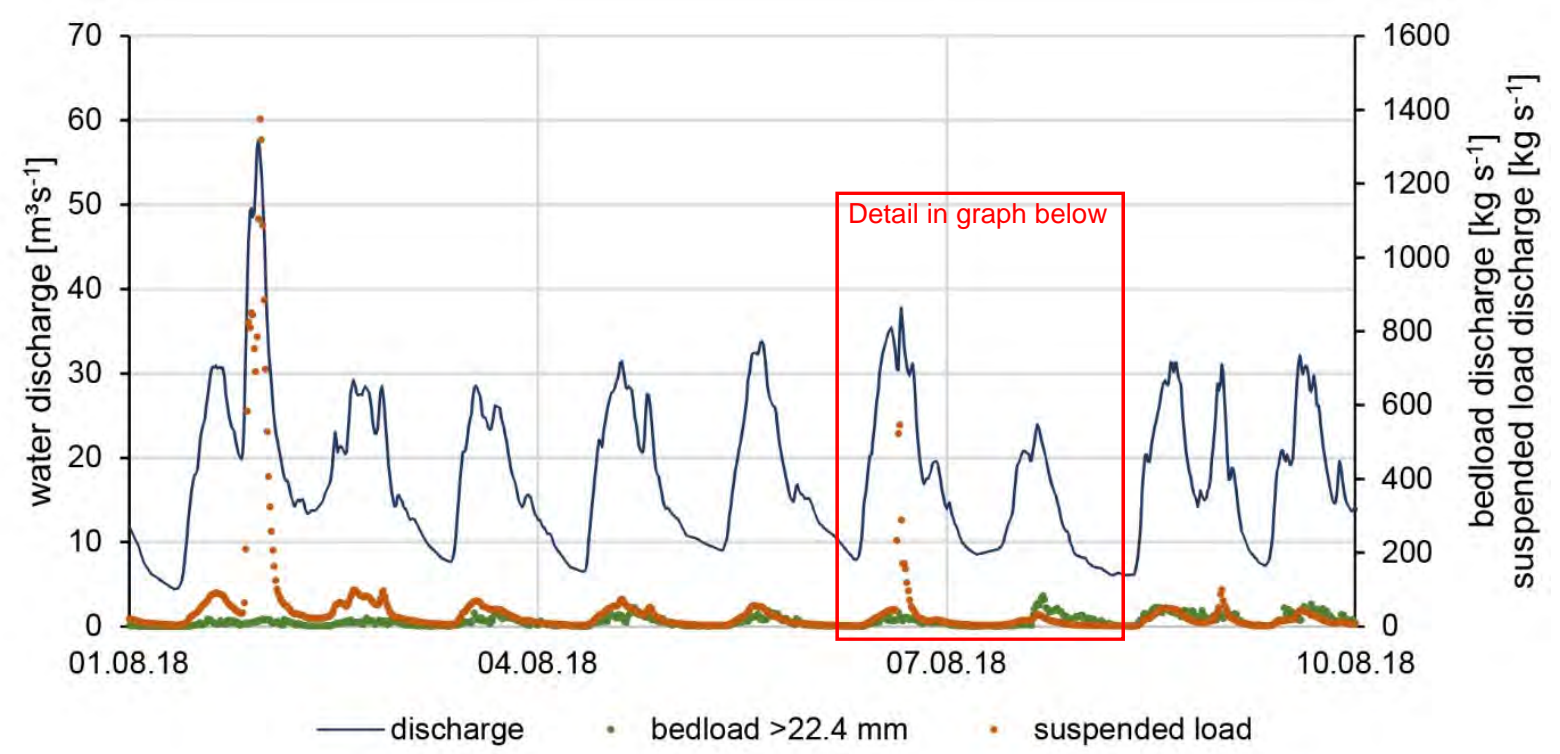

Figure 40: Vent summer event 2018

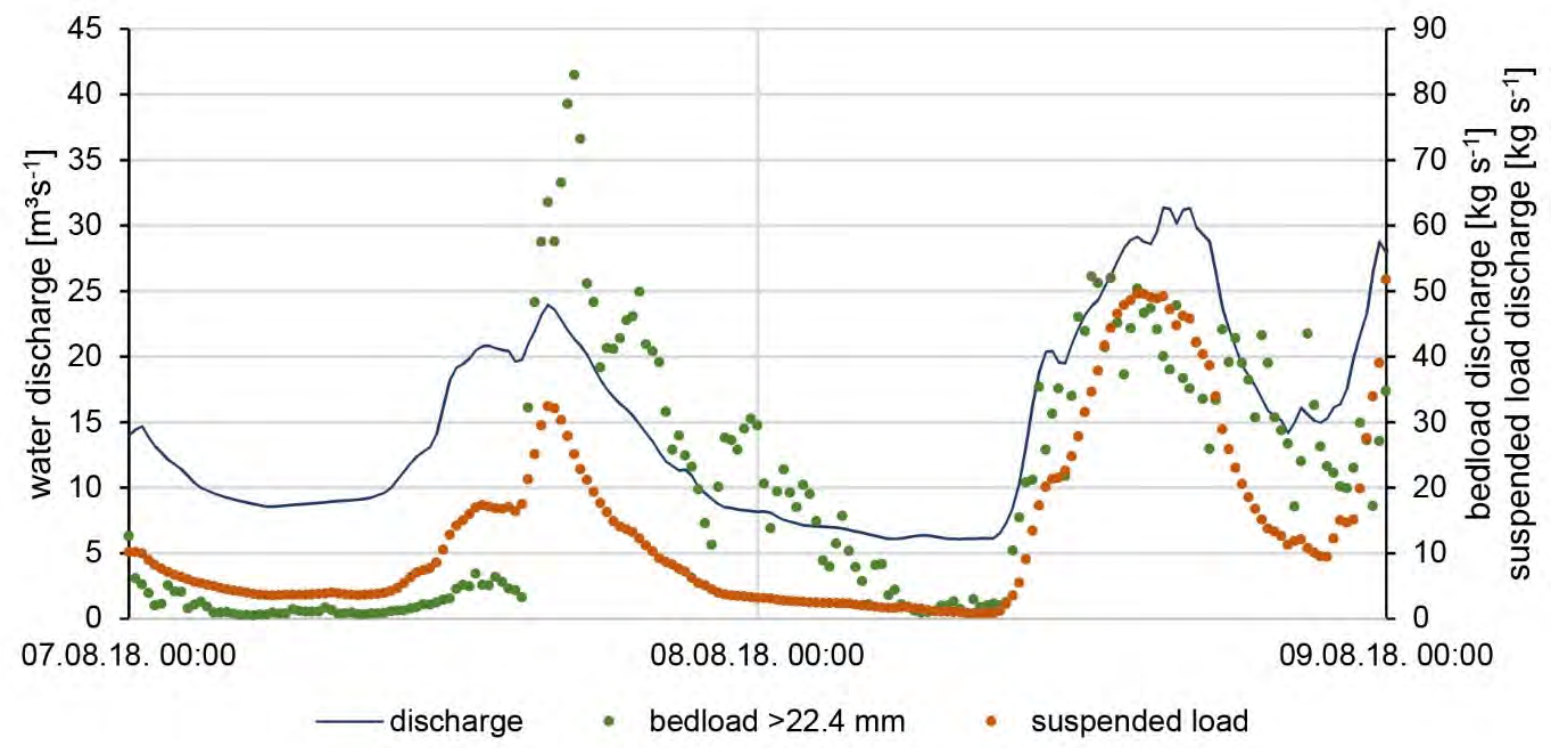

Figure 41: Vent summer event 2018 bedload peak in detail

The annual course of precipitation and mean daytime temperature in Figure 43 indicates that larger amounts of precipitation were recorded at the time of the event. The camera images from the Vernagt Glacier display that the precipitation event may have led to major morphological changes (e.g. debris flows). 

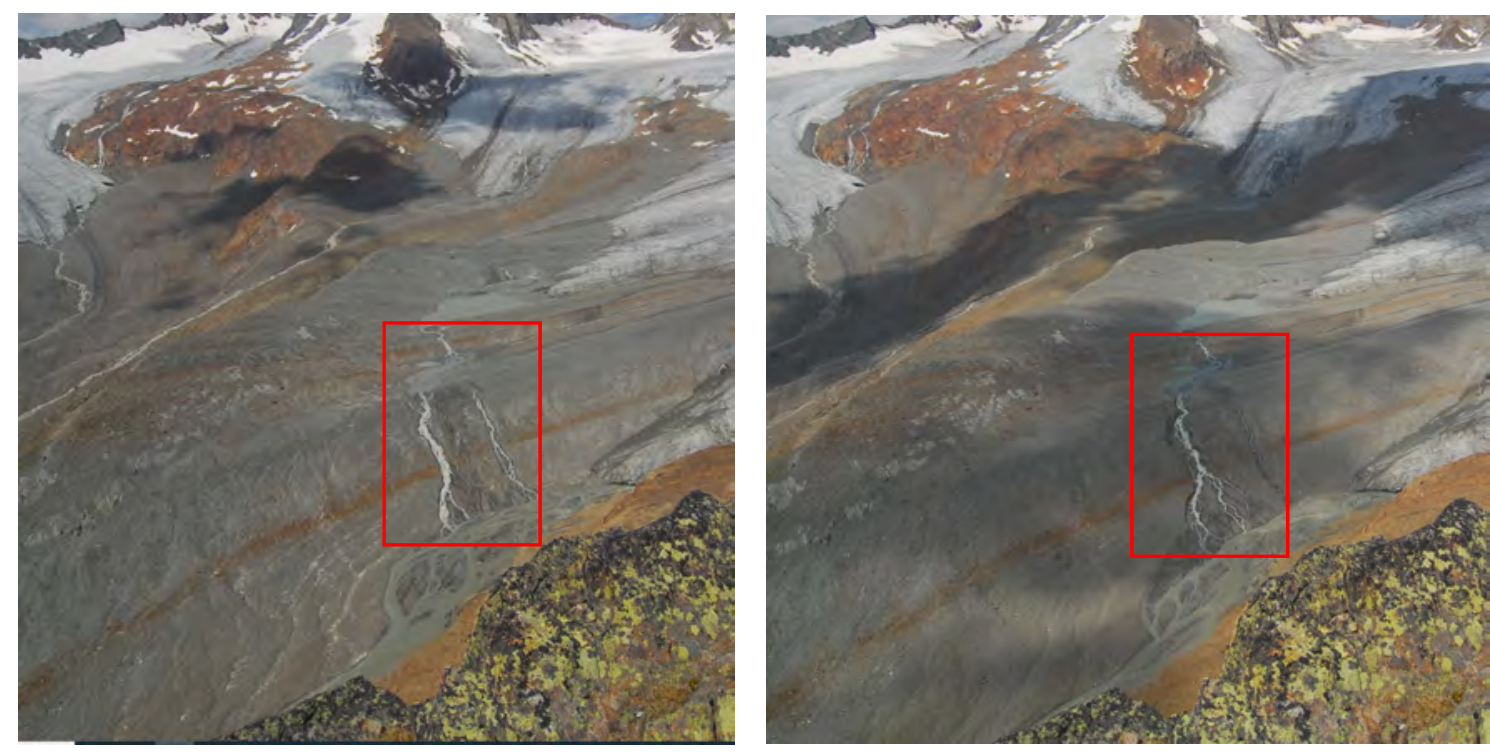

Figure 42 a: Photo 31.07.2018, b: Photo 08.08.2018 http://www.glaziologie.badw.de

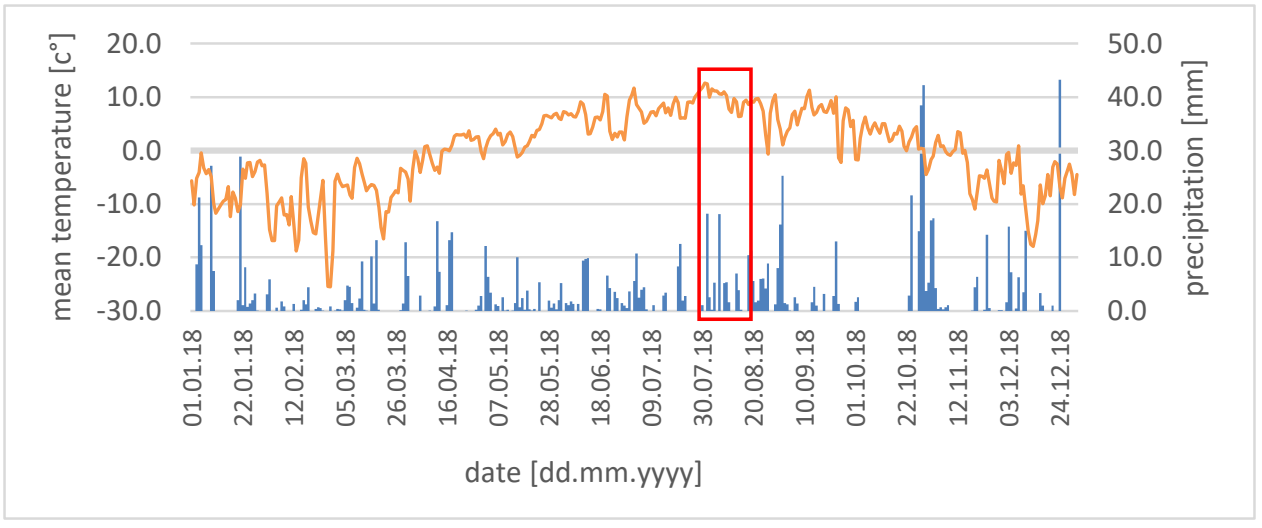

Figure 43: Course of mean temperature and precipitation

\section{Rainfall Event 2019}

In summer 2019, direct bed load measurements were carried out at the Rofenache on 08.08.2019 and 09.08.2019. The curves for bedload transport ( $D>22.4 \mathrm{~mm}$ ), suspended matter transport and flow rate are depicted in Figure 44. The strong increase of suspended sediment transport from 8.8.2019 onwards is remarkable in this period of time. The decoupling of suspended sediment transport from water flow has to be highlighted. Observations of the measuring team and talks in the population describe a "change of color" of the Rofenache. This "colour change" is due to a high input of suspended matter in the catchment are. On 10.08 an inspection of the catchment area was carried out and the source of the high suspended matter input - a debris flow just above the glacier snout - was discovered. Images are presented in Figure 45. 


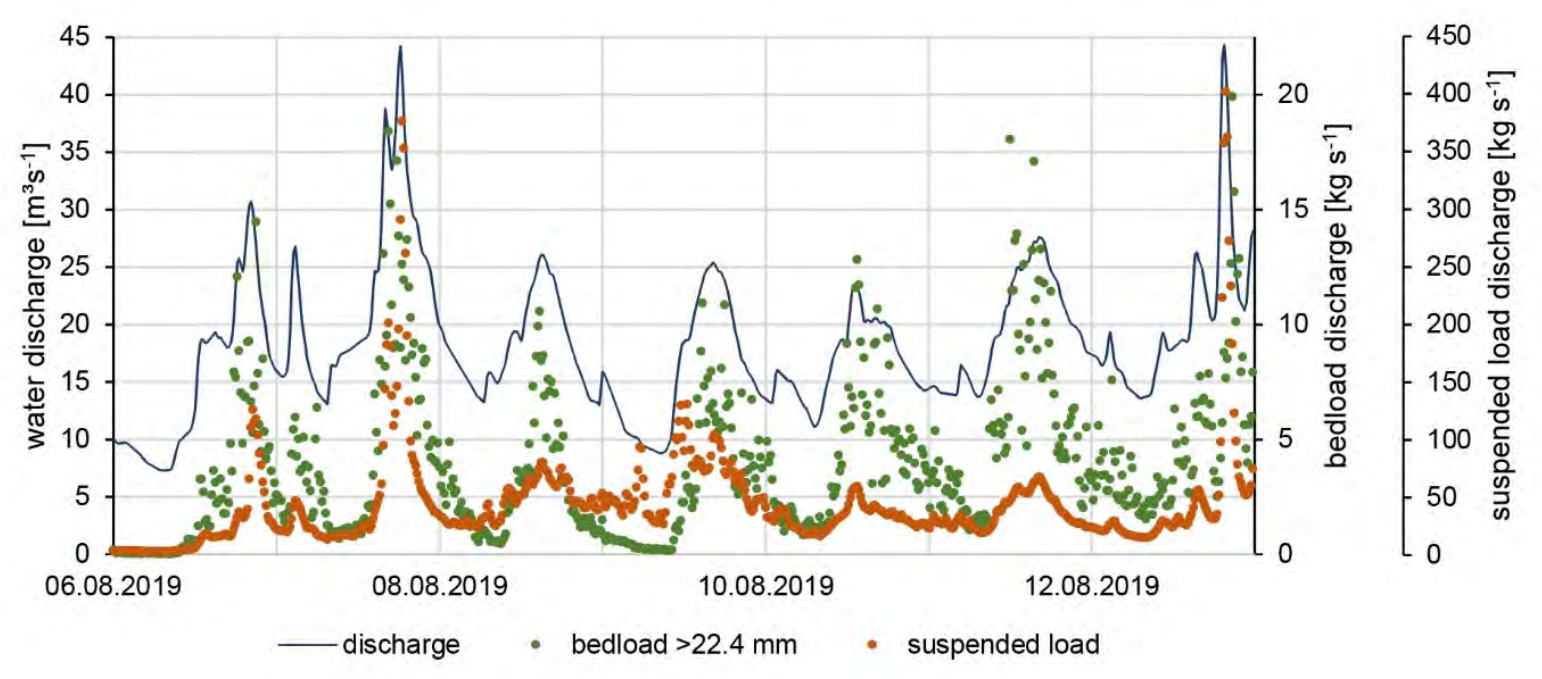

Figure 44: Vent summer event 2019
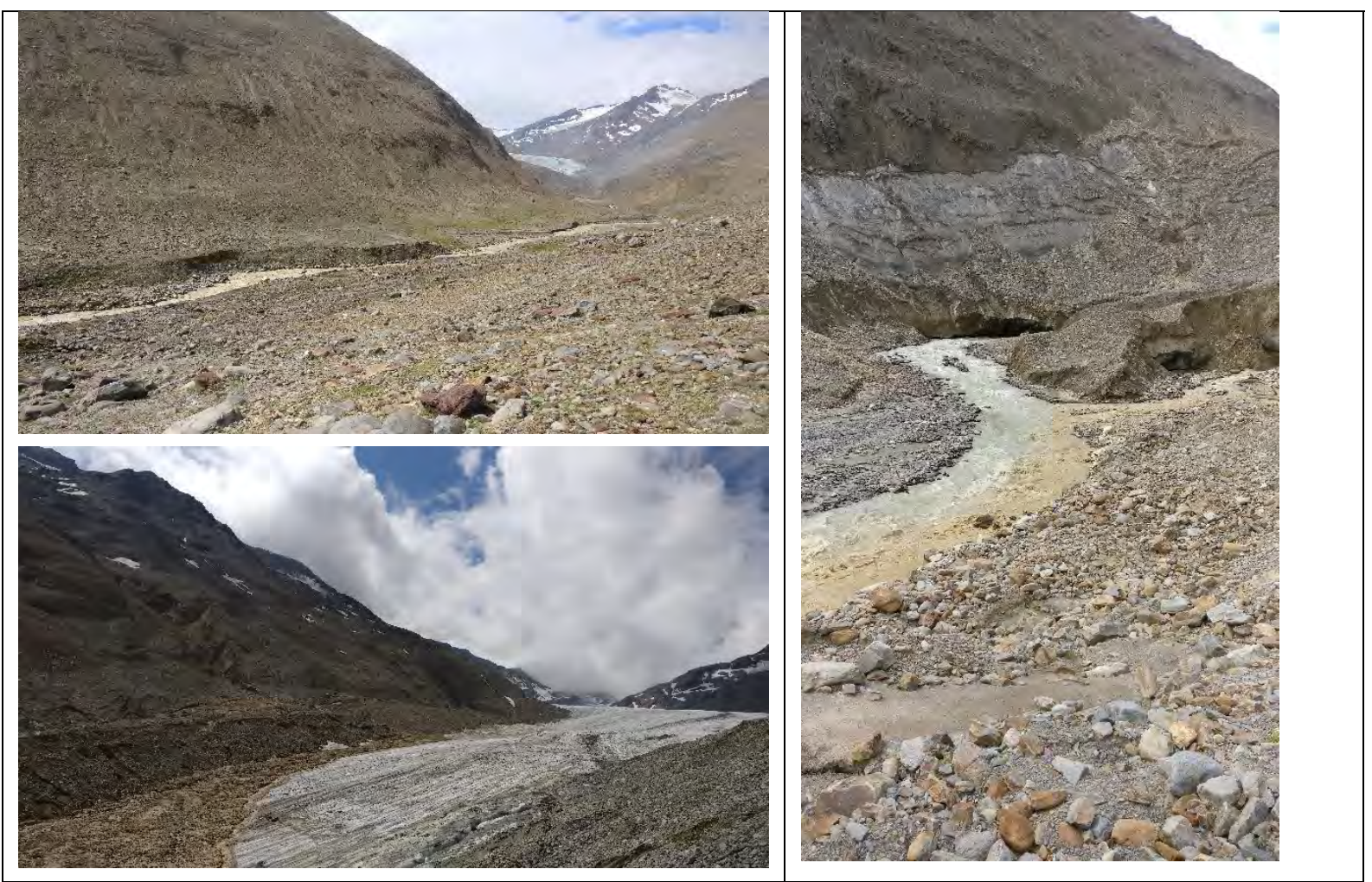

Figure 45 a: "muddy" Rofenache, in the background, the Hintereisferner is seen; b: sedimentary input into the Rofenache; c Mudflow in the area of the glacier snout

3.6.2. Example 2: Urslau (bedload availability strongly influences the transport)

At the Urslau stream only bedload data - no suspended load data -are available. The following graph gives an overview of possible event types at the Urslau. Figure 46 shows the snowmelt period. Similar to the curves at the Rofenache, the diurnal course of the flow is visible. The bedload transport follows this course. Total bedload mass of this event is $1651 \mathrm{t}(\mathrm{D}>22,4 \mathrm{~mm})$. 
The 2012 summer event (Figure 47) shows a different behavior, as a lot of bedload transport was mobilised during the first peak flow. Even after the peak flow has decreased, the bedload transport remains at a high level. Temporal fluctuation of bedload transport - not induced by discharge- are evident. It can be assumed that there was sufficient bedload material available at this event. In Figure 48 completely different characteristics can be observed. It can be seen that bedload availability decreases from peak flow to peak flow.

Based on these observations a conceptual model of bedload transport process types as a function of bedload transport efficiency and dimensionless stream power has been published by Kreisler et al. (2017) (see chapter 3.7.3).

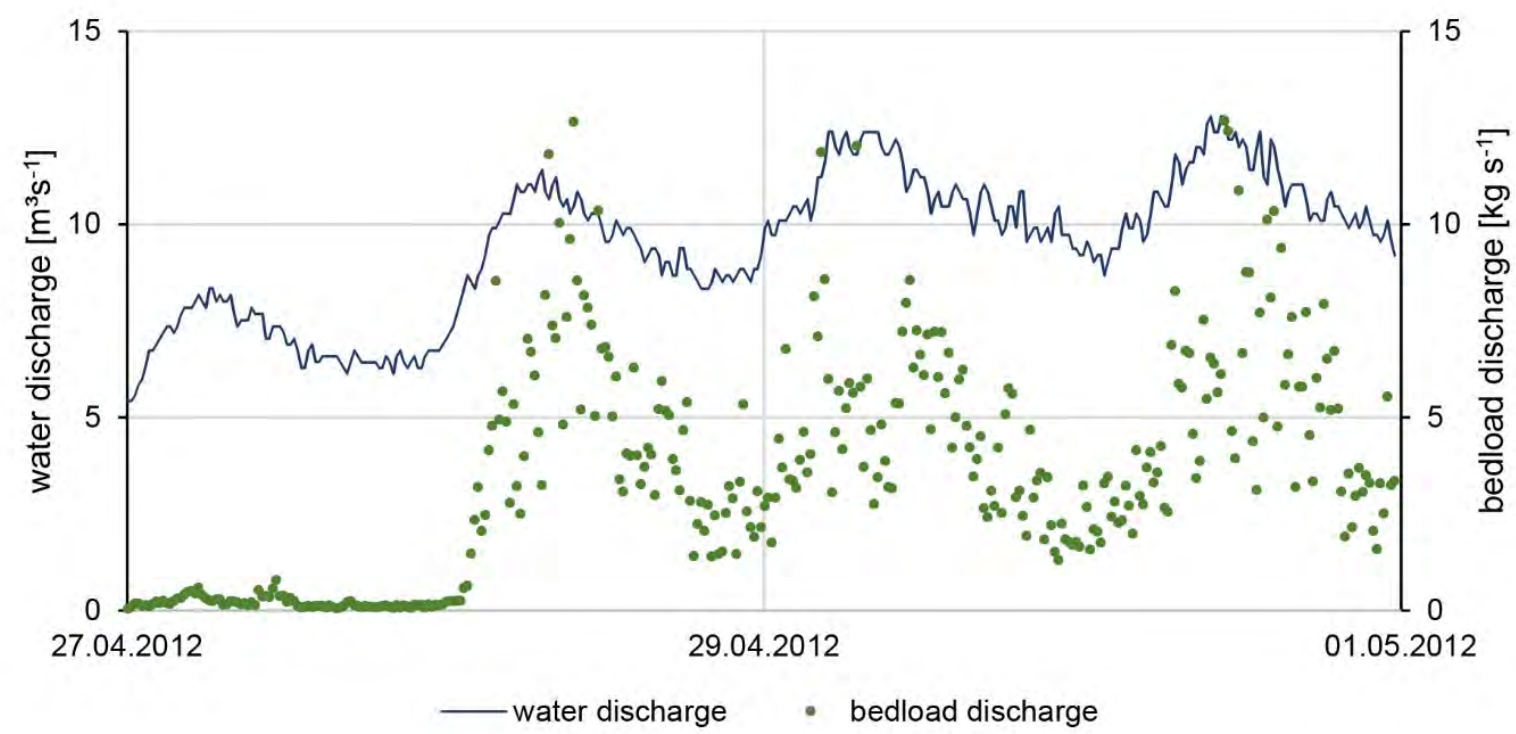

Figure 46: Urslau snowmelt event 2012

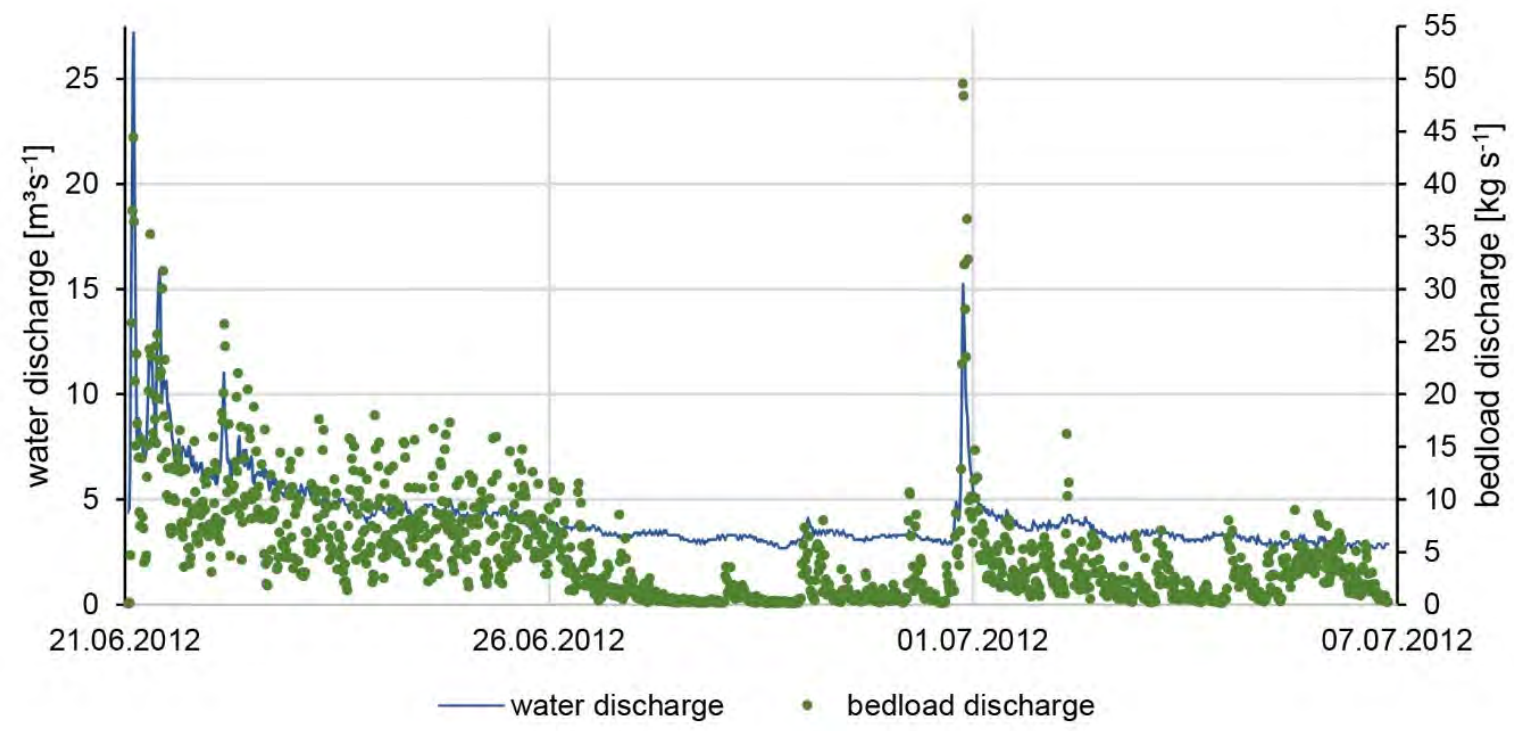

Figure 47: Urslau summer event 2012 


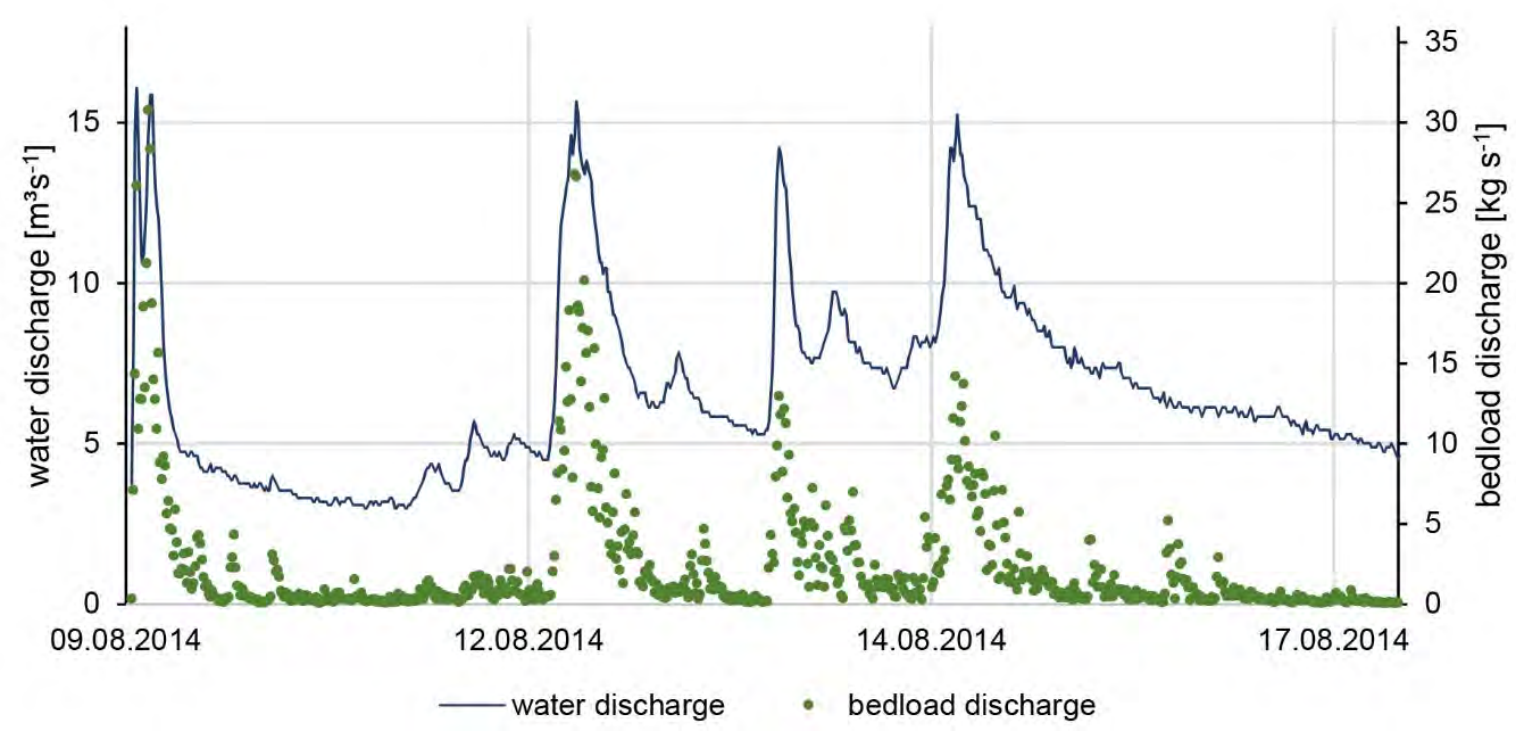

Figure 48: Urslau bedload supply limited

3.6.3. Example 3: Drava/Falkensteinsteg (Hydropower influence and bed armouring)

The bed load measurements at Falkensteinsteg/Drava are characterized by the upstream diversion power plant. About $26 \mathrm{~km}$ upstream of the measuring station is the diversion structure and the daily reservoir "Tassenbach". The discharge after the "Strassen Amlach" power house is located about $2 \mathrm{~km}$ upstream of the measuring station. The stretch of river upstream of the bedload measuring station is a residual water stretch (Figure 49).

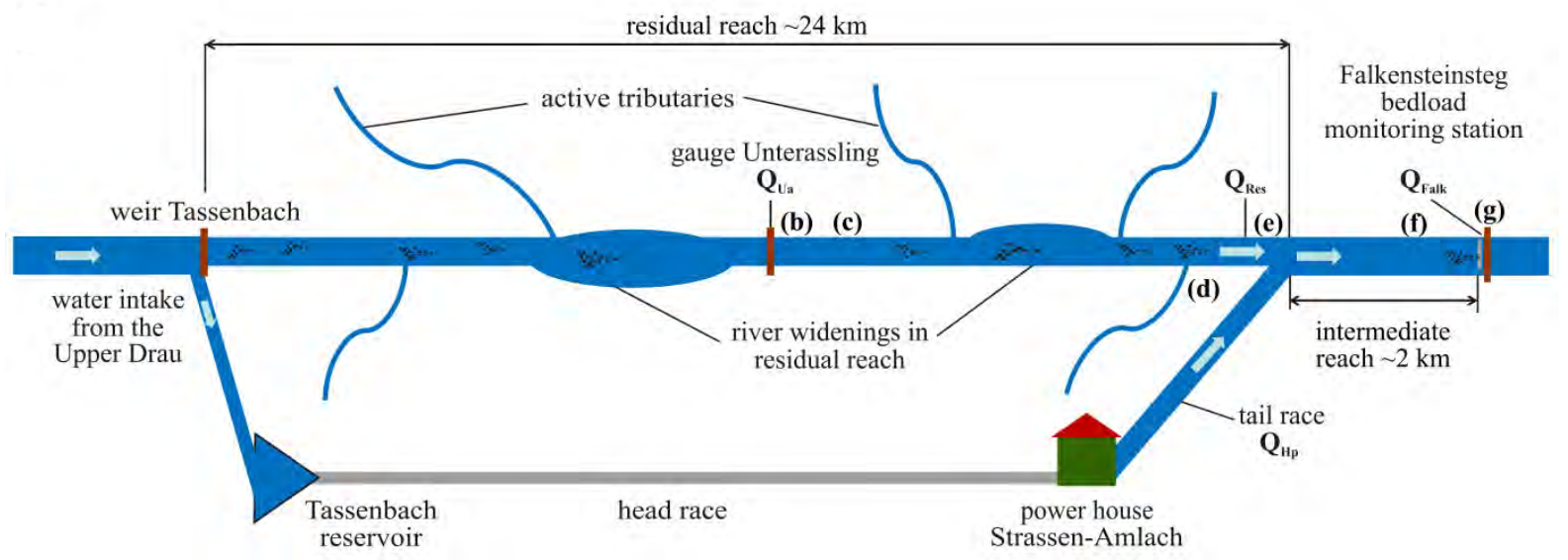

Figure 49: Sketch map of the Upper Drava River encompassing the hydrological system (Aigner et al, 2017)

Daily flow rate fluctuations due to hydroelectric power generation are shown in Figure 50 . The flow peaks lead to an increased bedload transport - the material for this is provided by the approximately $2 \mathrm{~km}$ long area between the intake structure and the measuring station (compare with Aigner et al., 2017). Suspended matter is not "stored" in this short section daily flow waves do not lead to any transport of suspended matter. On 13.4.2018 a small precipitation event led to a flow peak and to the activation of sediments in the residual water section and/or from the feeders. In addition to the bed load transport, a suspended matter wave was recorded. 
Another characteristic of the measuring station is a time lag effect between the peak runoff and bedload transport - this has been analyzed in detail by Aigner et al. 2017 and is described in chapter 3.7.1.

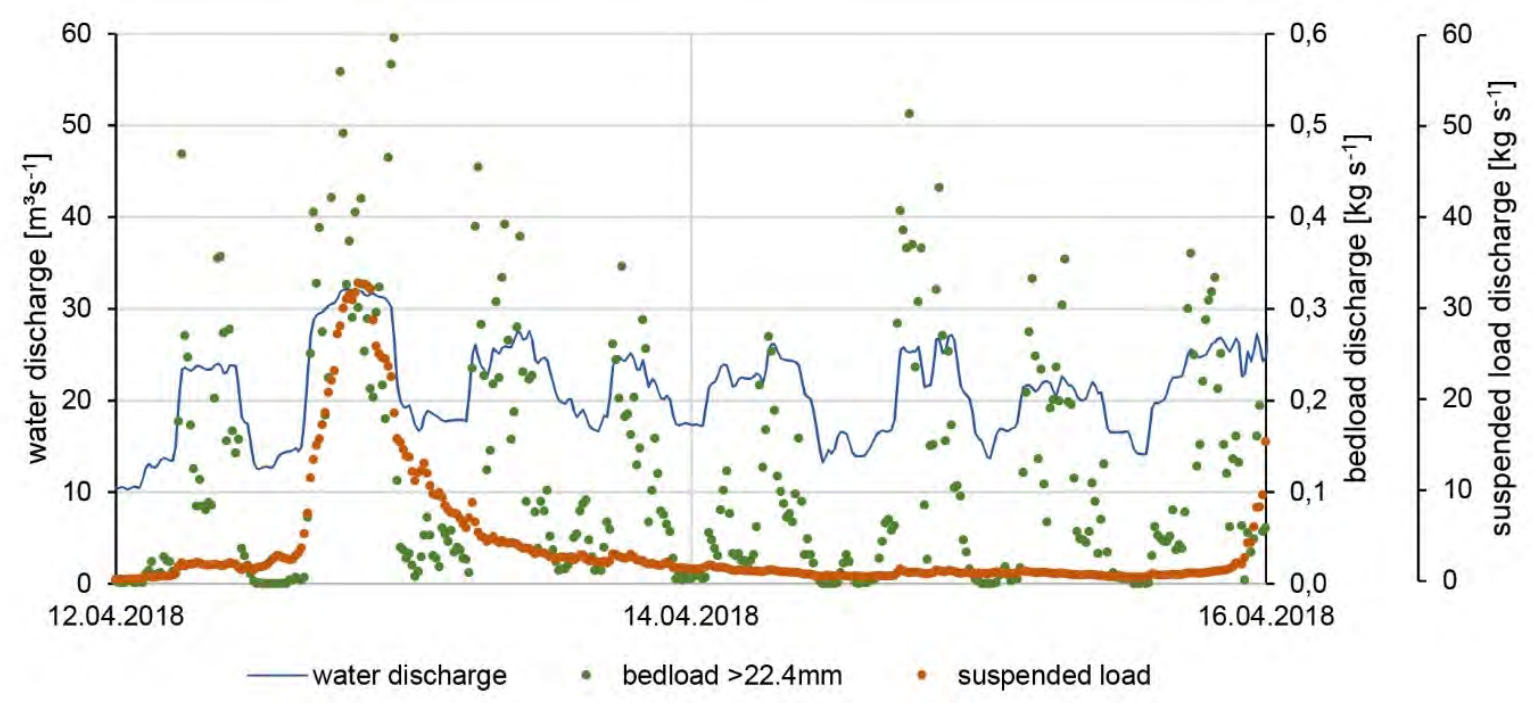

Figure 50: Falkensteinsteg (Drava/Lienz) snowmelt induced discharge 2018 (suspended load discharge raw data)

Figure 51 shows the flow, bed load transport and suspended sediment transport curves of the autumn flood 2018. During this event there were heavy landings in the measuring area - the processing of the data and further details about the flood are explained in chapter 3.7.2. The effects of the flood on the transport of bedload are shown in Figure 52. Here the hydrograph of the flow and the geophone impulses (daily average values) are shown. The graph illustrates that at comparable flow rates, the number of geophone pulses is greater after the flood event of 2018.

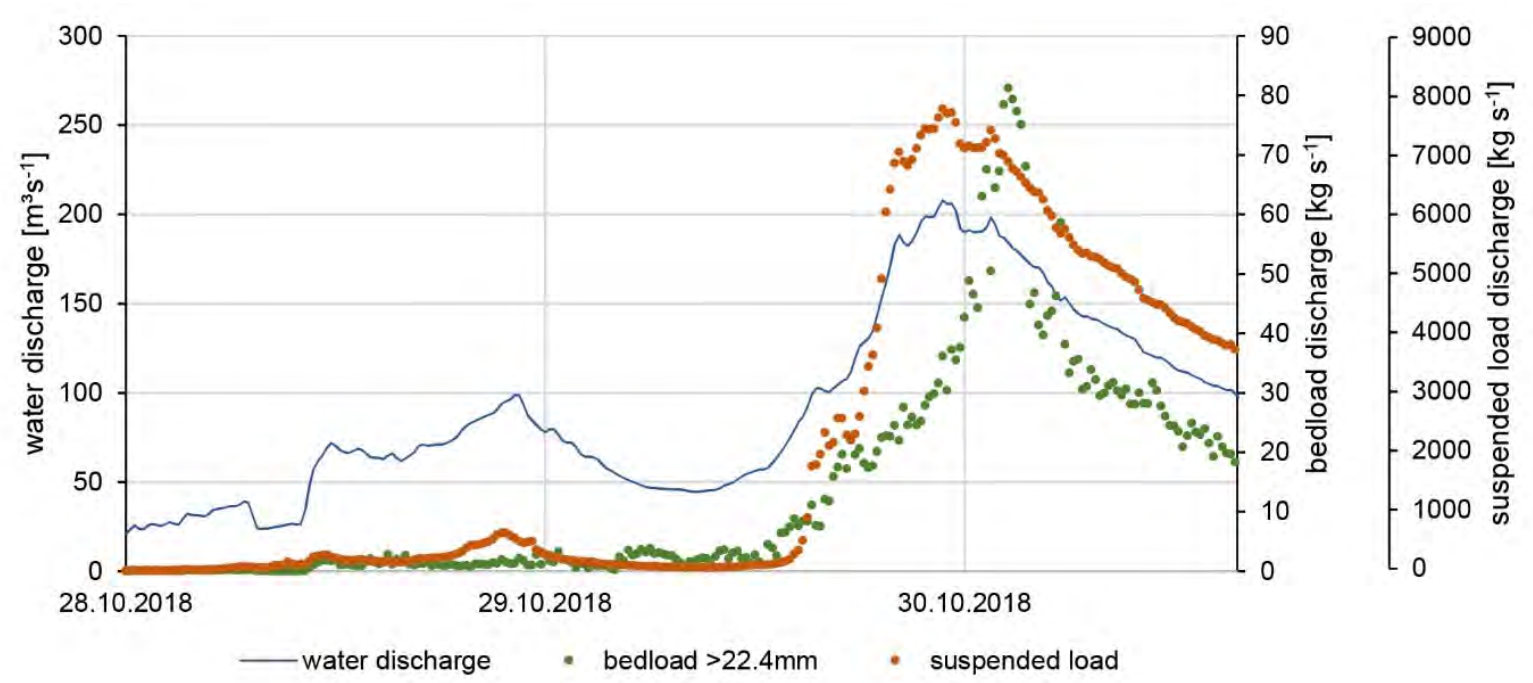

Figure 51: Falkensteinsteg (Drava/Lienz) fall event 2018 (shortly after bedload peak the data was reconstructed (see chapter 3.7.2.) 


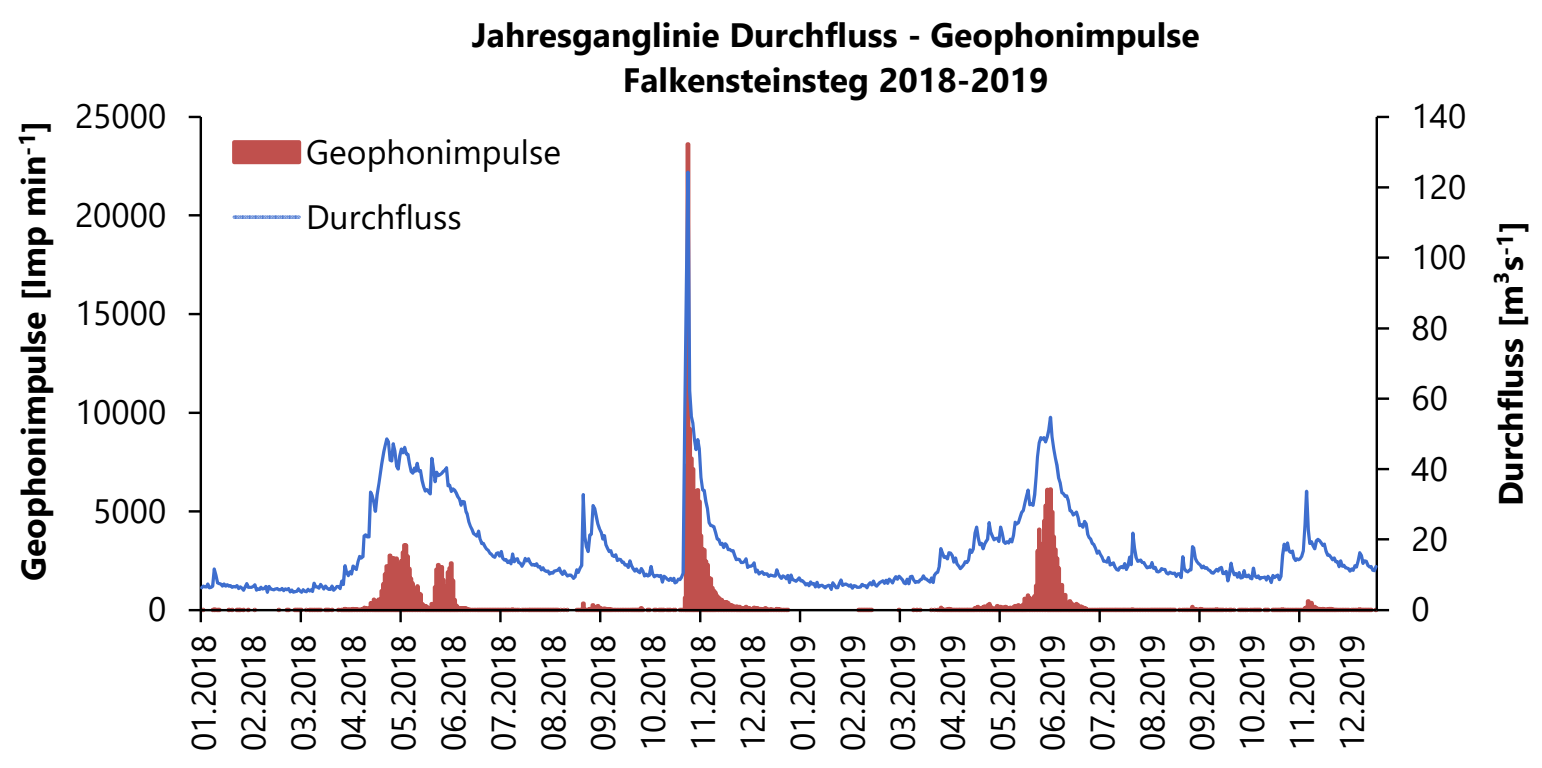

Figure 52: Annual hydrograph flow/geophone pulses (daily mean values), Falkensteinsteinsteg/Drava, 2018 to 2019

3.6.4. Example 4: Isel/Lienz (Different characteristics in different seasons of the year, hysteresis effect)

As already shown at the Urslau and Rofenache, the transport of solids on the Isel shows a similar course as the flow during the snowmelt period (Figure 53 ). During this snowmelt- event, the proportion of transported suspended matter in the total transport (4252 $\mathrm{t}$ suspended and $107 \mathrm{t}$ bedload transport load $\mathrm{D}>22,4 \mathrm{~mm}$ ) is $98 \%$.

During the autumn floods of 2018 (Figure 54), a total of $63155 \mathrm{t}$ of solid matter was transported on the Isel river, of which $1 \%$ bed load $\mathrm{D}>22,4 \mathrm{~mm}$ and $99 \%$ suspended matter).

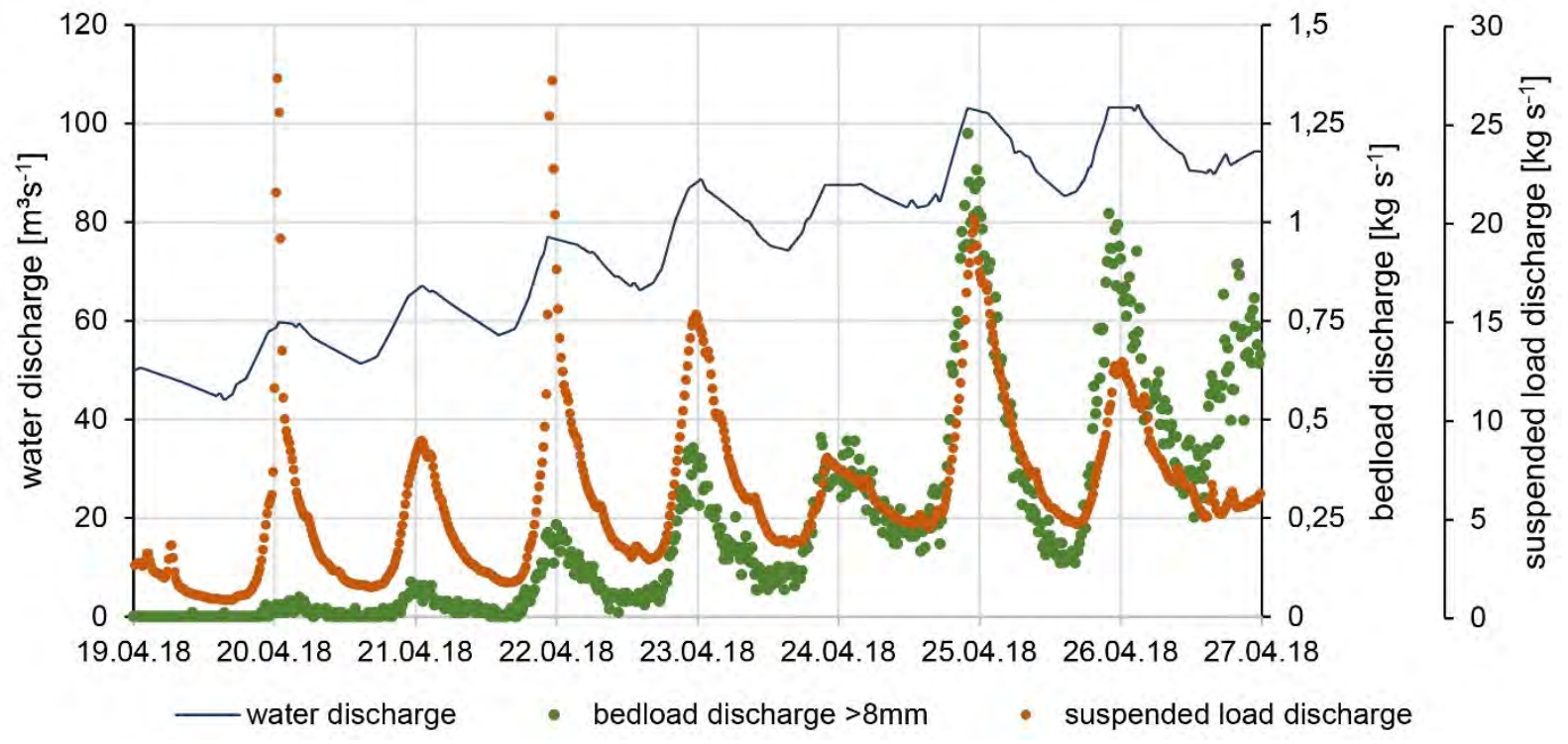

Figure 53: Isel/Lienz snowmelt induced discharge 2018 


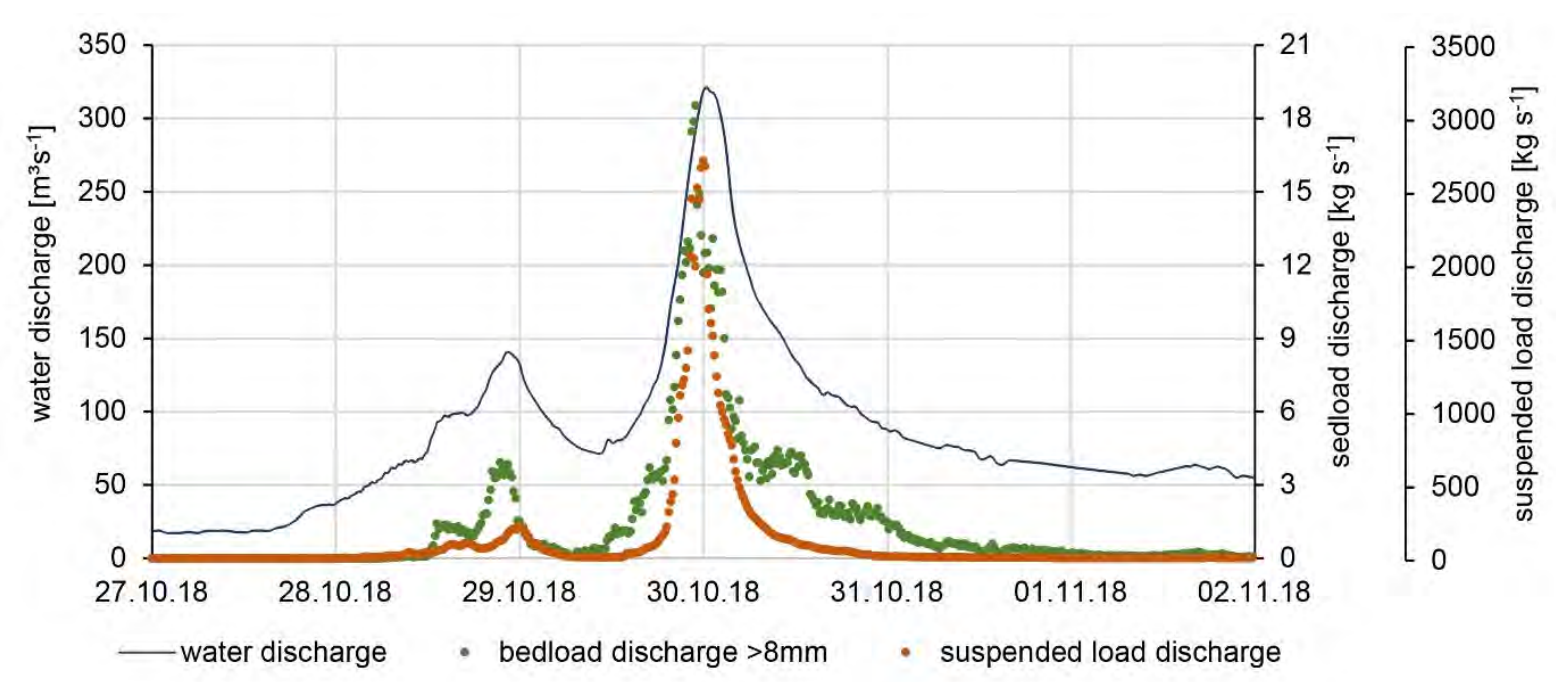

Figure 54: 15 Isel/Lienz fall event 2018

A remarkable characteristic of the Isel is that the bedload transport starts very early, almost ahead of the flow. In Figure 54 we can see the flood event due to the pronounced Adriatic depression in autumn 2018 and that the peak in bedload transport arrives in the flow before the peak. Finally, this hysteresis effect was illustrated in Figure 55. The knowledge about this hysteresis effect makes a big difference for monitoring but also for the interpretation of the data.

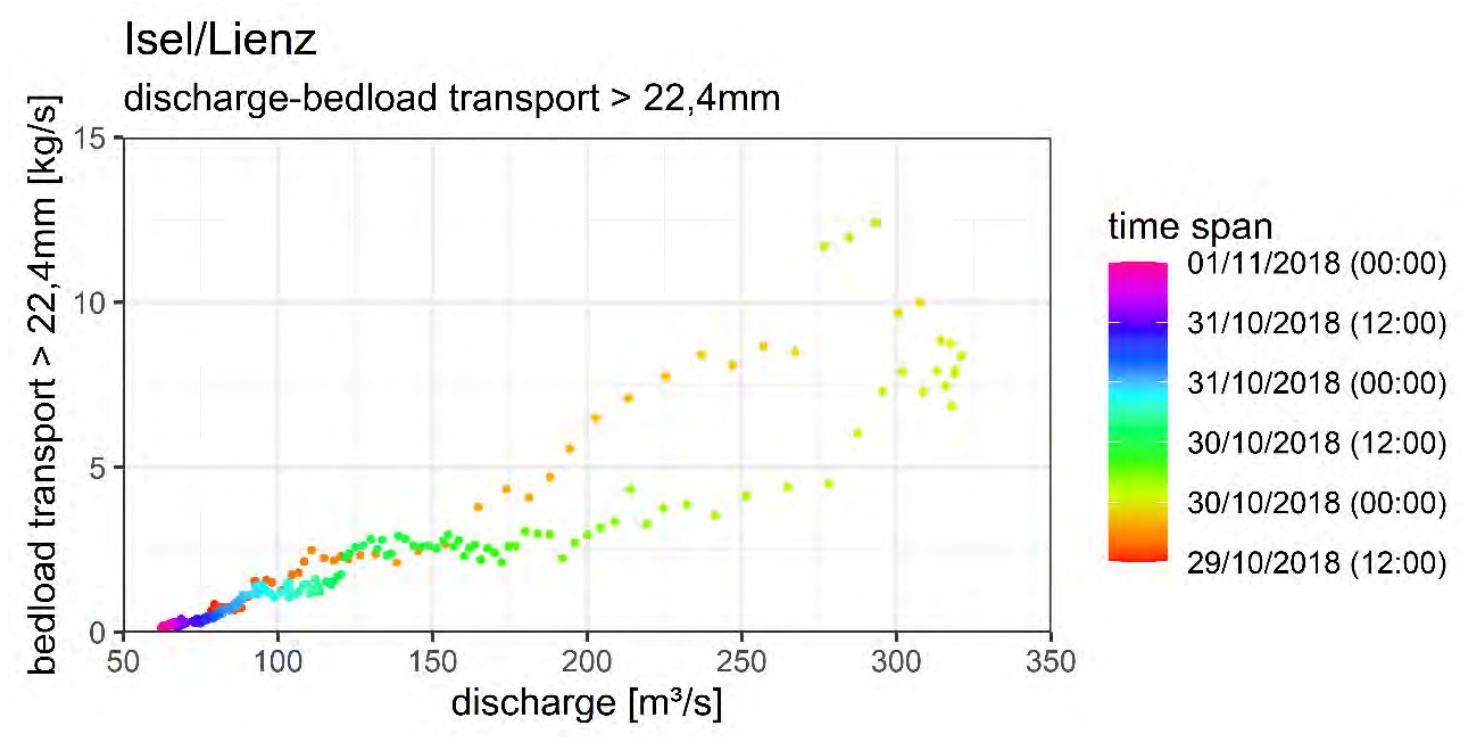

Figure 55: Scatterplot of discharge and bedload transport during the flood event 2018 showing a distinct clockwise hysteresis effect.

3.6.5. Example 5: Drava/Dellach (extreme event 2018 influences transport of the whole year 2019)

At Dellach the catchment area of the Drava River is $2131 \mathrm{~km}^{2}$. The measuring site is located approximately $27 \mathrm{~km}$ downstream of the Drava and Isel Rivers. The relatively large catchment area is reflected in the bedload transport behaviour. In comparison to other bedload measuring 
stations, this measuring station shows a better correlation between bedload transport and flow rate - i.e. sediment availability is more balanced. It is possible to calculate bedload quantities both via the correlation between direct and indirect measuring instruments and via a correlation between flow rate and direct measurements (Habersack et al. 2017).

Figure 56 shows the snowmelt period from 19.04.2018 to 23.04.2018. Here - similar to other measuring stations - the sediment transport follows the flow. In total (bedload and suspended transport) 7905 t have been transported.

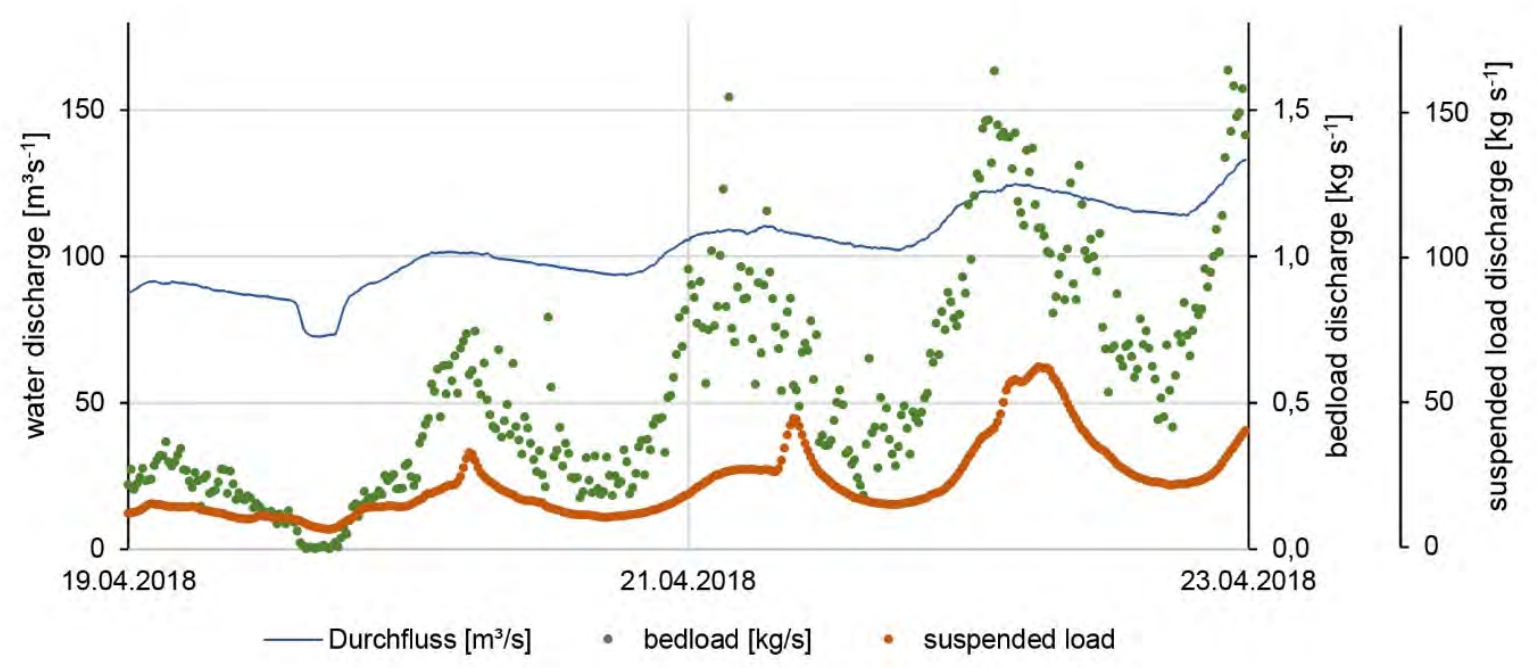

Figure 56: Drava/Dellach snowmelt induced discharge 2018

A similar course of bedload transport and water flow is shown for the flood event in autumn 2018 (28.10-01.11.2018, Figure 57). At the measuring station, the event can be assigned as $\mathrm{HQ}_{30}$ event. Figure 64 shows a photo of the measuring site. There are continuous indirect measurements of bedload transport from the event. In addition, two direct bedload measurements with the bedload traps were performed during the flood. Specific transport rates of $\sim 18 \mathrm{~kg} / \mathrm{ms}$ (30.10.2018 03:19-03:28) and $\sim 9 \mathrm{~kg} / \mathrm{ms}$ (30.10.2019 00:47-01:07) were measured. These data are unique for a large river like the Drava. During the entire event a total bedload yield of $4681 \mathrm{t}$ (24\% of the annual bedload yield) and a total of $534237 \mathrm{t}$ suspended sediments (69 \% of the annual suspended sediment yield), have been measured. 


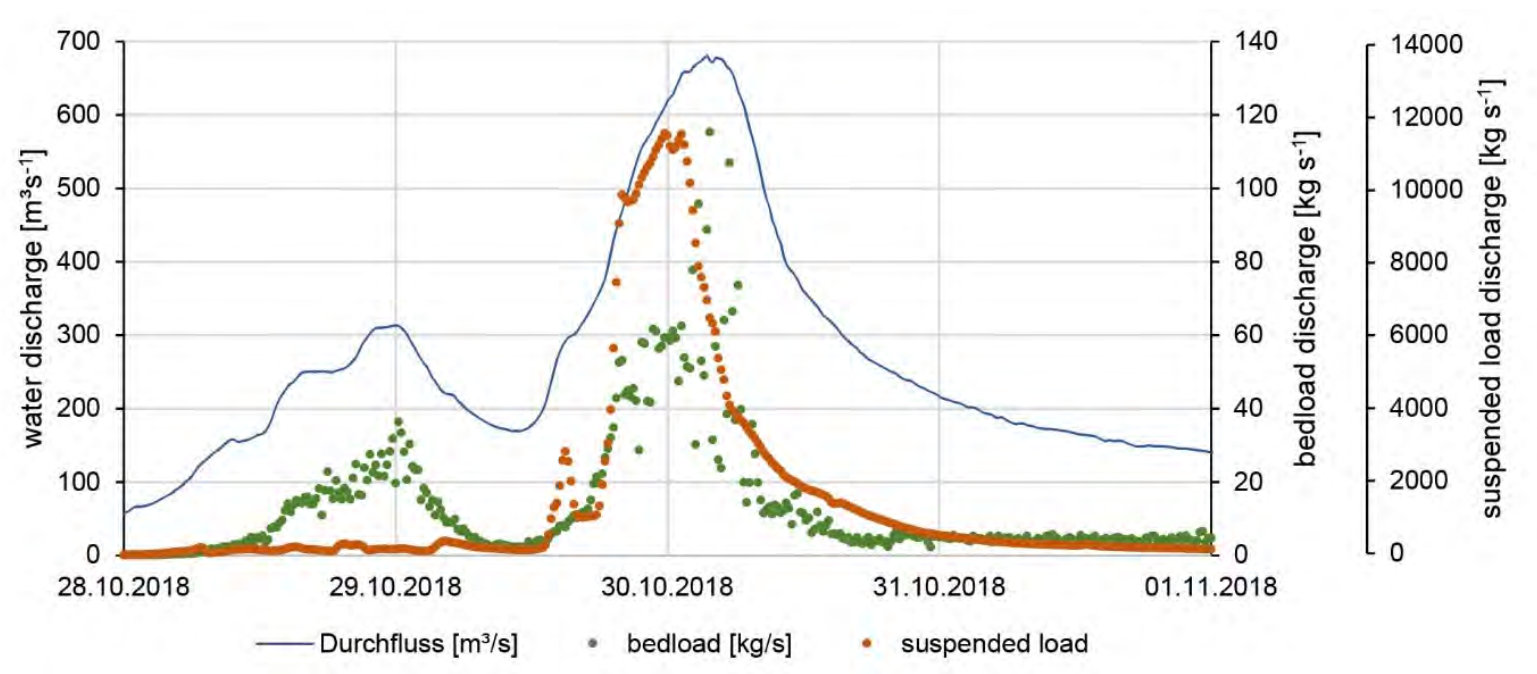

Figure 57: Drava/Dellach fall event 2018

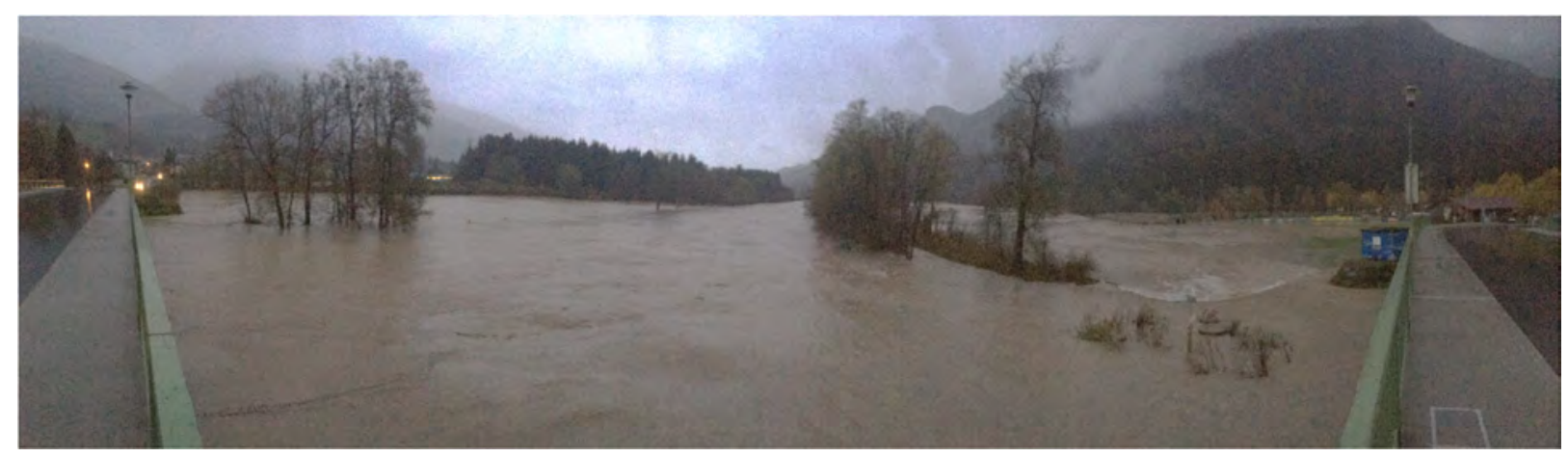

Figure 58: Flooded area in the area of the Dellach/Drava monitoring station

The effects of the flood on the solid matter budget of the Drava River can be seen in the comparison of the annual discharge load with the annual bedload load of previous years (Figure 59). The bedload of 2019 is very high compared to the recorded discharge load.

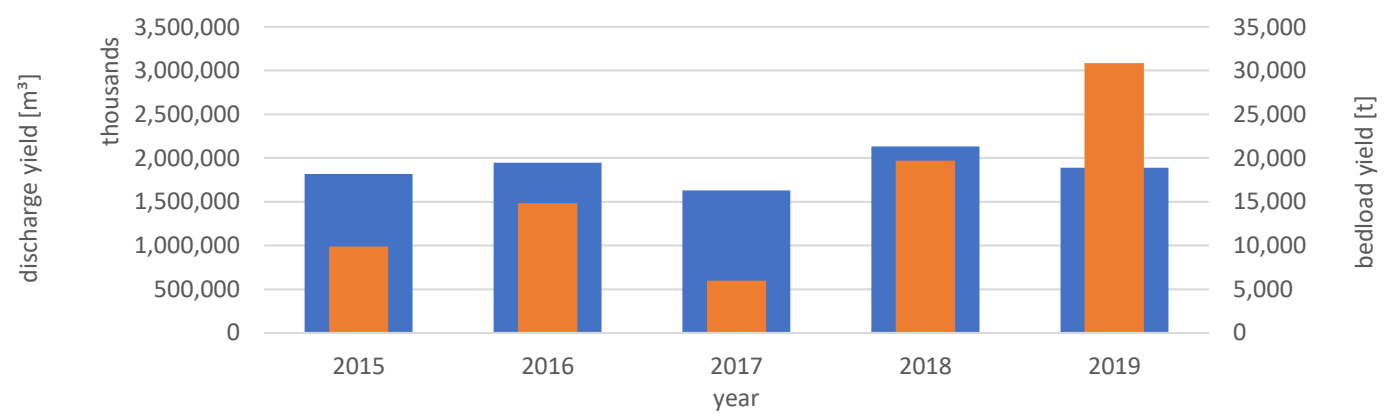

Figure 59: Annual water and bedload load Dellach/Drava

The width of the Drava is $\sim 50 \mathrm{~m}$ in the area of the measuring station. Therefore, the spatial variability can be well investigated at this measuring station. Figure 60 a displays the crosssectional distribution of the geophone pulses during the period of snow melting compared to the period of the flood event (Figure 60b). It can be seen that during the snowmelt the bedload transport takes place mainly between geophone \#20-30. During the flood event, the maximum 
share of bedload transport was recorded between geophones \#25-35. The spatial distribution of the geophone impulses during the flood event is also illustrated in Figure 61.
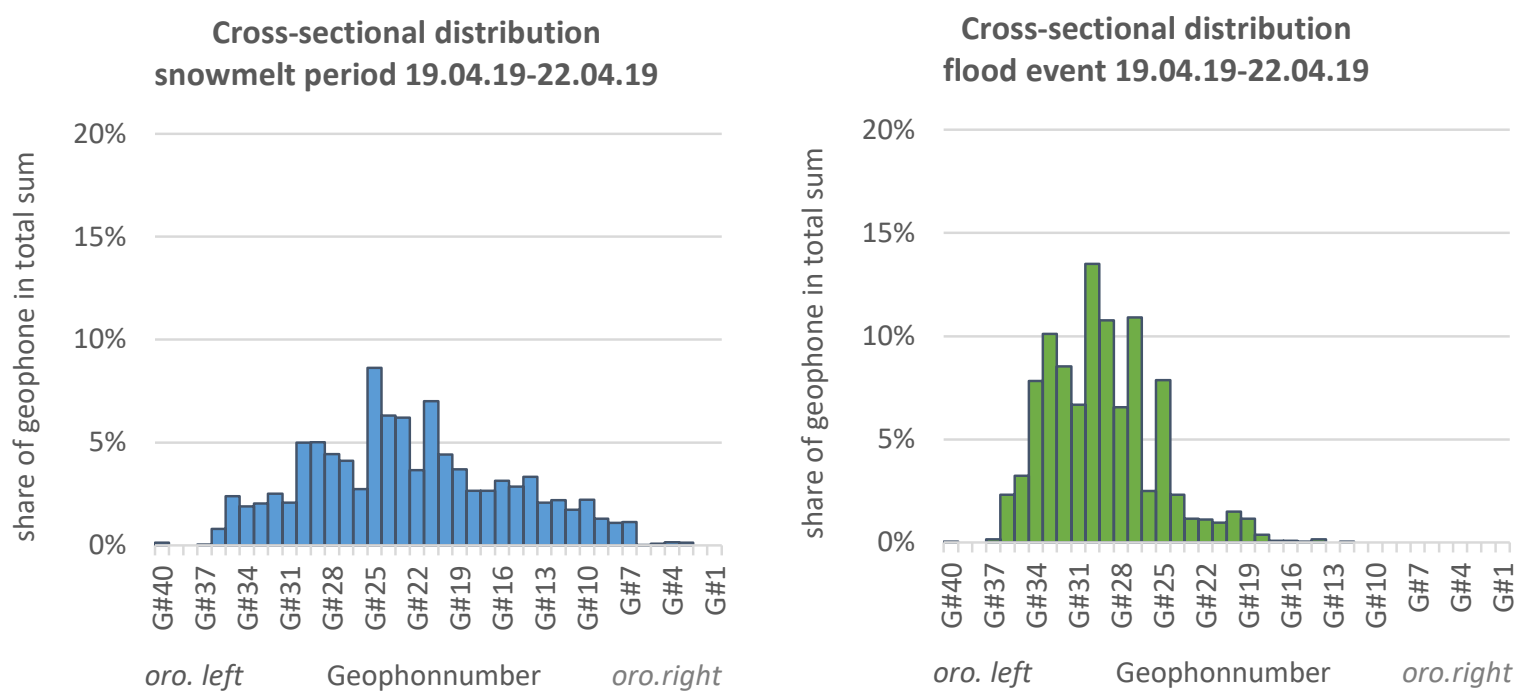

Figure 60: Cross-section distribution a) snowmelt period; b) flood event
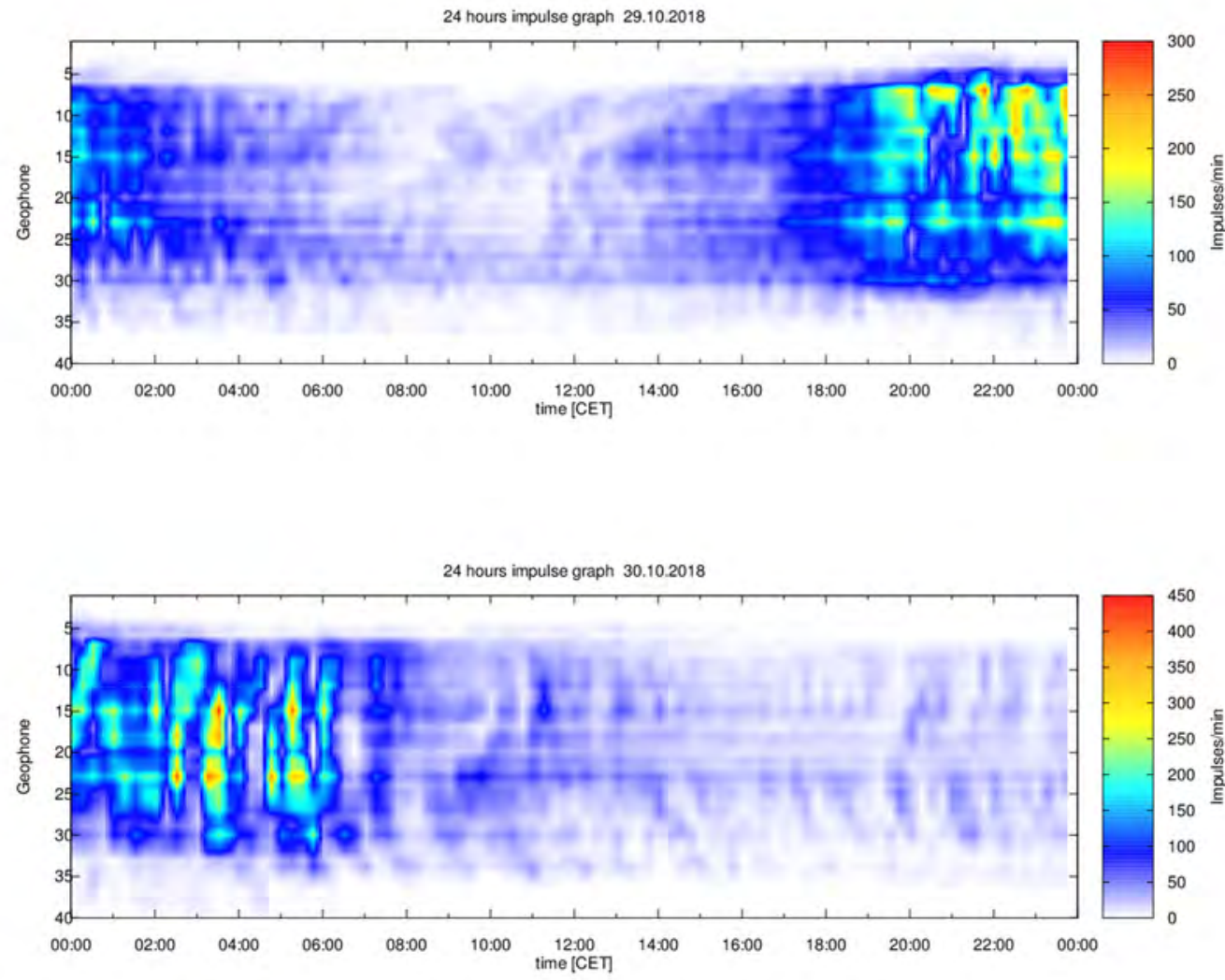

Figure 61: Spatial distribution of geophones 29.10/30.10.2018 (15min mean values) 


\subsection{Process studies on sediment transport leading to enhanced sediment management}

Based on the knowledge gained through process analysis (sediment forensics), management tasks can now be considered and improved through process understanding. In the following chapter five examples are given where these effects on sediment management have been studied and the added value for sediment management has been elaborated

\subsubsection{Example 1: Bedload pulses in a hydropower affected Alpine gravel bed river}

Continuous bedload monitoring at the upper Drava River is performed since nearly two decades. The impulse count gathered by geophones is known to scale linearly with bedload transport and is therefore a good proxy to study changes in bedload transport intensities. It is well documented that especially smaller rivers exhibit a large scatter in transport rates for a given discharge. This observed scatter of transport rates usually decreases for bigger rivers as they have a greater ability to buffer incoming changes in sediment supply and their relative changes in hydrology are usually smaller. The geophone dataset at the upper Drava, which drains a catchment area of $672 \mathrm{~km}^{2}$, shows a surprisingly large variability in measured transport rates. Using mean values of 15 minutes, geophone impulses display a scatter of over three orders of magnitude for similar hydraulic conditions.

What is the origin of this huge variability in the observed transport rates? Due to the usage of 15 minutes aggregates, short time fluctuations triggered by the movement of single particles can be precluded. The migration of particle clusters and the passage of low-angle bedload sheets are known to cause a substantial variance in bedload transport, yet both cannot explain the magnitude of the regularly measured variability at the monitoring station. The analysis of timeseries of geophone impulses and discharge gives an insight in the underlying process which causes the observed variability. The example shows a timeseries covering two weeks in late spring 2011 and include a minor flood event whose magnitude is rather typical for the Upper Drava River. Till the end of May, both timeseries relate rather well, suggesting that the changes in bedload transport are predominantly governed by discharge evolution. About three days after the flood peak, a huge and sudden increase in recorded geophone impulses can be observed. Over the course of the following week, the recorded geophone impulses slowly normalize to the level before the disruptive event. An analysis of the whole geophone dataset (Aigner et al. 2017) revealed, that the observed sudden increase in transport rates (Figure 62) occurs multiple times per year and can be explained by the formation of bedload pulses. 


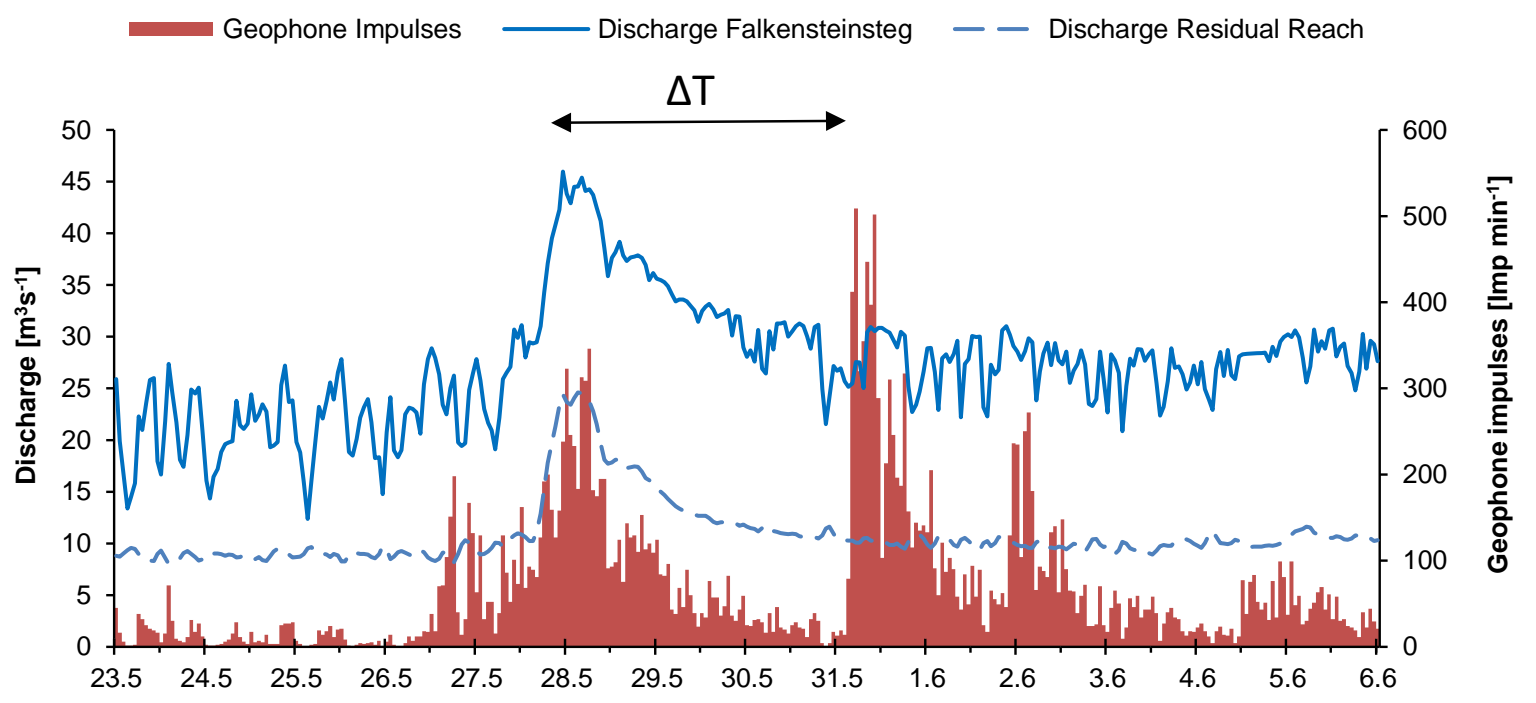

Figure 62: Time series of water discharge (monitoring station Falkensteinsteg and Residual reach) and geophone impulses between 23.5.2011 and 6.6.2011 show the occurrence of bedload pulses triggered by a small flood event. Note the time lag $\Delta T$ between the flood peak and the arrival of the bedload pulse at the monitoring station.

These pulses can lead to an increase in bedload transport (geophone impulses) in the order of two magnitudes within hours or even minutes. They have been found to be the main reason of the observed scatter in transported rates for a given discharge at the station and produce very high bedload fluxes while in transit. Further, bedload pulses tend to increase bedload flux in the post-event phase and can alter and reduce the upstream sediment storage leading to a lowering of bedload availability for future pulses.

The formation of bedload pulses is usually connected to a substantial increase in available bedload material - either due to sediment input from tributaries or the mobilization of sediment stored in the riverbed or the riverbanks. In the case of the Upper Drava river, an anthropogenic disturbance in the form of a hydropower plant, facilitates the repeated formation of bedload pulses. About $2 \mathrm{~km}$ upstream the monitoring station, a $24 \mathrm{~km}$ long river section can be classified as residual reach. Due to these altered conditions, the water level in this river section is often not sufficient to mobilize and transport bedload material downstream. This leads to sediment deprived conditions with the formation of a distinct armor layer directly upstream of the monitoring station. During flood events, the residual discharge repeatedly exceeds the critical discharge (about $10 \mathrm{~m}^{3} \mathrm{~s}^{-1}$ ) for the mobilization of sediment which, combined with the sediment influx by tributaries, leads to the formation of bedload pulses. The time lag between the flood event and the arrival of the bedload peak can be explained by the much slower movement speed of bedload particles. Based on the hydrological setup of the reach, the observed time lags allowed an estimation of pulse velocities in the range $0.002-0.05 \mathrm{~m} \mathrm{~s}^{-1}$, which is 2-3 magnitudes slower compared to measured flow velocities. Bigger flood events exhibit higher flow velocities with an increase in stress on bedload particles. Therefore, magnitude and duration of a flood event (presented here as mean discharge during event) correlate well with the observed time lags of bedload pulses (Figure 63). 


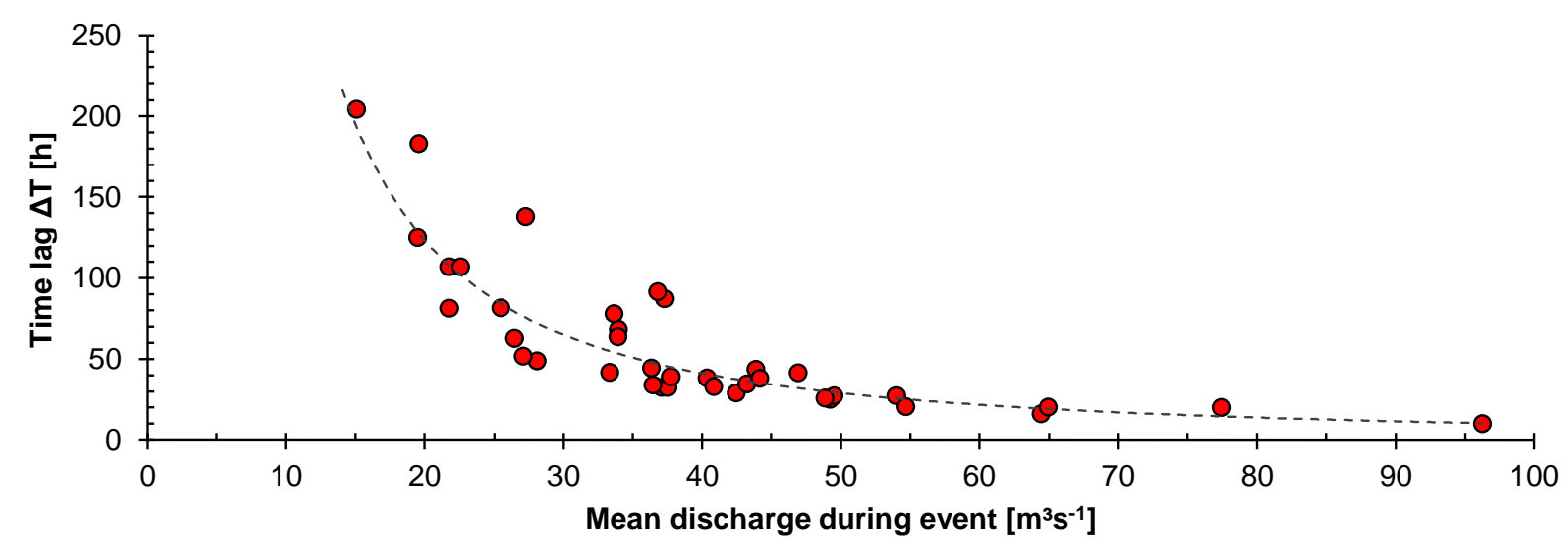

Figure 63: Scatterplot of the time lag until the arrival of the bedload pulses and the mean discharge during pulse propagation. Dashed line represents the best fit using a power function. (modified from Aigner et al, 2017).

The occurrence of bedload pulses is a widespread but often unrecognised transport process in many gravel bed rivers. A better understanding of their formation and propagation will enable the development of improved prediction tools for bedload transport. The presented results highlight the inherent problems in the currently widespread use of bedload transport formulas, which are usually based on bed shear stress estimation and neglect the influence of bedload availability.

3.7.2. Example 2: Falkensteinsteg/Drava: Correction of the data gap during the flood event 2018

The upper Drava River, upstream of Lienz is an alpine river. With the diversion hydropower station in Amlach (Strassen Amlach) the Drava River has a residual flow stretch of $24 \mathrm{~km}$ (Aigner et al. 2017). Since the year 2001 the bedload monitoring station Falkensteinsteg is in operation, located $2 \mathrm{~km}$ downstream of the water inlet. With a total of 16 geophone plates the entire cross section is covered. This setup enables the measurement of temporal and spatial distribution of the bedload transport (3.3.2.1 Geophone device). Using the Vent sampler for direct measurements, the actual bedload transport rates can be calculated.

In fall 2018 the upper Drava River was the scene of an extreme event, with a maximum of approx. $200 \mathrm{~m}^{3} \mathrm{~s}^{-1}\left(\mathrm{HQ}_{30}\right)$. This event was by far the greatest in the history of the bedload measuring station. During the event a great amount of sediments entered the river system by tributaries (e.g. Galitzenklamm Figure 64 ) which caused massive morphological changes in the main channel.

In the night of 29 to the 30.10 .2018 , shortly after the maximum discharge peak, the maximum bedload transport was exceeded. This extraordinary amount of sediments caused depositions of sediments in the entire river section. Surveys of the water management office of Lienz registered depositions of 0.5-0.75 $\mathrm{m}$ Figure 65. After the discharge peak the depositions were partly re-mobilized and partly cleared by the public authority.

The massive depositions at the bedload monitoring site interfered with the geophone measurements by dampening or entirely disabling the necessary plate vibrations. The recorded geophone data is therefore strongly inaccurate and does not represent the actual 
intensity of the bedload transport in that timespan (Figure 66). Therefore, with the given geophone data, an adequate bedload mass calculation is impossible.

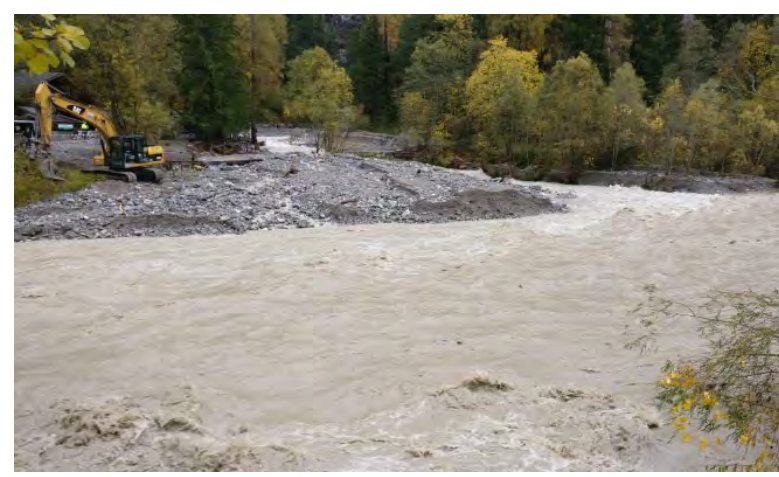

Figure 64: Massive bedload input from the Galitzenklamm (30.10.2018)

Falkensteinsteg/Drava

Flood event 2018 - raw data

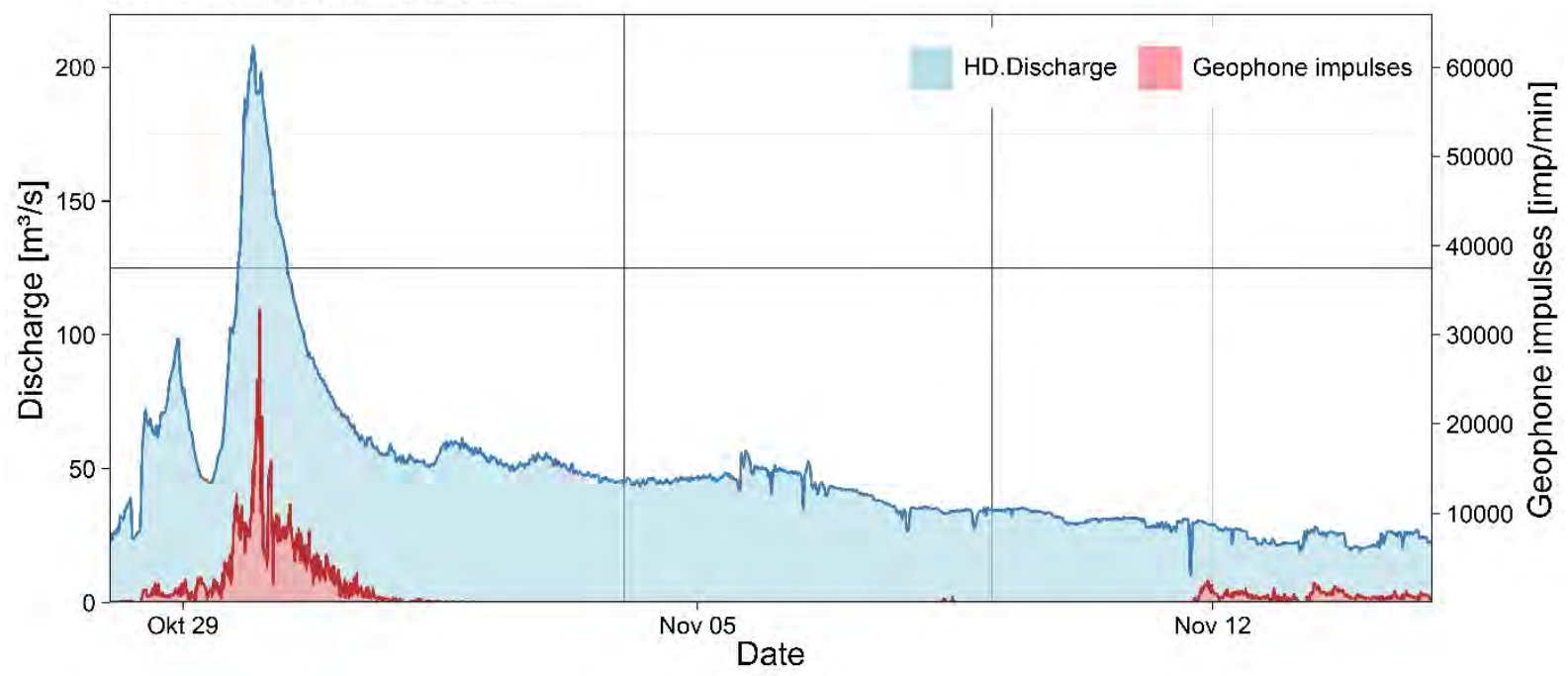

Figure 66: hydrograph and geophone impulses of the $\mathrm{HQ}_{30}$ flood event. Deposition of bedload material during the flood event. Total material cover over the geophone plates until the 12.11.2018

In order to obtain bedload transport data in the time of the flood, geophone data was corrected. Primarily the geophone data during the flood was compared to the entire data set of 20012018. Since the bedload transport was very high, it is assumed that the $25 \%$ quantile of the entire data set was exceeded. With that assumption the inaccurate geophone data were identified ( $<25 \%$ quantile) and removed from the data set. As the depositions did not occur at all geophone plates simultaneously, each geophone is examined separately.

In the next step, the missing data of each individual geophone is extrapolated. At this point it is necessary to point out, that the extrapolation in any case is a rough estimation of the actual bedload transport in that time frame. 
For the extrapolation following assumptions are made:

- The maximum possible sediment transport capacities in the river section are exceeded

- Due to the immense bedload availability the river is not supply limited. Neglecting sorting processes at the upper most layer, the bedload transport equals to the bedload transport capacity of the river

- In the past major bedload input from the residual flow stretch were monitored (Aigner et al. 2017). It is assumed, that the bedload transport ranged up to the bedload transport capacity of the river. This is likely, particularly at low and medium water discharges.

- The analysis of existing geophone data can provide information on maximum possible bedload transport for each geophone plate.

With these considerations the existing geophone data (timespan 2001-2018, 15min-value) for each geophone is analyzed and displayed graphically (Figure 67).

The maximum transport per water discharge in the time series were divided into water discharge classes. For each water discharge class, the quantiles (50\%, 95\% and 99\% quantile), as well as, statistical parameters like standard deviation, variance and covariance were calculated. Maximum values per water discharge class are biased by spikes and inaccurate measurements and are therefore not suitable to specify the maximum possible measuring values per discharge class. High quantile values (e.g. 99\% quantiles) on the other hand are much more robust and better suitable for estimating the maximum possible measuring values.

Transferring the quantile values into a mathematical function, missing geophone data can be reconstructed. For the mathematical function the power function $I=a^{\star}\left(Q-Q_{c}\right)^{\wedge} b$ was applied. Whereas, $I$ is the measured geophone data (99\% quantile), $Q$ Discharge, $Q_{c}$ critical discharge (beginning of motion), $a$ factor and $b$ factor. The applied regression calculates the parameters $a$ and $b$, as well as, the critical discharge $Q_{c}$ of the function. Since the variance of the measured data is not constant with the water discharge (heteroscedasticity), the datapoints were weighted on the basis of the inverse value of the calculated variance per discharge class. Thereby, measurements in low discharge classes were weighted more as the measurements in middle and high discharge classes. 


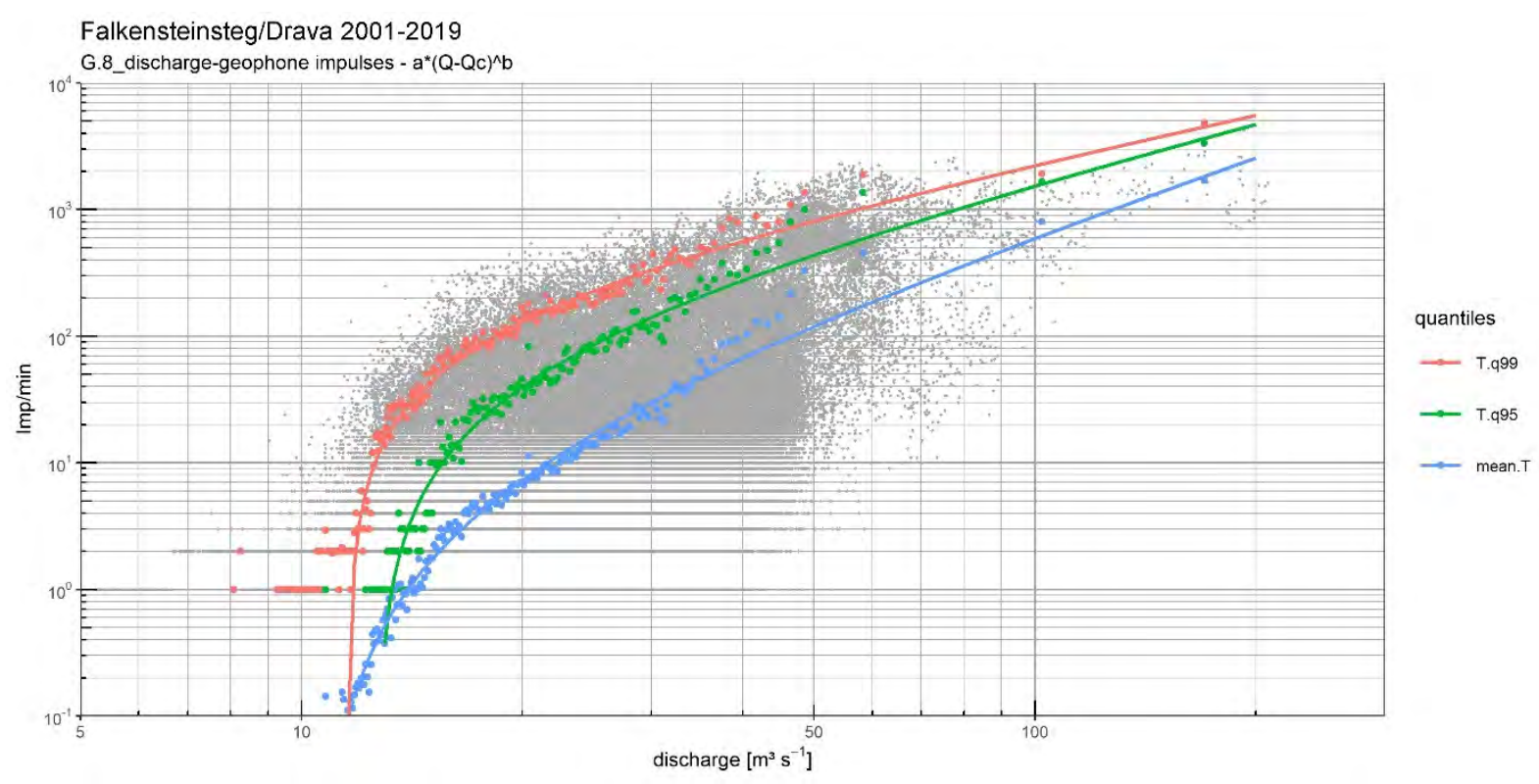

Figure 67: discharge geophone impulse relation at geophone 8. Dataset 2001-2018. Colorized data points are mean values per discharge class for the quantile 50\%, 95\% and 99\%. The colorized lines represent the power function at the critical discharge $\left(I=a^{*}\left(Q-Q_{c}\right)^{\wedge} b\right)$

Using the calculated regression (99\% quantile basis) the missing geophone data could be replaced according to the discharge. The calculated data fits the existing measurements very well and the transition from measured to calculated values is hardly noticeable. In the course of the data correction the weighting of data showed a much stronger impact as the chosen quantiles.

The described procedure was applied at all 16 geophones, according to the quality of data and the influence of sediment deposition. The cumulative display of the 16 geophones in the river cross section shows the final result of the data Figure 68. Compared to the measured data (Figure 66) a clear improvement could be achieved and the process dynamic of the extraordinary flood event could be reconstructed. With the data correction the bedload mass can be estimated with approximately $11500 \mathrm{t}$ (>22.4 mm). Further analysis of this event (grain size analysis of the cleared sediment material, sediment transport model, etc.) will enable the validation and improvement of the applied data correction. 


\section{Falkensteinsteg/Drava}

Hochwasser 2018 - hochgerechnet

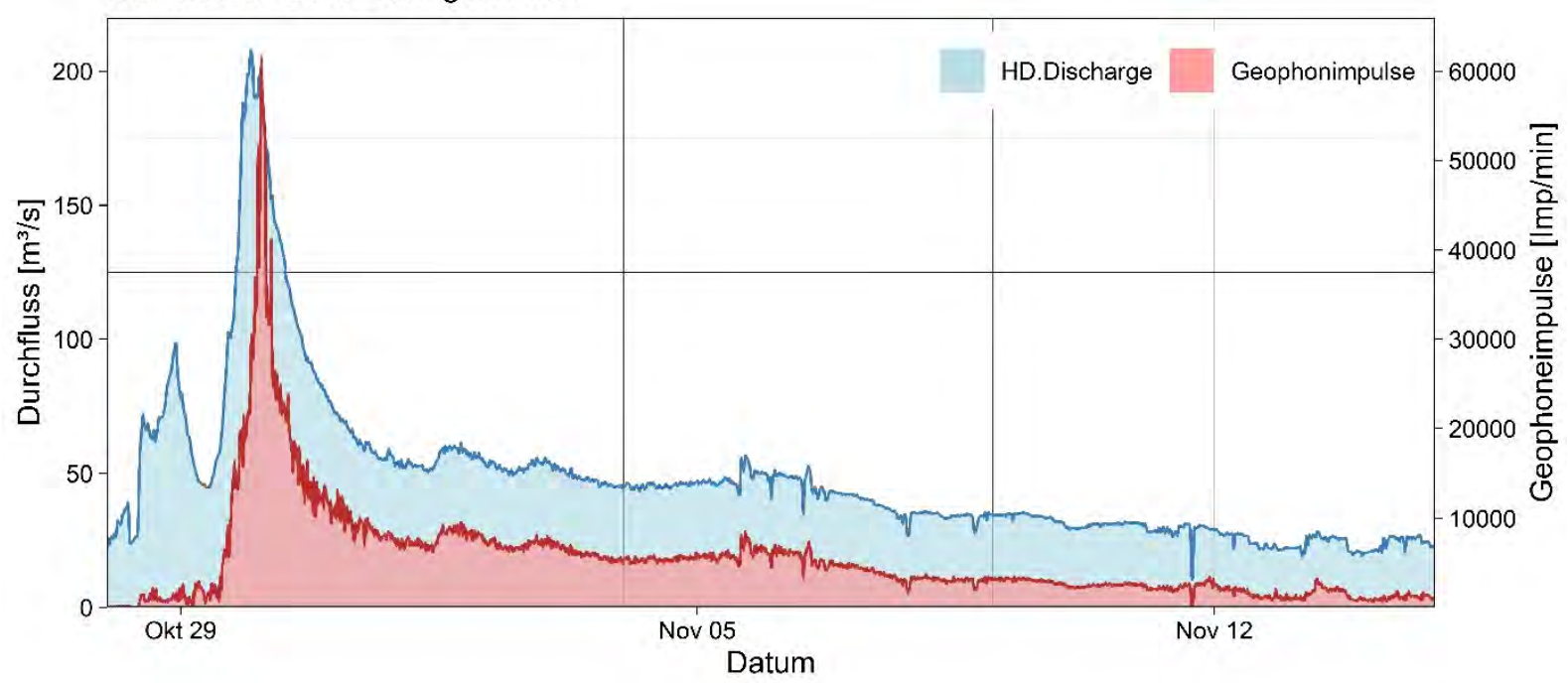

Figure 68: hydrograph and geophone impulses after data correction using the power function using the 99\% quantile.

3.7.3. Example 3: Classification of bedload transport events at the Urslau

Continuous data on the bedload transport process in the Urslau stream enabled assessing several bedload transport events. The investigation of bedload transport rate/discharge relationships reveals order-of-magnitude changes. For individual events shifts in the data, reflecting different bedload rates at comparable hydraulic conditions have been observed.

Bedload transport at the Urslau stream starts in spring, when snowmelt increases discharges. The snowmelt event of 2016 is shown in Figure 69 a. The graph reveals the characteristic snowmelt-related daily fluctuations of discharge. High flow data are recognizable during this snowmelt period. The bedload transport rate and discharge exhibit a similar temporal course. Accordingly, transport is controlled by the hydraulic conditions at this process type.

Bedload transport process shows variable characteristics at the Urslau when regarding exceptional flood events. In June/July 2012, an intense bedload transport event occurred. Figure $69 \mathrm{~b}$ shows the first part of this bedload transport event in detail. There is an initial rapid increase of discharge and bedload transport rates. Two subsequent smaller peaks occurred on the falling discharge limb. Although discharge decreased, bedload transport rates remained at a constant and intense level over 4 days (22.06-26.06.2012). 


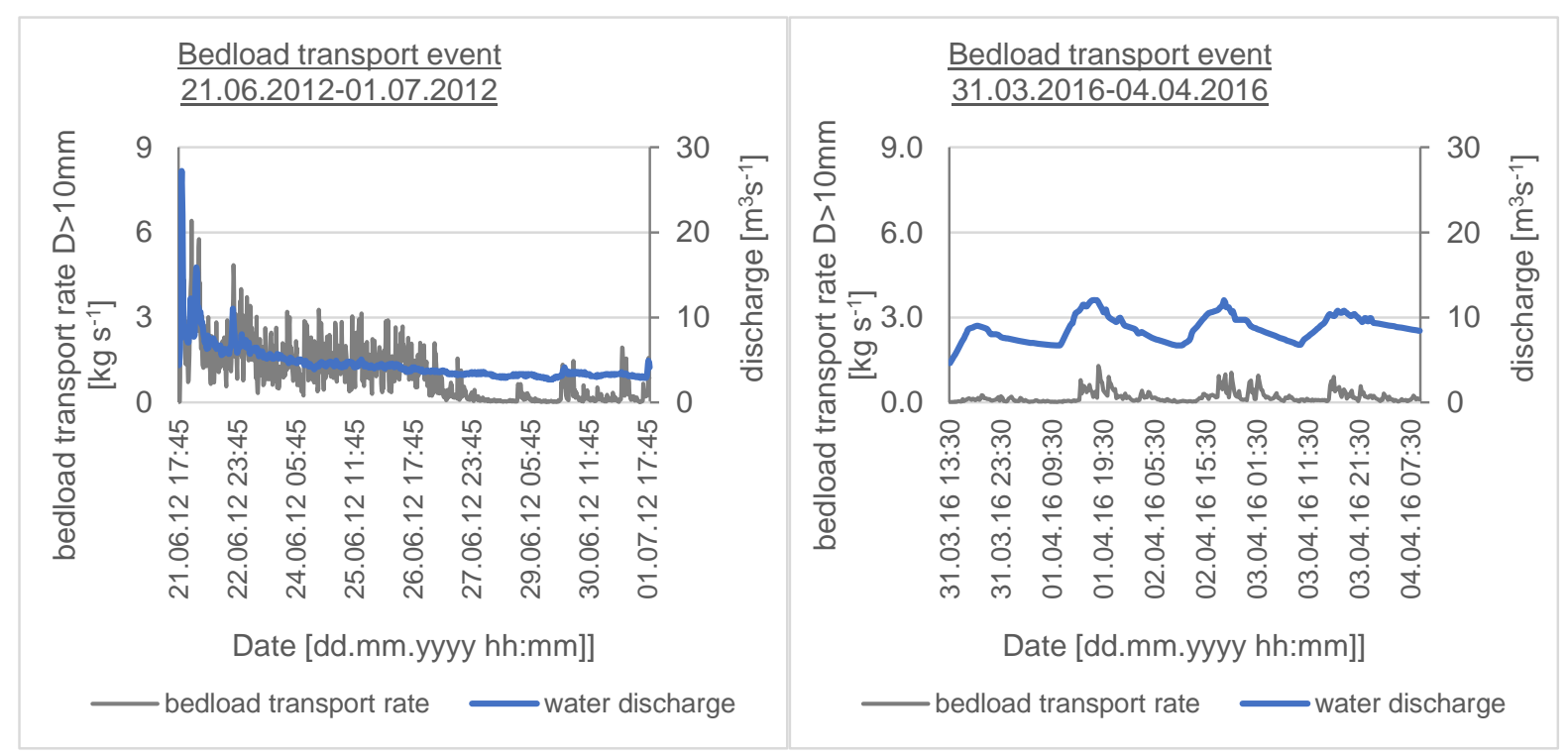

Figure 69: Bedload transport events at the Urslau stream: a)31.03.2016-04.04.2016, b)21.06.2012-01.7.2012;

Bedload transport/discharge relationships are presented in Figure 70 for these events. We calculated mean bedload transport rates for discharge classes of every $1 \mathrm{~m}^{3} \mathrm{~s}^{-1}$. This approach was chosen to consider temporal variations of the transport process due to bedload waves and variations of bedload transport rates at rising and falling limbs of the hydrograph. The graph reveals order-of-magnitude changes for bedload transport rates at comparable discharge classes.

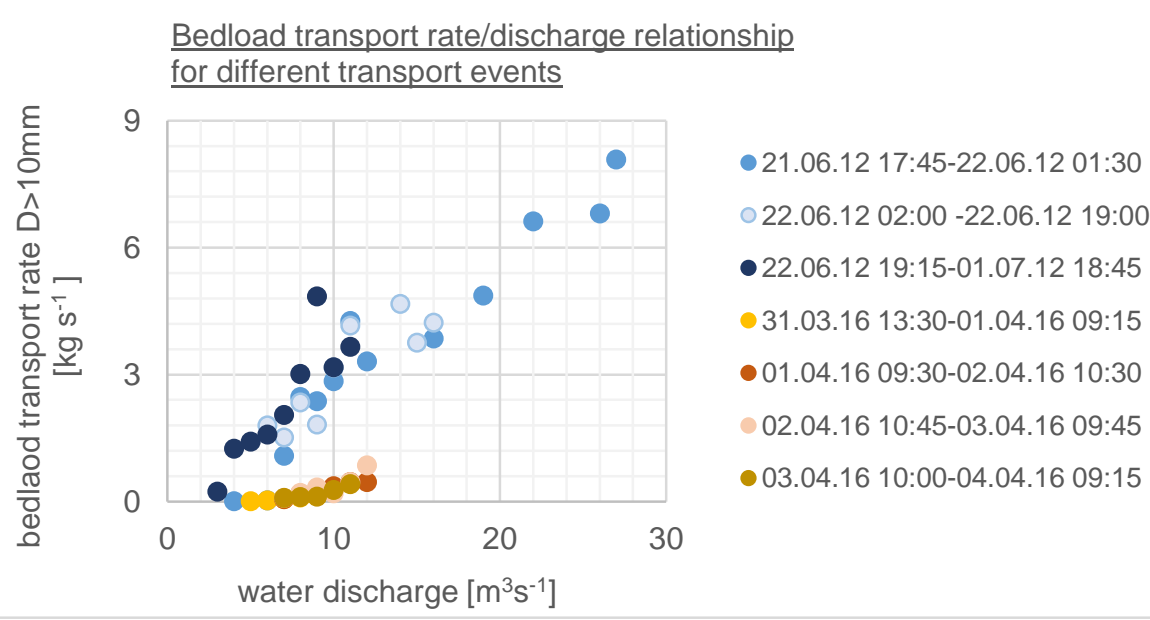

Figure 70: Bedload transport rate/discharge relationship for different transport events

Based on these observations we calculated the mean bedload transport efficiency (defined according to Bagnold, 1966) for each event and compared it to the hydraulic conditions. This comparison leads to a classification of bedload transport events into 4 types (Figure 71):

Type 1 describes those events where a large amount of bedload is mobilized and is transported at high flow rates (21.06.12 17:45 - 22.06.12 01:30 in Figure 69/Figure 70); type 2 is a followup event of type 1. Here, bedload material that was mobilized at type 1 and is available in large quantities for transport at comparatively low flow rates (22.06.12 02:00 - 01.07.12 18:45 in Figure 69/Figure 70). Type 3 mainly covers small, frequently occurring events. During these 
events, easily available sediments are transported from the river bed. Bedload events where little material is available (e.g. during snowmelt) are grouped under Type 4 (31.03.16 13:30 04.04.16 09:15 in Figure 69/Figure 70).

This classification of bedload transport events is an important tool for the practical understanding of the bedload transport - flow relationships on a mountain river with varying sediment availability. The analysis reveals that variable sediment supply conditions affect the prevailing bedload transport rates at the Urslau stream.

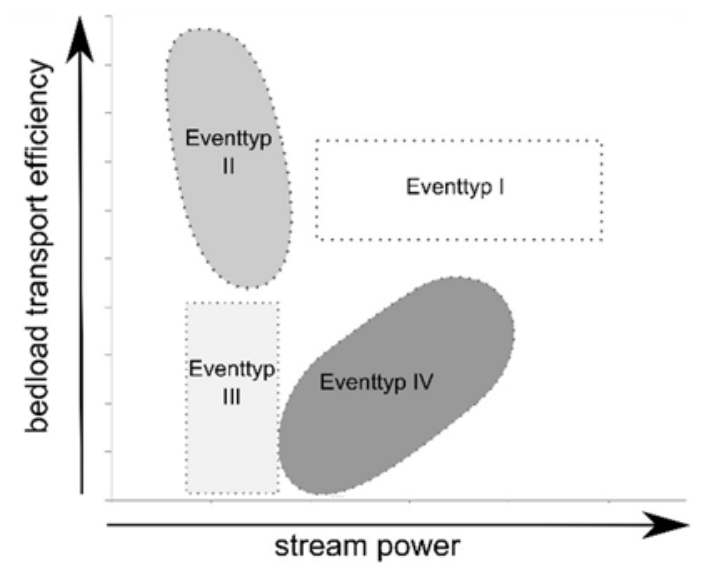

Figure 71: Conceptual model of bedload transport process types as a function of bedload transport efficiency and dimensionless stream power (simplified from Kreisler et al, 2017).

\subsubsection{Example 4: Transport distances Dellach following bedload input downstream}

In the data analysis in 2018 , special emphasis was placed on the detection of bed load impacts and the determination of transport distances. An example of this is the event of 6.11.2014, where a bedload impact from the Gailbergbach into the Drava was observed on site (see Figure 72).

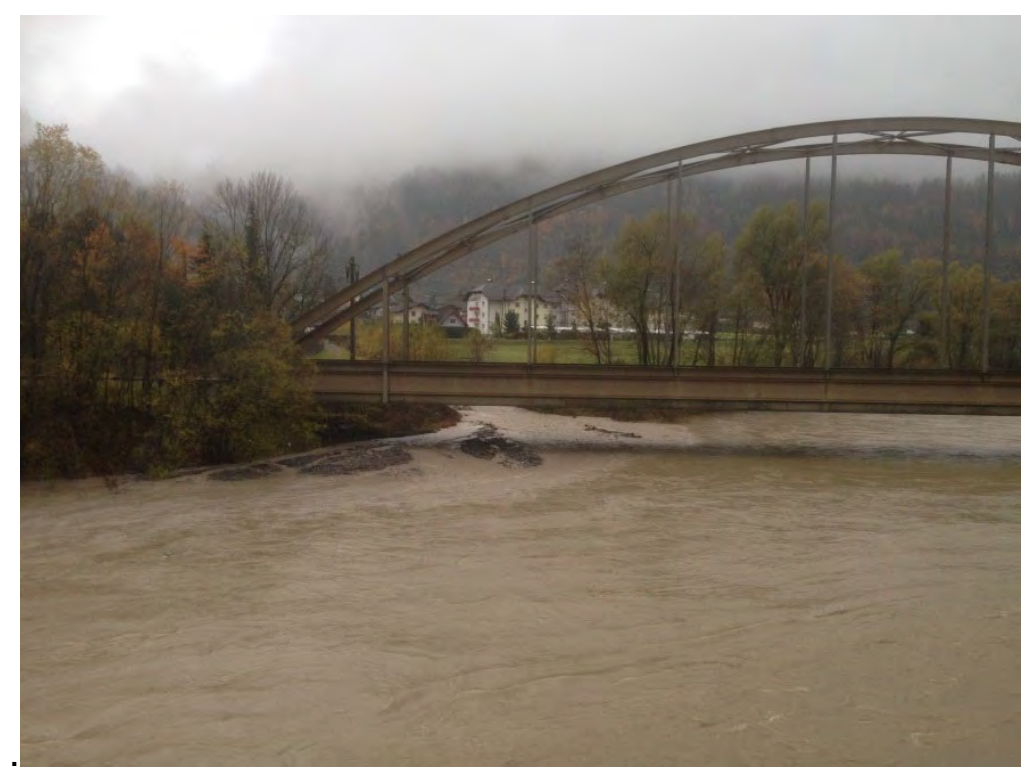

Figure 72: Bedload input Gailbergbach

Figure 73 shows the time period from 01.11.2014 - 01.06.2015. During the larger discharge event, bedload impacts were observed at the Gailberbach and Silberbach. This area was 
highlighted in grey in Figure 73 and defined as the starting area. The mouth of the Gailbergbach is $4.5 \mathrm{~km}$ and that of the Pirknerbach $7.5 \mathrm{~km}$ upstream of the Dellach/Drava bedload measurement station. Figure 74 shows an unusual impulse volume from 22.05.2015 onwards with a falling flow rate, which indicates an increased availability of bedload material. This phenomenon can also be seen in the scatterplot of flow and geophone pulses in Figure 75. Here an increased impulse volume at relatively low flow rates in the time range of 2430.05.2015 can clearly be seen.

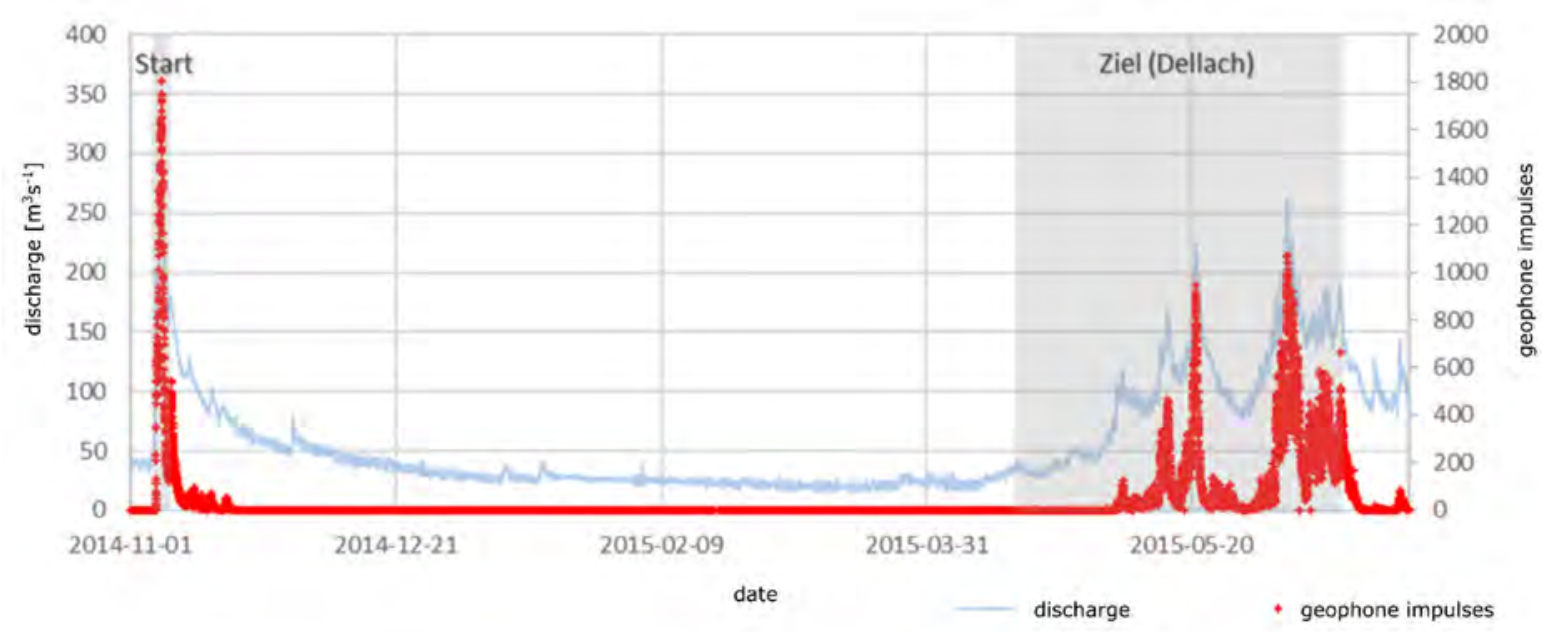

Figure 73: Flow and geophone pulses in the period from 01.11.2014 - 01.06.2015

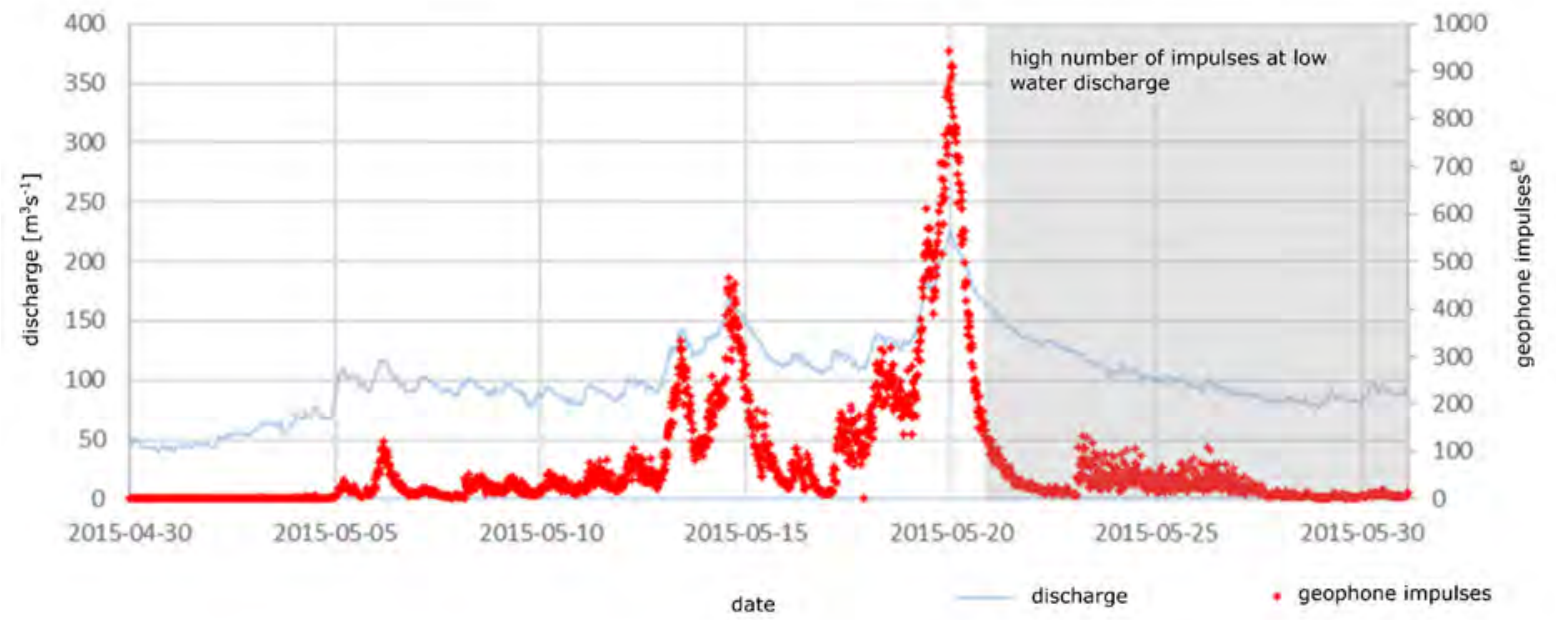

Figure 74: Flow and geophone pulses in the period from 30.04.2015-01.06.2015 


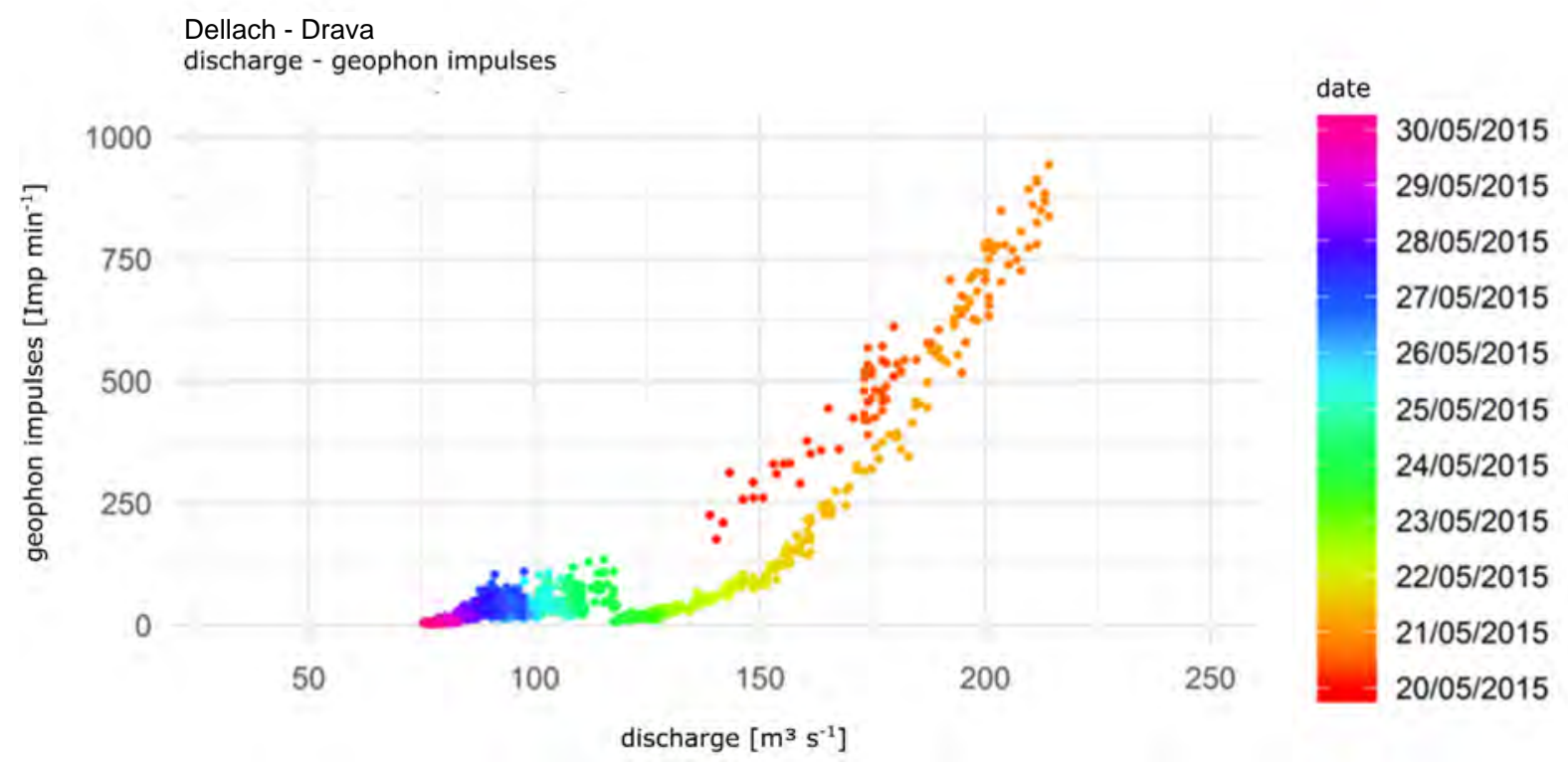

Figure 75: Scatterplot of flow and geophone pulses in the period from 20.5.2018-30.5.2018

To verify the hypothesis that bedload impacts can be detected with geophones, the HyMoCARES tool was used to estimate the transport speed of added or remobilized bedload. In Hymocare's project, a transport velocity formula for the Drava was explicitly determined based on tracer data on the Drava (see equation 1). Figure 6 shows the calculated transport velocities, for the grain diameters $20-50 \mathrm{~mm}$, for the Gailbergbach (black dots) and the Pirknerbach (red dots). In the analysis shown, the calculation was started on 06.11.2014 for the Gailbergbach and Pirknerbach and determined how long the different grain fractions need until they reach the measuring stadium Dellach/Drava. The time range in which the calculated grain fractions arrive in Dellach was highlighted in grey and this range coincides with the time period in which an increased impulse volume took place.

Equation 1: Transport velocity Drava

$$
V_{u}=0.21 e^{3.63\left(\frac{d}{d_{50}}\right)} \sqrt{\frac{\rho_{s}-\rho}{\rho} g d}\left[\frac{\tau}{\left(\rho_{s}-\rho\right) g d}-0.021\left(\frac{d}{d_{50}}\right)^{-0.485}\right]^{\frac{3}{2}}
$$

Vu Transport velocity Drava

d transported grain diameter

$d_{50} \quad$ average grain diameter of the surface course

$\rho_{\mathrm{s}} \quad$ Density sediment

$\rho \quad$ Density water

gravity

T $\quad$ shear stress 


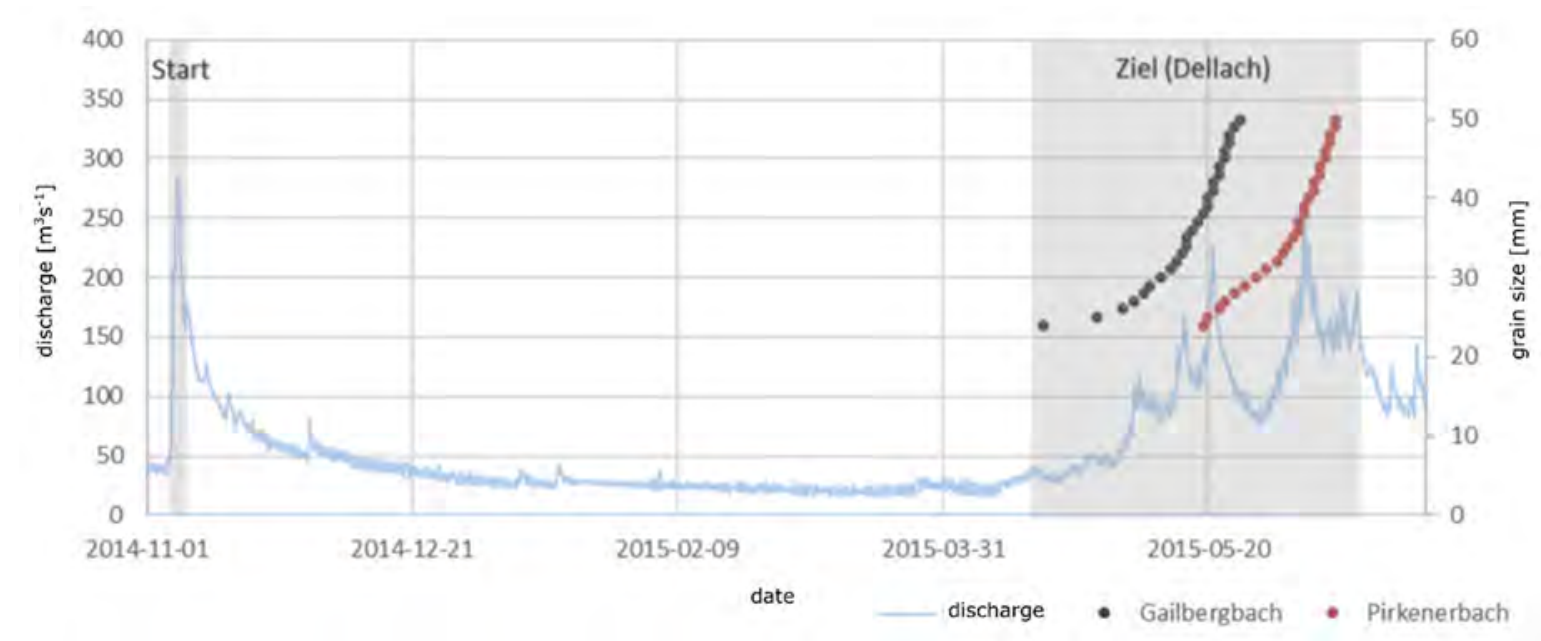

Figure 76: Arrival of the different grain diameters at the Dellach/Drava site

3.7.5. Example 5: Bedload balance between the integrative sediment monitoring system Drava-Isel

Bedload measurement data are of great importance for issues relating to flood protection, torrent and avalanche control, energy management, river engineering or waterway management. Bedload measurements are not always feasible - therefore, there are different approaches for bedload transport estimations. These estimates are based on bedload transport formulas (e.g. Meyer-Peter and Müller, 1948; Smart and Jäggi, 1983; Rickenmann, 1990, 2001), catchment area sizes, flushing processes of water catchments in rivers with torrent character (Kammerlander et al. 2017), changes of bed levels, erosion and abrasion (Hillebrand and Frings 2017).

In order to better understand the sediment transport processes, the Institute of Hydraulic Engineering and River Research at the University of Natural Resources and Life Sciences in Vienna has been monitoring bedload transport in the integrative sediment monitoring system Drava-Isel since 2007. For this purpose, direct and indirect measurements are realized every year and the calculation method is adapted. This measuring system consists of three bedload measuring stations. These are in Lienz, East Tyrol, on the river Drava (Falkensteinsteg), in Lienz on the river Isel (Iselsteg) and in Dellach in the Drava valley in Carinthia. The location of the stations is shown in Figure 77. 


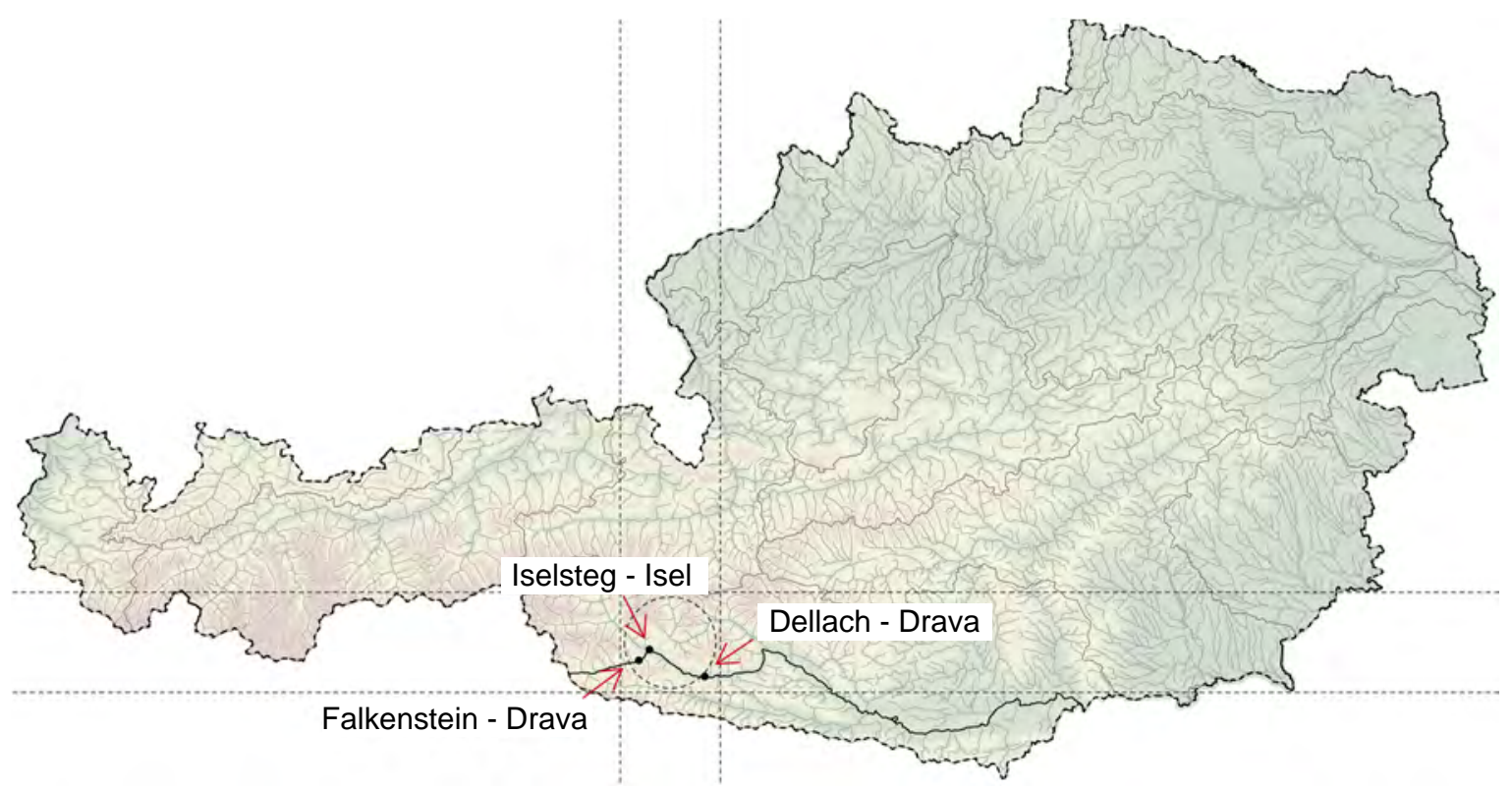

Figure 77: overview of the measurement station in the integrative sediment monitoring system Drava-Isel

From the bedload measurements carried out over many years, it became clear that the bedload transport rates at the downstream measuring station in Dellach were higher than those recorded at Iselsteg and Falkensteinsteg together. This information is used to formulate the basic question of this study: Does the intermediate catchment area contribute significantly to bed load availability in Dellach? In order to answer this question, a bed load balance was carried out on the Upper Drava. This bedload balance should provide information on whether the bedload difference between the Dellach measuring station and the stations in Lienz can originate from tributaries in the intermediate catchment area. This catchment area consists of 28 tributaries, has a size of $255 \mathrm{~km}^{2}$ and a river length of 27 kilometers.

As input data for the balance, the measuring results of the measuring stations in Lienz (for grain sizes $d>22.4 \mathrm{~mm}$ ) and as output data, the measuring results in Dellach of the integrative bedload measuring system Drava-Isel were used.

By estimating the transport duration of collected bedload grains from Lienz and the tributaries to Dellach, the investigation period was defined for the years 2015 and 2016. This estimation of a transport velocity of a bedload grain was calculated with the formula according to Klösch and Habersack (Klösch and Habersack 2018), which was developed especially for the river Drava.

For the bedload balancing five relevant tributaries were selected (Figure 78) by using reports, plans and expert opinions. Those were used to calculate the potential bedload at the mouth of the tributary rivers. 


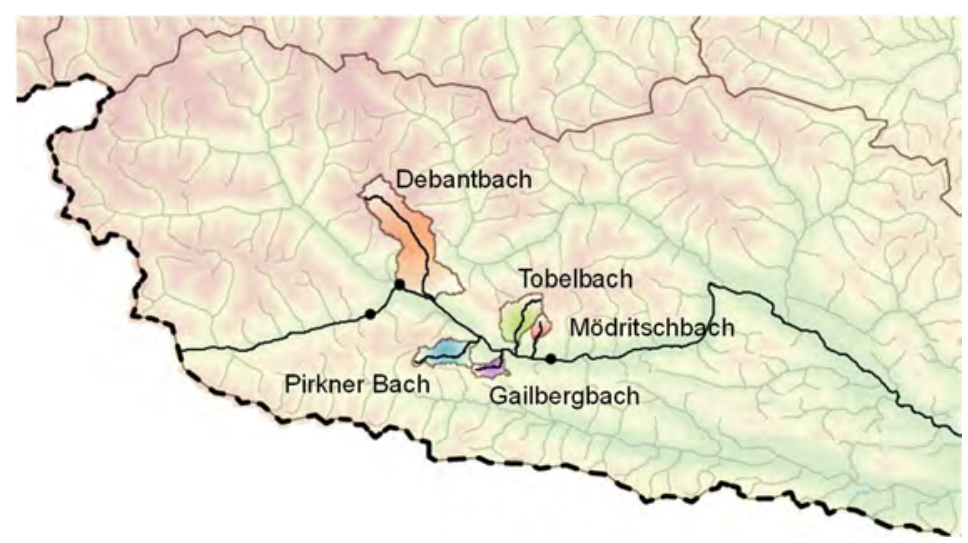

Figure 78: selection of the five relevant tributaries

The potential bedload transport rates were first calculated according to Rickenmann (Rickenmann 1990), Rickenmann (Rickenmann 1990, 2001), Smart and Jäggi (Smart and Jaeggi 1983) and Meyer-Peter and Müller (Meyer-Peter and Müller 1949). The Rickenmann formulas were calculated using the bed slope and a reduced bed slope. Due to the river characteristics and above all the gradient areas, the Rickenmann (Rickenmann 1990, 2001) formula with reduced energy line gradient was applied for the balance of bed load transport.

For this purpose, the input variables profile width, slope angle, slope, roughness, discharge hydrographs and grain size distributions were determined. Profile width, slope angle, slope and bed roughness were determined in the field and by literature values (for the roughness). Due to missing data, the discharges were estimated by means of a hydrological model by the Carinthian provincial government (Abbey 12). For the gradient, a digital elevation model of Austria was combined with the course of the river. The grain sizes were determined by 16 sieve analyses (B 2400), 16 Line-by-Number Analyses (Fehr 1987) and 14 Wolman-PebbleCount Analyses (Wolman 1954). In addition, the abrasion and the change of the riverbed levels in the investigated section were determined.

The abrasion was calculated according to Sternberg (1875). Thus, the potential bedload loads were reduced. The selective transport, which can contribute to bedload reduction, was not considered in this context.

The calculation of the changes of the bed levels was based on measurement data from HYMET (Klösch and Habersack 2017) in the period from 1991 to 2013. In this case, as with abrasion, the potential bedload loads from the intermediate catchment areas are reduced.

The bedload balance was drawn up based on the loads from Lienz, the calculated loads of the tributaries, the abrasion and the changes of bed levels.

\begin{tabular}{|c|c|c|c|c|c|}
\hline \multicolumn{6}{|c|}{$\begin{array}{c}\text { Equation 2: formulated balance equation } \\
Q_{\mathrm{m}, \text { Del }}=\left(Q_{\mathrm{m}, \mathrm{F}}+Q_{\mathrm{m}, \mathrm{I}}\right)+\left(Q_{\mathrm{pot}, \mathrm{D}}+Q_{\mathrm{pot}, \mathrm{P}}+Q_{\mathrm{pot}, \mathrm{G}}+Q_{\mathrm{pot}, \mathrm{T}}+Q_{\mathrm{pot}, \mathrm{M}}\right)-Q_{\mathrm{A}} \pm Q_{\mathrm{BL}}\end{array}$} \\
\hline$Q_{m, \text { Del }}$ & . & measured bedload in Dellach & $Q_{p o t, G}$ & & potential bedload Gailbergbach \\
\hline$Q_{m, F}$ & & measured bedload Falkensteinsteg & $Q_{p o t, T}$ & & potential bedload Tobelbach \\
\hline$Q_{m, l}$ & & measured bedload Iselsteg & Qpot,M & & potential bedload Mödritschbach \\
\hline Qpot,D & & potential bedload Debantbach & $\mathrm{Q}_{\mathrm{A}}$ & & sediment reduction due to abrasion \\
\hline Qpot,P & $\ldots$ & potential bedload Pirkner Bach & $\mathrm{QBL}_{\mathrm{BL}}$ & $\cdot$ & material exchange due to bed level changes \\
\hline
\end{tabular}

Figure 79 summarizes the input data of the measuring stations in Lienz $\left(Q_{m, F}, Q_{m, l}\right)$, the potential bedload estimations of the tributaries $\left(Q_{p o t}\right)$, the reduction in load due to abrasion $\left(Q_{A}\right)$ 
and the material exchange based on changes of river bed levels $\left(\mathrm{Q}_{\mathrm{BL}}\right)$. The balance of the potential bedload volumes ( $Q_{\text {culc }}$ ) resulted in a difference of approximately $+15,900$ tons compared to the measured loads in Dellach $\left(\mathrm{Q}_{\mathrm{m}, \mathrm{D}}\right)$.

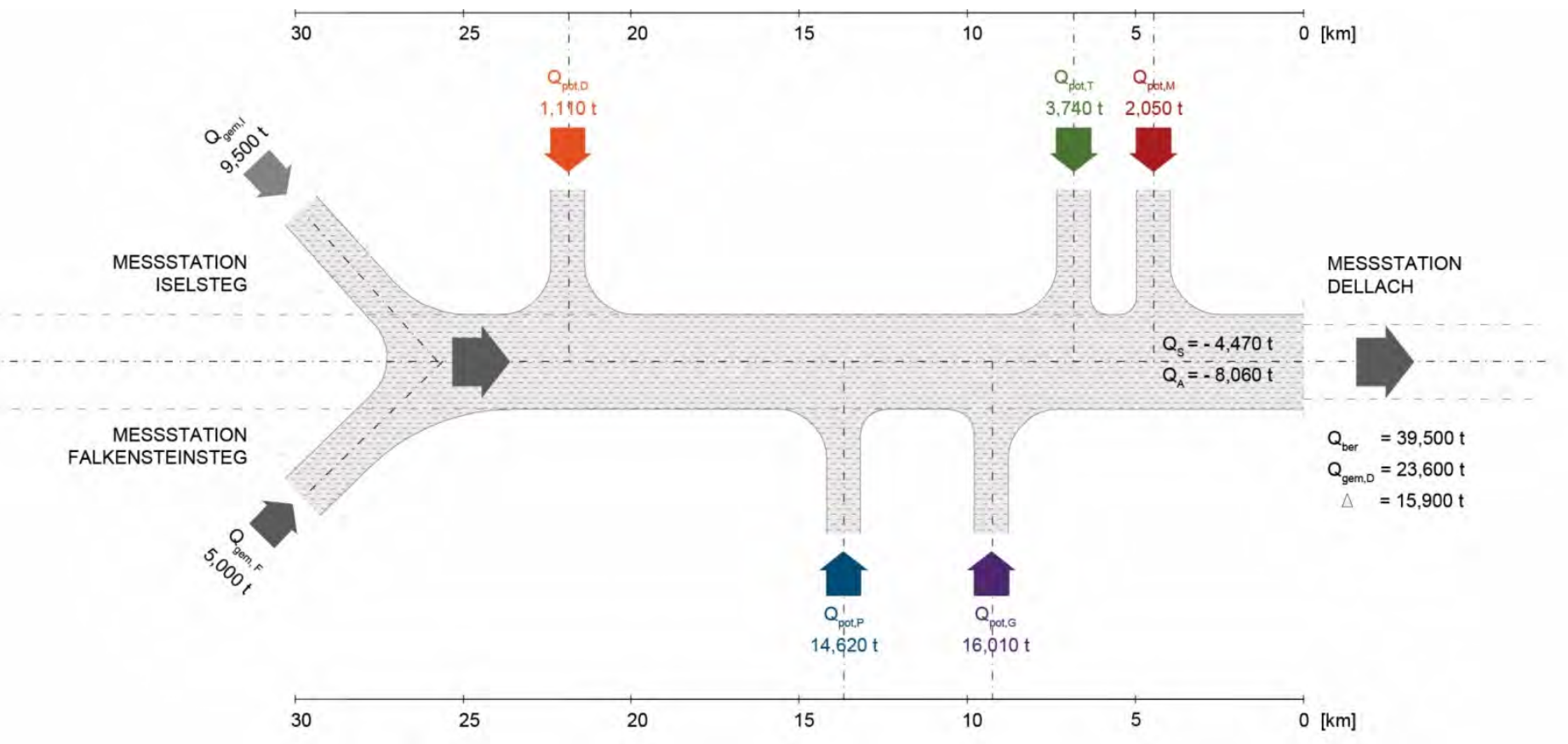

Figure 79: Results of the sediment balancing of the Upper Drava

The potential bedload calculations of the tributaries show that the Pirkner Bach and the Gailbergbach are the most significant for the balance equation. At these two tributaries, far more than twice the potential bedload load was calculated than at the other three tributaries. The Debantbach brings by far the least material despite the largest catchment area and the highest discharges. This is due to the grain sizes and the low gradient. Compared to the other tributaries, the Debantbach has coarser grain sizes. In the mouth of the tributary the roughness is very smooth due to the regulation of the profile, with a low gradient of $0.5 \%$. A low gradient and coarse grain sizes result in a high flow rate for the beginning of bedload movement, which influences the bedload calculation.

In contrast to the Debantbach, the Pirkner Bach has much higher bedload volumes. However, the slope is still in a low range (1.6\%) compared to the others. The grain sizes of the Pirkner Bach are much finer than those of the Debantbach, which means that the flow rate required to start the transport is reduced many times over. Therefore, the material can be mobilized earlier and consequently leads to higher transport rates.

Just as with the Pirkner Bach, very high annual bedload volumes were determined for the Gailbergbach. The grain sizes and the roughness are similar to the Debantbach. The difference lies in the slope - this is with $4 \%$ much higher. Thus, a very low flow rate is determined for the beginning of the transport.

At the Tobelbach and Mödritschbach the grain sizes of the Line-by-Number Analysis and Wolman-Pebble-Count Analysis were used. In contrast to the other tributaries, these are rather coarse. The Tobelbach lies in the same slope range (difference 0.09\%) as the Gailbergbach. However, the Tobelbach is about three meters wider (on average) and coarser material was used for the bedload calculation. This results in lower bedload volumes. 
The Mödritschbach has the steepest slope, the smallest cross-section, but also the smallest catchment area. As with the Tobelbach, the grain sizes are rather coarse in relation to the tributaries. Due to the grain sizes and the catchment area, the Mödritschbach has low bedload volumes.

For the balance, the abrasion was calculated from the measuring stations in Lienz and from the mouth of the tributaries into the Drava up to the station Dellach. This caused a bedload reduction of approximately $15 \%$ (-8,060 tons).

The determined mean material exchange rate from the riverbed is included in the balance with $-4,470$ tons (aggradation).

A large amount of input data is required for a sediment balance, which can also be affected by uncertainties - as well as the input variables used.

The generated discharge hydrographs are based on hourly values, which means that stronger, short-term precipitation events will be "lost". Hence the hydrographs could be underestimated. A higher peak leads to an earlier start of movement and subsequently to higher bedload transport rates. However, the discharge hydrographs are regarded as quite plausible, since they can be assigned to a river regime suitable for the study area (nivoglacial - high discharges in summer, lower ones in winter) and the catchment area sizes.

The abrasion coefficients for the calculation are based on literature values. These values depend on the type of rock. The left bank tributaries of the Drava (Isel, Debantbach, Tobelbach and Mödritschbach) supply mainly gneiss and slate. The two right bank tributaries Pirkner Bach and Gailbergbach are located in the limestone unit. According to the abrasion coefficients, slate and gneiss are less resistant to mechanical crushing by abrasion than limestone.

During the reduction process, not only the abrasion but also the selective transport is effective and it is often assumed that the effect of the abrasion is much lower (Mikos 1993). For a more precise survey of the reduction mechanisms in the Upper Drava, laboratory tests should be carried out concerning abrasion and selective transport.

Based on the extensive data set used for HYMET (Klösch and Habersack 2017), it was possible to determine an aggradation until 2013 due to the change in the bed levels. However, this value does not include any data on the possible changes of the $16 \mathrm{~km}$ between the Falkensteinsteg measuring station and the border between East Tyrol and Carinthia, nor any information on the change in the bed levels until 2016. For this reason, an average value was calculated from the data up to 2013 and included in the balance.

Another important input variable for bed load balancing is the number and type of channel control structures in the study area. How much sediment can pass through the structure depends on the type of structure, size and other local factors (Marchi et al. 2019). As there are no measurements of volumes, size, etc. for the structures in the study area, it is not possible to make any precise statements regarding the bedload availability of the tributaries.

Because of these uncertainties, we refer in this context to a possible bedload transport, as they could well be higher or even lower.

Nevertheless, the present study agrees with the hypothesis that higher bedload volumes can be measured at the Dellach bedload measuring station due to the bedload potential in the intermediate catchment area. 


\section{WP 3 - Numerical sediment transport and habitat modelling}

\subsection{Improvement of sediment transport models: Coupling of sediment transport and habitat model}

The sediment transport model iSed was coupled with the habitat evaluation model HEM. Hence, habitats on the micro-scale as well as the meso-scale can now be evaluated under consideration of the morphological changes taking place during flood events. By using this coupled model chain, it is now possible to track the availability of habitats throughout the occurrence of morphological changes as for example during the passage of a flood wave.

As exemplification, Figure 80 pictures modelled changes in bed level elevation after the passage of a one-year flood event within a groyne field at the study area Hainburg. According to iSed, highest increase in bed level elevation ( $+1 \mathrm{~m})$ occured at the upstream side of the groynes, whereas highest erosion could be calculated close to the groyne heads $(-0,35 \mathrm{~m})$. In general, bed elevation within the observed area of interest increased on average about $0.174 \mathrm{~m}$ as a consequence of modelled sedimentation. Figure 80

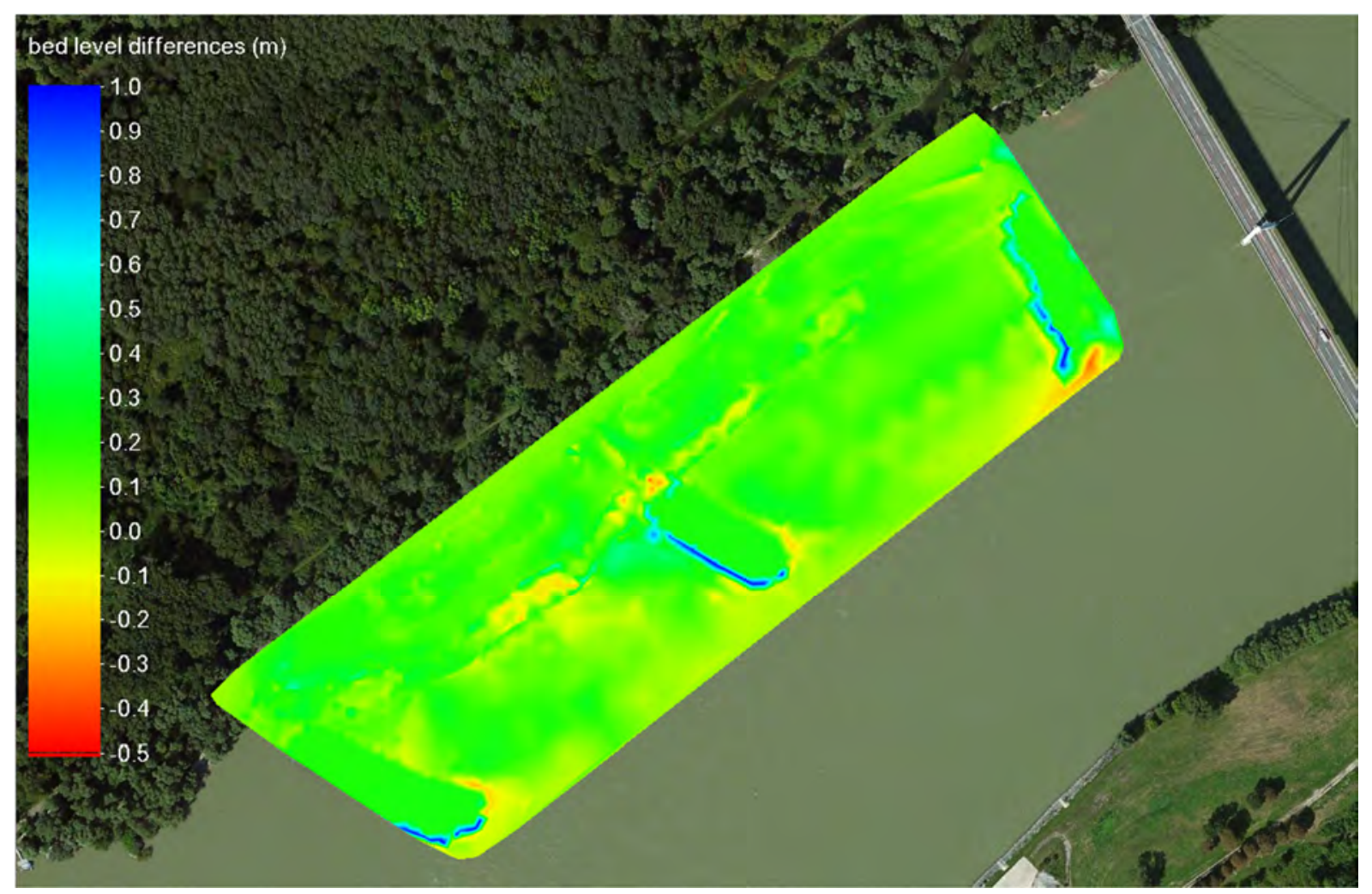

Figure 80: Calculated changes in bed level elevation within a groyne field as a result of a modelled flood event

Figure 81 shows changes in calculated microhabitat suitability due to morphological processes in a groyne field (Figure 80) caused by a one-years flood. Both pictures in Figure 79 were generated with die Habitat Evaluation Software (HEM). Moreover, the upper picture was derived from steady state flow conditions $\left(Q=1500 \mathrm{~m}^{3} / \mathrm{s}\right)$ whereas the lower one was calculated based on unsteady hydrodynamic modelling including sediment transport. 


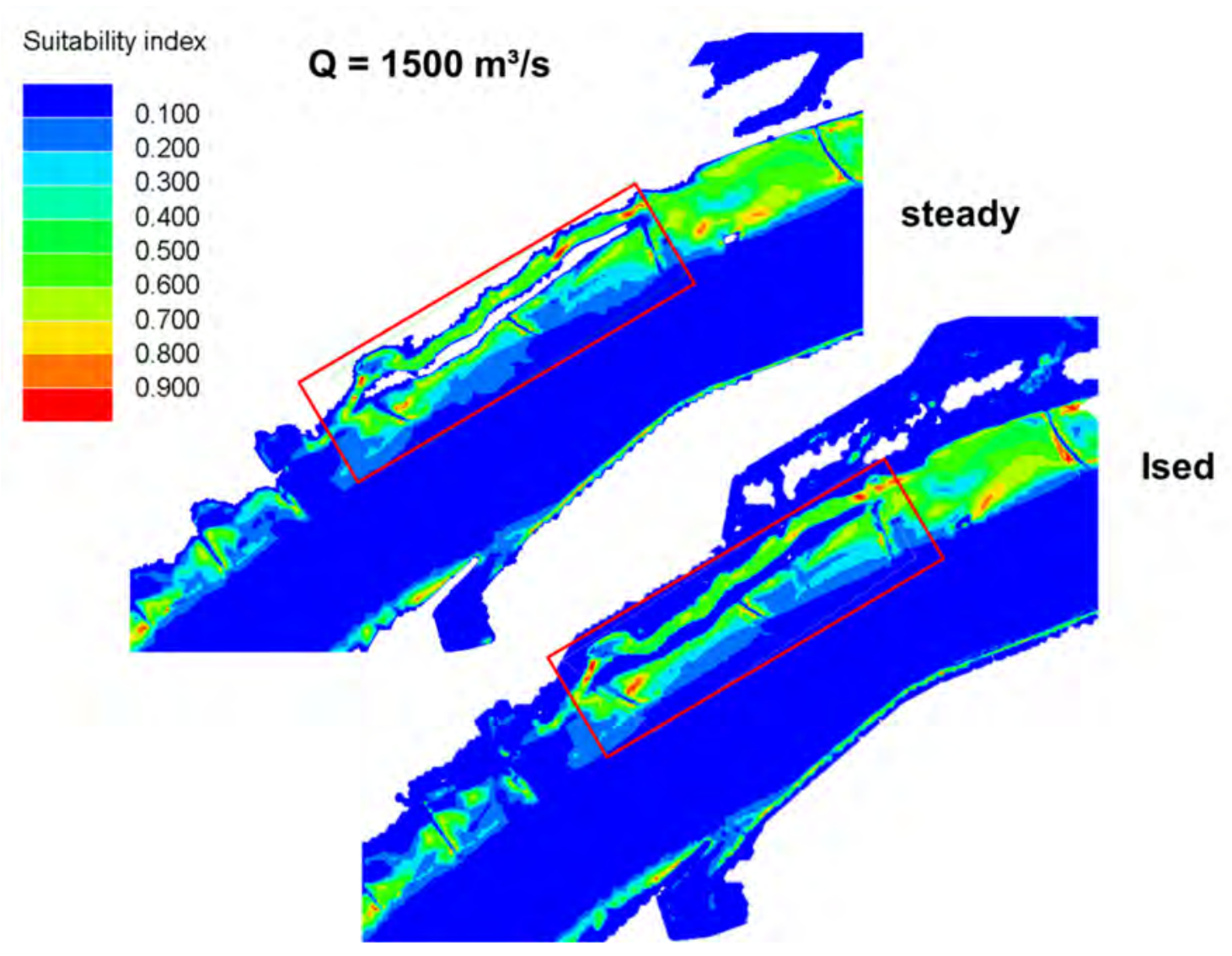

Figure 81: Comparison between derived fish - suitability based on steady-state hydrodynamic modelling and results based on unsteady hydrodynamic modelling including sediment transport (considered by Ised)

A quantification of modelled WUA depending on both concepts can be seen for selected discharges of the flood wave in Figure 84. WUA based on iSed is higher above $1930 \mathrm{~m} / \mathrm{s}$ compared to calculated WUA based on steady state modelling. However, for discharge lower than $1930 \mathrm{~m}^{3} / \mathrm{s}$ WUA based on iSed is higher compared to values gained from the conventional approach. This study case thus emphasizes the importance of considering morphological changes in the habitat evaluation, which is now possible using the coupled habitat and morphodynamic models.

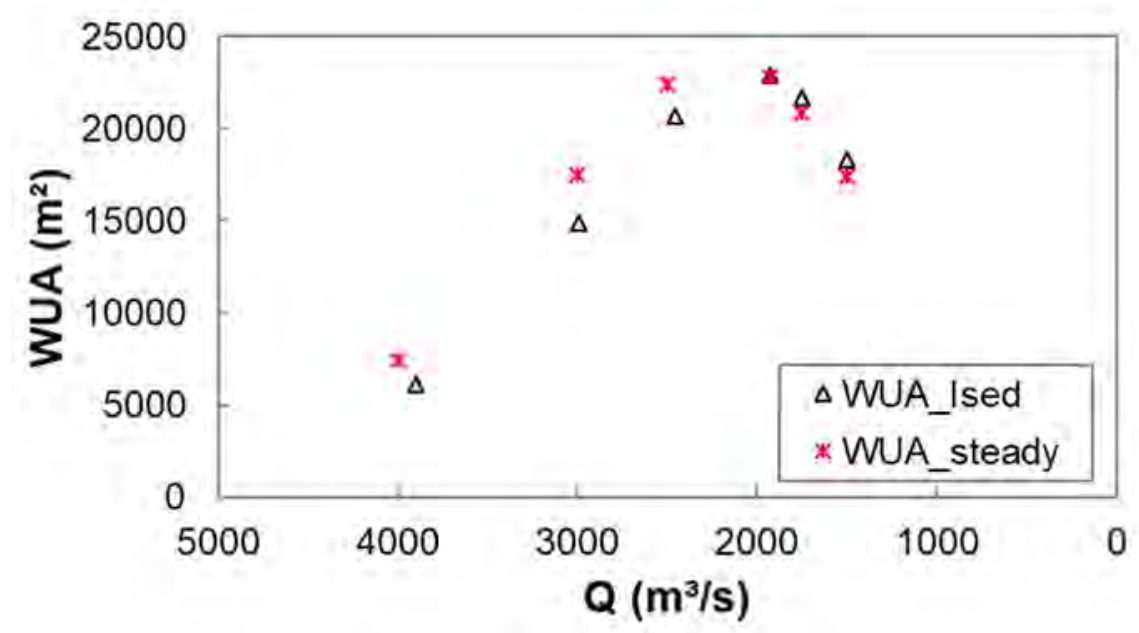

Figure 82: Comparison between modelled weighted usable area (WUA) based on steady-state hydrodynamic modelling and WUA based on unsteady hydrodynamic modelling including sediment transport (considered by Ised). 
The results presented in Figure 82 highlight two crucial issues in terms of investigating the aquatic environment from a hydraulic point of view. On the one hand the dynamics in flow, such as unsteady discharge, may be evaluated (magnitude of the one-years flood). On the other hand, crucial morphodynamical processes creating habitat diversity can be modelled and quantified.

\subsection{Setup, calibration and validation of model suite for selected river reaches}

\subsubsection{Numerical methods}

The analyses to improve the process understanding are supported by three-dimensional hydrodynamic numerical models on large, medium and small scale levels. Tritthart et al. (2019) provide an overview of the methods used.

\subsubsection{Investigation areas}

For answering various research questions different investigation areas located in Austria (Figure 83) were selected. Special focus was given on the catchment areas of the Drava, Rofenache, Danube and Urslau, due to the fact that reliable sediment transport monitoring data are available in these reaches.

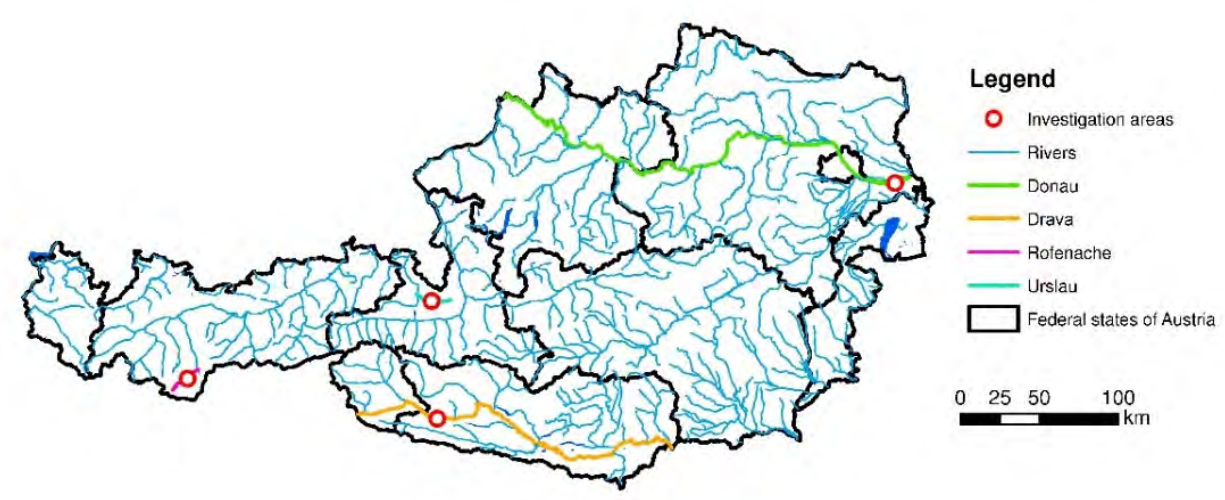

Figure 83: Overview of investigation areas

\subsubsection{Results}

\subsubsection{Drava}

Hydrodynamic simulation results serve as basis for sediment transport simulations. Therefore a hydrodynamic numerical model was set up using RSim-2D (Tritthart 2005) which was afterwards calibrated and validated at steady-state discharges based on existing field measurements of water surfaces.

In a next step the sediment transport model was established using iSed (Tritthart et al. 2011a; Tritthart et al. 2011b) The calibration and validation of this model was based on a correlation between discharge and bedload transport by means of a rating curve approach. Table 4 depicts good agreements between the observed and modelled bedload transport rates at certain discharges of $50,155,180$, and $255 \mathrm{~m}^{3} \mathrm{~s}^{-1}$. For the calculation of the bedload transport the well-known formula of Meyer-Peter and Müller (1949) in a non-uniform formulation was used, which had to be adjusted according to Table 4 . The reduction of the hiding-exposure 
exponent $\alpha$ at higher discharges was justified by a reduced possibility of hiding due to higher turbulences and bedload mobilizations. Additionally, it is assumed that the amour bed layer is broken up at discharges above 200 to $250 \mathrm{~m}^{3} \mathrm{~s}^{-1}$, whereby the bottom layer consisting of finer sediments is uncovered. Based on this assumption the critical shields parameter $\theta_{c, M P M}$ was additionally reduced at the highest discharge.

Table 4: Calibration (C) and Validation (V) of the sediment transport model by comparing measured (mea) and modelled (mod) bedload transport (BLT) at the Drava river

\begin{tabular}{lrrrrrr}
\hline & $\begin{array}{r}\mathrm{Q} \\
\left(\mathrm{m}^{3} \mathrm{~s}^{-1}\right)\end{array}$ & $\begin{array}{r}\mathrm{BLT}_{\text {mea }} \\
\left(\mathrm{kgs}^{-1}\right)\end{array}$ & $\begin{array}{r}\mathrm{BLT}_{\text {mod }} \\
\left(\mathrm{kgs}^{-1}\right)\end{array}$ & $\alpha$ & $\Theta_{\mathrm{c}, \mathrm{MPM}}$ & $\mathrm{C}_{\mathrm{MPM}}$ \\
\hline $\mathrm{C}$ & 155 & 5.31 & 5.36 & 0.4 & 0.052 & 5.0 \\
V1 & 50 & 0.00 & 1.18 & 0.4 & 0.052 & 5.0 \\
V2 & 180 & 10.37 & 10.50 & 0.3 & 0.052 & 5.0 \\
V3 & 255 & 49.28 & 48.92 & 0.3 & 0.028 & 5.0
\end{tabular}

Based on the abovementioned findings the sediment transport model was directly coupled with the hydrodynamic model, which allows unsteady simulations of extreme events. Three different simulation setups (Table 5) were tested, which led to the modelling results at a characteristic flood event with a 1-year peak depicted in Figure 84. Simulation setup S1 is based on quasisteady hydrodynamic simulations without any updates of the hydrodynamic parameters and with default values of the Meyer-Peter and Müller (1949) formula. This setup led to a substantial underestimation of the bedload transport in the numerical model. As a next step, simulations based on setup S2 were performed, which were also based on quasi-steady hydrodynamic simulations but considered intra-event modifications of the Meyer-Peter and Müller formula. Substantial improvements were achieved leading to good agreements with monitoring data. Finally updates of hydrodynamics in each time step of the simulation and a consideration of intra-event modifications of the Meyer-Peter and Müller (1949) formula were considered in simulation setup S3. This led to further improvements resulting in more continuous bedload transport time series.

Table 5: Simulation setups for bedload transport modelling of a characteristic flood event in June 2016

\begin{tabular}{|c|c|c|c|c|c|}
\hline \multirow[b]{2}{*}{ Setup } & \multirow{2}{*}{$\begin{array}{l}\text { Time } \\
\text { dependence }\end{array}$} & \multirow{2}{*}{$\begin{array}{l}\text { Q-range } \\
\left(\mathrm{m}^{3} \mathrm{~s}^{-1}\right)\end{array}$} & \multicolumn{3}{|c|}{ MPM } \\
\hline & & & $\alpha$ & $\Theta_{c, M P M}$ & $\mathrm{C}_{\mathrm{MPM}}$ \\
\hline S1 & Quasi-steady & $0-320$ & 0.4 & 0.052 & 5.0 \\
\hline \multirow[t]{3}{*}{ S2 } & Quasi-steady & $0-150$ & 0.4 & 0.052 & 5.0 \\
\hline & & $150-250$ & 0.3 & 0.052 & 5.0 \\
\hline & & $250-320$ & 0.3 & 0.028 & 5.0 \\
\hline \multirow[t]{3}{*}{ S3 } & Unsteady & $0-150$ & 0.4 & 0.052 & 5.0 \\
\hline & & $150-250$ & 0.3 & 0.052 & 5.0 \\
\hline & & $250-320$ & 0.3 & 0.028 & 5.0 \\
\hline
\end{tabular}




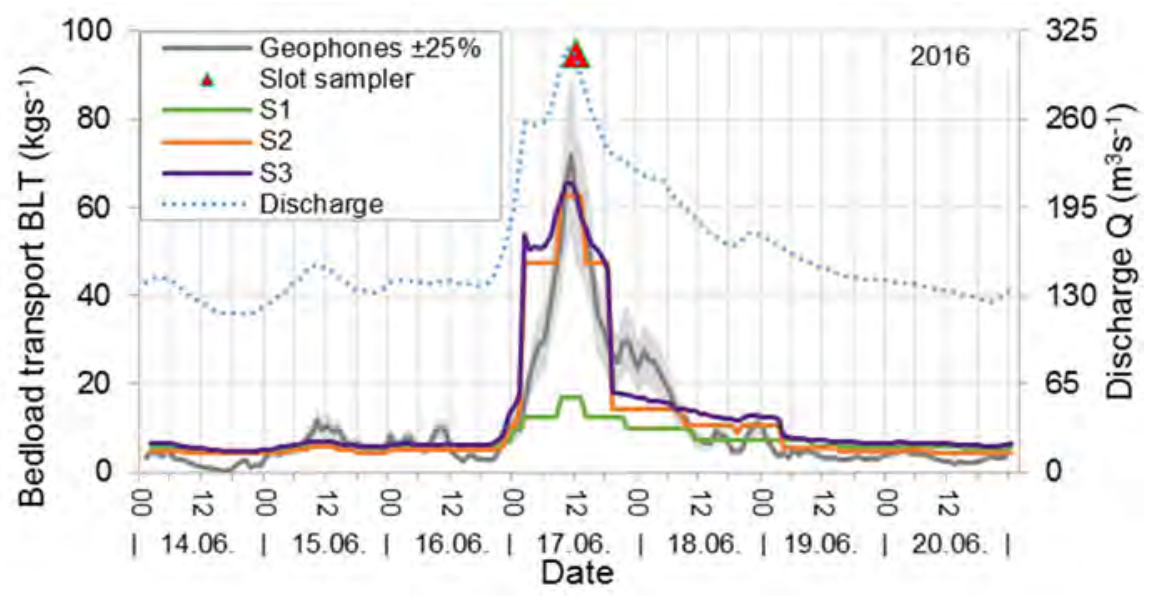

Figure 84: Comparison between monitoring and simulation results during a flood event in June 2016 at the Drava River

The scientific investigation dealing with numerical simulations at the Drava showed that monitoring data is indispensable for the calibration of a sediment transport model. Additionally, it was highlighted that an intra-event modification of the non-uniform Meyer-Peter and Müller parameters are necessary to achieve satisfying results. However, these substantial adaptions depict the difficulties on applying the empirical formula of Meyer-Peter and Müller in the numerical model at the Drava River and the necessity to evaluate additional sediment transport formulae.

Nevertheless, the coupled hydrodynamic and sediment transport models were successfully applied during flood events, whereby the results were substantial improved by using unsteady simulations.

The scientific investigations at the Drava were presented at the ISRS-conference (Glock et al. 2017) as well as at the IAHR-Europe conference (Glock et al. 2018).

\subsubsection{Rofenache}

Comparable to the case study Drava hydrodynamic numerical simulations were coupled with sediment transport simulations in the present investigation at the Rofenache. Therefore, $a$ hydrodynamic model, which served as a basis for bedload transport simulations, was set up, calibrated and validated using RSim-3D (Tritthart 2005).

Again the sediment transport model was set up using iSed (Tritthart et al. 2011a; Tritthart et al. 2011b) and calibrated as well as validated based on the specific rating curve approach of this investigation area. In Table 6 and Figure 85 are the good agreements between measured and modelled bedload transport rates at certain discharges of 21 and $40 \mathrm{~m}^{3} \mathrm{~s}^{-1}$ shown. The calculation of the bedload transport was based on the non-uniform Meyer-Peter and Müller (Meyer-Peter and Müller 1949) formula, which had to be adjusted according to Table 6 . Comparable to the investigation at the Drava the hiding-exposure exponent $\alpha$ was reduced at a discharge of $40 \mathrm{~m}^{3} \mathrm{~s}^{-1}$. This was again justified by a reduced possibility of hiding due to higher turbulences. 
Additionally, the bedload transport was simulated at an extreme discharge of $76 \mathrm{~m}^{3} \mathrm{~s}^{-1}$, which represents the highest recorded discharge at this gauge. Due to the fact that no bedload transport measurements are available at this event, the transport rates can only be predicted. The comparison of the prediction based on the classical rating curve approach and the prediction based on the bedload transport simulation highlight a substantial difference. Even by the reduction of the hiding-exposure exponent $\alpha$ to 0 the bedload transport model was not able to reproduce the value of the rating curve approach.

Table 6: Calibration (C) and Validation ( $V$ ) of the sediment transport model by comparing measured (mea) and modelled (mod) bedload transport $(B L T)$ at the Rofenache

\begin{tabular}{|c|c|c|c|c|c|c|}
\hline & \multirow{2}{*}{$\begin{array}{r}Q \\
\left(m^{3} s^{-1}\right)\end{array}$} & \multirow{2}{*}{$\begin{array}{r}\mathrm{BLT}_{\text {mea }} \\
\left(\mathrm{kgs}^{-1}\right)\end{array}$} & \multirow{2}{*}{$\begin{array}{c}\mathrm{BLT}_{\text {mod }} \\
\left(\mathrm{kgs}^{-1}\right)\end{array}$} & \multicolumn{3}{|c|}{ MPM } \\
\hline & & & & $\alpha$ & $\Theta_{c, M P M}$ & $\mathrm{C}_{\mathrm{MPM}}$ \\
\hline$C$ & 21 & 18.5 & 18.2 & 0.27 & 0.047 & 5.0 \\
\hline V1 & 40 & 101.0 & 100.1 & 0.20 & 0.047 & 5.0 \\
\hline V3 & 76 & 547 & 393 & 0.00 & 0.047 & 5.0 \\
\hline
\end{tabular}

In a second step, the bedload transport formula of Wu et al. (2000) was newly implemented into the modelling environment. The modelling results based on this approach are generally below the measurements and rating curve approach and therefore cannot be recommended for this investigation area.

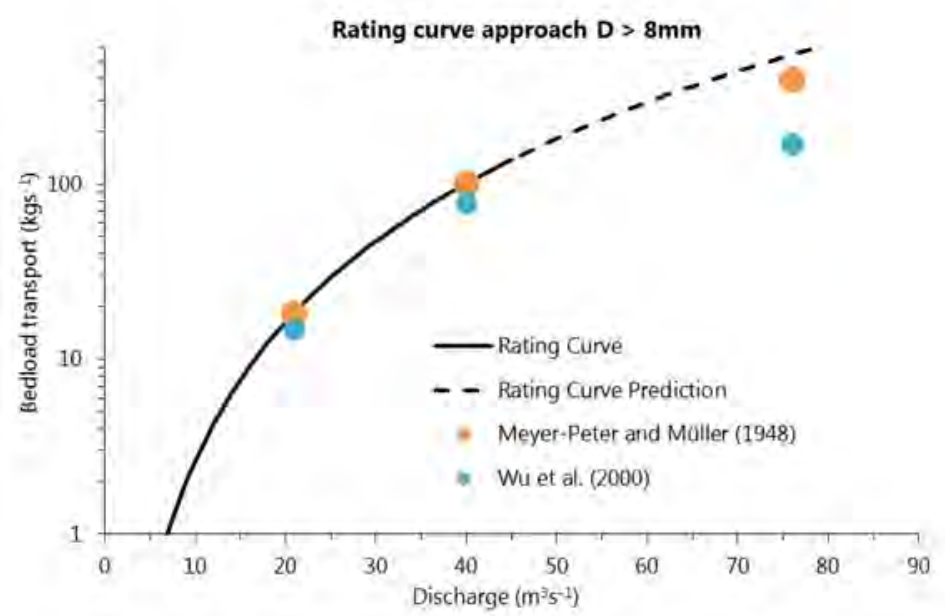

Figure 85: Rating curve approach at the Rofenache including simulation results based on Meyer-Peter and Müller (1948) and Wu et al. (2000).

The investigation at the Rofenache indicates that the measured bedload transport rates are only reproducible with iSed in a certain discharge range $\left(0-50 \mathrm{~m}^{3} \mathrm{~s}^{-1}\right)$, where also bedload measurements are available. Beyond that, substantial differences occurred between the predictions based on the rating curve and based on the numerical simulations, respectively. Further investigations might identify, if the classical rating curve approach cannot be extended to higher discharge, due to the fact, that the bedload rates are transport limited, which is not considered in this approach. Another explanation might be that the Meyer-Peter and Müller 
(1949) formula cannot represent the ongoing processes at such high discharges, due to a substantial process change (floods with bedload transport versus debris flow).

4.2.4. Improvement of conceptual habitat model components

The dynamic component in hydrology, sedimentology and, consequently, river morphology serves as a backbone for the entire river environment (Maddock 1999). In addition to water pollution, the hydro-morphological / sedimentological degradation is one of the main pressures on river systems (Ward and Stanford 1995; Dudgeon et al. 2006). The EU Water Framework Directive (EU, WFD 2000) mentions various aspects of hydro-morphological disturbances that must be addressed by management plans to achieve the aims of a good ecological status or a good ecological potential (Article 3 / Article 4). However, to reach these goals the sediment conditions of a river (e.g. sediment continuum) are not part of the evaluation needs. Here, to achieve 'good ecological status' it is assumed that the biotic criteria reflect the hydromorphological status, while direct assessments of dynamic sedimentological processes are not taken into account (Hauer 2015).

In general, sediments play a decisive role for diversification and composition and, hence, the quality of habitats, especially for the mid- to long-term development of habitat features. According to Leopold et al. (1964) there are eight factors forming the morphological traits of a river: channel width, depth, flow velocity, discharge, channel slope, roughness of channel material, sediment load and sediment size. Disturbances in any of those factors can alter the general habitat composition of the river and consequently the morphological type of a river. Sediments are both, habitat forming (e.g. boulders) or part of morphological structures (e.g. gravel at gravel bars) (Hauer et al. 2014) (Figure 86).

In the project RAISE the variable role of sediments was highlighted for the case study Urslau (compare to chapter 3.6). Here, an up to now neglected differentiation between fluvial, semifluvial and non-fluvial in mountainous areas was investigated. This differentiation is based on recent studies concerning sediment and habitat composition in the Artic and former glaciated areas of the Last Glacial Maximum (LGM) (Hauer and Pulg 2020, 2018). As the Alpine rivers contain glacial history and adaptation processes during the Holocene, the habitat concepts presented in Figure 1 were applied to the selected test case. In Figure 2, two sections of the Urslau river are presented. The indicator used for underlining the novel sediment related habitat concept is based on the delineation of the $d_{90}$ (max grain size) for a differentiation between fluvial formed stretches, with similar $d_{90}$ over the entire studied stretch and those which likely contain non-fluvial sediments by rock-fall, avalanches or glacial deposits.

The pictures of the various sites (Figure 87) clearly highlighted the variability concerning the impact on local flow patterns, especially when it comes to higher discharges. Beside the sheltering effects, reducing flow velocity (also compare to the boulder influence of local hydraulics at the Upper Ybbs river, Figure 86), also impacts on local substrate composition and stability for macroinvertebrates is given (only visible along the banks due to high turbidity). In general, the faunal structure of benthic macroinvertebrates depends on substrate type, diversity and spatial patch configuration (Beisel et al. 2000). Habitat conditions of macroinvertebrates are to a large extent determined by flow parameters affecting the 
macroinvertebrates through hydraulic stress near the bottom (Statzner 1981) which is linked to substrate composition (Percival and Whitehead 1929; Beisel et al. 2000). As a consequence, many species are associated to a certain extent to specific habitats, which are composed of either mineral substrate (e.g. sand, gravel stones) or organic matter (e.g. living plants, dead leaves, deadwood). However, habitat preferences frequently change within the life-cycle of invertebrate taxa, indicating the importance of mosaic habitat patterns on a micro-scale. Thus, the variability of the larges grains (indicating partially semi-fluvial and non-fluvial history) and the follow up sediment and habitat diversity is a novel parameter for habitat sampling and detecting in Alpine areas.

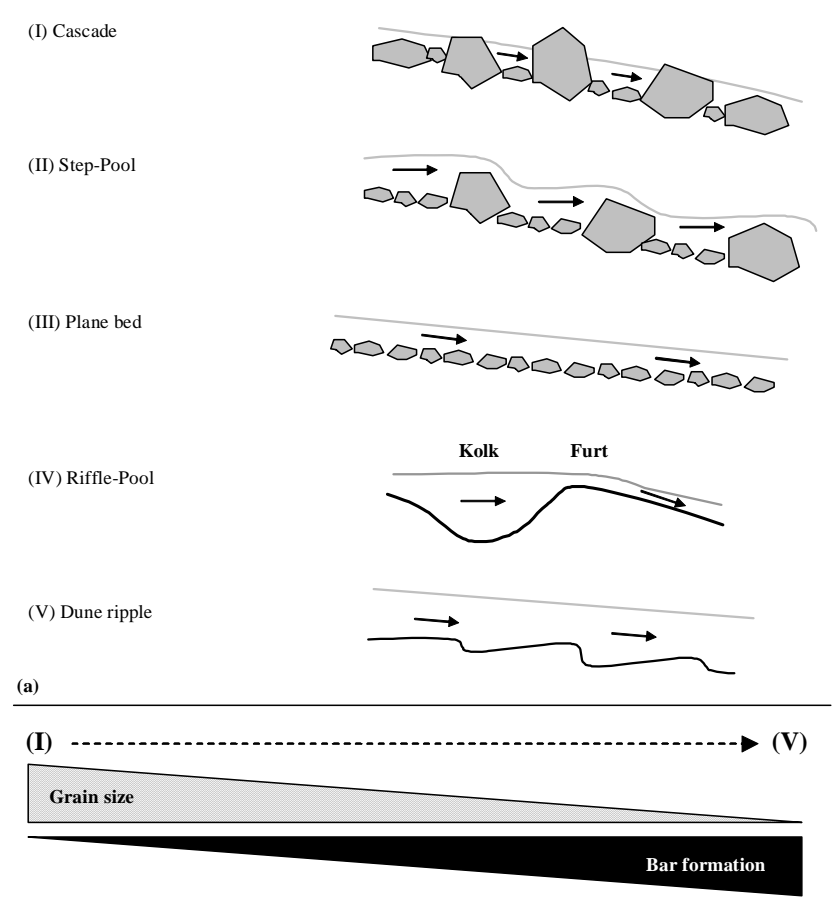

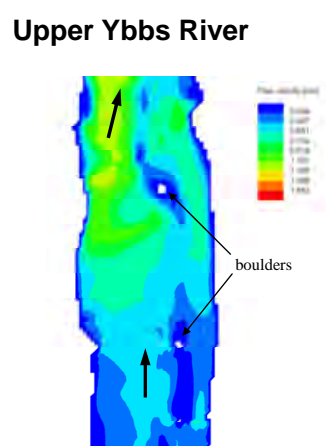

Pielach River

(c)

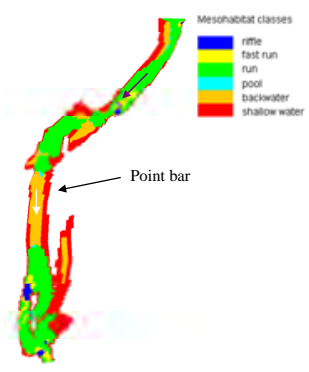

(b)

Figure 86: The role of sediments in the aquatic environment ranging according to various river types; - from habitat forming to bar formation; (a) Classification of morphological types according to Montgomery and Buffington (1997); (b) Hydraulic influence and contribution to habitat formation for the various Montgomery and Buffington (1997) types ranging from "Cascade" to Dune ripple types; (c) habitat modelling results for fluvial alpine rivers Upper Ybbs river and Pielach river underlining the role of sediments in habitat formation.

Moreover, based on the results of the RAISE project sediment management options for river restoration might be adjusted. Exemplarily, large boulders may be implemented in alpine rivers were glacial deposits are evident in form of terminal, lateral or hummocky moraines. Such structural measures on a patch scale (e. g. installation of boulders or dead wood) are useful to create patches of habitats providing the required substratum quality (Hauer 2015). Structural features, such as boulders, have the advantage that specifically during high (scouring) flows, they provide sheltering habitats in the wake zone accompanied by reduced flow velocities and/or bottom shear stress (compare to Figure 87a). Boulder placement or instream use of dead wood can also have effects on the hydraulic conditions and river morphology and, hence, indirectly affect the biota. For example, lateral scour pools with coarse substrate are formed if the flow is vertically or laterally constricted by boulders (WOOD-SMITH and Buffington 1996). 
Moreover, artificial gravel dumping, as an example of structural improvements, is a restoration measure frequently applied below dams (Brown and Pasternack 2008). It affects geomorphic units at meso-scales and thus hydraulic patterns on the micro-scale (Pasternack 2008). Wheaton et al. (2004) highlight the use of artificial gravel placement as one possible measure to restore or enhance hydro-morphologically suitable spawning habitat conditions for salmonids. Other restoration techniques include hydraulic structure placement (e.g., single boulders or groins), mainly to create suitable water depths and flow velocities combined with specific sediment sorting, or an "artificial enhancement" of existing spawning gravels by periodic turnovers of spawning substrate to reduce the amounts of aggregated fine sediments at spawning grounds. The problem inherent with all the above-mentioned spawning habitat improvement methods (gravel cleaning, gravel dumping, hydraulic adjustments) is that they were designed to increase the habitat suitability for target species during median or low flow conditions (spawning / incubation period, Wheaton et al. 2004) or to reduce the deposition of fine sediments (Pulg et al. 2013). However, the stability and/or scouring depth of spawning substrate during high flow conditions is typically not assessed in spawning habitat restoration design (short- to mid-term time scale), (e.g. DeVries 2008; Lisle 1989; Buffington et al. 2004). Thus, also the application of the studied framework in RAISE discussing the role of the exposed large roughness elements due to the glacial history and the options for implication are of great importance for future sediment management in rivers. 


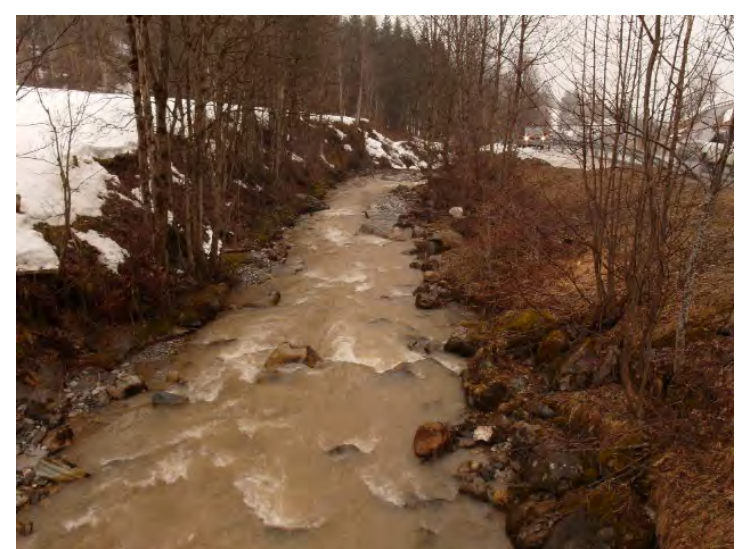

(a)

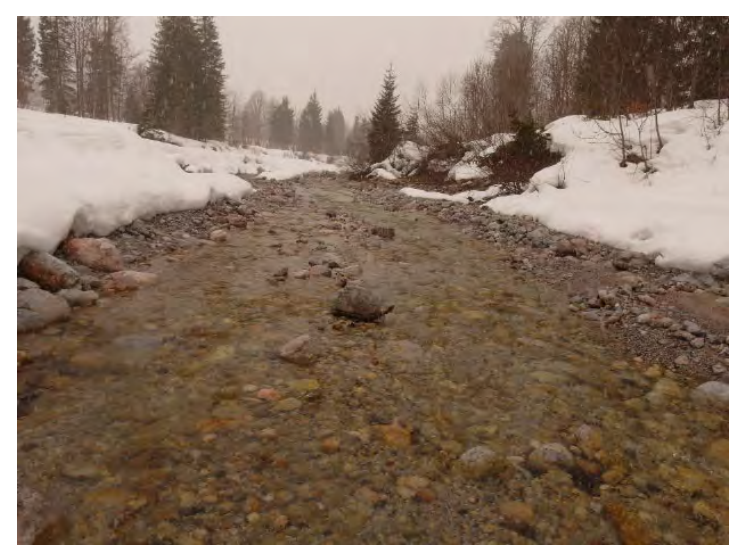

(b)

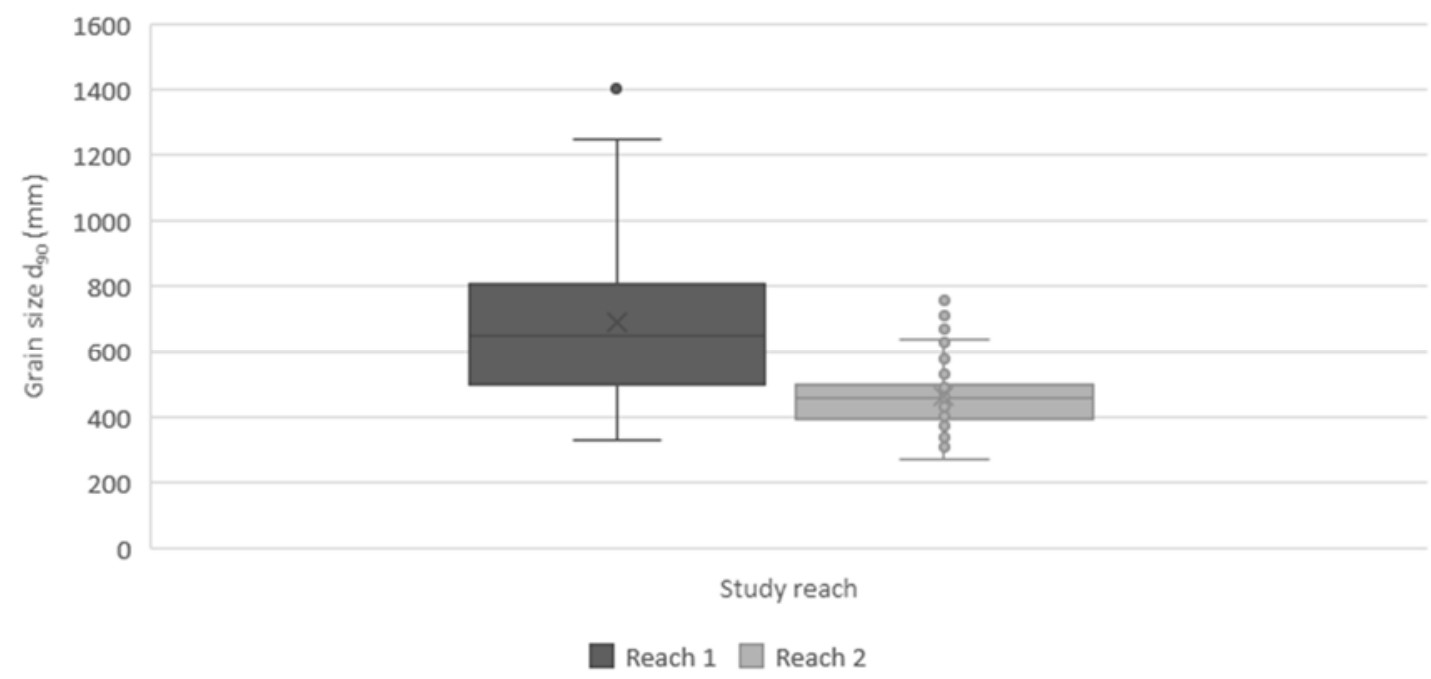

(c)

Figure 87: a) Semi-fluvial stretch of the Urslau river (downstream view); (b) fluvial stretch of the Urslau river (upstream view); (c) results of the variability in 190 according to the modified Wolman - count by Hauer \& Pulg (2018) underlining the different characteristics and impacts on local hydraulic patterns for the two different stretches. 


\section{WP 4 - Physical, laboratory-based modelling on sediment transport processes}

\subsection{Investigations on sediment particle entrainment}

Most sediment transport and entrainment equations like Shields (1936), Meyer Peter Müller (1949), Smart and Jäggi (1983) base on averaged flow parameters like the shear stress. These approaches follow the assumption that sediment motion takes place if the shear stress exceeds a certain value (critical shear stress). For general estimations of sediment transport this approach is popular. Particle dislodgment however does not take place at average flow conditions but during peak events concerning e.g. streamwise velocities, shear stress, drag and lift forces or impulses. It is assumed that coherent structures like sweeps are related to or are even the driving mechanisms for the before mentioned peak events. Coherent structures were studied in detail in the past, whereas the formation and interaction of large- and very/super large-scale coherent structures are still subject to research. There still is a research gap regarding large-scale coherent structures in interaction with particle entrainment, sediment transport as well as bedform evolutions. These large-scale motions and very large-scale motions can extend to the water surface (Adrian et al. 2000; Adrian 2007).

In this experiment a tomographic particle tracking velocimetry system (TOMO-PTV) is used to study large-scale structures causing single sediment particle entrainment (Figure 88). The difficulty regarding sediment dislodgment is the identification of the structure dislodging the particle.The difficulty regarding sediment dislodgment is the identification of the structure dislodging the particle. Therefore, a Proper Orthogonal Decomposition (POD) method (Holmes 1996) to distinguish between separate structures was used. The POD is a mathematical approach to decompose data into spatiotemporal modes. Separating the amount of turbulent kinetic energy (TKE) in the investigation area, in zones.

In total eight test runs were performed with a test particle originating from the Danube river with a b-axis of $11 \mathrm{~mm}$. The particle was placed on a concrete pocket with the shape of the particle to ensure the same starting conditions for all test runs and provided a certain resistance bevor particle dislodgement. 


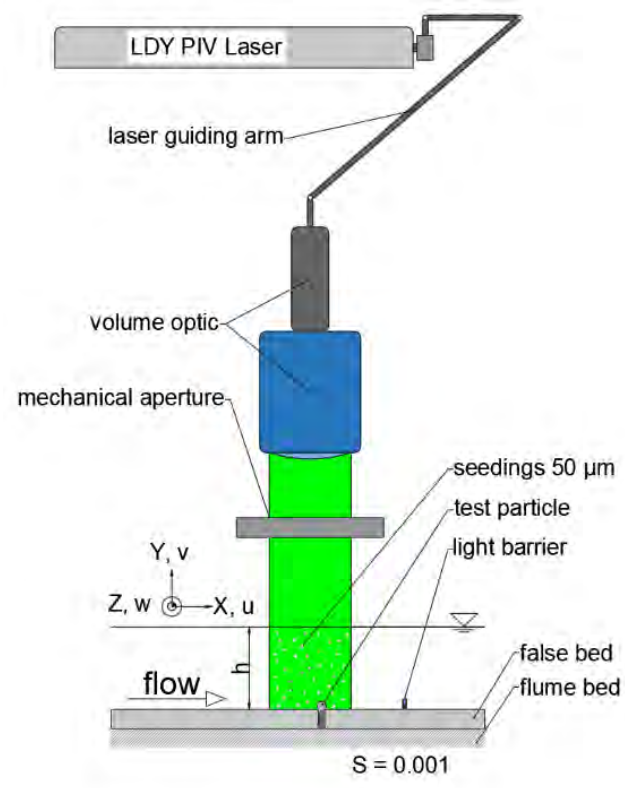

longitudinal section

Figure 88: Experimental setup (modified after Schobesberger et al. 2020)

\section{Results}

Linking the coherent structures to the turbulent energy was performed using the quadrant analysis, introduced by Lu and Willmarth (1973). This is a statistical approach to describe coherent structures. The quadrants can be described as outward interaction QI ( $u^{\prime}>0$ and $v^{\prime}>0$ ), ejections QII ( $u^{\prime}<0$ and $\left.v^{\prime}>0\right)$, inward interactions QIII ( $u^{\prime}<0$ and $\left.v^{\prime}<0\right)$ and sweeps QIV ( $u^{\prime}>0$ and v'<0). Whereby $u^{\prime}, v^{\prime}$ and $w^{\prime}$ are the decomposed Reynolds velocities. In Figure 89 the turbulent kinetic energy progression in comparison with the occurring fractions of quadrant events QII and QIV is displayed for the tests 6 S and 8S.
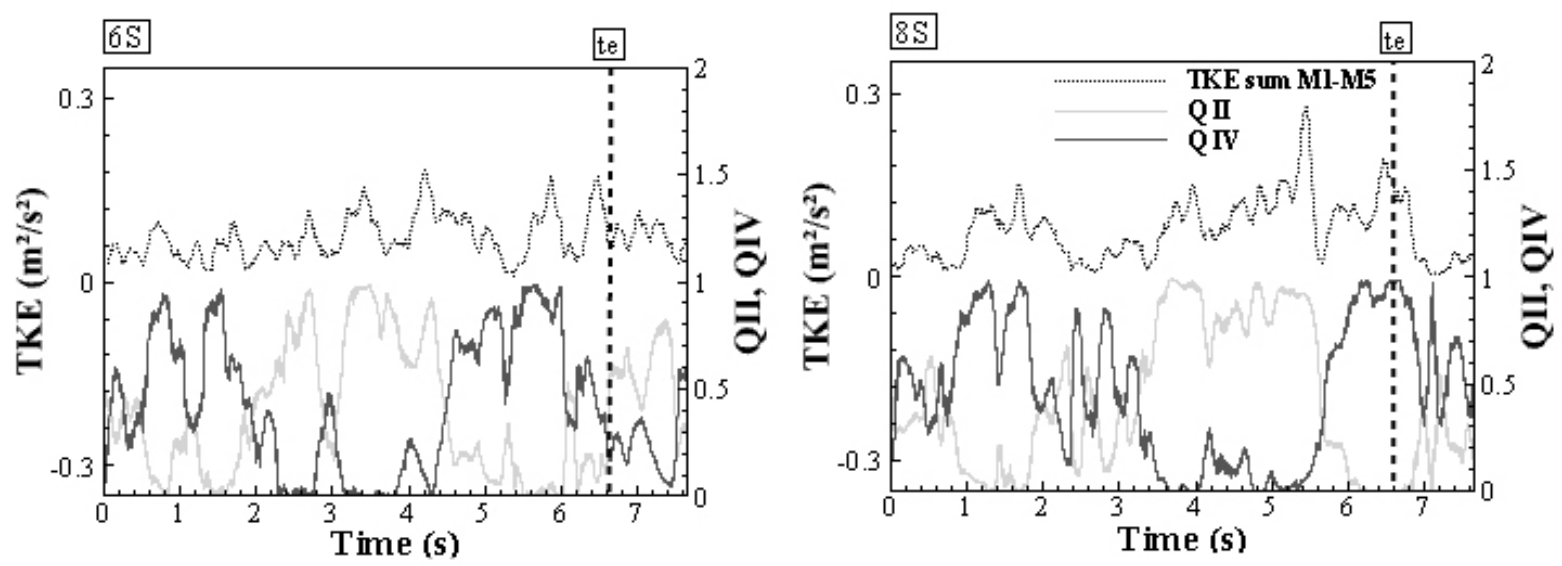

Figure 89: Quadrants Q II and Q IV plotted as light grey and dark grey lines in relation to the turbulent kinetic energy TKE based on the first five modes plotted as dotted line in the investigation volume over the measurement period. Particle Entrainment (te) is marked with a vertical dashed line. The axis related to quadrants describes the proportion of ejections Q II and sweeps Q IV in the investigation volume, where 1 correspond to 100 percent. (modified after Schobesberger et al. 2020) 
The 3D-abritary view in Figure 90 of the test $6 \mathrm{~S}$ and $8 \mathrm{~S}$ visualizes the different coherent structures measured in the flume.
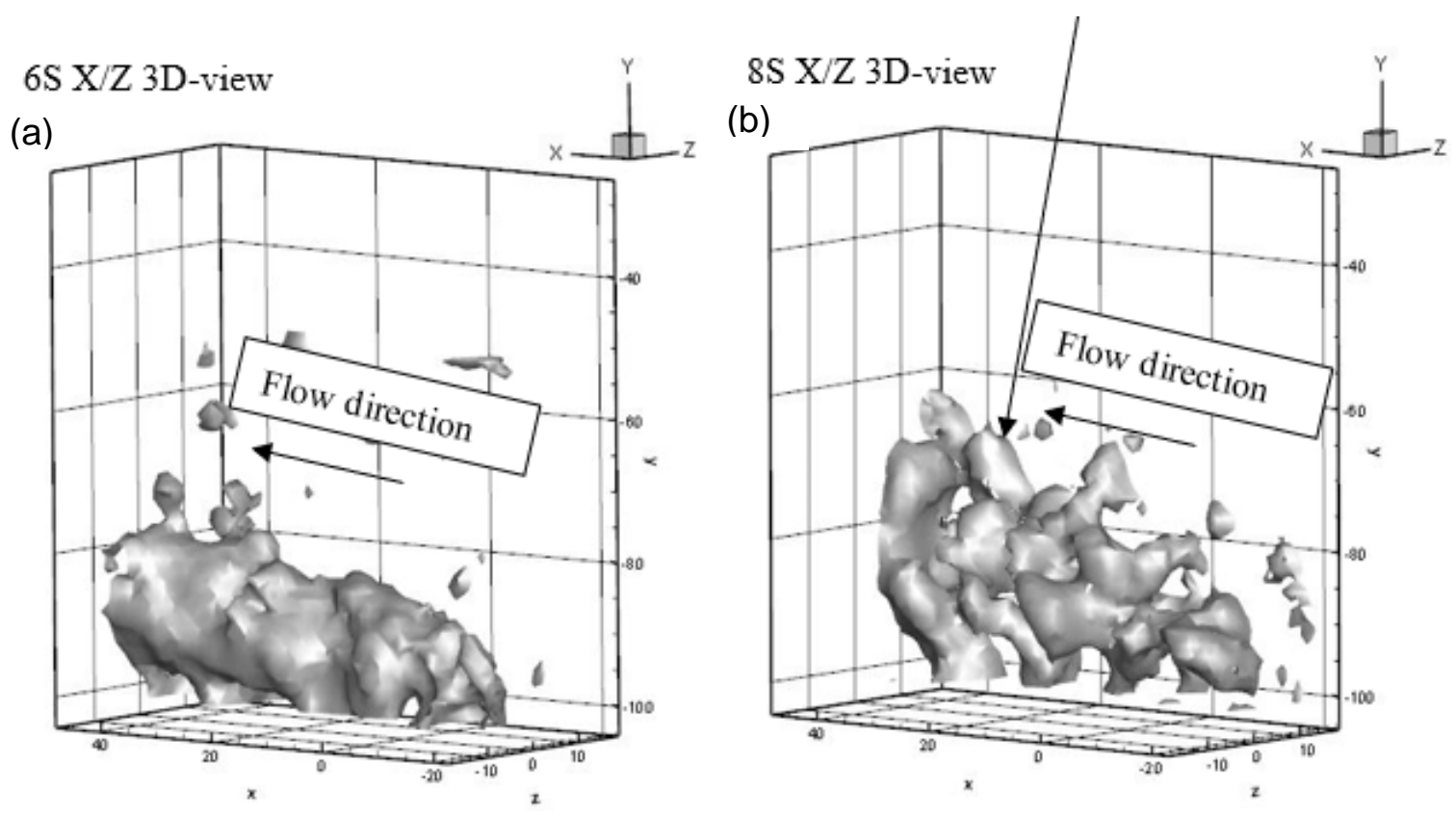

Figure 90: Coherent structures of test 6S (a) and 8S (b). For a better visibility the 3D-abritary view of two observed structures with the flow direction from right to left (modified after Schobesberger et al. 2020)

During the measurement timespan, fluctuating sweeps and ejections expanding over the entire investigation volume were observed. Zhong et al. (2015), Nakagawa and Nezu (1981) and Shvidchenko and Pender (2001) hypothesized that alternating large scale ejections and sweeps are linked to super streamwise vortices. These super streamwise vortices could be captured partly since it exceeded the investigation volume.

With this flume experiment sediment particle entrainment could be observed at turbulent kinetic energy peaks, calculated from the lowest five POD modes. These kinetic energy peaks were detected at super large scale coherent streamwise motions (Q IV).

\subsection{Delta formation at the reservoir of head of run-of-river hydropower plants in gravel bed rivers}

This section summarizes the findings of delta formation experiments at the head of run-of-river hydropower plants as reported in Sindelar et al. (2020). Human activities and climate changerelated effects have disturbed natural sediment dynamics in riverine systems on a global scale. In Austria we find approx. 2770 run-of-river hydropower plants (RoR), 87\% of which are located in small and medium-sized rivers. At the head of a RoR reservoir the coarsest fractions of the transported bed load material settle. Along the longitudinal axis the size of particles decreases until also suspended fractions settle. In medium-sized gravel bed rivers RoRs have hydraulic heads which are typically $<10 \mathrm{~m}$. They are classified as "low-head" hydropower. Their reservoirs are small in respect of length, width, depth and the ratio of reservoir storage capacity to mean annual runoff. Therefore, fine sediments hardly contribute to reservoir sedimentation, since they pass the turbines or the flood gates as suspended load. The gravel fractions are essential to maintain important ecosystem functions such as providing habitats and spawning 
gravel for fish. In the past operating rules of RoRs were designed to maximize energy revenue, neglecting sediment connectivity and continuity. Today hydropower plant (HPP) operators must consider ecological requirements, which is the subject of legal frameworks like the European Water Framework Directive. An effective way to prevent or reduce reservoir sedimentation is to flush the impoundment during natural flood events. At some RoRs, operating rules have already been changed from flushing a reservoir as rarely as possible to flushing a RoR reservoir frequently to reduce ecological impacts such as turbidity for each flushing event.

Most research and field reports on reservoir sedimentation focus on large dams with large storage capacities, where fine sediments play a key role. This experiment focuses on low-head RoRs. The objectives of this experiment are (i) to experimentally study sediment transport and sorting processes in the reservoir of a low-head RoR during turbine operation, (ii) to perform a supportive analysis using different bed-load transport models for both uniform sediments and sediment mixtures, (iii) to characterize the delta formation at the head of a reservoir and (iv) to discuss consequences of the results for HPP operators. The impounded section is termed "reservoir". The operation where the reservoir water level is lowered by opening the flood gate(s), such that a free surface flow develops is termed "flushing" (Sindelar et al., 2020).

\section{Experimental setup}

The experiments were conducted at the Hydraulic Engineering Laboratory of the University of Natural Resources and Life Science Vienna, Austria. The physical model was built at a scale of 1:20 in a $1.33 \mathrm{~m}$ wide and $14 \mathrm{~m}$ long straight flume consisting of an inlet basin with vertical and horizontal flow straighteners, a sediment feeder, a $9.5 \mathrm{~m}$ long experimental section, a sand trap with a steel box to collect and weigh the entrained sediments and a bottom hinged tail gate to manipulate the water level (Figure 91). The water came from the central water circulation system of the lab and was adjusted by frequency-controlled pumps. A magnetic flow meter was used to measure the discharge. Five ultrasonic probes were available to record the water levels during the experiments. The probes were mounted on a linear positioning system (Figure $91 \mathrm{~b}$ ). It was possible to measure longitudinal water surface profiles and to record the water levels over time at single points. 


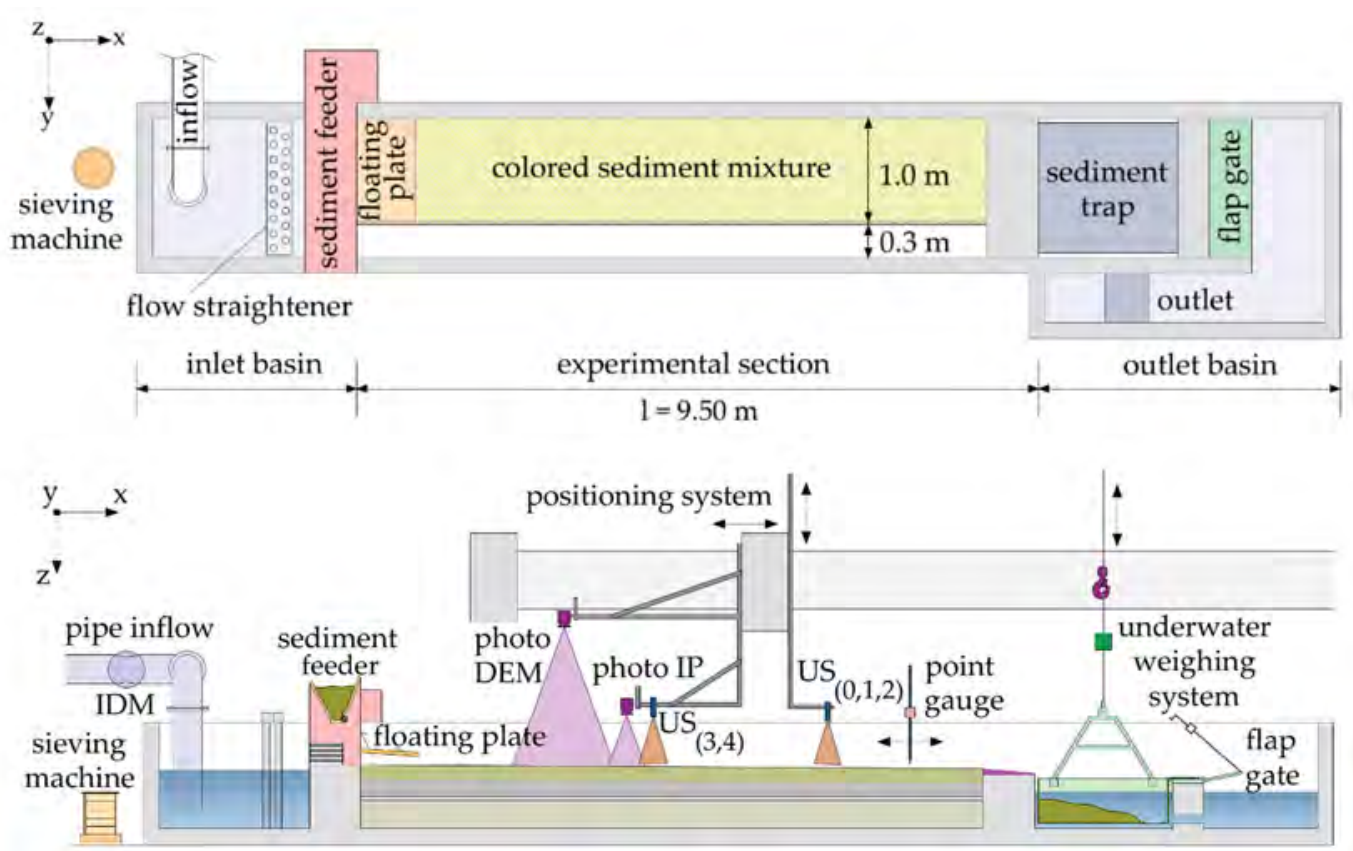

(a)

(b)

Figure 91: Experimental setup, (a) plan view; (b) longitudinal section of the straight flume. DEM = digital elevation model, IP = image processing, US = ultrasonic probe (Sindelar et al., 2020).

Sediment was added to the model via a sediment feeder. The feeder consisted of a sediment hopper with a bottom slit spanning the entire width. A rotating horizontal shaft was situated below the bottom slit of the hopper. The shaft had eight longitudinal slots to gather sediments from the hopper while rotating. The shaft was driven by a speed-controlled motor. With an accuracy of $5 \%$ a calibration could be established relating the driving speed $(\mathrm{Hz})$ to the sediment feeding rate $(\mathrm{kg} / \mathrm{h})$. Bed levels were recorded by means of photogrammetry. Ground control points on either side of the physical model were surveyed at an accuracy of $0.1 \mathrm{~mm}$.

The model sediment consisted of five different grain size classes of dyed quartz sand having a density of $2600 \mathrm{~kg} / \mathrm{m}^{3}$ and a bulk density of $1700 \mathrm{~kg} / \mathrm{m}^{3}$. The grain size classes of the 1:20 scale experiments and the corresponding grain sizes at 1:1 as well as the initial mass fraction and the color of each class are summarized in Table 7.

Table 7: Grain size classes of the 1:20 scale experiments and corresponding grain size classes at 1:1, initial mass fraction (\%) and non-uniformity parameters ${ }^{1} U$ and $\sigma$.

\begin{tabular}{lllll}
\hline Fraction No. & $\begin{array}{l}\text { Grain size } \\
1: 20(\mathrm{~mm})\end{array}$ & $\begin{array}{l}\text { Grain size } \\
1: 1(\mathrm{~mm})^{2}\end{array}$ & Color & $\begin{array}{l}\text { Initial mass } \\
\text { fraction }(\%)\end{array}$ \\
\hline 1 & $0.7-1.2$ & $14-24$ & Yellow & 15 \\
2 & $1.2-2.0$ & $24-40$ & Red & 15 \\
3 & $2.0-3.0$ & $40-60$ & Green & 20 \\
4 & $3.0-4.0$ & $60-80$ & Black & 25 \\
5 & $4.0-6.0$ & $80-120$ & White & 25 \\
\hline
\end{tabular}

${ }^{1}$ The nonuniformity parameters are $U=d_{60} / d_{10}=3.29 \mathrm{~mm}$ and $\sigma=\left(\mathrm{d}_{84} / \mathrm{d}_{16}\right)^{0.5}=2.25 \mathrm{~mm}$.

${ }^{2} \mathrm{~d}_{30}=40 \mathrm{~mm}, \mathrm{~d}_{\mathrm{m}}=60 \mathrm{~mm}, \mathrm{~d}_{90}=102 \mathrm{~mm}$ 
To determine the grain size distribution of the bed surface material an image processing method was developed making use of the fact that each grain size class had a different color (Sindelar et al., 2020). Figure 92 (a) illustrates the compound orthophoto of the experimental section covered with the colored sediments $(9.2 \times 1 \mathrm{~m} 2)$. Contour lines are illustrated in black. The orthophoto represents the surface layer after a flow rate of $0.7 \times \mathrm{HQ1}$. The flow direction is from left to right. Different areas are discernible with the naked eye, where different colors are dominant. At this flow rate sediments are transported as dunes. Three of these dunes are marked with blue lines. The red square indicates an arbitrary section of the bed surface where the image processing method is further illustrated. Figure 92 (b) represents the zoomed red square of the orthophoto, (c) its reduction to five different colors only and (d) the resulting grain size distribution.
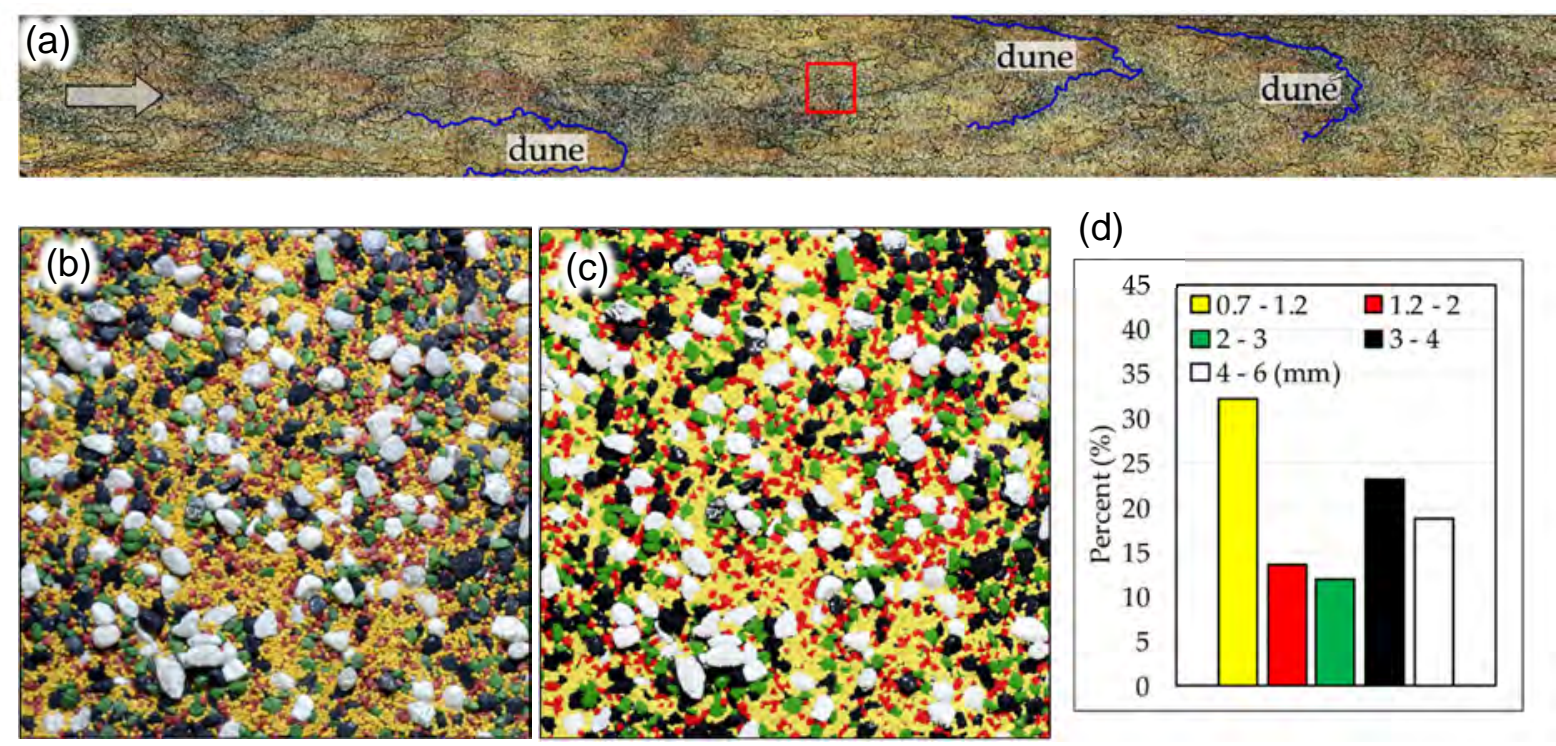

(d)

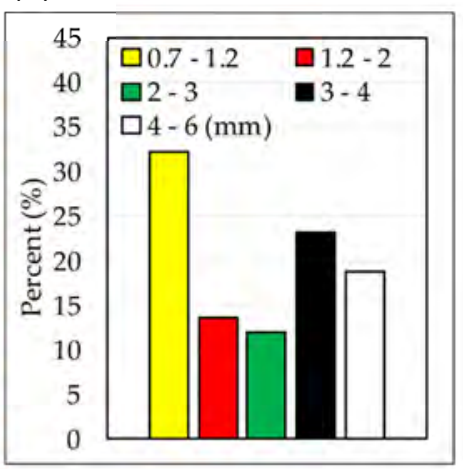

Figure 92 (a): Compound orthophoto of the bed surface material of the experimental section. The arrow indicates the flow direction. The red square indicates the location of the $0.12 \times 0.12 \mathrm{~m}$ section detail; (b) red square detail of the orthophoto; (c) red square detail of the processed orthophoto which is reduced to five different colors only, each pixel belongs only one-color class; (d) grain size distribution of the red square detail (Sindelar et al., 2020).

\section{Sediment transport analysis}

Prior to the experiments the sediment transport capacities were determined from five models and were later compared with the measured transport rates. Specifically, the following models were used: the formula of Meyer-Peter \& Mueller (Meyer-Peter and Müller 1949) with two different constant factors, labelled "MPM-5" and "MPM-8"; the formula of Smart \& Jaeggi (Smart and Jaeggi 1983); the model of Wu (Wu et al. 2000) for nonuniform sediment transport in alluvial rivers, "WU"; and the surface-based transport model for sediment mixtures developed by Wilcock and Crowe (Wilcock and Crowe 2003), "WC".

The MPM formula uses the mean grain diameter $d_{m}$ as a characterization of the sediment mixture. In addition to the mean diameter $d_{m}$, the $S J$ formula considers the non-uniformity of the sediments by introducing a factor $\left(d_{90} / d_{30}\right)^{0.2}$, where $d_{90}$ and $d_{30}$ are the grain diameters for which $90 \%$ and $30 \%$ of the sediment mixture are finer. Both approaches calculate a single transport rate for the entire sediment mixture. In contrast, the models of WU and WC provide transport rates for each grain size class 


\section{Experimental procedure}

In Figure 93a longitudinal sketch of a RoR is illustrated where three sections are plotted: a free-flowing section Sec 1 which is not affected by the backwater of the dam, the head of the reservoir (Sec 2) where the backwater effect starts and a section Sec 3 immediately upstream of the dam structure. Assuming a representative dam height of $h_{d}=5 \mathrm{~m}$ for a typical RoR located at the Muerz River, the reservoir length $\mathrm{I}_{\mathrm{res}}$ can be calculated from the water depth $\mathrm{h}_{0}$ and the bed slope $S_{0}$ of the free-flowing section.

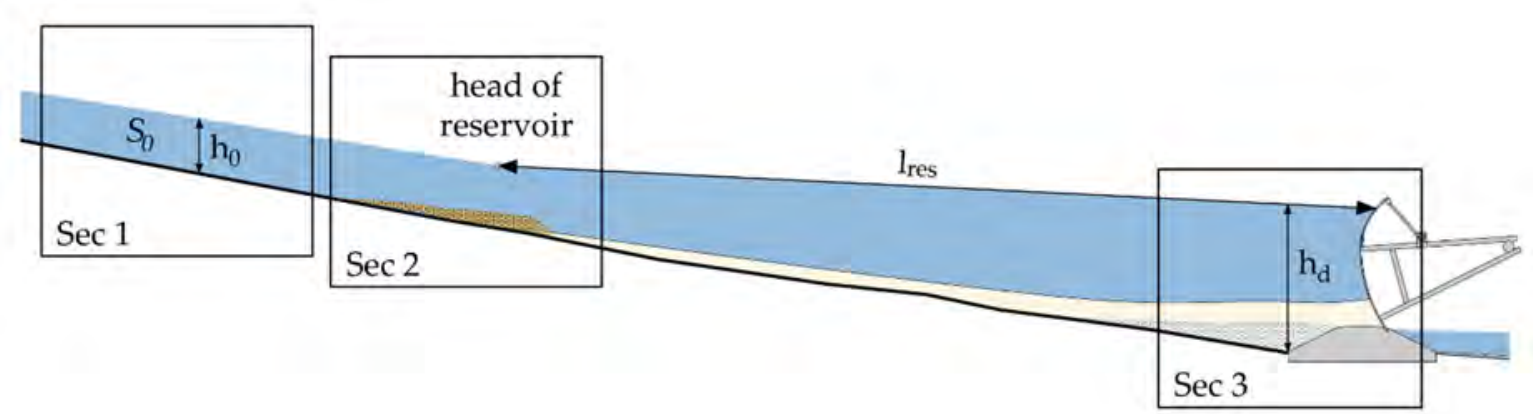

Figure 93: Section of a RoR with a free-flowing section not affected by the backwater effect from the RoR (Sec 1), the head of the reservoir (Sec 2) and the RoR with a concrete weir and a radial gate with an installed flap as spillway (Sec 3) (Sindelar et al., 2020).

The experiments for studying delta formation were divided into two major test series. First, the sediment transport capacity for a free-flowing section was examined for different flow rates (Sec 1 in Figure 93). Secondly, the sedimentation process during turbine operation was determined at the head of a reservoir where the backwater starts (Sec 2 in Figure 93). The backwater curve approaches the free-flowing upstream river section asymptotically. A meaningful criterion to determine the location where the backwater effect is negligible is where the water depth $\mathrm{h}$ does not exceed the water depth of the free-flowing section $\mathrm{h}_{0}$ by more than $+1 \%$. In the present study the head of the reservoir was defined as the location where $h=1.01 \cdot h_{0}$. Sec 3 in Figure 93 is located at the RoR and illustrates the section through the spillway represented as a concrete weir and a radial gate with an installed flap. This kind of spillway is a typical building design in Austria's gravel bed rivers.

\section{Results}

In Figure 94 longitudinal water and bed surface profiles are illustrated at the head of the reservoir for test run D2. The flap gate at the downstream end of the physical model was adjusted such that the reservoir head was located at $X=1.5 \mathrm{~m}$. The bed surface at the beginning of the test run represented the bed levels of the free-flowing section (Sec1) in a state of dynamic equilibrium where bed and water surface levels are parallel. The water levels of the Sec1 are shown in grey for comparison. The black line illustrates the measured water surface levels of the backwater curve at the beginning of the experiment (Oh). The purple dashed-dot line represents that calculated backwater curve (BWC) showing good agreement with the measured BWC. The measured backwater curve is virtually horizontal from $X=4.0-X=8.5$ and approaches the water levels of the free- flowing section further upstream. Due to the backwater effect the transport is decelerated. Sediments accumulate in upstream and 
downstream direction from the reservoir head. The delta formation is clearly visible from these measurements. Different areas characterizing the delta formation are striking: a steep front termed "delta front" followed by an almost horizontal area termed "delta top" and a "delta tail". During the first two hours, the front of the delta formation travels until $X=6.5 \mathrm{~m}$. Over time the delta front travels shorter distances in equal time intervals (2 hours) but increases in height. After eight hours of experimental time the delta front reaches the end of the experimental section at $X=8.5$. It has a height of $0.031 \mathrm{~m}$ and the slope is about $35 \%$. The delta top is virtually horizontal.

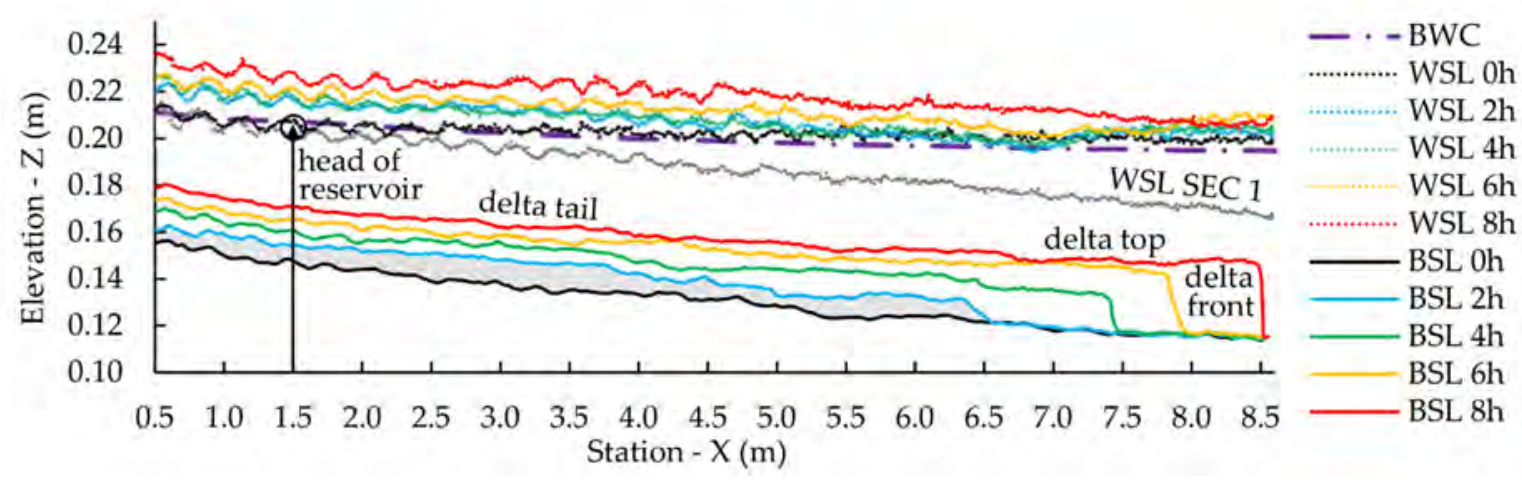

Figure 94: Bed and water surface profiles for test run D2 at the head of the reservoir at a flow rate of $0.7 \times$ HQ1 during turbine operation. The grey line represents the water surface profile of the free-flowing section which corresponds to the bed levels at hour 0 (black line). The head of the reservoir is located at $X=1.5 \mathrm{~m}$. Different areas of the delta formation, namely "delta front", "delta top" and "delta tail", are indicated. WSL = water surface levels, $B S L=$ bed surface levels, BWC = calculated backwater curve (Sindelar et al., 2020).

For the third test case D3 the reservoir head was located at $X=4.0 \mathrm{~m}$. The focus of this test was to study the delta formation process in upstream direction. The delta front reached the downstream end of the experimental section after 2 hours. Thus, the delta front could not be observed any longer for the following 6 hours. The bed and surface levels upstream of the delta front revealed another interesting process. The bed levels and water surface levels increased evenly in longitudinal direction, building bed and surface profiles almost parallel to that of the free-flowing section only at a higher elevation (Figure 95).

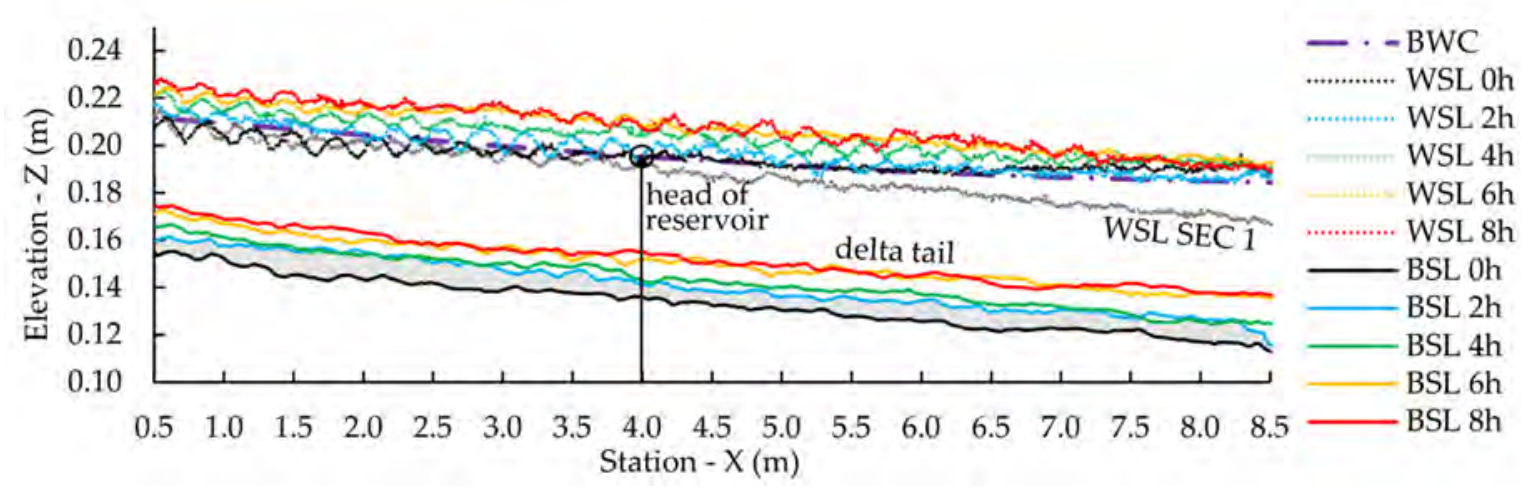

Figure 95: Bed and water surface profiles for D3 at the head of the reservoir at a flow rate of $0.7 \times$ HQ1 during turbine operation. The profiles were measured every two hours. The grey line represents the water surface profile of the free-flowing section which corresponds to the bed levels at hour 0 (black line). The head of the reservoir is located at $X=4.0$. BWC = calculated backwater curve (Sindelar et al, 2020). 
For each flow rate $0.5 \times \mathrm{HQ}_{1}, 0.6 \times \mathrm{HQ}_{1}, 0.7 \times \mathrm{HQ}_{1}$ and $0.8 \times \mathrm{HQ}_{1}$ the conditions for dynamic equilibrium were determined iteratively by keeping the bed slope of 0.005 constant and by varying the sediment feeding rate. In addition, the grain size distribution (GSD) of the added sediment was adopted step by step to align the GSDs of the sediment input and sediment output. For all flow rates a dynamic equilibrium was found where bed and water levels were virtually parallel along the channel (Table 8).

Table 8: Transport rates, ratio of fed sediment (input) vs transported sediment (output), bed and water surface slopes at dynamic equilibrium for the investigated flow rates. "n.d." = not determined.

\begin{tabular}{|c|c|c|c|c|c|c|}
\hline $\begin{array}{l}\text { Flow } \\
\text { rate }\end{array}$ & duration & $\begin{array}{c}\text { Repetition } \\
\text { nbr. }\end{array}$ & $\begin{array}{c}\text { transport } \\
\text { rate } \\
(\mathbf{k g} / \mathbf{h})\end{array}$ & $\begin{array}{c}\text { input } I \\
\text { output } \\
(-)\end{array}$ & $\begin{array}{l}\text { Bed } \\
\text { slope } \\
(-)\end{array}$ & $\begin{array}{l}\text { Water } \\
\text { surface } \\
\text { slope }\end{array}$ \\
\hline $\begin{array}{l}0.5 x \\
H Q_{1}\end{array}$ & $8 \mathrm{~h}$ & 1 & 7 & 0.93 & 0.0046 & 0.0047 \\
\hline $\begin{array}{l}0.6 x \\
H Q_{1}\end{array}$ & $8 \mathrm{~h}$ & 1 & 27 & 1.04 & 0.0045 & 0.0050 \\
\hline $\begin{array}{l}0.7 x \\
H Q_{1}\end{array}$ & $8 \mathrm{~h}$ & 1 & 51 & 0.98 & 0.0048 & 0.0048 \\
\hline $\begin{array}{l}0.7 x \\
H Q_{1}\end{array}$ & $8 \mathrm{~h}$ & 2 & 52 & 1.02 & 0.0048 & 0.0049 \\
\hline $\begin{array}{l}0.7 x \\
H Q_{1}\end{array}$ & $8 \mathrm{~h}$ & 3 & 53 & 0.98 & 0.0049 & 0.0048 \\
\hline $0.8 x$ & $4 \mathrm{~h}$ & 1 & 117 & n.d. & n.d. & n.d. \\
\hline
\end{tabular}

In Figure 96 the calculated sediment transport rates for discharges ranging from $0.5 \times \mathrm{HQ}_{1}$ to $0.9 \times \mathrm{HQ}_{1}$ are illustrated. The predicted transport rates are similar for WC and SJ. The rates of WU are higher but have about the same gradient. The model of MPM-5 has a much steeper gradient. Per definition the gradient of MPM-8 is 1.6 times larger than that of MPM-5. In Figure 96 the range between $0.5 \times \mathrm{HQ}_{1}$ to $0.7 \times \mathrm{HQ}_{1}$ is shaded in grey because this range is often recommended as threshold criterion for starting a reservoir drawdown (Knoblauch 2006).

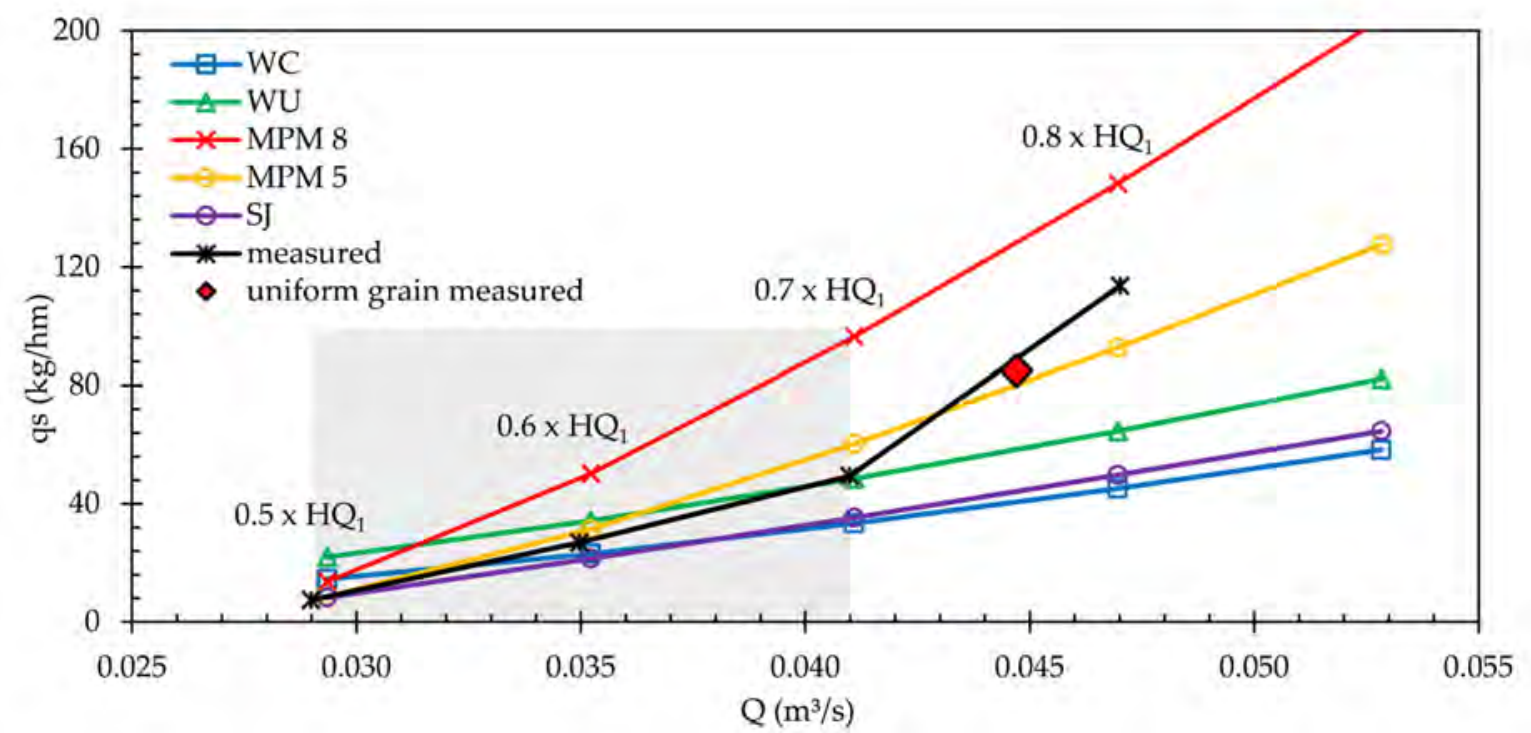

Figure 96: Sediment transport rates flow rates ranging from $0.5 \times \mathrm{HQ}_{1}-0.9 \times \mathrm{HQ}_{1}$ : Calculated sediment transport rates according to models of MPM, SJ, WC and WU. Measured transport rates of present study (black line) and of a previous study under similar conditions (red diamond) (Sindelar et al, 2020). 
The measured transport rates show a bimodal trend (Figure 96). They are approximately linear for discharges ranging from $0.5 \times \mathrm{HQ}$ to $0.7 \times \mathrm{HQ}_{1}$. Then there is a sudden increase in transport rates for $0.7 \times \mathrm{HQ} 1$. The measured transport rate for uniform sediment $\left(d_{50}=2.6 \mathrm{~mm}, \sigma=1.17\right.$, $\mathrm{S}=0.005$ ) from a previous study (Sindelar et al. 2017) fits well to the steep side of the transport curve for discharges $\geq 0.7 \times \mathrm{HQ}_{1}$. Neither of the sediment transport models predicts the bimodal trend of the experiments. The transport rates of MPM- 5 has the best least squares fit. In Table 9 calculated vs measured total sediment load for a representative flood event are summarized. The results are given in the dimension 1:1. The total load was calculated for flow rates of $0.6 \times \mathrm{HQ}_{1}$ and $0.7 \times \mathrm{HQ}_{1}$ lasting for 72 and 36 hours. Transport rates for $0.5 \times \mathrm{HQ}_{1}$ were not considered in the calculations assuming that in this period the discharge is not freeflowing because of gate operations restricting the flow. Thus, the transport rates can be neglected. For the considered flood event the transport rates of WU deviate by $13 \%$ from the measured transport rate. Except of MPM- 8 all calculated sediment loads are within $+/-25 \%$ of the measured transport rate.

For flow rates $\geq 0.7 \times \mathrm{HQ}_{1}$ the transport rates are high and seem to be suited to enhance sediment continuity if the reservoir is drawn down. For flow rates $<0.7 \times \mathrm{HQ}_{1}$ transport rates are low and can even be considered as negligible. Therefore, for this particular case, $0.7 \mathrm{x}$ $\mathrm{HQ}_{1}$ is the turning point where reservoir drawdown might be considered. This is why this flow rate was chosen to study delta formation to assess pros and cons of a drawdown.

Table 9: Calculated and measured total sediment load $\left(\mathrm{kg} \times 10^{3}\right)$ for a representative $0.7 \times$ HQ1 flood event in 1:1 dimension.

$\begin{array}{cccccc}\text { SJ } & \text { WC } & \text { WU } & \text { MPM-5 } & \text { MPM-8 } & \text { Measured } \\ 252(-24 \%) & 256(-23 \%) & 376(+13 \%) & 396(+19 \%) & 517(+56 \%) & 332\end{array}$

\section{Delta formation at the head of the reservoir}

The delta formation tests were carried out three times. They will be referred to as D1, D2 and D3, respectively. The experimental conditions were the same for all test runs except of the location of the head of the reservoir. For D1, D2 and D3 the location of the reservoir head was at $X=2.5 \mathrm{~m}, X=1.5 \mathrm{~m}$ and $X=4.0 \mathrm{~m}$, respectively, where $X=0 \mathrm{~m}$ is at the beginning of the experimental section which is $9.5 \mathrm{~m}$ long. Therefore, for D1 and D2, the reservoir head is located in the upper quarter of the experimental section and for D3 the reservoir head is about halfway of the experimental section's length. All delta formation tests were carried out at a flow rate of $0.7 \times \mathrm{HQ}_{1}$ because this flow rate was determined to be the turning point of the bimodal transport curve (Figure 96) 
Table 10: Delta formation test runs D1-D3: Transport rates, ratio of fed sediment (input) vs transported sediment (output), transported fractions of the yellow $(0.7-1.2 \mathrm{~mm})$ and red $(1.2-2 \mathrm{~mm})$ grain size class after 8 hours.

\begin{tabular}{cccccc}
\hline $\begin{array}{c}\text { Test } \\
\text { run }\end{array}$ & input (kg/h) & $\begin{array}{c}\text { output } \\
\mathbf{0 - 4 h}(\mathbf{k g} / \mathbf{h})\end{array}$ & $\begin{array}{c}\text { output } \\
\mathbf{4 - 8} \mathbf{~ h}(\mathbf{k g} / \mathbf{h})\end{array}$ & $\begin{array}{c}\text { yellow } \\
\text { fraction (\%) }\end{array}$ & $\begin{array}{c}\text { red } \\
\text { fraction (\%) }\end{array}$ \\
\hline D1 & 45 & 1.5 & 1.4 & 46 & 36 \\
D2 & 52 & 0.5 & 0.28 & 45 & 35 \\
D3 & 52 & 1.4 & 23.5 & 15 & 23 \\
\hline
\end{tabular}

By combining D2 and D3 the following summary can be drawn for a $0.7 \times \mathrm{HQ}_{1}$ flood event which lasted for 36 hours. All dimensions are given at full scale (1:1). The delta formation which developed moved $120 \mathrm{~m}$ into the reservoir. After the flood event the delta formation was responsible for a water level rise which reached as far as $100 \mathrm{~m}$ into the reservoir. 70 meters upstream of the reservoir head the bed levels were parallel to the initial bed levels of the freeflowing section only at a higher elevation $(+0.4 \mathrm{~m})$. Analogously, the water levels raised by $0.4 \mathrm{~m}$. Presumably the delta tail extension is longer than $70 \mathrm{~m}$. However, the experimental section was not long enough to capture the entire delta tail and to locate the upstream position where the delta formation merged into the initial river bed. This terminal section will be termed the "delta appendix". Given that the delta tail is virtually parallel to the initial bed, it becomes obvious that for the appendix to merge into the initial river bed the appendix has to be flatter than the initial bed slope. The flatter appendix is visible for test run D2 and test run D3 where the bed levels after two hours almost reconnect with the initial bed levels of hour 0 . Similar observations were made for D1.

Finally, the experimental results are compared with the sediment transport models. As transport rates were only measured at the downstream end of the model three different areas are compared: the section downstream of the delta after four hours of test run D2, the delta top of test run D2 after eight hours and the delta tail of test run D3 after eight hours. After four hours of test run D2 the models of MPM- 5 and SJ predict that there is no sediment transport for the section downstream of the delta. The models of WC and WU predict very little sediment transport. Their results are quite close to the measured transport (Table 11). According to WU only the two smallest fractions are in motion. The model of WC predicts that the two smallest fractions comprise $65 \%$ of the transported material. This is quite close to the experimentally determined $78 \%$.

For the delta top section of D2 after eight hours, the models of MPM-5 and SJ predict no sediment transport. For the models of WC and WU the transport rate is negligibly small. The model of WU predicts that only the smallest fraction is in motion. According to WC, all fractions are in motion which coincides with the experimental observation. WC predicts that $65 \%$ of the total sediment load belong to the two smallest fractions. The measured proportion of the two smallest grain size classes was $68 \%$. For the decelerated flow cases the model of WC is better suited to predict the GSDs of the transported material than the model of WU. 
Table 11: Calculated and measured transport rates in $(\mathrm{kg} / \mathrm{hm})$ of sections which are located at the downstream end of the experimental section.

\begin{tabular}{lllllllll}
\hline $\begin{array}{l}\text { Test } \\
\text { run }\end{array}$ & Hour & $\begin{array}{l}\text { Delta } \\
\text { section }\end{array}$ & $\theta$ & MPM-5 & SJ & WC & WU & Exp \\
\hline D2 & 4 & downstream & 0.024 & 0 & 0 & 0.12 & 0.14 & 0.4 \\
\hline D2 & 8 & top & 0.017 & 0 & 0 & $5 \times 10^{-3}$ & $4 \times 10^{-6}$ & 0.2 \\
\hline D3 & 8 & tail & 0.051 & 82 & 10 & 14 & 14 & 36 \\
\hline
\end{tabular}

After eight hours of test run D3, the delta tail resembles the free-flowing section. Both models WC and WU predict the GSD of the transported material with reasonable agreement. However, they underestimate the measured transport rate by far. The model of MPM-5 overestimates the transport rate. Summarizing, each of the tested models has its advantages and disadvantages, whereas none of the models is capable to predict all experimentally observed transport phenomena sufficiently.

The delta formation experiments revealed that virtually all incoming sediments accumulated at the head of the reservoir. Over time, the resulting delta formation grows in height and moves further into the reservoir. Four areas of the delta can be distinguished: a steep delta front followed by a virtually horizontal (ii) delta top which transitions into a (iii) delta tail. The delta tail has a substantial extent in upstream direction raising bed and water levels and approaching the slope of the free-flowing section. Upstream of the tail a (iv) flat appendix merges into the original river bed. The delta has the potential to increase the flood risk for high floods. It also has ecological impacts. Important spawning gravel fractions might accumulate on and in the delta and are missing further downstream. From this point of view, it might be recommended to drawdown the reservoir for a flow rate of $0.7 \times \mathrm{HQ}_{1}$. The measured transport rates have a small gradient for flow rates $<0.7 \times \mathrm{HQ}_{1}$ and a gradient about three times larger for flow rates $\geq 0.7 \times \mathrm{HQ}_{1}$. Reservoir drawdowns for flood events with a peak flow $<0.7 \times \mathrm{HQ}_{1}$ don't seem to be recommended for RoR yet. However, if flow events with peak flows $\geq 0.7 \times \mathrm{HQ}_{1}$ are not used for a drawdown there is a danger of a rapid delta formation increasing flood risk. 


\section{WP 5 - Interrelations between abiotic and biotic earth surface processes, human influences and socioeconomics}

\subsection{Integrative Sediment Management Concept}

6.1.1. Development of a questionnaire on the need for action regarding sediment budget, sediment transport and river morphology

The project SEDAT (Habersack et al. 2014) has shown and presented the need for action on the different sectoral levels with regard to sediment budget, sediment transport and river morphology. Therefore, NGP2015 aimed for the development of a sediment management concept, which is to be elaborated for selected catchment areas in the current period.

Based on this effort, a questionnaire for the basic survey of the need for action in the field of sediment budget, sediment transport and river morphology were prepared in the course of the RAISE project. The aim of this questionnaire is to collect as much knowledge as possible about a river or its catchment area together with stakeholders and affected persons of different disciplines. The questionnaires should make it possible BEFORE the planning and conception within the framework of a sediment management concept to query and collect all existing knowledge that is distributed among different involved persons and stakeholders. This should make it possible, for example, to select the locations of sediment monitoring station well, to compile problems regarding solid matter management in the catchment area (where and which ones?) and to record the positive and negative experiences of measures already taken.

The questionnaire was based on the need for action identified in the course of the SEDAT project for the respective sectors. The sectors are as follows: Torrent control, river engineering, energy management and ecology.

The developed questionnaire (in German) is illustrated below and is divided into:

1) General information

2) Investigation of the problems concerning solid matter balance/sediment transport and river morphology

3) Actions and measures

4) Measurement data and relevant information

5) Conception of solids management concept 


\section{Grundlagenerhebung zum Handlungsbedarf Feststoffhaushalt, Sedimenttransport und Flussmorphologie}

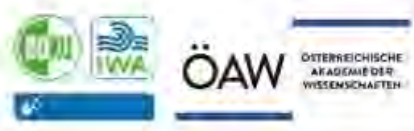

\begin{tabular}{|l|l|}
\hline 1. Allgemeines & \\
\hline Name: & Datum: \\
\hline Funktion/Dienstgeber: & Gewässer/Gewässerabschnitt: \\
\hline
\end{tabular}

2. Probleme bezüglich Feststoffhaushalt/ Sedimenttransport und Flussmorphologie

2.1 Welche Problemen bezüglich Feststoffhaushalt/ Sedimenttransport und Flussmorphologie treten an dem Fluss/Bach auf? Mit welchen sind Sie konfrontiert?

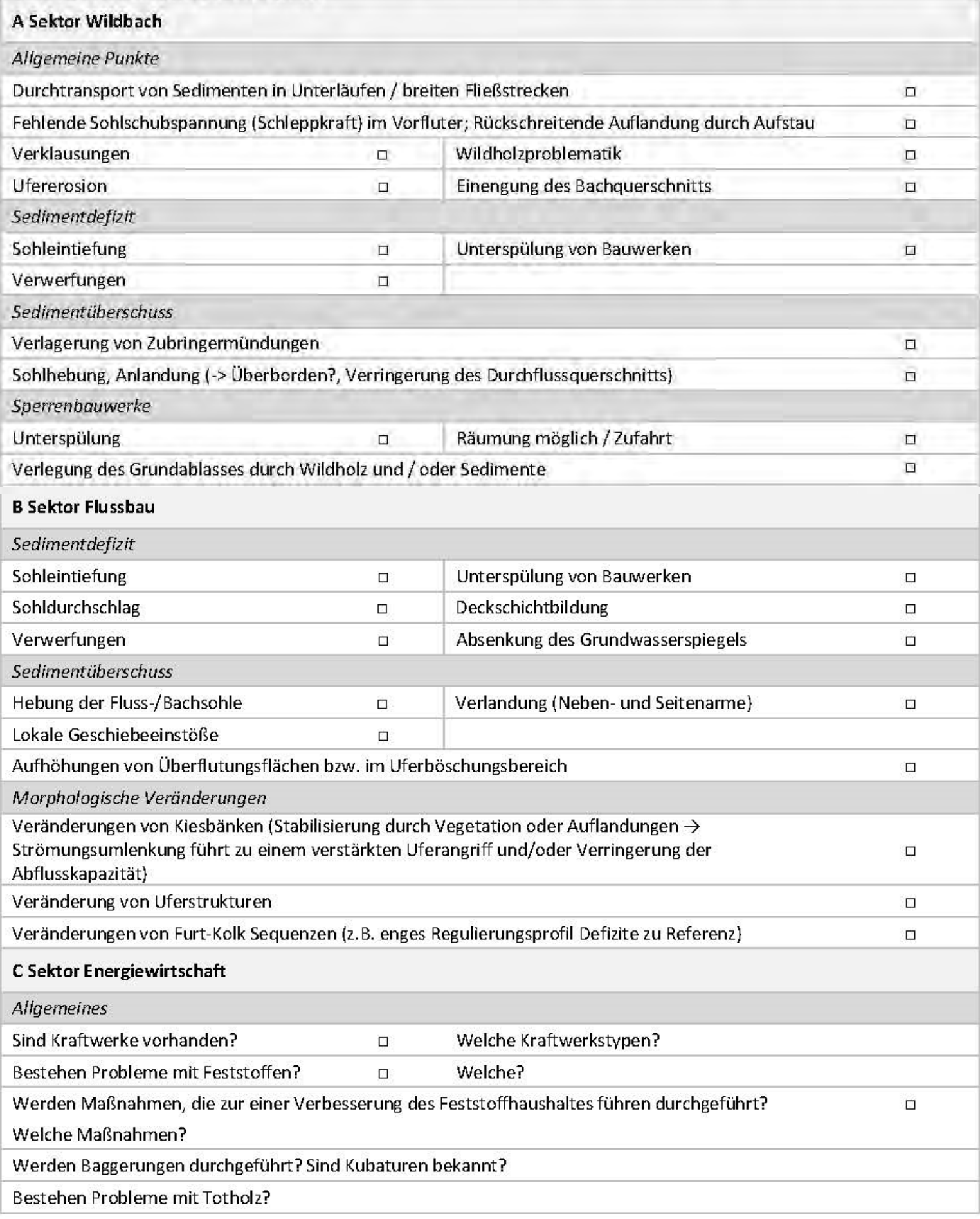




\begin{tabular}{|c|c|c|c|}
\hline \multicolumn{4}{|l|}{ Sedimentüberschuss } \\
\hline Stauraumverlandung & $\square$ & Hochwassersicherheit bei Laufkraftwerken & $\square$ \\
\hline Kolmation & $\square$ & Auflandungen in der Ausleitungsstrecke & $\square$ \\
\hline \multicolumn{4}{|l|}{ D Sektor Ökologie } \\
\hline \multicolumn{4}{|l|}{ Sedimentdefizit } \\
\hline Sedimentrückhalt in Wildbächen & $\square$ & Verringerung von Habitat (Schotterbänken) & $\square$ \\
\hline \multicolumn{4}{|l|}{ Sonstiges: } \\
\hline \multicolumn{4}{|l|}{ Sedimentüberschuss } \\
\hline Verlandung von Seitenarmen & $\square$ & Kolmation von Kiesbänken & $\square$ \\
\hline \multicolumn{4}{|l|}{ Sonstiges: } \\
\hline \multicolumn{4}{|l|}{ Energiewirtschaft } \\
\hline Schwall- und Sunkbelastung & $\square$ & Kontinuumsunterbrechung & $\square$ \\
\hline Restwassersituation & $\square$ & & \\
\hline \multicolumn{4}{|l|}{ Linienführung } \\
\hline Uferverbau & $\square$ & Abflussregulierung & $\square$ \\
\hline Begradigung & $\square$ & & \\
\hline \multicolumn{3}{|c|}{ Sohleintiefung, fehlende Aubereiche, fehlende Uferdynamik, Habitatverlust } & $\square$ \\
\hline 2.2 Wo treten diese Probleme geo & & & \\
\hline
\end{tabular}




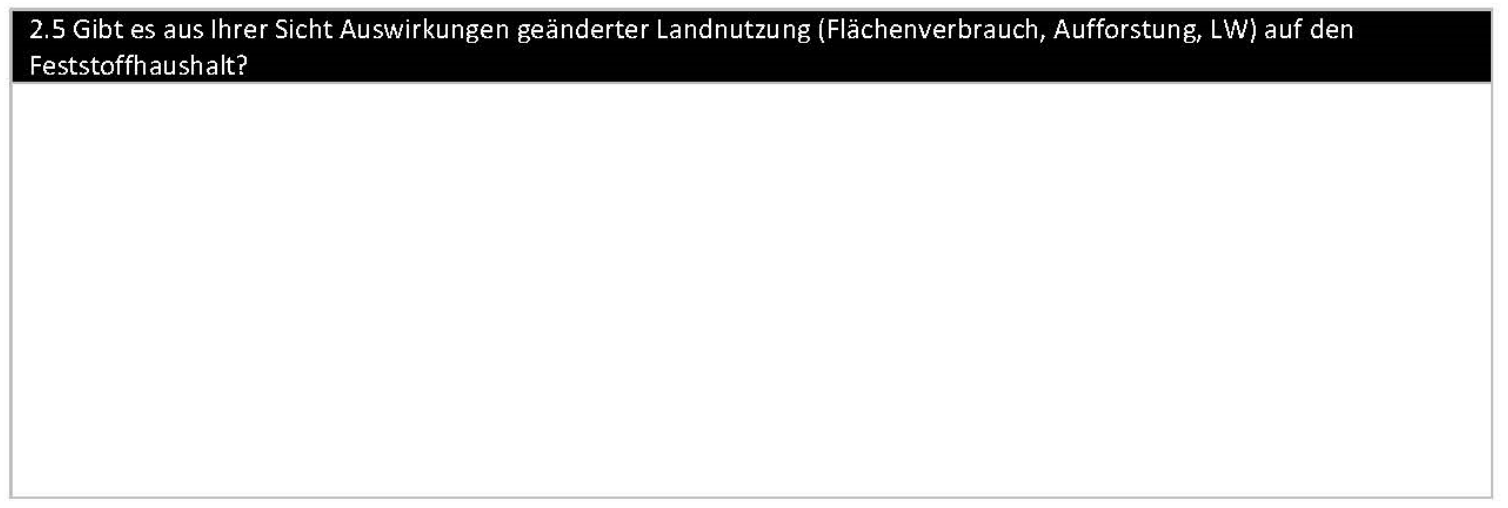

3. Handlungen, Problemlösungen

3.1 Unternehmen Sie persönlich Handlungen bezüglich Feststoffmanagement/Sedimenttransport/Flussmorphologie?

3.2 Wissen Sie ob von anderen Handlungen bezüglich Feststoffmanagement/Sedimenttransport/Flussmorphologie unternommen werden?

3.3 Wissen Sie ob es übergeordnete/koordinierte Strategien (Gewässermanagement) zum Feststoffhaushalt des Gewässers gibt? Haben Sie hierzu Vorschläge?

3.4 Bestehen Abstimmungsthemen und / oder Interessenskonflikte zwischen den einzelnen Sektoren (z.B. Wasserbau, Wasserwirtschaft, Energieversorger etc.). Was könnte aus Ihrer Sicht unternommen werde um die Abstimmung zwischen den Sektionen zu optimieren?

\section{Messdaten und andere relevante Informationen?}

4.1 Welche Messdaten und andere relevante Informationen gibt es im Einzugsgebiet?

\begin{tabular}{|c|c|c|c|}
\hline $\begin{array}{l}\text { Durchfluss } \\
\text { Messstation/(-en): } \\
\text { Betreiber: } \\
\text { Sind die Messdaten verfügbar? }\end{array}$ & $\square$ & $\begin{array}{l}\text { Wasserstand } \\
\text { Messstation/(-en): } \\
\text { Betreiber: } \\
\text { Sind die Messdaten verfügbar? }\end{array}$ & $\square$ \\
\hline $\begin{array}{l}\text { Schwebstoff } \\
\text { Messstation/(-en): } \\
\text { Betreiber: } \\
\text { Sind die Messdaten verfügbar? }\end{array}$ & $\square$ & $\begin{array}{l}\text { Geschiebe } \\
\text { Messstation/(-en): } \\
\text { Betreiber: } \\
\text { Sind die Messdaten verfügbar? }\end{array}$ & 口 \\
\hline $\begin{array}{l}\text { Sohlschubspannung } \\
\text { Messstation/(-en): } \\
\text { Betreiber: }\end{array}$ & $\square$ & $\begin{array}{l}\text { Erosion } \\
\text { Messstation/(-en): } \\
\text { Betreiber: }\end{array}$ & 口 \\
\hline
\end{tabular}




\begin{tabular}{|l|l|} 
Sind die Messdaten verfügbar? & Sind die Messdaten verfügbar? \\
\hline $\begin{array}{l}\text { Fotos zu Dokumentationszwecke: } \\
\text { In welchen Bereichen? }\end{array}$ & $\begin{array}{l}\text { Kubaturen zu Anlandung und Eintiefung? } \\
\text { In welchen Bereichen? } \\
\text { Wer hat sie erstellt? } \\
\text { Sind die Fotos verfügbar? }\end{array}$ \\
\hline Andere Daten und Informationen: & \begin{tabular}{l} 
Sind die Messdaten verfügbar? \\
\hline
\end{tabular} \\
\hline 4.2 Wer könnte (zusätzliche) Messdaten erheben? \\
\hline
\end{tabular}

5. Konzipierung Feststoffmanagementkonzept

5.1 Haben Sie Ideen und Vorschläge welche weiteren Themen in ein Feststoffmanagement einfließen sollten?

5.2 Was könnten Sie und Ihre Umgebung dazu beitragen? (z.B Messungen, Beobachtungen..) 


\subsubsection{First application of the questionnaire - Test area Gail}

The test area "Gail" was selected to test the questionnaire. In the catchment area of the Gail, IWA is working on various sediment transport projects, which means that comprehensive knowledge is available at the institute. 3 employees of IWA participated in the survey. The aim of the "test survey" was to check whether the knowledge can be inquired on the basis of the developed questionnaire and the questions asked in the interview. Due to the intensive project activities of IWA, the questioned knowledge could then be "validated" on the basis of the existing knowledge. In addition, the intensive survey brought together a lot of new and important knowledge for the IWA.

The following persons were interviewed:

1. Carinthian provincial government; Department 12 - Wasserwirtschaft; Wasserwirtschaft Hermagor: DI Hannes Poglitsch, Ing. Erwin Schumi, Ing. Dietmar Koller

2. Water supervision: Thomes Janach

3. Alpine Club Hermagor: Dr. Hermann Verderber

4. Farmers and Residents - affected by flood impacts

In the course of the interviews a broad knowledge about the Gail and its sediment budget could be gained.

In the survey of the employees of the Carinthian provincial government, well-founded expert knowledge was conveyed. A recurring change between bedload deficits and bedload surpluses at the Gail was noticed. The current situation at the Gail sections (Lesachtaler Gail, Upper Gail, Middle Gail and Lower Gail) can be summarized as follows on the basis of the survey: In the Lesach valley there is too little basic data to be able to make concrete statements about material relocation. However, it can be stated that a lot of debris as well as woody debris are transported during an extreme event. In the Upper Gail, apart from a bed load deposition site, erosion of the river bed occurs. The erosion processes are counteracted by already implemented and planned bed stabilization measures. At the Upper Gail temporary aggradation is noticeable due to local bed load impacts. In the section of the Middle Gail, the erosion processes of the Upper Gail valley are transformed into a landfill problem due to a flat gradient and the different types of abrasion-resistant rock ("soft" limestone of the Upper Gail and "hard" metamorphic rock of the Lesach valley). Here, for example, dredging is carried out as an immediate measure after a flood event. A Life-Project addressing river widening by using alternating banks, groynes and alternating gravel bars was also implemented. At the Lower Gail, in comparison to the upstream Gail sections, finer sediment is transported, which leads to channel narrowing in the discharge profile due to aggradation in the bank areas. In order to counteract the resulting accumulations, these sediments are removed. With regard to climate change, increasing intensities in precipitation and the resulting problems (e.g. at the transverse structures, embankments) are mentioned by the interviewed persons of the water management Hermagor. Changes in land use also effect the Gail area regarding hydraulic engineering, such as an acceleration of runoff due to clearing for the Nassfeld ski area and the lack of the protective function of the forest. From the survey it can be concluded that on the 
whole that sometimes even data on the transport of solids exist in the water management sector, but it cannot be adequately used as the following essentials should be clarified first: "Which parameters must be measured" or "What kind of data is essential" or "How can the data be combined". In this context, the interviewees also mention that not only offices provide sediment data, but that construction workers should be asked directly about, for example, bed load removal.

The interview with a person in charge of water supervision provided insight into ecological aspects of the Gail. Among other things, it was mentioned that problems have been caused by the beaver (dam construction and dam failure) for several years (e.g. Dellacherbach). The vegetation at the Gail does not lead to critical areas in the discharge profile. Sediment aggradations were observed by the employee in the area of Möderndorf - Nötsch. The employee also observed strong fluctuations of the groundwater level during the year (spring rising, summer falling, autumn rising) and noted that there are hardly noticeable differences to other years. With regard to land use changes, he stated that the growth of the ash tree (Fraxinus) is decreasing. A surprising and interesting detail was his observation that the transport of solids could be influenced by the moon phases.

In the course of the interview with a farmer it could be clearly determined that there is an awareness within the surrounding population for the Gail river and the associated challenges regarding flood- and sediment management. We had the chance to get information on historical observations and also gather more details about the 2018 flood event (e.g. ring dam Straning, only $30 \mathrm{~cm}$ freeboard due to material on the surface). The interviewee reported that the floods did not have such an high impact in the past and that the mud on the agricultural areas caused little damage. In 1965/66 he witnessed the first major flood. At that time a dam broke and the south side was flooded (mud meters high, no bed load). He reported that the fish population has not regenerated since that flood. It is also worth mentioning that he has appreciated the early warning system (including the fire department).

The interview with a representative of the Alpine Club Hermagor gave a good general overview on the Gail river as a living environment. The interviewee highlighted the recreational benefits of the Gail. Gravel islands would be used for recreation by bathers and rafters. In his opinion, climate change is noticeable in increasing precipitation events. Climate change can also be observed in the flora and fauna. For example, different animals (butterflies, spiders) from the south can be found in the Gailtal. The interviewee has observed a rise of the tree line and the appearance of flora from the Mediterranean area (hop beech, laburnum).

\subsection{Integration of numerical and physical model results with socio-economic indicators}

\subsubsection{Introduction}

Both nationally and internationally, the status of the hydromorphology of rivers is described as one of the decisive factors influencing the habitat quality of aquatic organisms. Particularly with regard to the objectives of the European Water Framework Directive (EU, WFD 2000), the river basin specific sediment budget has a decisive role, especially with regard to the 
sustainability of measures and remediation objectives. Negative impacts on the aquatic fauna due to changes in sediment production and transport in alpine catchments are often characterized by an imbalance between transport capacity and sediment availability at the river bed level with the consequence of river deepening up to bed break-through or paving of the river bed. Depending on the geomorphology, however, contrary medium to long-term developments can also occur in rivers (e.g. sediment surplus), which in turn challenges seminatural hydraulic engineering with regard to sustainable sediment management. In addition, there are still many (small) rivers in Austria without permanent bed load measuring sites, which often causes a lack of a deeper understanding of the sediment processes in these streams. For example, the Mühlviertel (Upper Austria) and Waldviertel (Lower Austria), located north of the Danube, show some river morphological characteristics and unique issues compared to alpine watercourses due to the geomorphological conditions. Therefore, in the following it will be shown how the sediment budget can be also determined.

Specific problems in relation with the sediment budget arise in these catchments due to the increased input of fines as bedrock weathering products of granite and gneiss (grain sizes from $1 \mathrm{~mm}$ to $10 \mathrm{~mm}$ ) from the tributaries into the larger watercourse systems. Although these grain size classes can technically be assigned to the coarse sand and fine gravel fractions, the problem of the so-called "silting" of rivers is mentioned here. Particularly in the transition zones from the highlands to the flood plains of the Danube, the decrease in gradient leads to strong accumulation tendencies ( $>50$ tons $\mathrm{a}^{-1}$ ). Due to the associated reduction in the discharge capacity of the watercourse (often in combination with the emergence and stabilization mechanisms of vegetation), there is an additional risk and damage potential in these areas in the event of flood events (lower discharge capacity and higher roughness), up to an immediate threat to the flood protection objective $\left(\mathrm{HQ}_{100}\right)$. In addition to the deposits in stretches relevant to the flood protection, hydromorphological habitat structures are also altered by the increased coarse sand and fine gravel input in near-natural stretches of water. In general, three river morphological types are dominant in the watercourses of the Mühlviertel and Waldviertel. Most of the rivers can be assigned to the so-called plane-bed type. However, in low-gradient areas with meandering river courses, there are also stretches of streams with a riffle-pool sequence and in the steep steps between the low-gradient areas sections of the so-called cascade type. Particularly in the riffle-pool and also in the plane-bed sections, "silting" sometimes leads to a significant change in the morphology of the watercourse leading to a transformation to a highmobile "dune-ripple" type. At present, the needed frequent removal of the deposited material to ensure the necessary flood channel is not sustainable from both an economic and ecological point of view.

6.2.2. Assessment of sediment input and identification of sensitive areas

For the determination of the sediment input and the transport capacity in the different sections of the river, hydrodynamic models are an appropriate approach to gain a better understanding of the processes in the catchment area.

The following data are used for processing:

- Digital Elevation Model (1 m grid (or smaller) 
- Survey data of the river channels

- Digitized geological maps

- Land use information (e.g. CORINE, digital Cadastre, GIS-InVeKoS dataset: agricultural land parcel)

- Hydromorphological mapping

- Hydrological data (e.g. discharge recordings, rainfall recordings)

- Grain size analyses (surface and sub-surface layer) in the longitudinal river course

Software Packages:

- GIS Software (ESRI ArcGIS)

- Hydrodynamic-model (HEC-RAS)

For the Aist catchment area, the necessary data and work procedures are described and discussed. The first step was to define the main catchment areas. Here, the Aist catchment area can be divided into three major sections: (i) Feldaist, (ii) Waldaist, and after the confluence of the two rivers (iii) Aist, which then flows into the Danube (Figure 97a). Using GIS software, the sub-catchment areas of the smaller tributaries and brooks were calculated (Figure 97b).

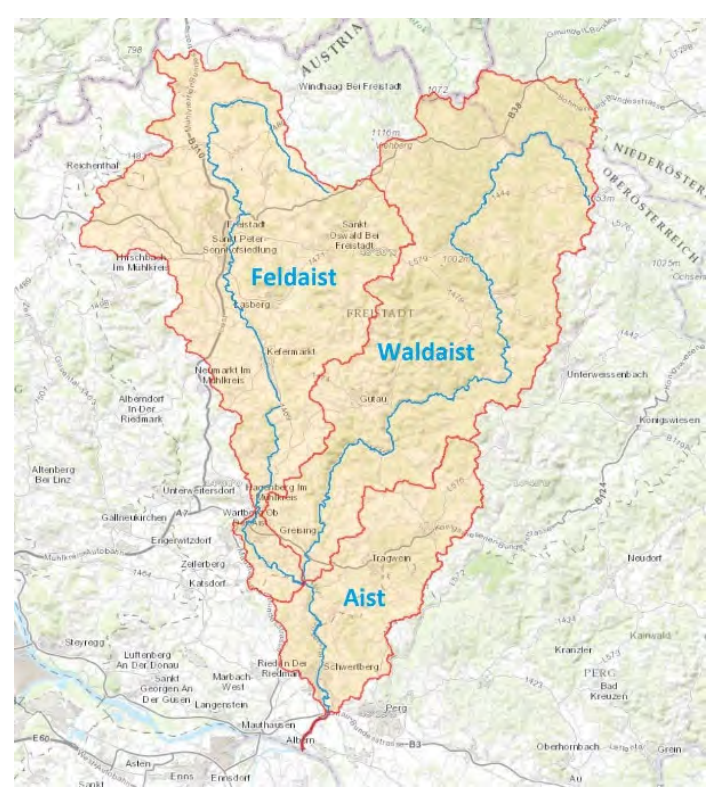

(a)

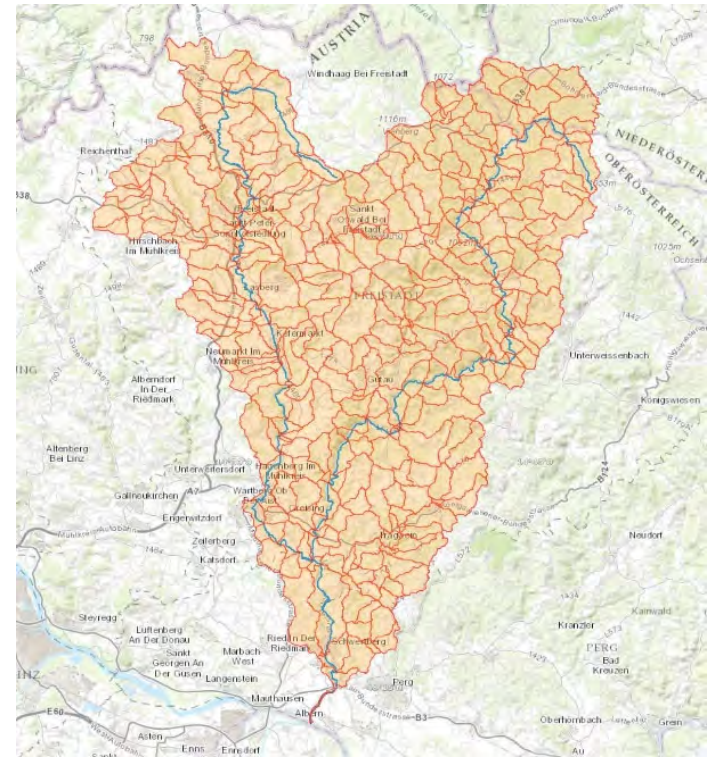

(b)

Figure 97 (a): Main catchment areas Feldaist, Waldaist and Aist and (b): the related sub-catchment areas of the tributaries.

The terrain model was then merged with the field-based terrestrial survey data (mostly total stations), because the infrared laserscan (LiDAR) data usually represent only the floodplain. The reason for this is that the infrared laser (which is used for this purpose) has only a small penetration depth in the water and therefore usually only records the water surface, but not the river bed. However, such requested detailed terrestrial survey data are usually missing for smaller tributaries. An analysis in these areas was therefore carefully evaluated and validated. The digital elevation model was also checked for plausibility. Therefore, the raw data (Figure 98a) was checked for holes (missing data values) and the hillshade (Figure 98b) is optically checked further. Afterwards the potential flow paths were determined. For this purpose, it was necessary to calculate the flow direction (Figure 98c) in the main compass direction for each 
grid cell. In this way slopes and valleys can be distinguished. Subsequently, the (main) flow paths (Figure 98d) were derived from this.

Initial evaluations were carried out on the basis of this data set. These included the classification of the bed gradient, catchment area variables and determination of essential hydraulic parameters (e.g. hydraulic radius, cross-sectional area of the river channel).

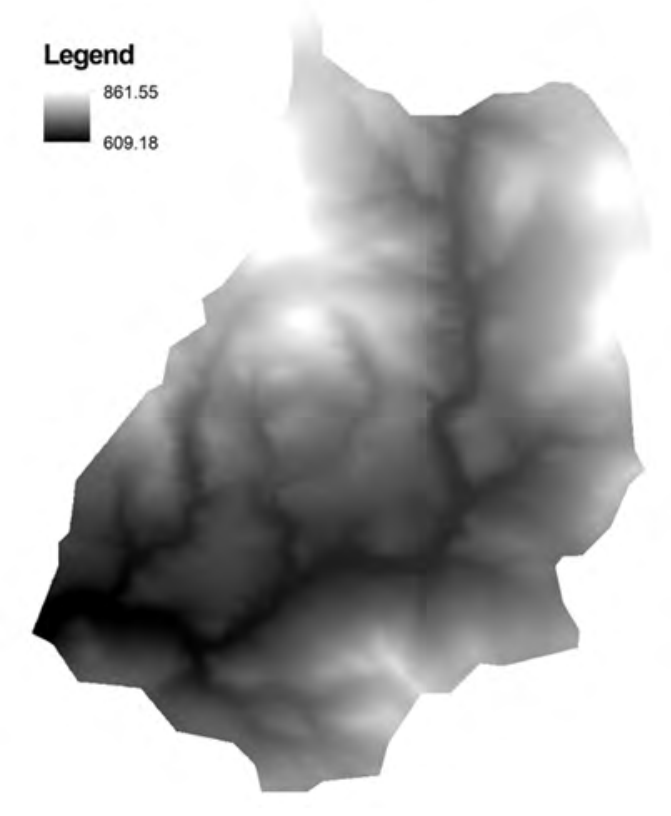

(a)

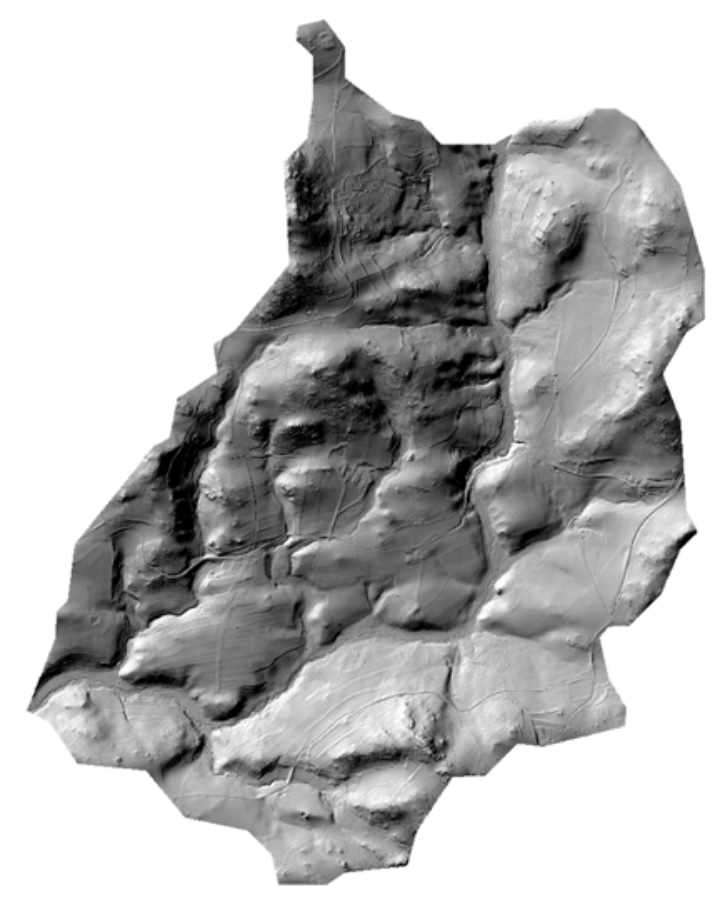

(b)
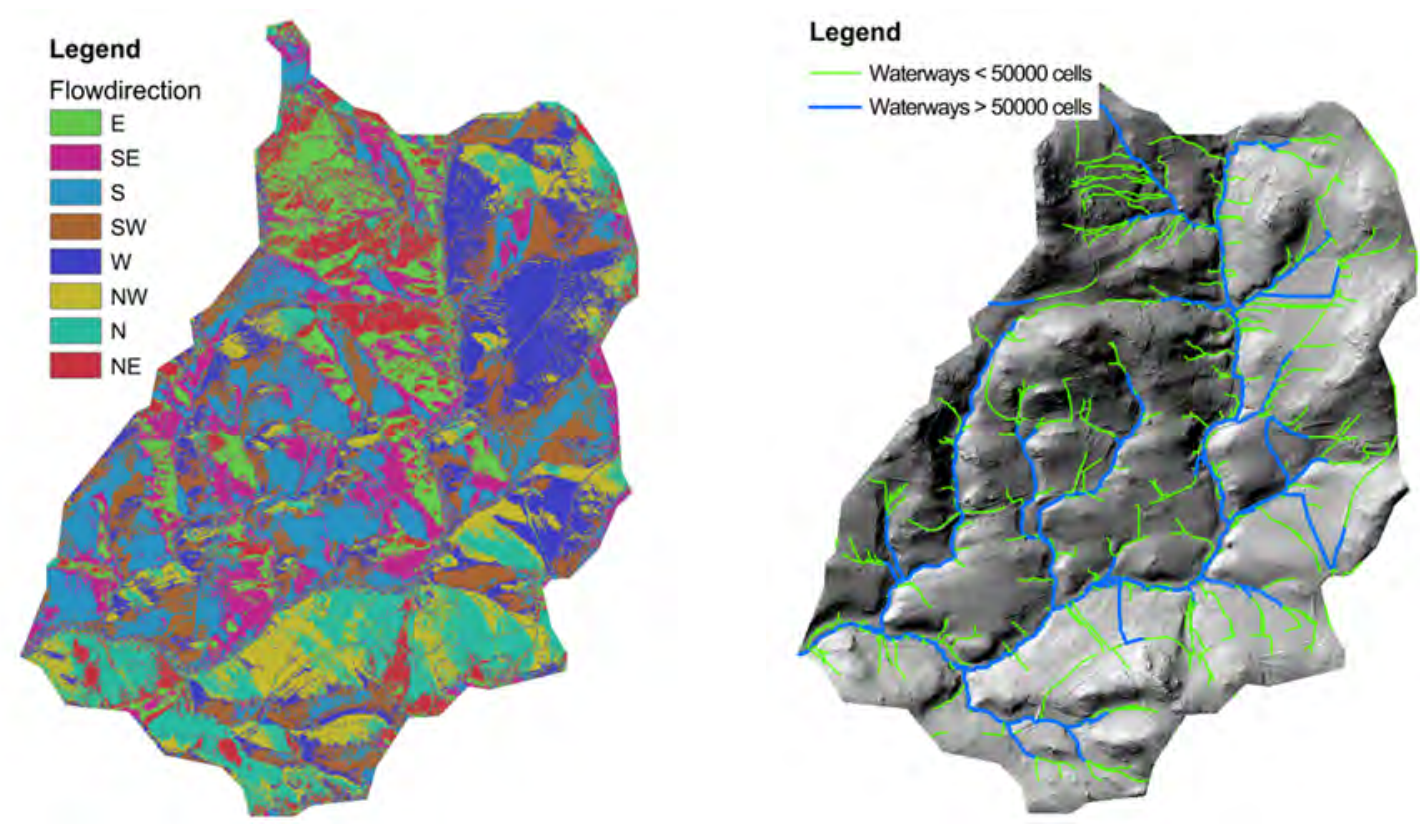

(c)

(d)

Figure 98 (a): Digital elevation model; (b) example of a hillshaded raster data for a sub-catchment; (c) flow direction of surface runoff; (d) derived center lines of the smaller tributaries. 
For hydraulic modelling, this prepared terrain model was further used and extended with additional information. The land use data (Figure 99a) were used for the allocation of certain boundary conditions (e.g. roughness allocation) and discharge areas (e.g. channel, no-flow zones in areas where buildings are located). For the further calculations of hydraulic parameters, certain discharge values were used: low flow, mean annual discharge and flood discharge (uncertainties concerning the quality of the DTM must be considered especially for the lower discharges). For this purpose, water level recordings in the catchment area are used or derived from precipitation data in the catchment area. In addition, the bank-full discharge for river sections of a certain length were defined and then used to calculate important hydraulic parameters for these stretches. This helps in particular to set flow velocities and bottom shear stresses in relation to other river sections and (sub-) catchment areas. As a result of this hydraulic modelling, those areas with increased flow velocities and bottom shear stresses can be shown where material is theoretically transported further or the banks and the river bed could be eroded. There are also those areas where low flow velocities occur (e.g. lowlands, sections with low river bed gradients, river widenings) and where material is more likely to be deposited. For the identification of potentially silting zones, the critical bottom shear stresses (those forces at which the measured grain sizes start to move) are compared to the calculated bottom shear stress.

The result is shown in Figure 99. Along the Feldaist and the Aist there are long stretches with an increased risk of silting up, whereas the risk on the Waldaist is only present in the upper reaches or in shorter sections along the longitudinal course downstream. By interpreting geological maps (Figure 99b), estimates of the potentially entered grain sizes can be concluded. These initial estimates were supplemented and verified by grain size analyses in the longitudinal course of the river. In addition, the results of the field mapping were used to validate those areas that were identified by the hydrodynamic model as silting risk stretches. This revealed a good agreement, allowing further socio-economic aspects (e.g. flood hazard) and ecological issues (e.g. habitat quality of specific aquatic life) to be investigated and discussed. 


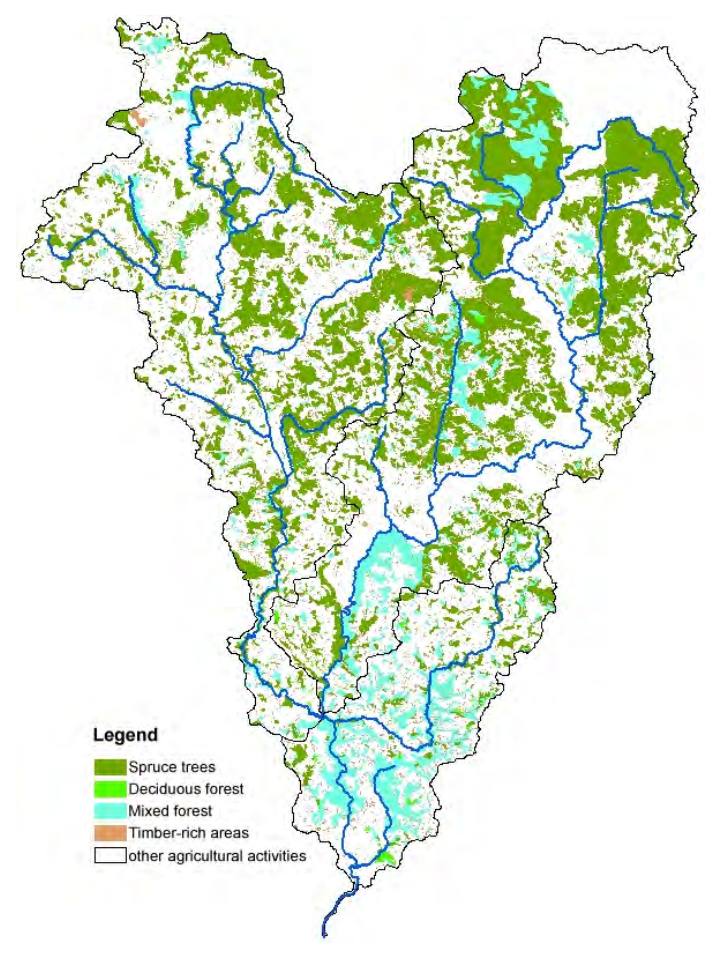

(a)

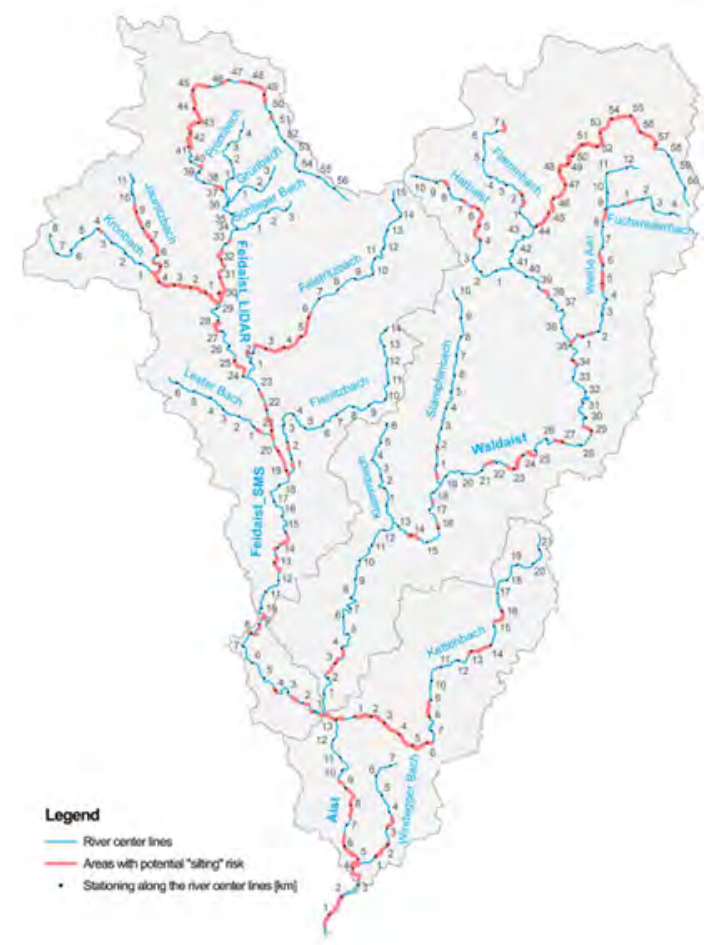

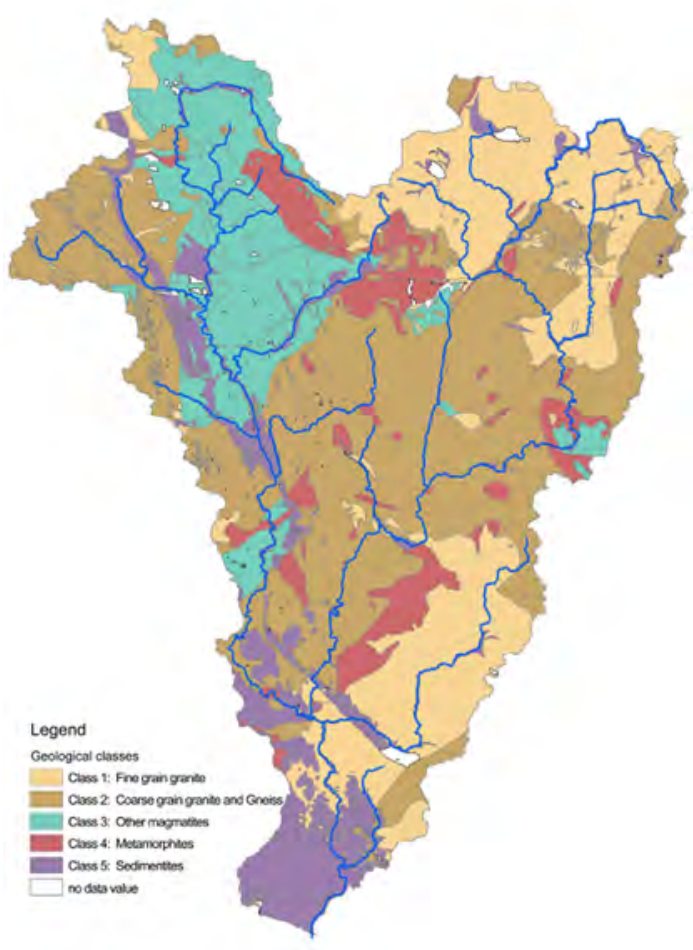

(b)

(c)

Figure 99: Presentation of (a) land use, (b) geology and (c) derived siltation risk areas. 


\subsubsection{Discussion}

This case study shows the effects of anthropogenic activities on the sediment budget in a catchment with increased sediment budget due to geologic preconditions and anthropogenic activities. Due to its geological conditions, the Waldaist has a higher potential for silting, but fewer risky areas due to the lower human impact. The area is mainly used for forestry and due to the steep slopes, it is not suitable for settlement or industry. On the other hand, the risk of silting up would be lower in the Feldaist, but land use is significantly different there. Along the Feldaist there is a higher population density and land use is also characterised by agriculture (arable farming, grassland). In addition, the sediment transport potential is usually reduced by channel widening and transverse structures as a result of flood protection measures. This is particularly evident in those river stretches where the (historically) dimensioning of the flood protection measures in urbanized areas is too small and the damage potential is particularly high due to the existing infrastructure.

Socio-economic issues could also be investigated. For example, the potential sediment input due to changes in land was estimated. For this purpose, historical records of settlement development were used to investigate the effects on the sediment budget of water bodies. The consequences of changes in the morphology of the water body (e.g. Constriction of the discharge cross section, longitudinal structures) have also a major impact on the flood protection, due to the under dimensioning of the implemented measures. In addition, initial findings on the habitat quality of aquatic organisms have been recorded. 


\subsubsection{Result dissemination}

As a dissemination strategy, the publication of the report was announced in addition to the publication activity in scientific journals. Furthermore, the key findings will be available beyond the project duration on the following homepage: https://boku.ac.at/wau/iwa/raise

This strategy was chosen to make the topic accessible to a broader public in the sense of a transdisciplinary approach

\section{Publications in scientific Journals:}

- Liedermann, M; Aigner, J; Kreisler, A; Klösch, M; Rindler, R; Gmeiner, P; Pessenlehner, S; Tritthart, M; Hauer C; Habersack, H. (2019): Forschung zu alpinen Sedimentprozessen als Basis für ein verbessertes Feststoffmanagement unter Berücksichtigung extremer Ereignisse Österreichische Wasser- und Abfallwirtschaft, 71, 148-159; ISSN 0945-358X

- Tritthart, M; Glock, K; Glas, M; Yücesan, S; Liedermann, M; Gmeiner, P; Hauer, C; Habersack, H. (2019): Erfahrungen in der numerischen Sedimenttransportmodellierung auf unterschiedlichen Skalen - von RANS bis LES Österreichische Wasser- und Abfallwirtschaft, 71, 170-178; ISSN 0945-358X.

- Aigner, J; Kreisler, A; Rindler, R; Hauer, C; Habersack, H. (2017): Bedload pulses in a hydropower affected alpine gravel bed river GEOMORPHOLOGY. 2017; 291: 116-127

- Kreisler, A; Moser, M; Aigner, J; Rindler, R; Tritthart, M; Habersack, H. (2017): Analysis and classification of bedload transport events with variable process characteristics GEOMORPHOLOGY. 2017; 291: 57-68.

- Liedermann, M; Gmeiner, P; Kreisler, A; Tritthart, M; Habersack, H. (2018): Insights into bedload transport processes of a large regulated gravel-bed river EARTH SURF PROC LAND. 2018; 43(2): 514-523.

- Klosch, M; Habersack, H. (2018): Deriving formulas for an unsteady virtual velocity of bedload tracers EARTH SURF PROC LAND. 2018; 43(7): 1529-1541.

- Rascher, E; Rindler, R; Habersack, H; Sass, O. (2018): Impacts of gravel mining and renaturation measures on the sediment flux and budget in an alpine catchment (Johnsbach Valley, Austria) GEOMORPHOLOGY. 2018; 318: 404-420.

- Glock, K; Tritthart, M; Habersack, H; Hauer, C. (2019): Comparison of Hydrodynamics Simulated by 1D, 2D and 3D Models Focusing on Bed Shear Stresses. WATER-SUI. 2019; 11(2), 226

- Lalk, P; Haimann, M; Aigner, J; Gmeiner, P; Habersack, H. (2019): Monitoring des Sedimenttransports in der Hydrographie Österreichs. Österreichische Wasser- und Abfallwirtschaft, 71, 43-50; ISSN 0945-358X

- Schobesberger, J; Lichtneger, P; Hauer, C; Habersack, H; Sindelar, C. (2020): ThreeDimensional Coherent Flow Structures during Incipient Particle Motion. J HYDRAUL ENG. 2020; 146(5), DOI: 10.1061/(ASCE)HY.1943-7900.0001717

- Sindelar, C., Gold, T., Reiterer, K., Hauer, C., Habersack, H. (2020). Delta formation at the reservoir head of run-of-river hydropower plants in gravel bed rivers; Processes influencing sediment connectivity and practical implementation into sediment management. WATER-SUI. 2020; DOI: 10.3390/w12072035 


\section{Proceedings:}

- Liedermann, M; Rindler, R; Aigner, J; Kreisler, A; Glock, K; Pessenlehner, S; Klösch, M; Habersack, H. (2019): Research on alpine sediment processes, morphodynamics and ecosystem behaviour considering extreme events. In: International Association for HydroEnvironment Engineering and Research -IAHR (Ed.), IAHR World Congress Proceedings, 422432; DOI 10.3850/38WC092019-1637

- Glock, K; Tritthart, M; Rindler, R; Liedermann, M; Habersack, H;. (2017): Analysis of bedload transport processes during flood events based on numerical simulations. In: International Society for River Science (Ed.), INTEGRATING MULTIPLE AQUATIC VALUES

- Glock, K; Tritthart, M; Rindler, R; Liedermann, M; Habersack, H;. (2018): Numerical investigation of bedload transport processes during flood events at the Drava River. In: Aronne Armanini (Ed.) and Elena Nucci (Ed.), Proceedings of the 5th IAHR EUROPE CONGRESS New Challenges in Hydraulic Research and Engineering; ISBN: 978-981-11-2731-1

- Schobesberger, J; Lichtneger, P; Worf, D; Hauer, C; Habersack, H; Sindelar, C. (2019): COHERENT STRUCTURES DURING PARTICLE ENTRAINMENT. In: International Association for Hydro-Environment Engineering and Research -IAHR (Ed.), IAHR World Congress Proceedings, 5910-5918; doi:10.3850/38WC092019-0758; ISBN: 2521-716X

\section{Master Theses, Dissertations:}

- Tobias Aschbacher (2018): Analyse des Geschiebetransports an der Rofenache Rofenache in Vent, Tirol.

- Florian Derntl (2018): Untersuchung der zeitlichen Variabilität von Geschiebetransportprozessen an der Urslau

- Dorian Shire-Peterlechner (2020): Pre-study for a large-scale RFID tracer sediment transport process investigation at the Urslau Stream. pp 113

- Sabrina Schwarz (2019): Massenbilanzierung im Bereich des integrativen Geschiebemesssystems Drava-Isel. pp 124.

- Kurt Glock (2019): Planning and evaluation of river engineering measures based on numerical simulations of hydrodynamics, sediment transport and ecology. Dissertation. pp 132. 


\section{List of Tables}

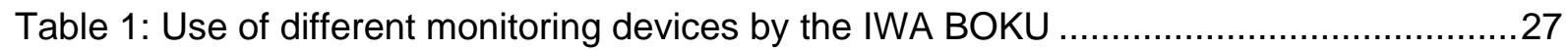

Table 2: Correction Factor of the basket samplers ...................................................... 30

Table 3: Comparison of discharge $\mathrm{Q}$, mean suspended sediment concentration $\mathrm{S}_{\mathrm{m}}$ and suspended sediment transport $\mathrm{Q}_{\mathrm{s}}$

Table 4: Calibration (C) and Validation (V) of the sediment transport model by comparing measured (mea) and modelled (mod) bedload transport (BLT) at the Drava river .75 Table 5: Simulation setups for bedload transport modelling of a characteristic flood event in June 2016. .75

Table 6: Calibration (C) and Validation (V) of the sediment transport model by comparing measured (mea) and modelled (mod) bedload transport (BLT) at the Rofenache .77 Table 7: Grain size classes of the 1:20 scale experiments and corresponding grain size classes at 1:1, initial mass fraction (\%) and non-uniformity parameters ${ }^{1} U$ and $\sigma$. .86 Table 8: Transport rates, ratio of fed sediment (input) vs transported sediment (output), bed and water surface slopes at dynamic equilibrium for the investigated flow rates. "n.d." = not determined. .90

Table 9: Calculated and measured total sediment load $\left(\mathrm{kg} \times 10^{3}\right)$ for a representative $0.7 \times$ HQ1 flood event in 1:1 dimension.

Table 10: Delta formation test runs D1-D3: Transport rates, ratio of fed sediment (input) vs transported sediment (output), transported fractions of the yellow $(0.7-1.2 \mathrm{~mm})$ and red $(1.2$ $-2 \mathrm{~mm}$ ) grain size class after 8 hours. .92

Table 11: Calculated and measured transport rates in $(\mathrm{kg} / \mathrm{hm})$ of sections which are located at the downstream end of the experimental section. .93 


\section{List of Figures}

Figure 1: Sediment related process, influences and triggering factors within a river catchment.

Figure 2: Two steps of hydromorphological evaluation: 1. Catchment evaluation assessing sediment connectivity along the entire river network as basis for all evaluations along the river network, 2. Reach evaluation with displayed assessment of artificiality (contact with artificial channel constraints at four elevations).

Figure 3: River network of the Upper Drava with disrupted connectivity to catchments given the three major hydropower plants, with indicated location of the evaluated, restored reach (Klösch and Habersack, 2017).

Figure 4: Sediment connectivity after construction of the second major hydropower plant and before the construction of the third major hydropower plant.

Figure 5: Sediment connectivity after construction of the second major hydropower plant and before the construction of the third major hydropower plant.

Figure 6: Artificiality along the low flow water edge, vegetation threshold and bank edge, already including buffer lengths to account for the larger-scale effect of bank protections as

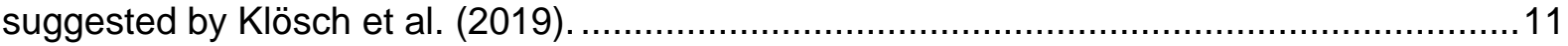

Figure 7: Suspended sediment measuring sites in Austria .......................................... 13

Figure 8: Bedload transport measuring sites in Austria operated by the BOKU Vienna ........14

Figure 9: Characteristics of bedload monitoring sites

Figure 10: Plan view Hainburg Strassenbrücke / Donau - November 2014 - flow direction from

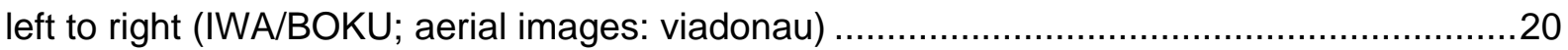

Figure 11: US-P63 (left) and US-P61 A1 point-integrating samplers (right) (IWA/BOKU) .....22

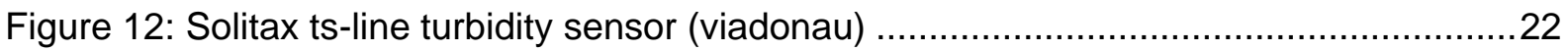

Figure 13: The trailer on the bridge with the sediment sampler and the ADV on cable (IWA/BOKU)

Figure 14: Geophone device: a) geophone device installed at Drava river, b) geophone device and c) steel plate with mounted sensor.

Figure 15: Bedload trap: a) sketch of bedlaod trap (Kreisler et al., 2017); b) Bedload trap installed at Urslau stream; c) bedload sample; d: maintenance work at Drava river......

Figure 16: Large Helley-Smith sampler: mounted in the research flume (left), sketch after DVWK (Deutscher Verband für Wasserwirtschaft und Kulturbau 1992) (right)

Figure 17: Vent sampler: in research channel (left), sketch by IWA (right)

Figure 18: BfG sampler: in research flume (left), sketch after DVWK (Deutscher Verband für Wasserwirtschaft und Kulturbau 1992) (right)

Figure 19: Flume test setup of the BfG Sampler: ADV yellow box, BfG Sampler green box and

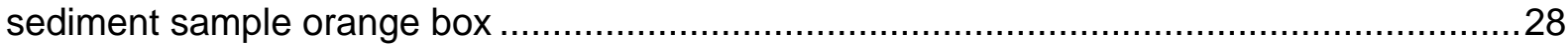

Figure 20: Flow velocities of the zero state and at the basket sampler inlet ........................28

Figure 21: Hydraulic Efficiency - Basket Sampler to Zero State .......................................29

Figure 22: Sampling efficiency of different grain sizes classes ......................................29

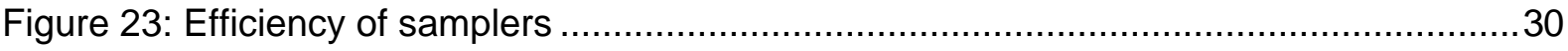

Figure 24: Multi-point measurement 23.05.2019 (Q = 4,720 m3/s) .................................32 
Figure 25: Relationship between suspended sediment concentration close to the sensor and mean suspended concentration at the monitoring site Hainburg Road Bridge/Danube.

Figure 26: example of the bedload measurement at the Danube on the 263.05.2019. a) bed load texture, b) transport rates in each vertical (including bed load transport - shaded area middle panel), c) measurement cross section (IWA/BOKU) ............................................33

Figure 27: Measurement Bedload Trap Urslau River 06.04.2019 ....................................34

Figure 28: Relation of bedload transport rate $D>22.4 \mathrm{~mm}$ and geophon impulses 2012-2019 Urslau stream

Figure 29: Comparison of the rating curve and integrated approach for two different monitoring periods; (a) water discharge between 97 and $132 \mathrm{~m}^{3} \mathrm{~s}^{-1}$ on June 3, 2012 and (b) water discharge between 172 and $303 \mathrm{~m}^{3} \mathrm{~s}^{-1}$ on June 23, 2012. (Habersack et al. 2017) .............36 Figure 30: Comparison of mean sediment load and catchment area ..................................37 Figure 31: specific annual yield of runoff, specific suspended load and bedload $(>22.4) \ldots . .38$

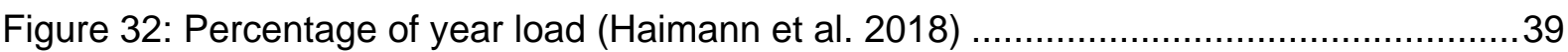
Figure 33: Development of a profile at the Gail river in the time between 2016 and $2018 \ldots . .40$

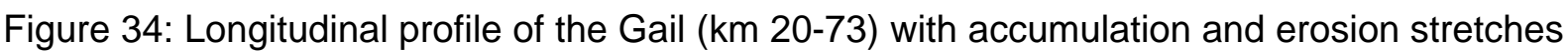

Figure 35: Accumulation of sediments in the river stretch km 20-73 in the time of Jul 2016- Nov 2018

Figure 36: schematic overview of the estimated sediment yield balance of the flood event $\left(27^{\text {th }}\right.$ to $30^{\text {th }}$ October) 2018 at the Gail river ..... .42

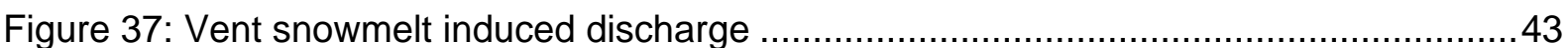

Figure 38 a: sum line discharge Vernagtbach, b: minimum and maximum temperature .......44 Figure 39 a: Photo 24.05.2018; b: Photo 8.06.2018 (http://www.glaziologie.badw.de).........44

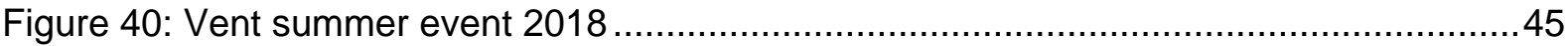

Figure 41: Vent summer event 2018 bedload peak in detail .............................................45

Figure 42 a: Photo 31.07.2018, b: Photo 08.08.2018 http://www.glaziologie.badw.de .........46

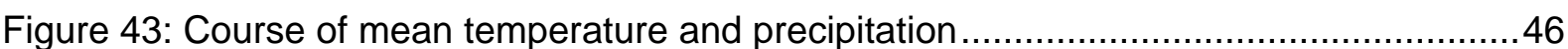

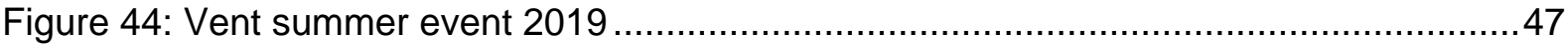

Figure 45 a: "muddy" Rofenache, in the background, the Hintereisferner is seen; b: sedimentary input into the Rofenache; c Mudflow in the area of the glacier snout ...............47

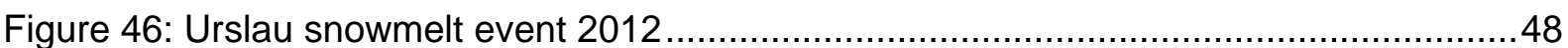

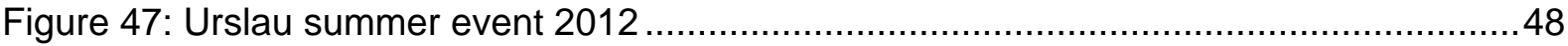

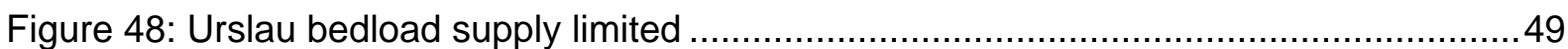

Figure 49: Sketch map of the Upper Drava River encompassing the hydrological system (Aigner et al, 2017)

Figure 50: Falkensteinsteg (Drava/Lienz) snowmelt induced discharge 2018 (suspended load discharge raw data).

Figure 51: Falkensteinsteg (Drava/Lienz) fall event 2018 (shortly after bedload peak the data was reconstructed (see chapter 3.7.2.)....

Figure 52: Annual hydrograph flow/geophone pulses (daily mean values), Falkensteinsteinsteg/Drava, 2018 to 2019

Figure 53: Isel/Lienz snowmelt induced discharge 2018 
Figure 54: 15 Isel/Lienz fall event 2018

Figure 55: Scatterplot of discharge and bedload transport during the flood event 2018 showing a distinct clockwise hysteresis effect. 52

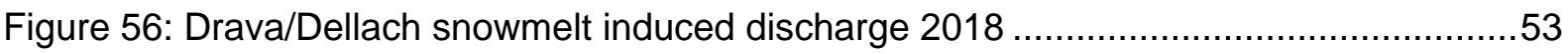

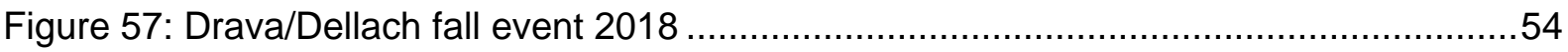

Figure 58: Flooded area in the area of the Dellach/Drava monitoring station ......................54

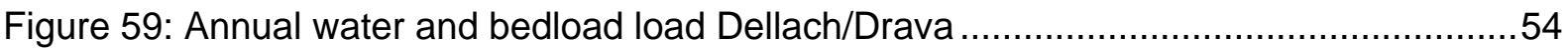

Figure 60: Cross-section distribution a) snowmelt period; b) flood event................................55

Figure 61: Spatial distribution of geophones 29.10/30.10.2018 (15min mean values) ..........55

Figure 62: Time series of water discharge (monitoring station Falkensteinsteg and Residual reach) and geophone impulses between 23.5.2011 and 6.6.2011 show the occurrence of bedload pulses triggered by a small flood event. Note the time lag $\Delta T$ between the flood peak and the arrival of the bedload pulse at the monitoring station.

Figure 63: Scatterplot of the time lag until the arrival of the bedload pulses and the mean discharge during pulse propagation. Dashed line represents the best fit using a power function. (modified from Aigner et al, 2017). .58

Figure 64: Massive bedload input from the Galitzenklamm (30.10.2018) ........................59

Figure 65: Lateral depositions downstream of the bedload measuring station (15.11.2018).59 Figure 66: hydrograph and geophone impulses of the $\mathrm{HQ}_{30}$ flood event. Deposition of bedload material during the flood event. Total material cover over the geophone plates until the 12.11.2018 .59

Figure 67: discharge geophone impulse relation at geophone 8. Dataset 2001-2018. Colorized data points are mean values per discharge class for the quantile 50\%, 95\% and $99 \%$. The colorized lines represent the power function at the critical discharge $\left(I=a^{\star}\left(Q_{-}-Q_{c}\right)^{\wedge} b\right)$

Figure 68: hydrograph and geophone impulses after data correction using the power function using the $99 \%$ quantile.

Figure 69: Bedload transport events at the Urslau stream: a)31.03.2016-04.04.2016, b)21.06.2012-01.7.2012;

Figure 70: Bedload transport rate/discharge relationship for different transport events........63 Figure 71: Conceptual model of bedload transport process types as a function of bedload transport efficiency and dimensionless stream power (simplified from Kreisler et al, 2017). .64 Figure 72: Bedload input Gailbergbach. .64

Figure 73: Flow and geophone pulses in the period from 01.11.2014 - 01.06.2015 ...........65

Figure 74: Flow and geophone pulses in the period from 30.04.2015-01.06.2015 .65

Figure 75: Scatterplot of flow and geophone pulses in the period from 20.5.2018-30.5.2018

Figure 76: Arrival of the different grain diameters at the Dellach/Drava site.....

Figure 77: overview of the measurement station in the integrative sediment monitoring system

Drava-Isel.....

Figure 78: selection of the five relevant tributaries. 69

Figure 79: Results of the sediment balancing of the Upper Drava..... .70

Figure 80: Calculated changes in bed level elevation within a groyne field as a result of a modelled flood event..... 
Figure 81: Comparison between derived fish - suitability based on steady-state hydrodynamic modelling and results based on unsteady hydrodynamic modelling including sediment transport (considered by Ised).....

Figure 82: Comparison between modelled weighted usable area (WUA) based on steady-state hydrodynamic modelling and WUA based on unsteady hydrodynamic modelling including

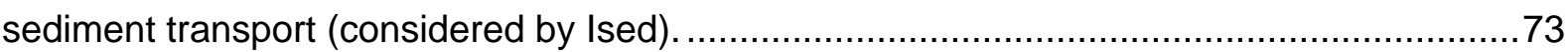

Figure 83: Overview of investigation areas

Figure 84: Comparison between monitoring and simulation results during a flood event in June 2016 at the Drava River .76

Figure 85: Rating curve approach at the Rofenache including simulation results based on Meyer-Peter and Müller (1948) and Wu et al. (2000).

Figure 86: The role of sediments in the aquatic environment ranging according to various river types; - from habitat forming to bar formation; (a) Classification of morphological types according to Montgomery and Buffington (1997); (b) Hydraulic influence and contribution to habitat formation for the various Montgomery and Buffington (1997) types ranging from "Cascade" to Dune ripple types; (c) habitat modelling results for fluvial alpine rivers Upper Ybbs river and Pielach river underlining the role of sediments in habitat formation.

Figure 87: a) Semi-fluvial stretch of the Urslau river (downstream view); (b) fluvial stretch of the Urslau river (upstream view); (c) results of the variability in d90 according to the modified Wolman - count by Hauer \& Pulg (2018) underlining the different characteristics and impacts on local hydraulic patterns for the two different stretches. .81

Figure 88: Experimental setup (modified after Schobesberger et al. 2020) .83 Figure 89: Quadrants Q II and Q IV plotted as light grey and dark grey lines in relation to the turbulent kinetic energy TKE based on the first five modes plotted as dotted line in the investigation volume over the measurement period. Particle Entrainment (te) is marked with a vertical dashed line. The axis related to quadrants describes the proportion of ejections Q II and sweeps Q IV in the investigation volume, where 1 correspond to 100 percent. (modified after Schobesberger et al. 2020).

Figure 90: Coherent structures of test 6S (a) and 8S (b). For a better visibility the 3D-abritary view of two observed structures with the flow direction from right to left (modified after Schobesberger et al. 2020)

Figure 91: Experimental setup, (a) plan view; (b) longitudinal section of the straight flume. DEM = digital elevation model, IP = image processing, US = ultrasonic probe (Sindelar et al., 2020).

Figure 92 (a): Compound orthophoto of the bed surface material of the experimental section. The arrow indicates the flow direction. The red square indicates the location of the $0.12 \times 0.12$ $\mathrm{m}$ section detail; (b) red square detail of the orthophoto; (c) red square detail of the processed orthophoto which is reduced to five different colors only, each pixel belongs only one-color class; (d) grain size distribution of the red square detail (Sindelar et al., 2020).

Figure 93: Section of a RoR with a free-flowing section not affected by the backwater effect from the RoR (Sec 1), the head of the reservoir ( $\operatorname{Sec} 2)$ and the RoR with a concrete weir and a radial gate with an installed flap as spillway (Sec 3) (Sindelar et al., 2020). 
Figure 94: Bed and water surface profiles for test run D2 at the head of the reservoir at a flow rate of $0.7 \times \mathrm{HQ1}$ during turbine operation. The grey line represents the water surface profile of the free-flowing section which corresponds to the bed levels at hour 0 (black line). The head of the reservoir is located at $X=1.5 \mathrm{~m}$. Different areas of the delta formation, namely "delta front", "delta top" and "delta tail", are indicated. WSL = water surface levels, BSL = bed surface levels, BWC = calculated backwater curve (Sindelar et al., 2020).

Figure 95: Bed and water surface profiles for D3 at the head of the reservoir at a flow rate of $0.7 \times \mathrm{HQ1}$ during turbine operation. The profiles were measured every two hours. The grey line represents the water surface profile of the free-flowing section which corresponds to the bed levels at hour 0 (black line). The head of the reservoir is located at $X=4.0$. BWC $=$ calculated backwater curve (Sindelar et al, 2020).

Figure 96: Sediment transport rates flow rates ranging from $0.5 \times \mathrm{HQ}_{1}-0.9 \times \mathrm{HQ}_{1}$ : Calculated sediment transport rates according to models of MPM, SJ, WC and WU. Measured transport rates of present study (black line) and of a previous study under similar conditions (red diamond) (Sindelar et al, 2020) .90

Figure 97 (a): Main catchment areas Feldaist, Waldaist and Aist and (b): the related subcatchment areas of the tributaries. 102

Figure 98 (a): Digital elevation model; (b) example of a hillshaded raster data for a subcatchment; (c) flow direction of surface runoff; (d) derived center lines of the smaller tributaries.

Figure 99: Presentation of (a) land use, (b) geology and (c) derived siltation risk areas. ....105 


\section{Bibliography}

Adrian, R. J. (2007): Hairpin vortex organization in wall turbulence. In Physics of Fluids 19 (4), p. 41301. DOI: 10.1063/1.2717527.

Adrian, R. J.; MEINHART, C. D.; TOMKINS, C. D. (2000): Vortex organization in the outer region of the turbulent boundary layer. In J. Fluid Mech. 422, pp. 1-54.

Aigner, J.; Kreisler, A.; Rindler, R.; Hauer, C.; Habersack, H. (2017): Bedload pulses in a hydropower affected alpine gravel bed river. In Geomorphology 291, pp. 116-127. DOI: 10.1016/j.geomorph.2016.05.015.

Beisel, J. N.; Usseglio-Polatera, P.; Moreteau, J. C. (2000): The spatial heterogeneity of a river bottom: a key factor determining macroinvertebrate communities. In Hydrobiologia 422/423, pp. 163-171. DOI: 10.1023/A:1017094606335.

BMLFUW (2017): Schwebstoffe im Fließ-Gewässer; Leitfaden zur Erfassung des Schwebstofftransportes. Available online at https://www.bmlrt.gv.at/.

Brown, R. A.; Pasternack, G. B. (2008): Engineered channel controls limiting spawning habitat rehabilitation success on regulated gravel-bed rivers. In Geomorphology 97 (3-4), pp.631-654. DOI: 10.1016/j.geomorph.2007.09.012.

Buffington, J. M.; Montgomery, D. R.; Greenberg, H. M. (2004): Basin-scale availability of salmonid spawning gravel as influenced by channel type and hydraulic roughness in mountain catchments. In Can. J. Fish. Aquat. Sci. 61 (11), pp. 2085-2096. DOI: 10.1139/f04-141.

Bunte, K.; Abt, Steven, R.; Potyondy, J. P.; Ryan, S. E. (2004): Measurement of Coarse Gravel and Cobble Transport Using Portable Bedload Traps. In J. Hydraul. Eng. 130 (9), pp. 879-893. DOI: 10.1061/(ASCE)0733-9429(2004)130:9(879).

Deutscher Verband für Wasserwirtschaft und Kulturbau (1992): Geschiebemessungen. DK 551.51/.54 Fliessgewässer, DK 556.535.6 Geschiebefracht. Hamburg: Parey (DVWK-Regeln zur Wasserwirtschaft, 127).

DeVries, P. (2008): Bed disturbance processes and the physical mechanisms of scour in salmonid spawning habitat. Vol. 65. American Fisheries Society Symposium, 2008.

Dudgeon, D.; Arthington, A. H.; Gessner, M. O.; Kawabata, Z. I.; Knowler, D. J.; Lévêque, C. et al. (2006): Freshwater biodiversity: importance, threats, status and conservation challenges. In Biological reviews of the Cambridge Philosophical Society 81 (2), pp. 163-182. DOI: 10.1017/S1464793105006950.

EU, WFD (2000): Water Framework Directive 2000/60/EC, revised L327. In Official Journal of the European Communities.

Fehr, R. (1987): Einfache Bestimmung der Korngrössenverteilung von Geschiebematerial mit Hilfe der Linienzahlanalyse. DOI: 10.5169/seals-76710.

Glock, K.; Tritthart, M.; Rindler, R.; Liedermann, M.; and Habersack, H. (2018): Numerical investigation of bedload transport processes during flood events at the Drau River. 5th IAHR Europe Congress New Challenges in Hydraulic Research and Engineering. Trento, Italy, 2018.

Glock, K.; Tritthart, M.; Rindler, R.; Liedermann, M.; Dörler, S.; and Habersack, H. (2017): Analysis of bedload transport processes during flood events based on numerical simulations. The 5 th Biennial Symposium of the International Society for River Science Integrating Multiple Aquatic Values. Hamilton, New Zealand, 2017.

Gmeiner, P.; Liedermann, M.; Haimann, M.; Tritthart, M.; Habersack, H. (2016): Grundlegende Prozesse betreffend Hydraulik, Sedimenttransport und Flussmorphologie an der Donau. In Österr Wasser- und Abfallw 68 (56), pp. 208-216. DOI: 10.1007/s00506-016-0308-5. 
Habersack, H.; Blamauer, B.; Villwock, H.; Prenner, D.; Hauer, C. (2014): SED_AT - Feststoffhaushalt, Sedimenttransport und Flussmorphologie im Rahmen des Nationalen Gewässerbewirtschaftungsplans. In Österr Wasser- und Abfallw 66 (9-10), pp. 327-339. DOI: 10.1007/s00506-014-0176-9.

Habersack, H.; Kreisler, A.; Rindler, R.; Aigner, J.; Seitz, H.; Liedermann, M.; Laronne, J. B. (2017): Integrated automatic and continuous bedload monitoring in gravel bed rivers. In Geomorphology 291, pp. 80-93. DOI: 10.1016/j.geomorph.2016.10.020.

Habersack, H.; Nachtnebel, H. P. (1995): Short-term effects of local river restoration on morphology, flow field, substrate and biota. In Regul. Rivers: Res. Mgmt. 10 (2-4), pp. 291-301. DOI: 10.1002/rrr.3450100222.

Habersack, H.; Piégay, H. (2007): 27 River restoration in the Alps and their surroundings: past experience and future challenges. In : Gravel-Bed Rivers VI: From Process Understanding to River Restoration, vol. 11: Elsevier (Developments in Earth Surface Processes), pp. 703-735.

Haimann, M.; Aigner, J.; Gmeiner, P.; Lalk, P.; Habersack, H. (2018): Hochwasser und Feststoffe: vom Sedimenttransport zum flussmorphologischen Raumbedarf. In Österr Wasser- und Abfallw 70 (1-2), pp. 78-89. DOI: 10.1007/s00506-017-0450-8.

Hauer, C. (2015): Review of hydro-morphological management criteria on a river basin scale for preservation and restoration of freshwater pearl mussel habitats. In Limnologica 50, pp.40-53. DOI: 10.1016/j.limno.2014.11.002.

Hauer, C.; Blamauer, B.; Mühlmann, H.; Habersack, H. (2014): Morphodynamische Aspekte der Ökohydraulik und Habitatmodellierung im Kontext der rechtlichen Rahmenbedingungen. In Österr Wasser- und Abfallw 66 (5-6), pp. 169-178. DOI: 10.1007/s00506-014-0151-5.

Hauer, C.; Pulg, U. (2018): The non-fluvial nature of Western Norwegian rivers and the implications for channel patterns and sediment composition. In CATENA 171, pp. 83-98. DOI: 10.1016/j.catena.2018.06.025.

Hauer, C.; Pulg, U. (2020): Buried and forgotten-The non-fluvial characteristics of postglacial rivers. In River Res. Applic. 86, p. 743. DOI: 10.1002/rra.3596.

Hillebrand, G.; Frings, R. M. (2017): Von der Quelle zur Mündung. Die Sedimentbilanz des Rheins im Zeitraum 1991-2010. Utrecht: Sekretariat KHR (Bericht Nr. II der KHR 2, Report No II of the CHR = Berichte unter der Schirmherrschaft der KHR, 22).

Holmes, D. (1996): Computerized method for decomposing a geometric model of surface or volume into finite elements on 3/5/1996. App. no. 5,497,451.

Kammerlander, J.; Achleitner, S.; Schöber, J.; Hofer, B. (2017): Geschiebehaushalt in kleinen Hochgebirgsbächen der Nordtiroler Zentralalpen. In Österr Wasser- und Abfallw 69 (3-4), pp. 114-124. DOI: 10.1007/s00506017-0378-z.

Klösch, M.; Habersack, H. (2017): The Hydromorphological Evaluation Tool (HYMET). In Geomorphology 291, pp. 143-158. DOI: 10.1016/j.geomorph.2016.06.005.

Klösch, M.; Habersack, H. (2018): Deriving formulas for an unsteady virtual velocity of bedload tracers. In Earth Surf. Process. Landforms 43 (7), pp. 1529-1541. DOI: 10.1002/esp.4326.

Klösch, M.; Hornich, r.; Baumann, N.; Puchner, G.; Habersack, H. (2011): Mitigating Channel Incision via Sediment Input and Self-Initiated Riverbank Erosion at the Mur River, Austria. Scientific Approaches, Analyses, and Tools 194, pp. 319-336. Available online at http://gbv.eblib.com/patron/FullRecord.aspx?p=1187855.

Knoblauch, H. (2006): Sustainable Sediment Management in Alpine Reservoirs considering ecological and economical aspects. In Alpreserv report.

Kreisler, A.; Moser, M.; Aigner, J.; Rindler, R.; Tritthart, M.; Habersack, H. (2017): Analysis and classification of bedload transport events with variable process characteristics. In Geomorphology 291, pp. 57-68. DOI: 10.1016/j.geomorph.2016.06.033. 
Lalk, P.; Haimann, M.; Aigner, J.; Gmeiner, P.; Habersack, H. (2019): Monitoring des Sedimenttransports in der Hydrographie Österreichs. In Österr Wasser- und Abfallw 71 (1-2), pp. 43-50. DOI: 10.1007/s00506-0180538-9.

Leopold, L. B.; Wolman, M. G.; Miller, J.P (1964): Fluvial processes in geomorphology. CA, 522 pp.

Liedermann, M.; Gmeiner, P.; Kreisler, A.; Tritthart, M.; Habersack, H. (2018): Insights into bedload transport processes of a large regulated gravel-bed river. In Earth Surf. Process. Landforms 43 (2), pp. 514-523. DOI: $10.1002 /$ esp.4253.

Lisle, T. E. (1989): Sediment transport and resulting deposition in spawning gravels, north coastal California. In Water Resour. Res. 25 (6), pp. 1303-1319. DOI: 10.1029/wr025i006p01303.

Lu, S. S.; Willmarth, W. W. (1973): Measurements of the structure of the Reynolds stress in a turbulent boundary layer. In J. Fluid Mech. 60 (03), p. 481. DOI: 10.1017/S0022112073000315.

Maddock, I. (1999): The importance of physical habitat assessment for evaluating river health. In Freshwater Biol 41 (2), pp. 373-391. DOI: 10.1046/j.1365-2427.1999.00437.x.

Marchi, L.; Comiti, F.; Crema, S.; Cavalli, M. (2019): Channel control works and sediment connectivity in the European Alps. In The Science of the total environment 668, pp.389-399. DOI: 10.1016/j.scitotenv.2019.02.416.

Meyer-Peter, E.; Müller, R. (1949): Formulas For Bed-Load Transport. In IAHSR second meeting, pp. 39-64.

Mikos, M. (1993): Fluvial abrasion of gravel sediments. Zürich (Mitteilungen / Versuchsanstalt für Wasserbau, Hydrologie und Glaziologie der Eidgenössischen Technischen Hochschule Zürich, 123).

Montgomery, D. R.; Buffington, J. M. (1997): Channel-reach morphology in mountain drainage basins. In Geological Society of America Bulletin 109 (5), pp. 596-611. DOI: 10.1130/00167606(1997)109<0596:CRMIMD>2.3.CO;2.

Nakagawa, H.; Nezu, I. (1981): Structure of space-time correlations of bursting phenomena in an open-channel flow. In J. Fluid Mech. 104, pp. 1-43. DOI: 10.1017/S0022112081002796.

B 2400, 2016: ÖNORM.

Pasternack, G. B. (2008): Spawning habitat rehabilitation: Advances in Analysis Tools. 321-349. In: Sear D.A., DeVries, P. (eds). Salmon Spawning Habitat in Rivers. American Fisheries Symposium 65, 2008.

Percival, E.; Whitehead, H. (1929): A Quantitative Study of the Fauna of Some Types of Stream-Bed. In The Journal of Ecology 17 (2), p. 282. DOI: 10.2307/2256044.

Pulg, U.; Barlaup, B. T.; Sternecker, K.; Trepl, L.; Unfer, G. (2013): Restoration of spawning habitats of Brown Trout (Salmo Trutta)in a regulated chalk stream. In River Res. Applic. 29 (2), pp. 172-182. DOI: 10.1002/rra.1594

Rickenmann, D. (1990): Bedload transport capacity of slurry flows at steep slopes. ETH Zurich.

Rickenmann, D. (2001): Comparison of bed load transport in torrents and gravel bed streams. In Water Resour. Res. 37 (12), pp. 3295-3305. DOI: 10.1029/2001WR000319.

Rickenmann, D.; Turowski, J. M.; Fritschi, B.; Wyss, C.; Laronne, J.; Barzilai, R. et al. (2014): Bedload transport measurements with impact plate geophones: comparison of sensor calibration in different gravel-bed streams. In Earth Surf. Process. Landforms 39 (7), pp. 928-942. DOI: 10.1002/esp.3499.

Shields, A. (1936): Anwendung der Ähnlichkeitsmechanik und der Turbulenzforschung auf die Geschiebebewegung. Berlin: Eigenverlag.

Shvidchenko, A. B.; Pender, G. (2001): Large flow structures in a turbulent open channel flow. In Journal of Hydraulic Research 39 (1), pp. 109-111. DOI: 10.1080/00221680109499810. 
Sindelar, C.; Gold, T.; Reiterer, K.; Hauer, C.; Habersack, H. (2020): Experimental Study at the Reservoir Head of Run-of-River Hydropower Plants in Gravel Bed Rivers. Part I: Delta Formation at Operation Level. In Water 12 (7), p. 2035. DOI: 10.3390/w12072035.

Sindelar, C.; Schobesberger, J.; Habersack, H. (2017): Effects of weir height and reservoir widening on sediment continuity at run-of-river hydropower plants in gravel bed rivers. In Geomorphology 291, pp. 106-115. DOI: 10.1016/j.geomorph.2016.07.007.

Smart, G. M.; Jaeggi, M. (1983): Sediment Transport on Steep Slopes. In Mitteilungen der Versuchsanstalt fuer Wasserbau, Hydrologie und Glaziologie (64).

Statzner, B. (1981): The relation between" hydraulic stress" and microdistribution of benthic macroinbertebrates in a lowland running water system, the Schierenseebrooks (North Germany). In Archiv fur Hydrobiologie (91), pp. 192-218.

Sternberg, H. (1875): Untersuchungen über das Längen- und Querprofil geschiebeführender Flüsse. In Zeitschrift Bauwesen (25).

Tritthart, M. (2005): Three-dimensional numerical modelling of turbulent river flow using polyhedral finite volumes. Available online at https://resolver.obvsg.at/urn:nbn:at:at-ubtuw:1-9025.

Tritthart, M.; Glock, K.; Glas, M.; Yücesan, S.; Liedermann, M.; Gmeiner, P. et al. (2019): Erfahrungen in der numerischen Sedimenttransportmodellierung auf unterschiedlichen Skalen - von RANS bis LES. In Österr Wasser- und Abfallw 71 (3-4), pp. 170-178. DOI: 10.1007/s00506-018-0550-0.

Tritthart, M.; Liedermann, M.; Schober, B.; Habersack, H. (2011a): Non-uniformity and layering in sediment transport modelling 2: river application. In Journal of Hydraulic Research 49 (3), pp. 335-344. DOI: 10.1080/00221686.2011.583487.

Tritthart, M.; Schober, B.; Habersack, H. (2011b): Non-uniformity and layering in sediment transport modelling 1: flume simulations. In Journal of Hydraulic Research 49 (3), pp. 325-334. DOI: 10.1080/00221686.2011.583528.

Turowski, J. M.; Rickenmann, D.; Dadson, S. J. (2010): The partitioning of the total sediment load of a river into suspended load and bedload: a review of empirical data. In Sedimentology 57 (4), pp. 1126-1146. DOI: 10.1111/j.1365-3091.2009.01140.x.

Ward, J. V.; Stanford, J. A. (1995): Ecological connectivity in alluvial river ecosystems and its disruption by flow regulation. In Regul. Rivers: Res. Mgmt. 11 (1), pp. 105-119. DOI: 10.1002/rrr.3450110109.

Wheaton, Joseph M.; Pasternack, Gregory B.; Merz, Joseph E. (2004): Spawning habitat rehabilitation - II. Using hypothesis development and testing in design, Mokelumne river, California, U.S.A. In International Journal of River Basin Management 2 (1), pp. 21-37. DOI: 10.1080/15715124.2004.9635219.

Wilcock, P. R.; Crowe, J. C. (2003): Surface-based Transport Model for Mixed-Size Sediment. In J. Hydraul. Eng. 129 (2), pp. 120-128. DOI: 10.1061/(ASCE)0733-9429(2003)129:2(120).

Wolman, M. G. (1954): A method of sampling coarse river-bed material. In Trans. AGU 35 (6), p. 951. DOI: 10.1029/TR035i006p00951.

WOOD-SMITH, R. D.; Buffington, J. M. (1996): Multivariate geomorphic analysis of forest streams: implications for assessment of land use impacts on channel condition. In Earth Surface Processes and Landforms (21(4)), pp. 377-393.

Wu, W.; Wang, S. S.Y.; Jia, Y. (2000): Nonuniform sediment transport in alluvial rivers. In Journal of Hydraulic Research 38 (6), pp. 427-434. DOI: 10.1080/00221680009498296.

Zhong, Q.; Li, D.; Chen, Q.; Wang, X. (2015): Coherent structures and their interactions in smooth open channel flows. In Environ Fluid Mech 15 (3), pp. 653-672. DOI: 10.1007/s10652-014-9390-z. 